\title{
BIOLOGICAL
}

MONITORING OF LANDINGS OF COMMERCIALLY IMPORTANT SPECIES 2017-2019

Contract - N 56/29/09/2017 Contract -N 161/28/05/2018 


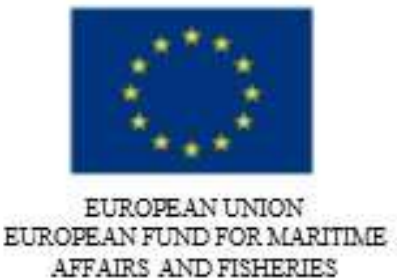

AFFAIRS AND FISHERIES

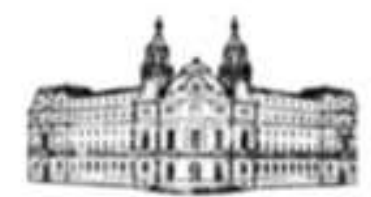

AINISTRY OF AGRICULTURE, FOOD AND FORESTRY
MLARITLE AFFAIRS AND FISHERIES PROGRAM

\title{
INSTITUTE OF OCEANOLOGY „FRIDTJOF NANSEN“
} BULGARIAN ACADEMY OF SCIENCES

\section{List of contributors:}

\author{
Assoc. Prof. Maria Yankova, Ph.D. \\ Assoc. Prof. Violin Raykov, Ph.D. \\ Assoc. Prof. Petya Ivanova, Ph.D. \\ Chief Asst. Nina Djembekova, Ph.D \\ Neli Valcheva (Technician) \\ Dobroslav Dechev (Technician) \\ Diana Hristova (Technician) \\ Petar Trandafilov (Logistics) \\ Snejina Bacheva (Editor)
}




\section{$\frac{*^{*}}{*}+\ldots$ \\ EUROPEAN UNTON \\ EUROPE.AN FUND FOR MLARITIIE} AFFAIRS AND FISHERIES

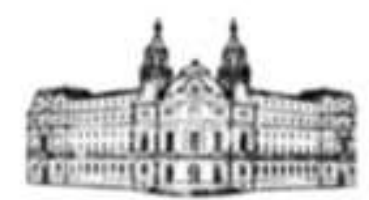

AINISTRY OF AGRICULTURE, FOOD AND FORESTRY $=x$

MLARITLIE AFFAIRS AND FISHERIES PROGRAM

\section{Table of Contents}

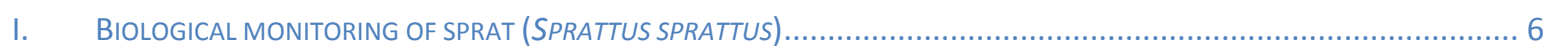

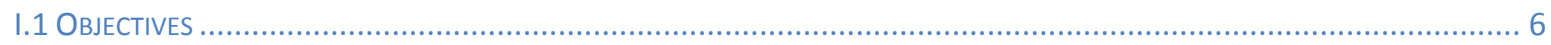

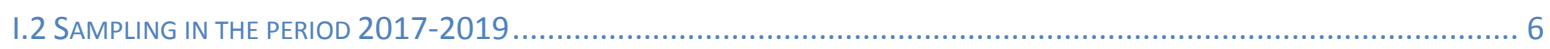

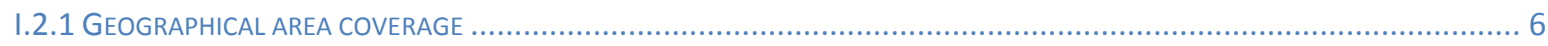

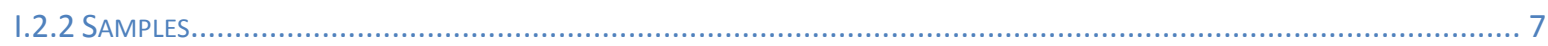

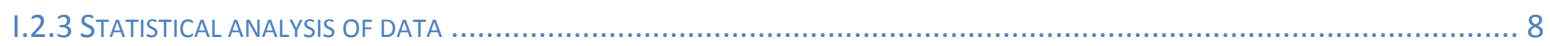

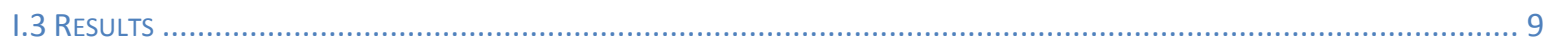

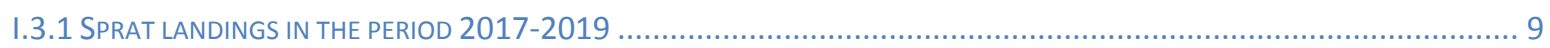

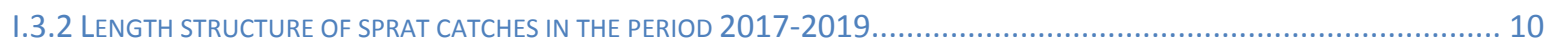

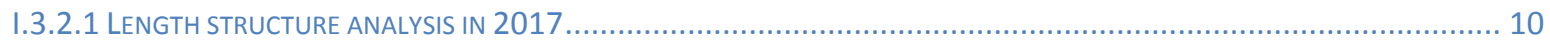

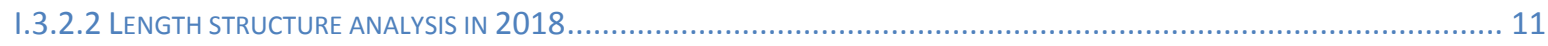

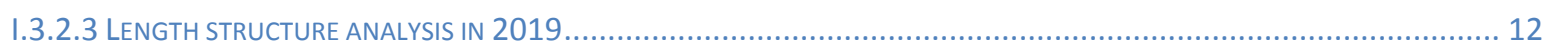

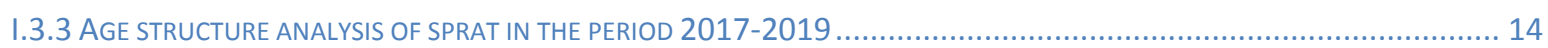

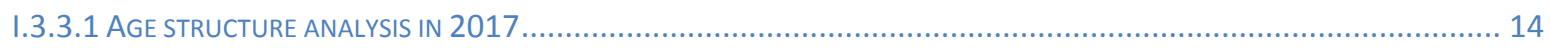

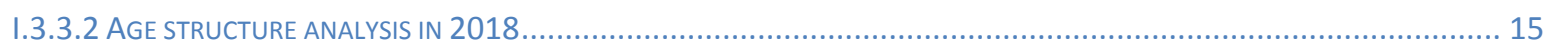

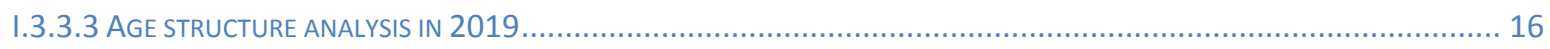

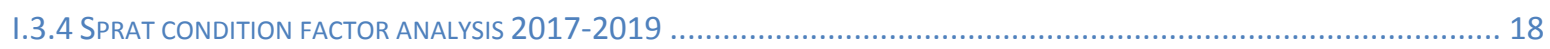

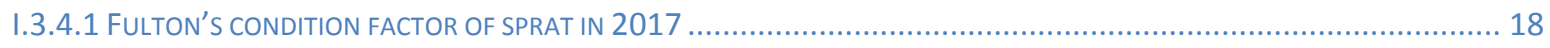

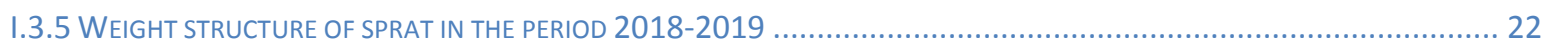

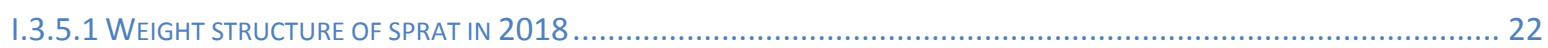

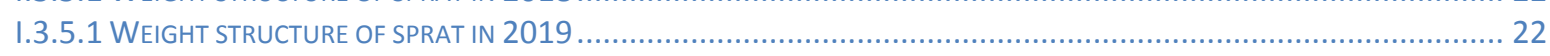

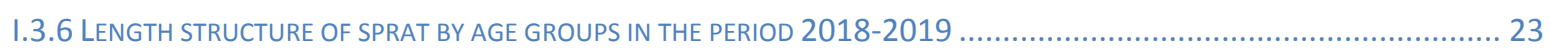

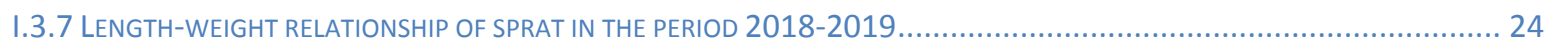

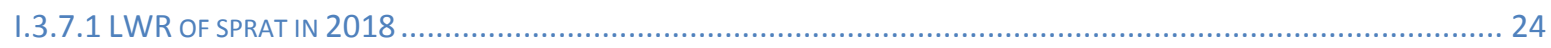

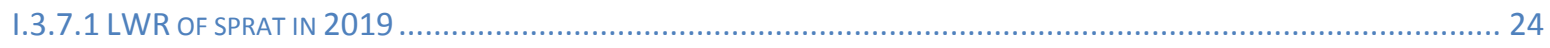

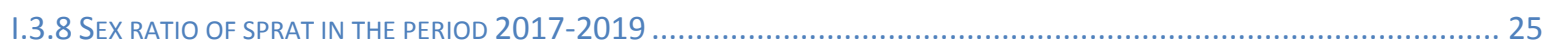

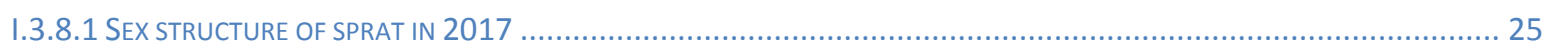

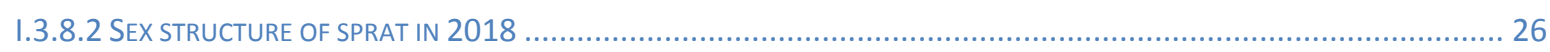

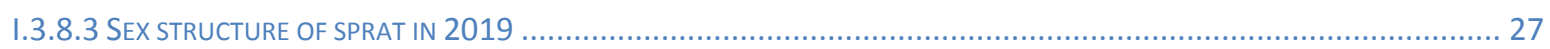

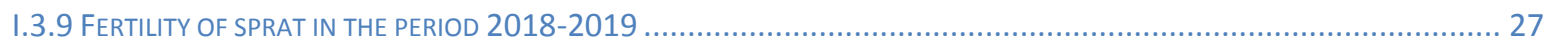

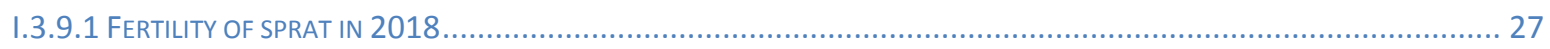

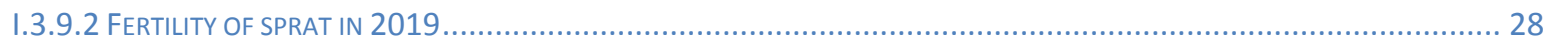

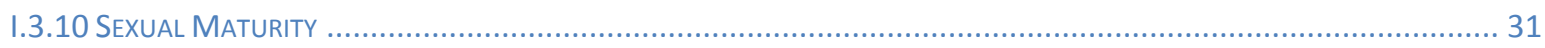

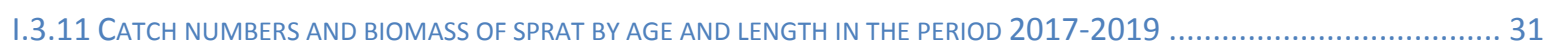

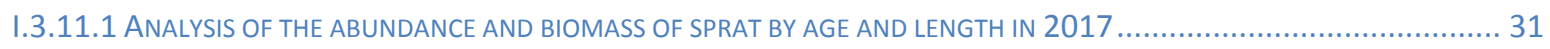

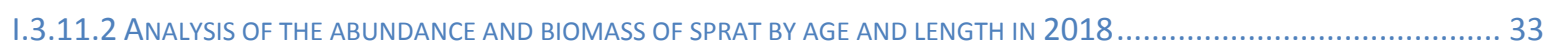

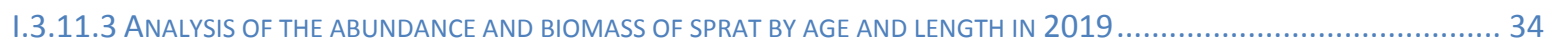

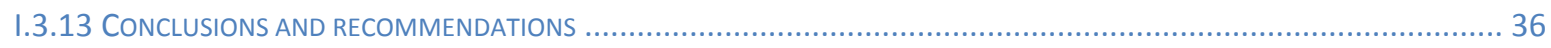

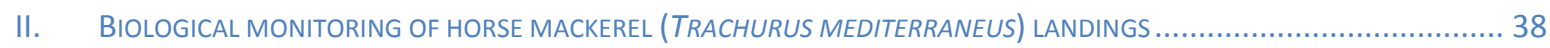

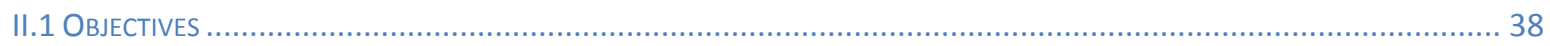

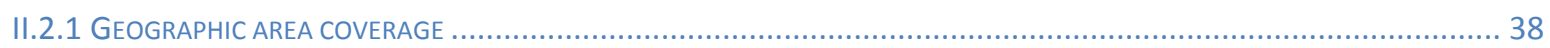

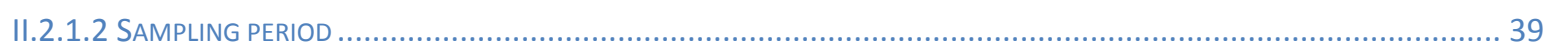

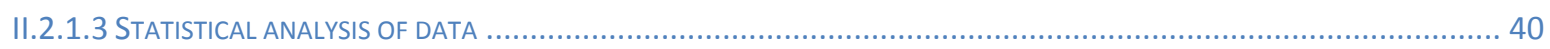

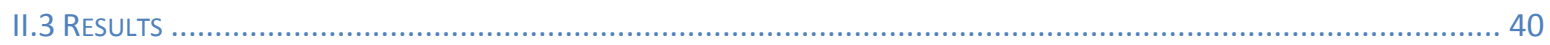

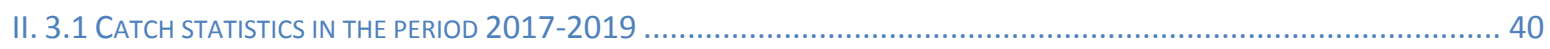

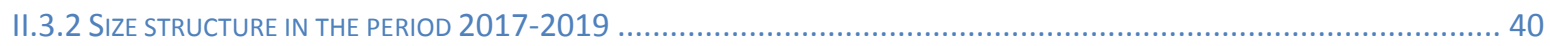

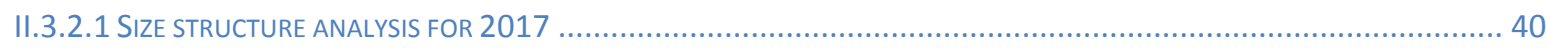

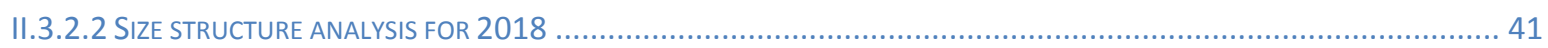

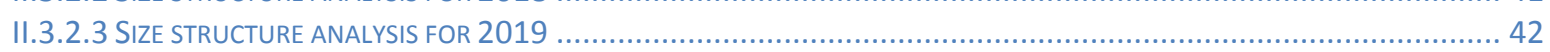

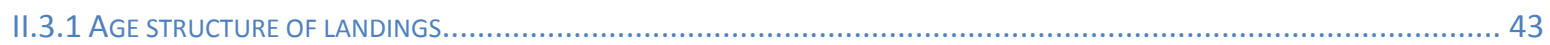

Project proposal № BG14MFOP001-3.003-0001 "Collection, management and use of data for the purposes of scientific analysis and implementation of the Common Fisheries Policy for the period 2017-2019", funded by the Maritime Affairs and Fisheries Program, co-financed by the European Union through the European Maritime and Fisheries Fund 


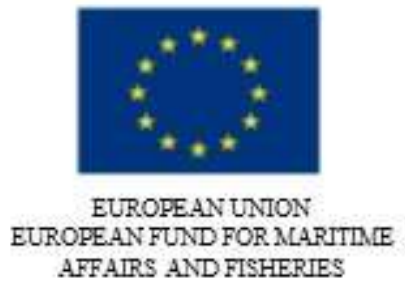

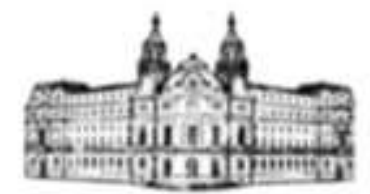

AMNISTRY OF AGRICUITURE, FOOD AND FORESTRY

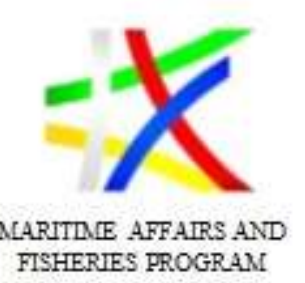

II.3.4 CONDITION FACTOR

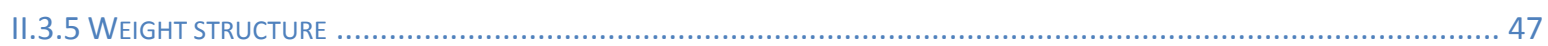

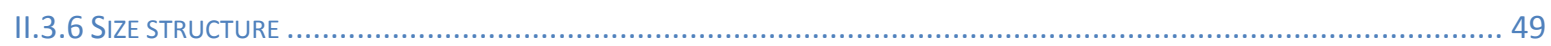

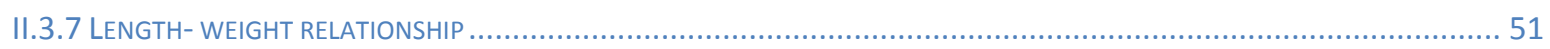

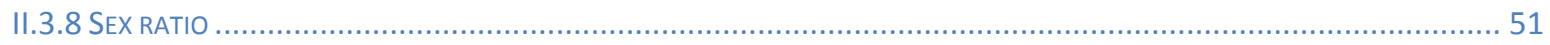

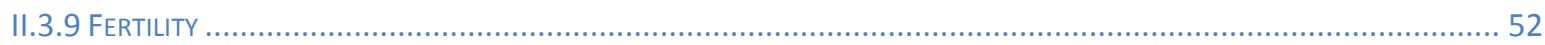

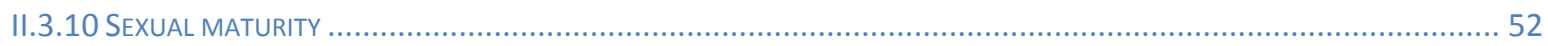

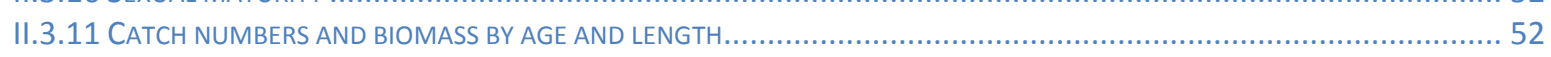

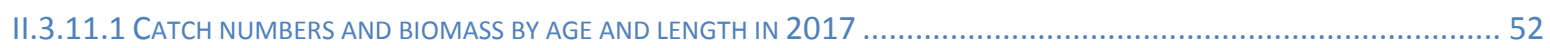

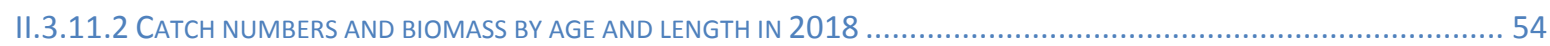

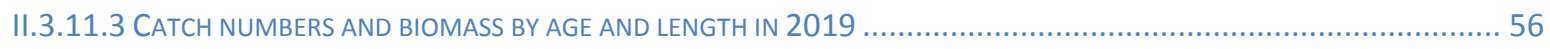

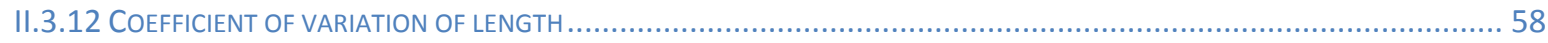

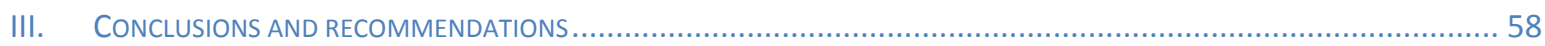

III. BIOLOGICAL MONITORING OF WHITING (MERLANGIUS MERLANGUS) LANDINGS ..................................................5 59

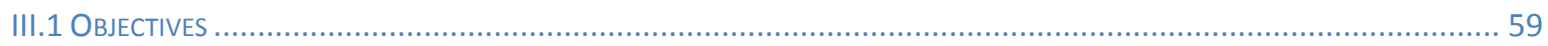

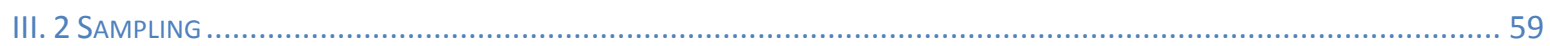

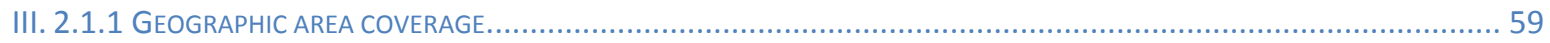

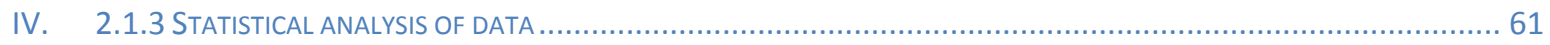

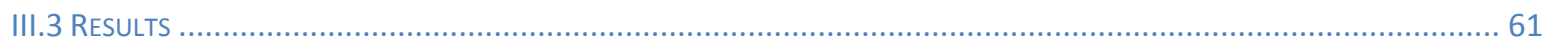

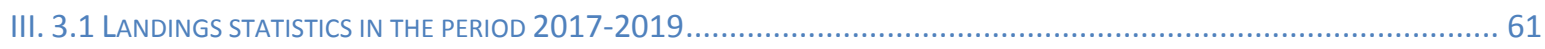

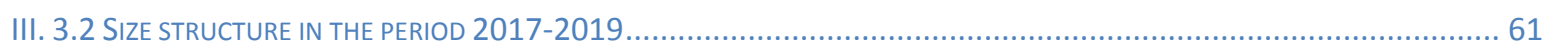

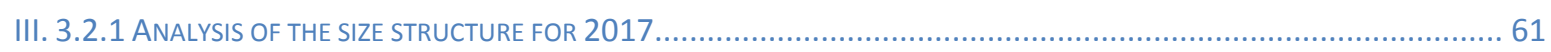

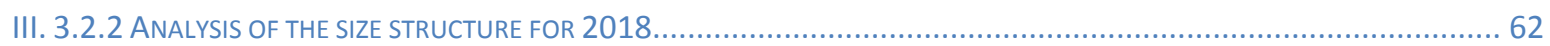

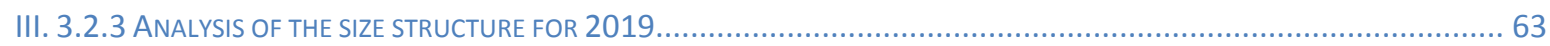

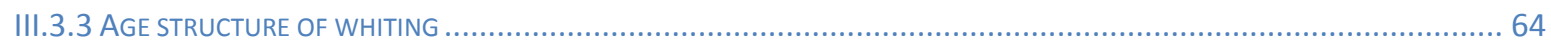

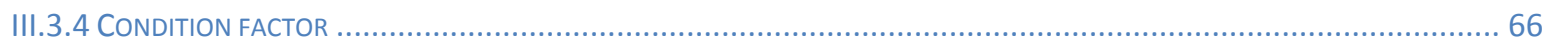

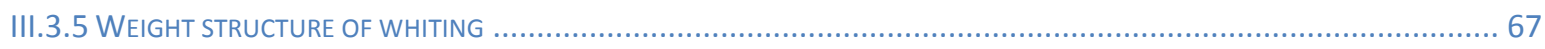

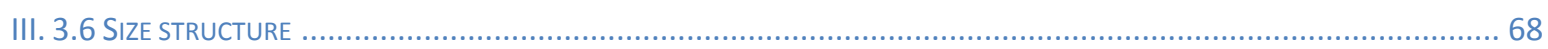

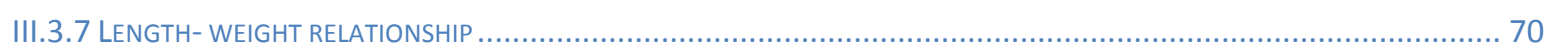

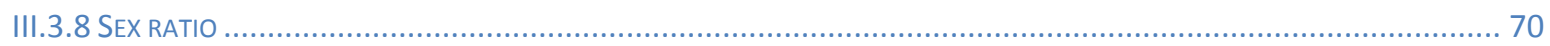

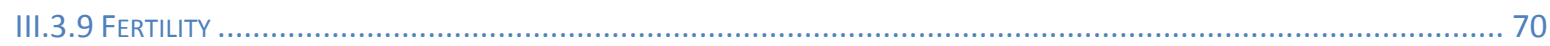

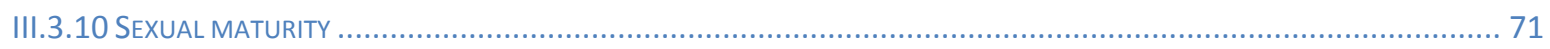

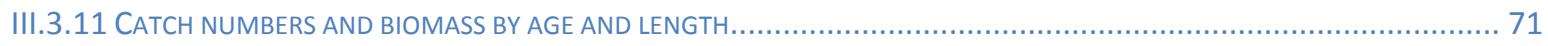

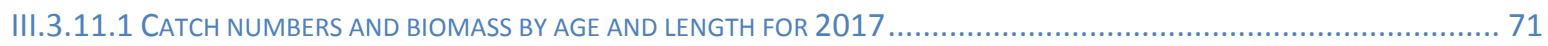

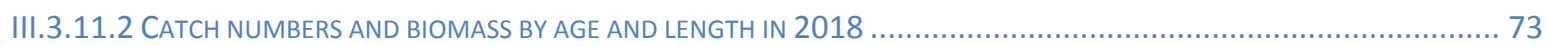

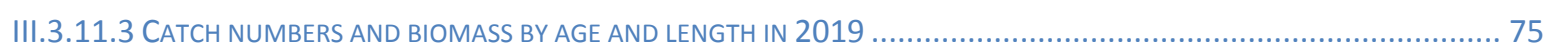

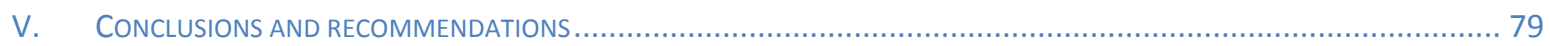

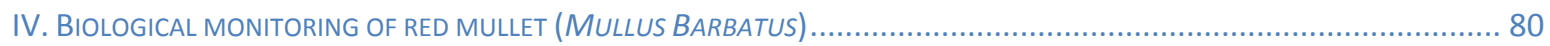

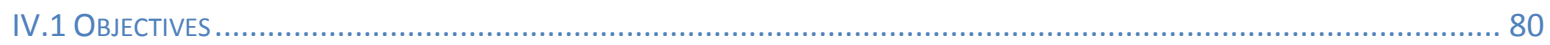

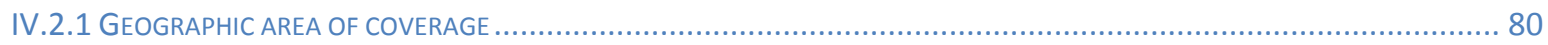

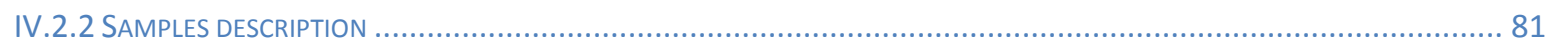

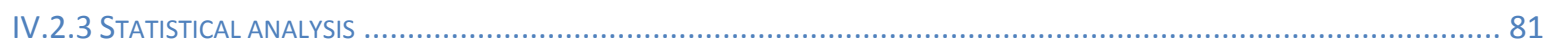

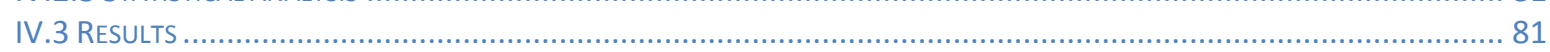

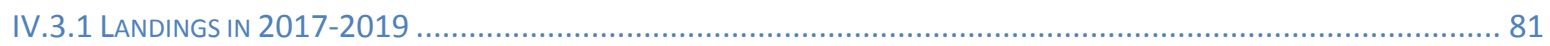

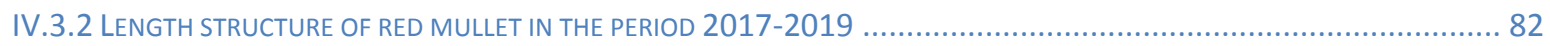

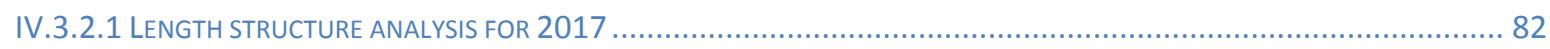

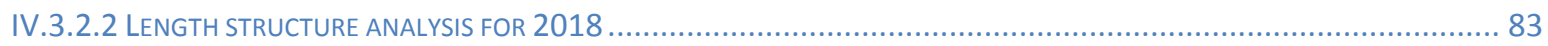

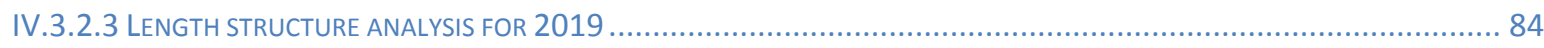

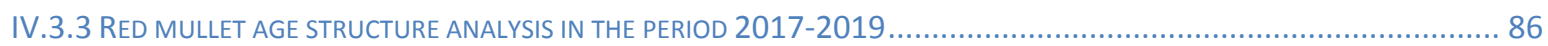

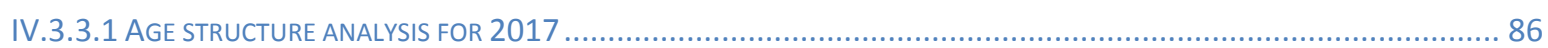

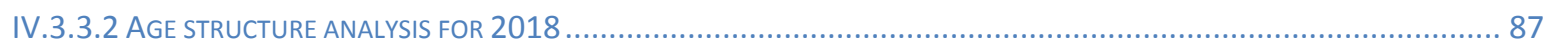

Project proposal № BG14MFOP001-3.003-0001 "Collection, management and use of data for the purposes of scientific analysis and implementation of the Common Fisheries Policy for the period 2017-2019", funded by the Maritime Affairs and Fisheries Program, co-financed by the European Union through the European Maritime and Fisheries Fund 


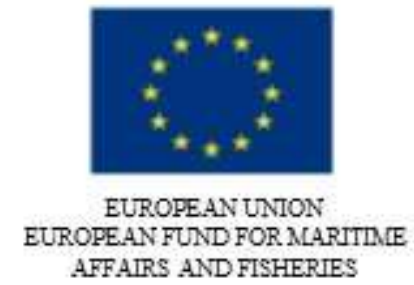

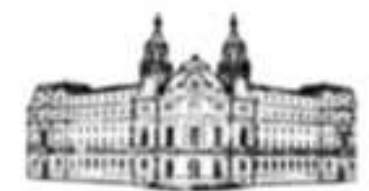

AMNISTRY OF AGRICUITURE, FOOD AND FORESTRY

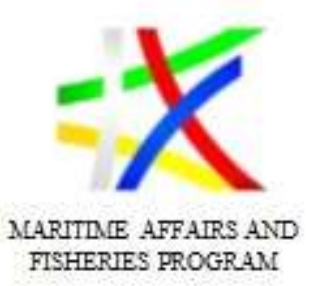

IV.3.3.3 AGE STRUCTURE ANALYSIS FOR 2019

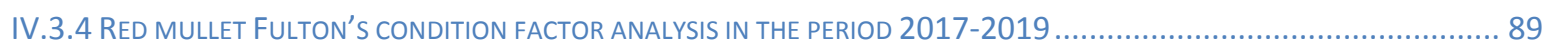

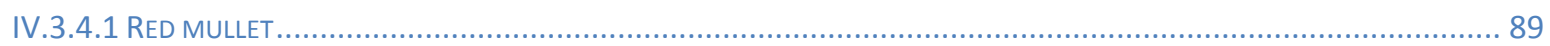

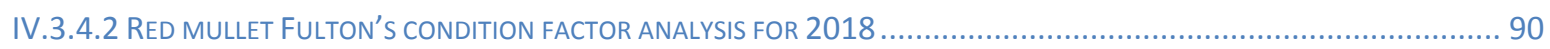

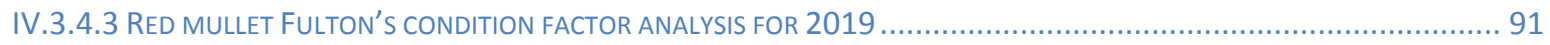

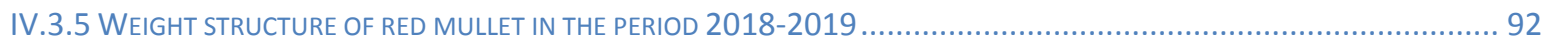

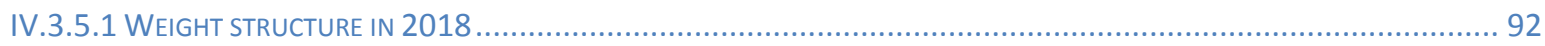

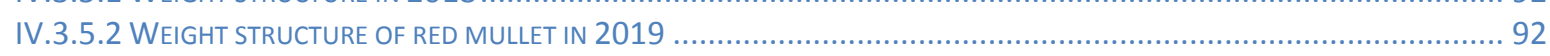

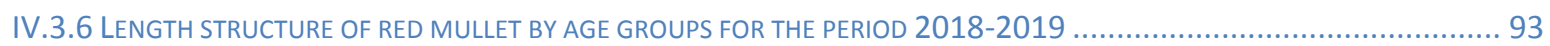

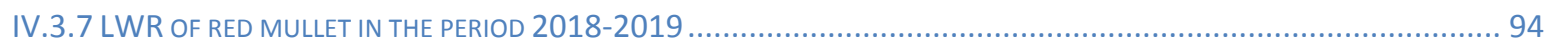

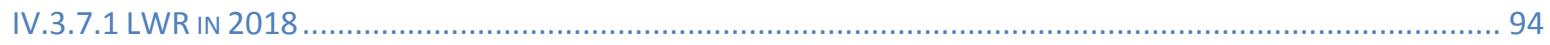

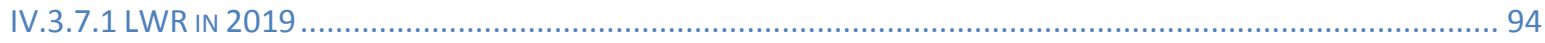

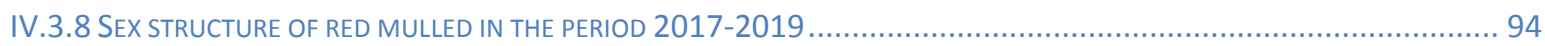

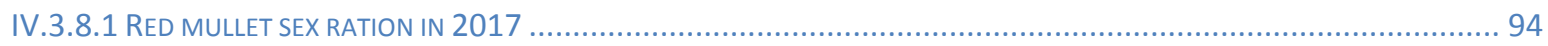

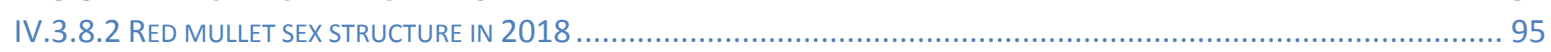

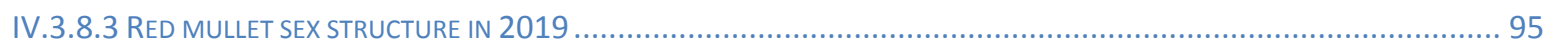

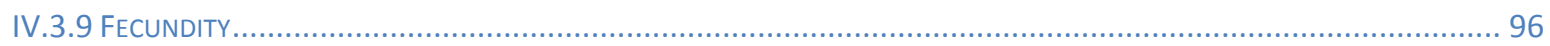

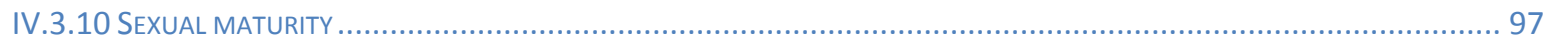

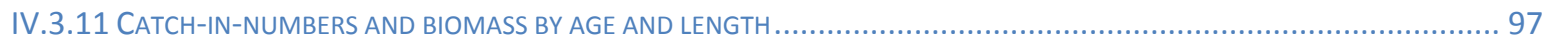

IV.3.11.1 CATCH-IN-NUMBERS AND BIOMASS ANALYSIS OF RED MULLET BY AGE AND LENGTH FOR 2017 ...........................97

IV.3.11.3 CATCH-IN-NUMBERS AND BIOMASS ANALYSIS OF RED MULLET BY AGE AND LENGTH FOR 2019 .......................... 101

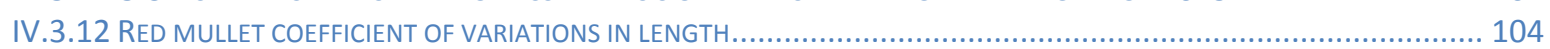

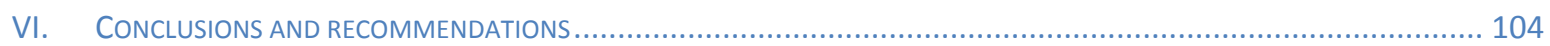

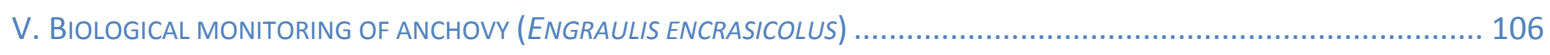

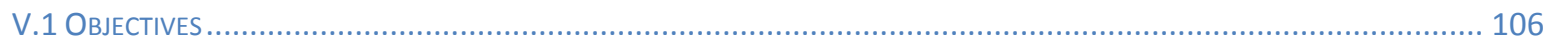

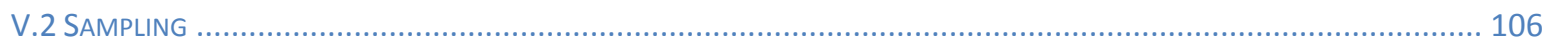

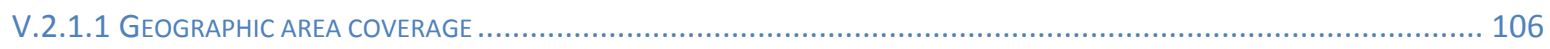

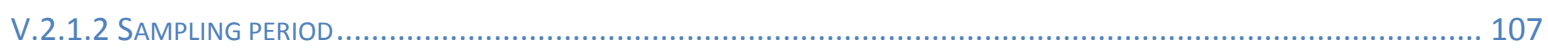

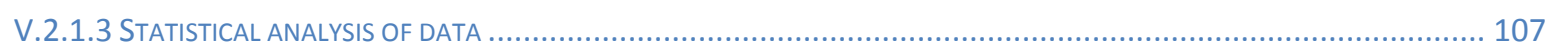

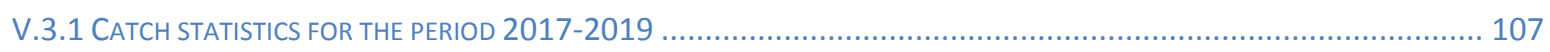

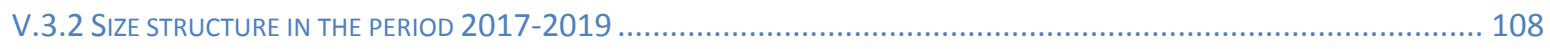

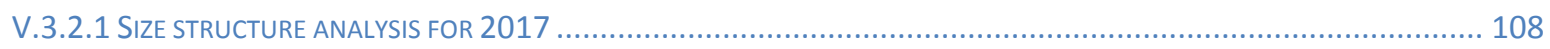

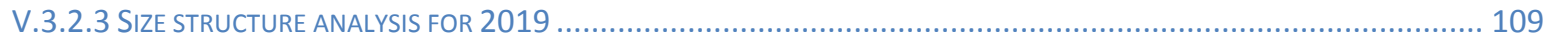

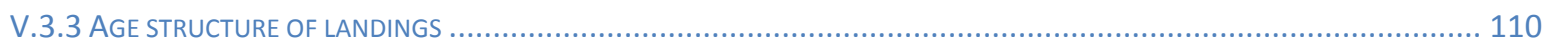

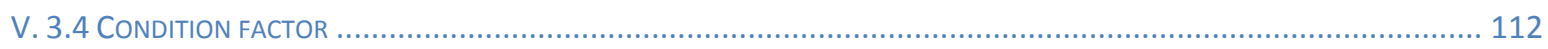

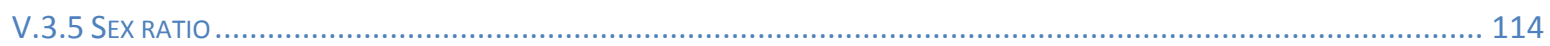

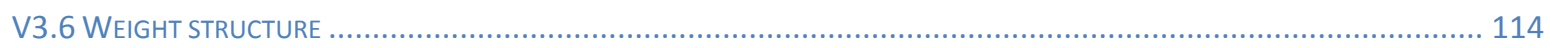

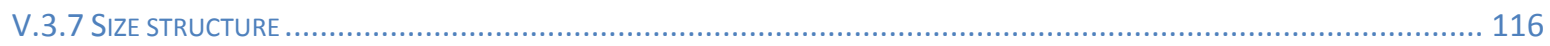

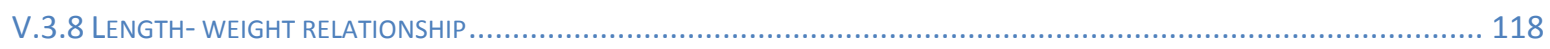

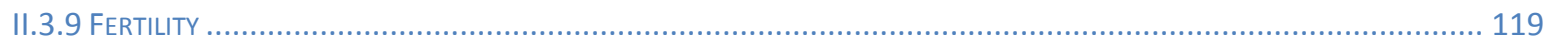

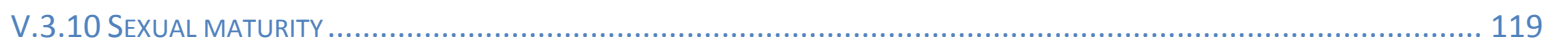

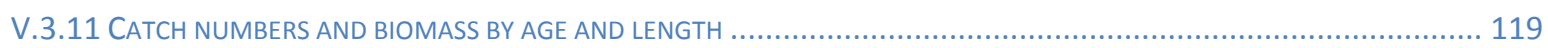

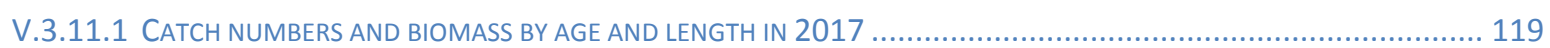

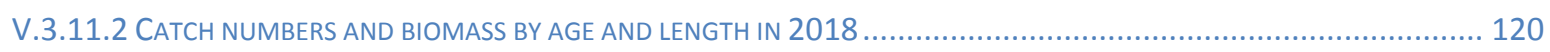

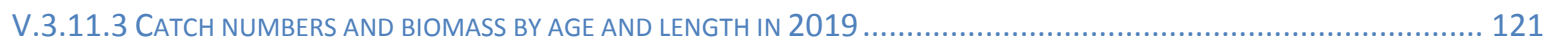

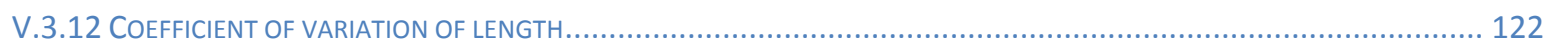

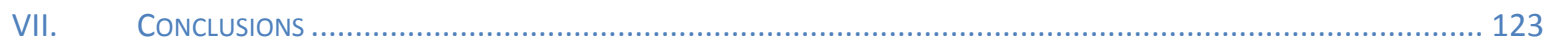

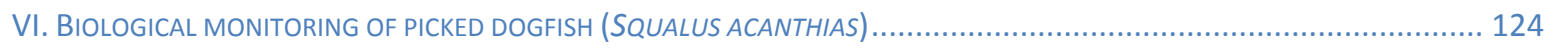

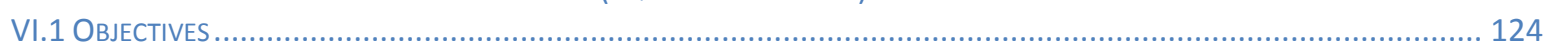

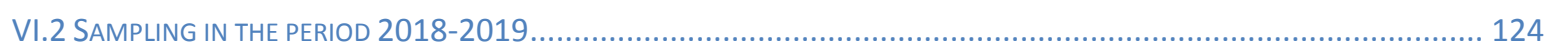

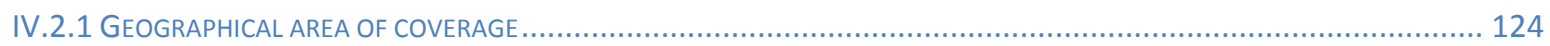

Project proposal № BG14MFOP001-3.003-0001 "Collection, management and use of data for the purposes of scientific analysis and implementation of the Common Fisheries Policy for the period 2017-2019", funded by the Maritime Affairs and Fisheries Program, co-financed by the European Union through the European Maritime and Fisheries Fund 


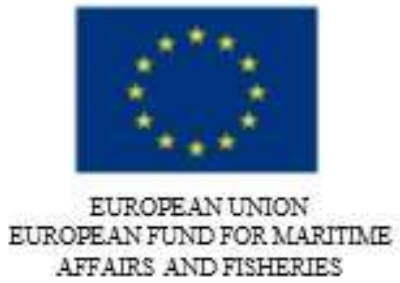

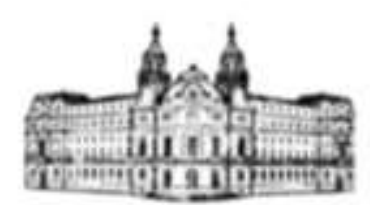

MINISTRY OF AGRICUITURE, FOOD AND FORESTRY
MLARITLE AFFAIRS AND FISHERIES PROGRAM

VI.2.2 SAMPLING DESCRIPTION 124

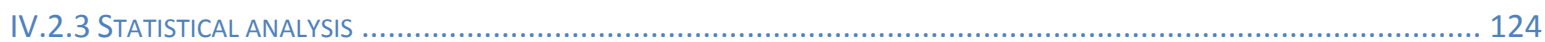

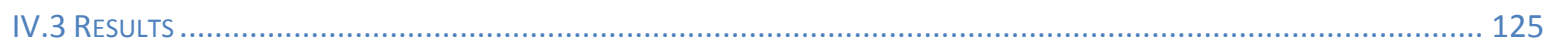

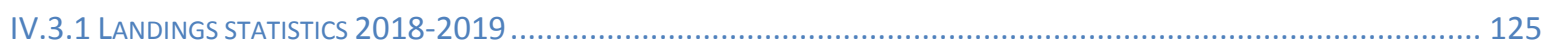

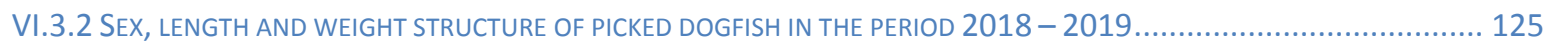

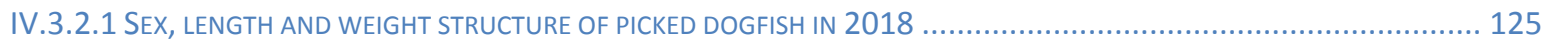

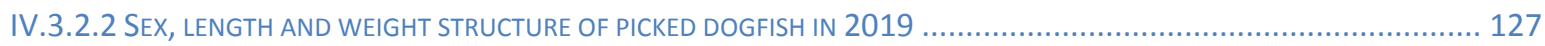

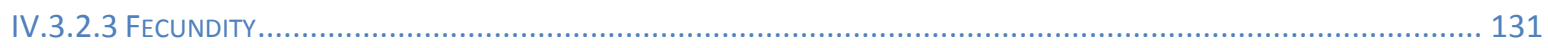

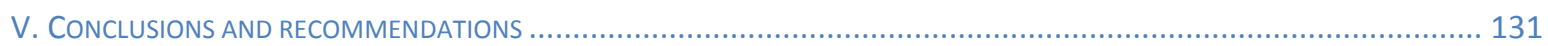

Project proposal № BG14MFOP001-3.003-0001 "Collection, management and use of data for the purposes of scientific analysis and implementation of the Common Fisheries Policy for the period 2017-2019", funded by the Maritime Affairs and Fisheries Program, co-financed by the European Union through the European Maritime and Fisheries Fund 


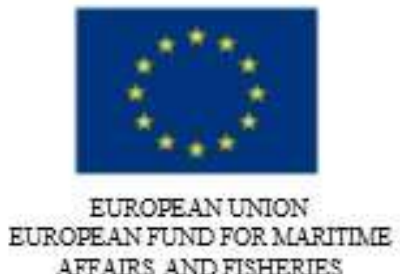

AFFAIRS AND FISHERIES

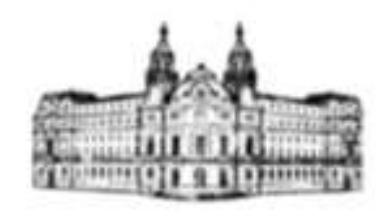

AINISTRY OF AGRICULTURE, FOOD AND FORESTRY

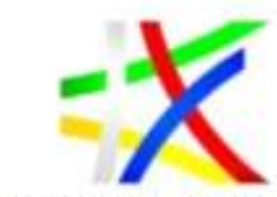

MLARITLE AFFAIRS AND FISHERIES PROGRAM

\section{Biological monitoring of sprat (Sprattus sprattus)}

\section{I.1 Objectives}

Fish are an important component of aquatic ecosystems through their role as consumers of other organisms and they can have a significant influence on the structure and function of these ecosystems. Because of this, adverse effects on fish can have adverse flow-on effects on other aquatic organisms even if they are not directly affected by those changes in water quality. Monitoring of fish communities can, therefore, provide a useful indicator of the ecological health of natural waters. Fish are sensitive to many changes in water quality and habitat structure caused by human activities and by natural causes. Common adverse anthropogenic effects on fish can result from many factors including: contamination of water by waste metal pollution, pesticides, salinity and organic wastes and nutrients causing either direct effects on fish health or indirect effects on the oxygen climate in the water through eutrophication; and physical habitat changes such as thermal pollution, changes in stream flow regime, stream bed aggradation, de-snagging, and land clearance, especially in riparian zones. Consequently, as well as their intrinsic biodiversity value and the human food value of some species, fish can be useful indicators of the impact of many different human activities on the environmental health of a water body. Multiannual biological monitoring on landings provides the so called "Fishery dependent" information. The Black Sea sprat (Sprattus sprattus L.) is a key species in the Black Sea ecosystem. The aim of this study was to collect and to analyze dynamics in length, weight and age distribution as well as to determine the condition of the sprat species using the so-called Fulton's condition factor. The condition factor is also a useful index for monitoring of feeding intensity, age, and growth rates in fish. It is strongly influenced by both biotic and abiotic environmental conditions and can be used as an index to assess the status of the aquatic ecosystem in which fish live. Biological information on sprat species collected each month, analyzed and compared to previous periods could be used for estimation of growth parameters. These indicators are very important for the short-lived species. Reliable and informative long-term data are crucial for the assessment of fish stocks, fisheries management and the decision-making process in general.

\section{I.2 Sampling in the period 2017-2019}

\section{I.2.1 Geographical area coverage}

The samples used for the present analysis were gathered directly from landings at ports of fishing vessels in the Bulgarian region of the Black sea (Fig. 2.1.1).

Project proposal № BG14MFOP001-3.003-0001 "Collection, management and use of data for the purposes of scientific analysis and implementation of the Common Fisheries Policy for the period 2017-2019", funded by the Maritime Affairs and Fisheries Program, co-financed by the European Union through the European Maritime and Fisheries Fund 


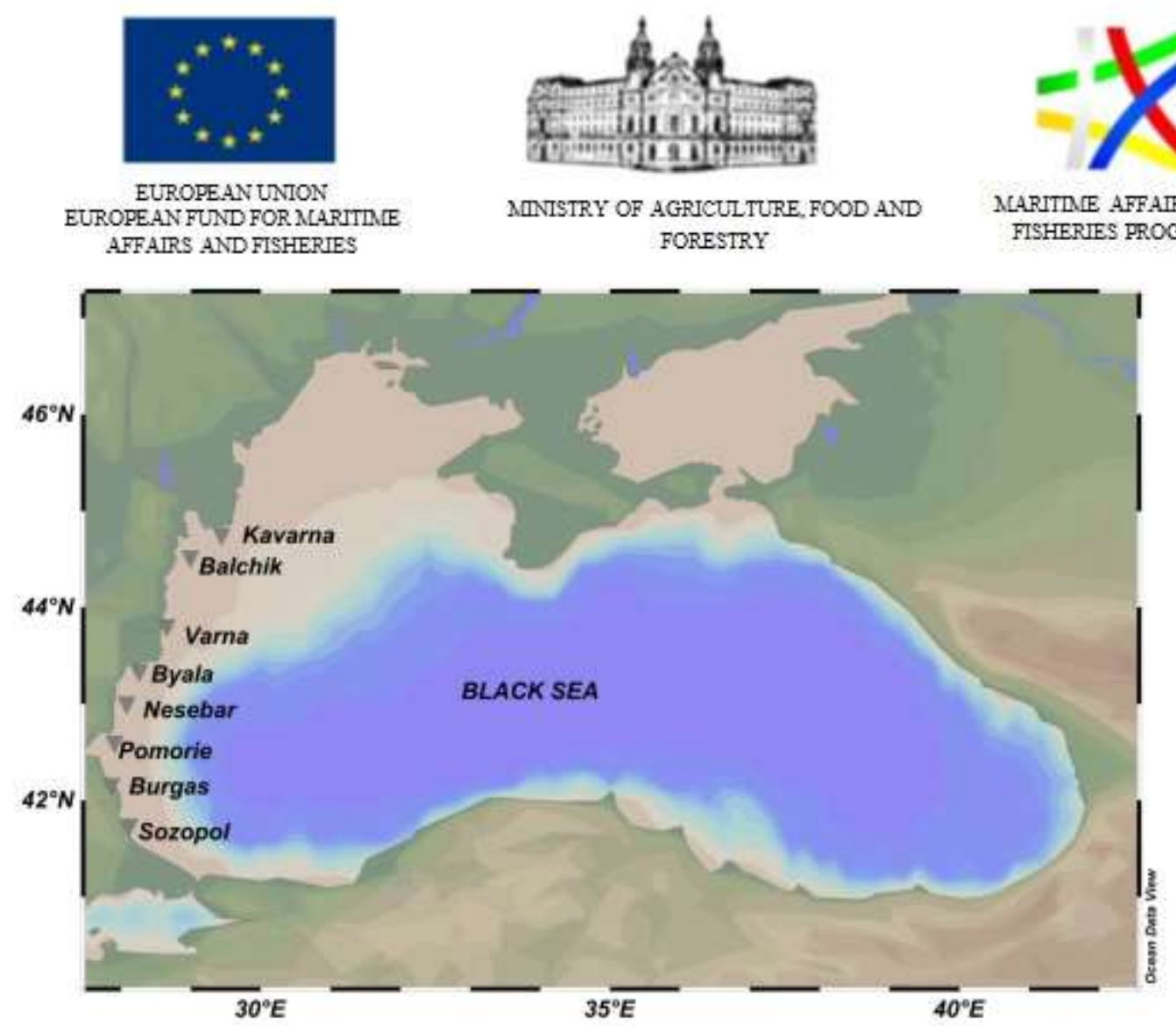

Fig. 2.1.1 Sampling area along the Bulgarian Black sea coast

\section{I.2.2 Samples}

In 2017 the fish was caught at depths varying from $40 \mathrm{~m}$ to $60 \mathrm{~m}$ with the majority caught at $45 \mathrm{~m}$ by pelagic trawls. The collected statistical sample in November 2017 presented 2368 specimens.

In 2018 the samples collected in the period March - April for analysis of length, weight and age structure represented 1781 specimens in total.

In 201925 samples (5882 specimens) were collected and processed to ensure the analysis of the length, weight and age structure of sprat presented in the commercial catches.

\begin{tabular}{|c|c|c|c|c|c|}
\hline \multicolumn{2}{|c|}{2017} & \multicolumn{2}{|c|}{2018} & \multicolumn{2}{|r|}{2019} \\
\hline Date & Fishing vessel & Date & Fishing vessel & Date & Fishing vessel \\
\hline & & 12. 03. 2018 & FV 40 & 22.02 .2019 & FV ISHTAR HC 1182 \\
\hline & & 03.2018 & FV Herson & 06.03 .2019 & FV 27 БС290 \\
\hline & & & & 07.03 .2019 & FV Barbun Vn7979 \\
\hline & & & & 11.03 .2019 & FV BL21-33 \\
\hline & & & & 21.03 .2019 & FV KB5636 \\
\hline & & & & 21.03 .2019 & FV KB5465 \\
\hline & & & & 22.03 .2019 & FV БЧ 5156 \\
\hline & & & & 01.04 .2019 & FV TAIS VN393 \\
\hline & & 02.04 .2018 & FV 40 & 03.04 .2019 & FV KB 5465 \\
\hline
\end{tabular}

Project proposal № BG14MFOP001-3.003-0001 "Collection, management and use of data for the purposes of scientific analysis and implementation of the Common Fisheries Policy for the period 2017-2019", funded by the Maritime Affairs and Fisheries Program, co-financed by the European Union through the European Maritime and Fisheries Fund 


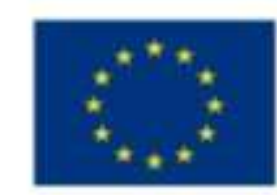

EUROPEAN UNTON EUROPEAN FUND FOR MAARTIME AFFAIRS AND FISHERIES

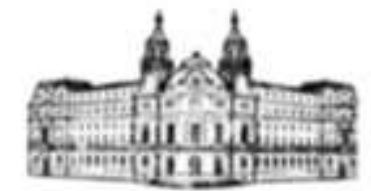

AINISTRY OF AGRICULTURE, FOOD AND FORESTRY
MLARITLE AFFAIRS AND FISHERIES PROGRAM

\begin{tabular}{|c|c|c|c|c|}
\hline & & & 04.04 .2019 & $\begin{array}{l}\text { FV Sv.Nicola-I"- } \\
\text { Nesebar }\end{array}$ \\
\hline & & & 10.04 .2019 & FV Herson БС210 \\
\hline & & & 06.05 .2019 & FV VN 3261 \\
\hline & & & 14.05 .2019 & FV VN 3261 \\
\hline & & & 08.06 .2019 & FV 29 БС 222 \\
\hline & & & 29.07.2019 & FV 29БС222 \\
\hline & & & 01.08 .2019 & FV 41 БС 259 \\
\hline & & & 18.08 .2019 & FV 40 БС258 \\
\hline & & & 07.09 .2019 & FV 40БС258 \\
\hline & & & 27.09 .2019 & FV 40БС258 \\
\hline & & & 02.10 .2019 & FV40 БС258 \\
\hline & & & 29.10 .2019 & FV 40 БС258 \\
\hline 27.11 .2017 & ELEKTA EOOD & & 19.11 .2019 & FV 40 БС258 \\
\hline & & & 29.11 .2019 & TAIS VN393 \\
\hline & & & 5.12 .2019 & TAIS VN393 \\
\hline & & & 07.12 .2019 & TAIS VN393 \\
\hline 1 sar & with 2368 sp. & 3 samples with 1781 sp. & 25 & es with 5882 sp. \\
\hline
\end{tabular}

\section{I.2.3 Statistical analysis of data}

The samples listed in paragraph I.2.2 were randomly collected in compliance with the requirements for sampling a population of fish species. It is important to be noted that 20172019 sprat catches were not abundant compared to previous years due to a current shift of key species (for example bluefish Pomatomus saltatrix), as well as the absence of significant agglomerations of the studied species registered within the period of the present research.

The samples were processed under laboratory conditions. Total length (TL, $\pm 0.5 \mathrm{~cm}$ precision) was measured using an ichtyometer and total fresh weight was measured using an electronic analytical balance (W, $\pm 1 \mathrm{~g}$ precision). The study used otoliths to determine age, which was determined from otolith rings. Otoliths were removed and dried in a laboratory and stored in labeled envelopes. Age was determined by microscope Olympus CX 31RTSF-6 and recorded. Thus, the yearly annulus was detected as hyaline and opaque zones, shifting active growing with period of growth stagnation. For ageing estimation 1090 fish were examined. Sections from the other otoliths were judged illegible and were excluded from the study. In order to check the accuracy of the age readings in the present study, an ageing intercalibration exercise was carried out between the authors. Age readings were compared using a signed rank statistical test. A consistent agreement between readers with low average percentage error (APE) values was established.

Determination of individual growth parameters is of crucial importance, especially for key species, not only for the proper analysis of length, weight and age structure but also for the proper stock management - definition of minimal length presented in catches and recommendations for the selectivity of the fishing gears and etc.

Project proposal № BG14MFOP001-3.003-0001 "Collection, management and use of data for the purposes of scientific analysis and implementation of the Common Fisheries Policy for the period 2017-2019", funded by the Maritime Affairs and Fisheries Program, co-financed by the European Union through the European Maritime 


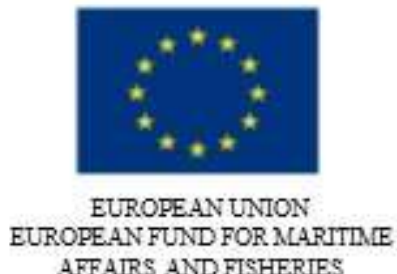

AFFAIRS AND FISHERIES

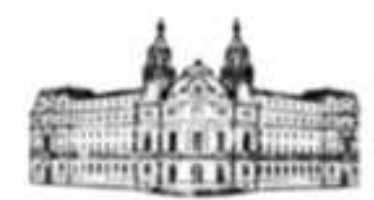

AINISTRY OF AGRICULTURE, FOOD AND FORESTRY

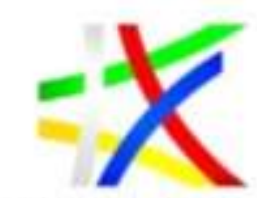

MCARITLE AFFAIRS AND FISHERIES PROGRAM

The mathematical expression of von Bertalanffy growth model points out the length $(L)$ as a function of age $t: L(t)=L_{\infty}\left[1-\exp \left(-K\left(t-t_{0}\right)\right)\right]$, where: $t$ is the age of individual, $L_{\infty}-$ is the asymptotic length, to which a given biological species increases in length during their lifespan, $K$ - curvature parameter, which reflects the speed of approaching the asymptotic length, $t_{0}$ - initial condition parameter (determines the moment, when the length of the studied species is equal to 0 ).

LWR model is widely applied in analysis of the of marine living resources as it represents the condition of the stocks. LWR analysis results can be implemented to provide weight estimates on the base of length measurements and vice versa, as well as for comparison of growth parameters of one and the same species spread in different geographical areas.

The model assumes that with the increase of the total length the species also increases in weight, which determines the following functional relationship between the two parameters $W$ and $L$, which is nonlinear:

$W(i)=q * L(i)^{b}$, where: $W(i)$ is the weight of the studied species, $L(i)$ is length, $q$ is a scale coefficient, and $b-$ is the alometric coefficient, which determines the body form and the type of the growth: isometric or alometric. For most species it was found to be close to 3.00, while $q$ varied in value per different fish species. Fulton coefficient (condition factor): $K=\frac{W}{L^{B}} * 100$, where: $W$ is the weight of the studied species, $L-$ length, is also of significant interest when the condition of fish species stocks are being studied.

Batch fecundity can vary considerably during the short spawning season, low at the beginning, peaking during high spawning season and declining again towards the end. Annual egg production is the product of the number of batches spawned per year and the average number of eggs spawned per batch. Batch fecundity of sprat was determined using the 'Hydrated Oocyte Method' (Hunter et al., 1985). Oily hydrated females were used. After sampling their body cavity was opened and they were preserved in a buffered formalin solution (Hunter et al., 1985). Three tissue samples of ca. $50 \mathrm{mg}$ were removed from different parts of the ovary and their exact weight determined. Under a binocular, the number of hydrated oocytes in each of the three subsamples was determined. Hydrated oocytes can easily be separated from all other types of oocytes because of their large size, their translucent appearance and their wrinkled surface which is due to formalin preservation. Batch fecundity was estimated based on the average number of hydrated oocytes per unit weight of the three subsamples. Gonadosomatic Index (GSI) was determined monthly. GSI was calculated as: $G S I=\frac{G W}{S W} X 100$, where, GW is gonads weight and SW is somatic weight (represents the BW without GW).

\section{I.3 Results}

\section{I.3.1 Sprat landings in the period 2017-2019}

Project proposal № BG14MFOP001-3.003-0001 "Collection, management and use of data for the purposes of scientific analysis and implementation of the Common Fisheries Policy for the period 2017-2019", funded by the Maritime Affairs and Fisheries Program, co-financed by the European Union through the European Maritime and Fisheries Fund 

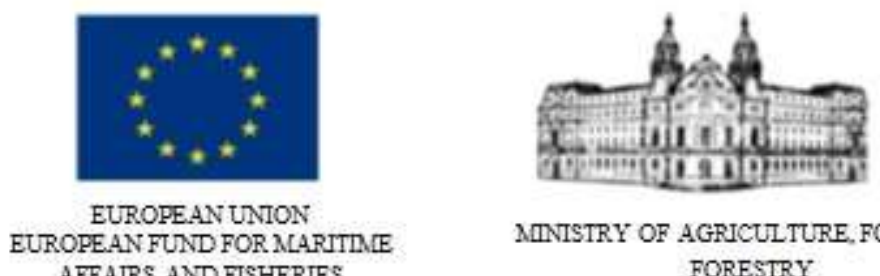

AINTSTRY OF AGRICUITURE, FOOD AND FORESTRY

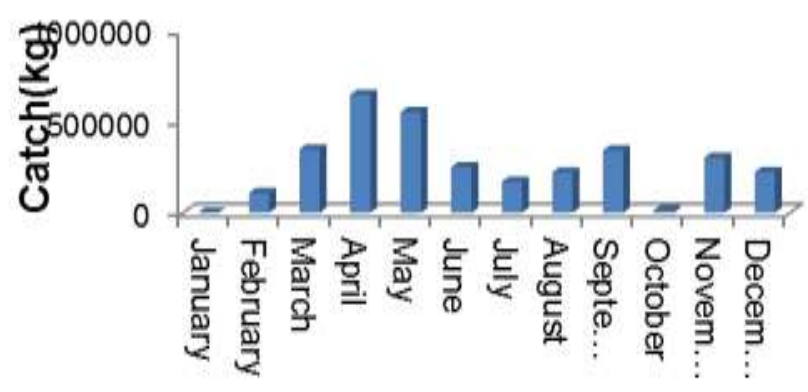

Fig. 3.1.1 Sprat landings in 2017
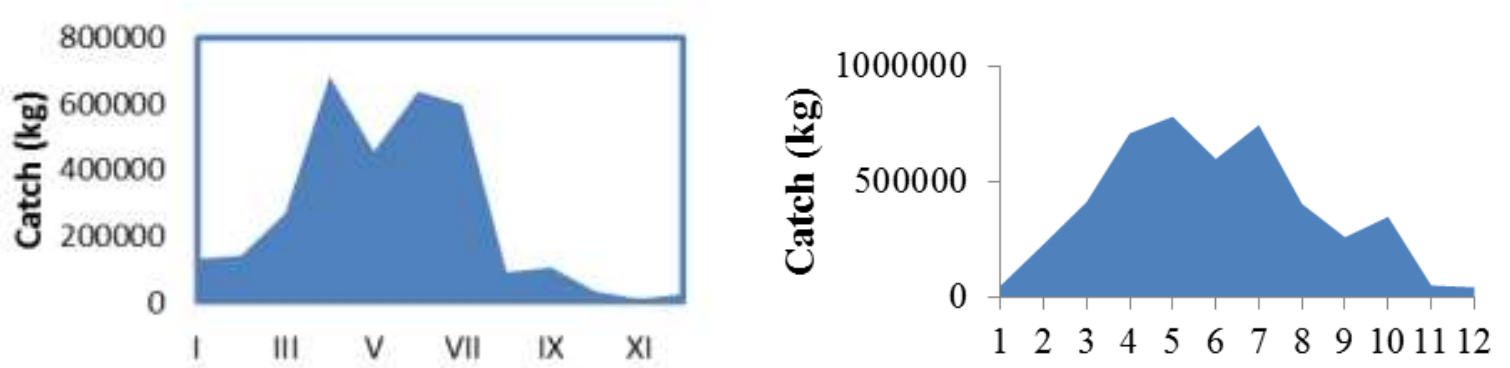

Fig. 3.1.2 Sprat landings in 2018 (left) and 2019 (right)

The official statistics showed that in 2017 the biggest catches and intensity of sprat fishery was registered in the period April - May, and in 2018 and 2019 in the months between April and July.

\section{I.3.2 Length structure of sprat catches in the period 2017-2019}

\section{I.3.2.1 Length structure analysis in 2017}

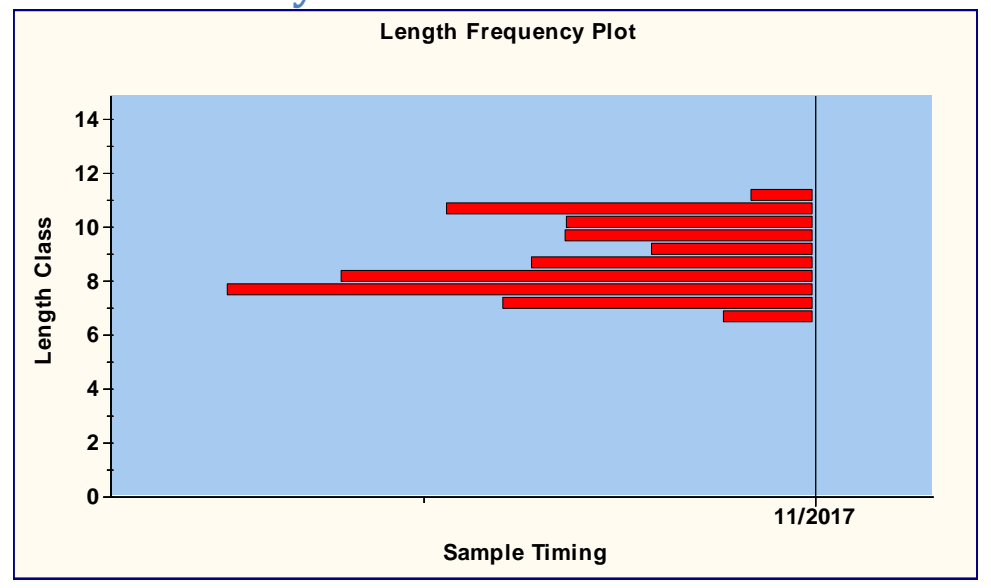

Fig. 3.2.1.1 Length structure of sprat, presented in the catches in November 2017

The length structure of sprat in 2017 is presented in Fig. 3.2.1.1. The total length of the specimens presented in the catches varied within the rage $6.5 \mathrm{~cm}-11.0 \mathrm{~cm}$, the biggest percentage shares were registered for length classes $7.5 \mathrm{~cm}, 9.0 \mathrm{~cm}$ and $10 \mathrm{~cm}$.

Project proposal № BG14MFOP001-3.003-0001 "Collection, management and use of data for the purposes of scientific analysis and implementation of the Common Fisheries Policy for the period 2017-2019", funded by the

Maritime Affairs and Fisheries Program, co-financed by the European Union through the European Maritime and Fisheries Fund 


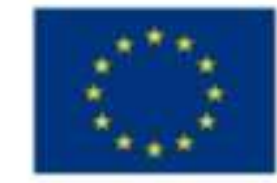

EUROPEANUNTON EUROPEAN FUND FOR MLARITIIE AFFAIRS AND FISHERIES

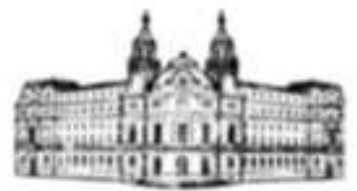

AINISTRY OF AGRICULTURE, FOOD AND FORESTRY
MLARITLE AFFAIRS AND FISHERIES PROGRAM

\section{I.3.2.2 Length structure analysis in 2018}

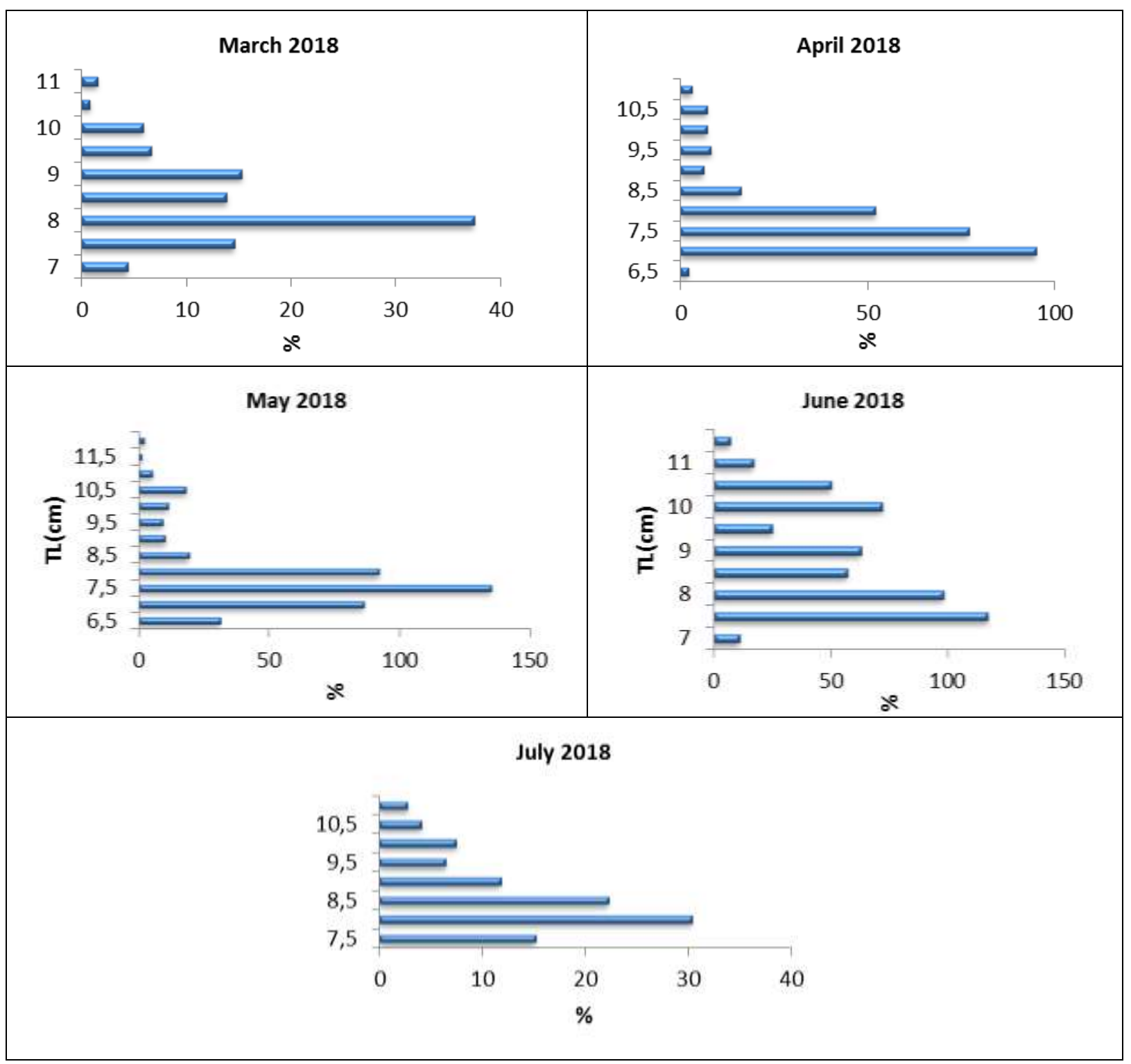

Fig. 3.2.2.1 Length structure of sprat, presented in the catches in the period March-July 2018

In March the total length of the sampled specimens varied in the range $7-11 \mathrm{~cm}$, as with the biggest share in the length structure was presented the length class of $8 \mathrm{~cm}$, the smallest share was registered for the length class $10.5 \mathrm{~cm}$. In April the total length of the sampled specimens varied in the range $6.5-11 \mathrm{~cm}$, the biggest percentage share in the length structure had length classes $7,7.5$ and $8 \mathrm{~cm}$, and the smallest one was registered for the length class $6.5 \mathrm{~cm}$. In May the total length of the sampled specimens varied in the range $6.5-12 \mathrm{~cm}$, the biggest percentage

Project proposal № BG14MFOP001-3.003-0001 "Collection, management and use of data for the purposes of scientific analysis and implementation of the Common Fisheries Policy for the period 2017-2019", funded by the Maritime Affairs and Fisheries Program, co-financed by the European Union through the European Maritime and Fisheries Fund 


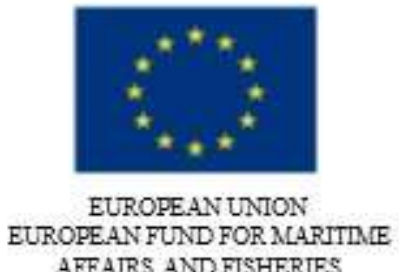

AFFAIRS AND FISHERIES

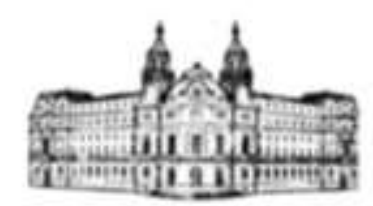

AINISTRY OF AGRICULTURE, FOOD AND FORESTRY

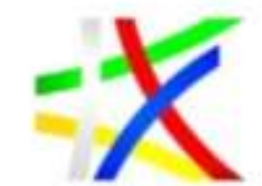

MCARITLE AFFAIRS AND FISHERIES PROGRAM

share in the length structure had the length classes $7,7.5$ and $8 \mathrm{~cm}$, and with the smallest percentage shares were registered the length classes 11.5 and $12 \mathrm{~cm}$. In June, the length classes $7.5,8$ and $10 \mathrm{~cm}$ were registered with the biggest percentage shares, and the smallest one was registered for the length class $11.5 \mathrm{~cm}$. In July with the biggest shares were the length cclasses $8 \mathrm{~cm}$ and $8.5 \mathrm{~cm}$, and with the smallest $-11.5 \mathrm{~cm}$.

\section{I.3.2.3 Length structure analysis in 2019}

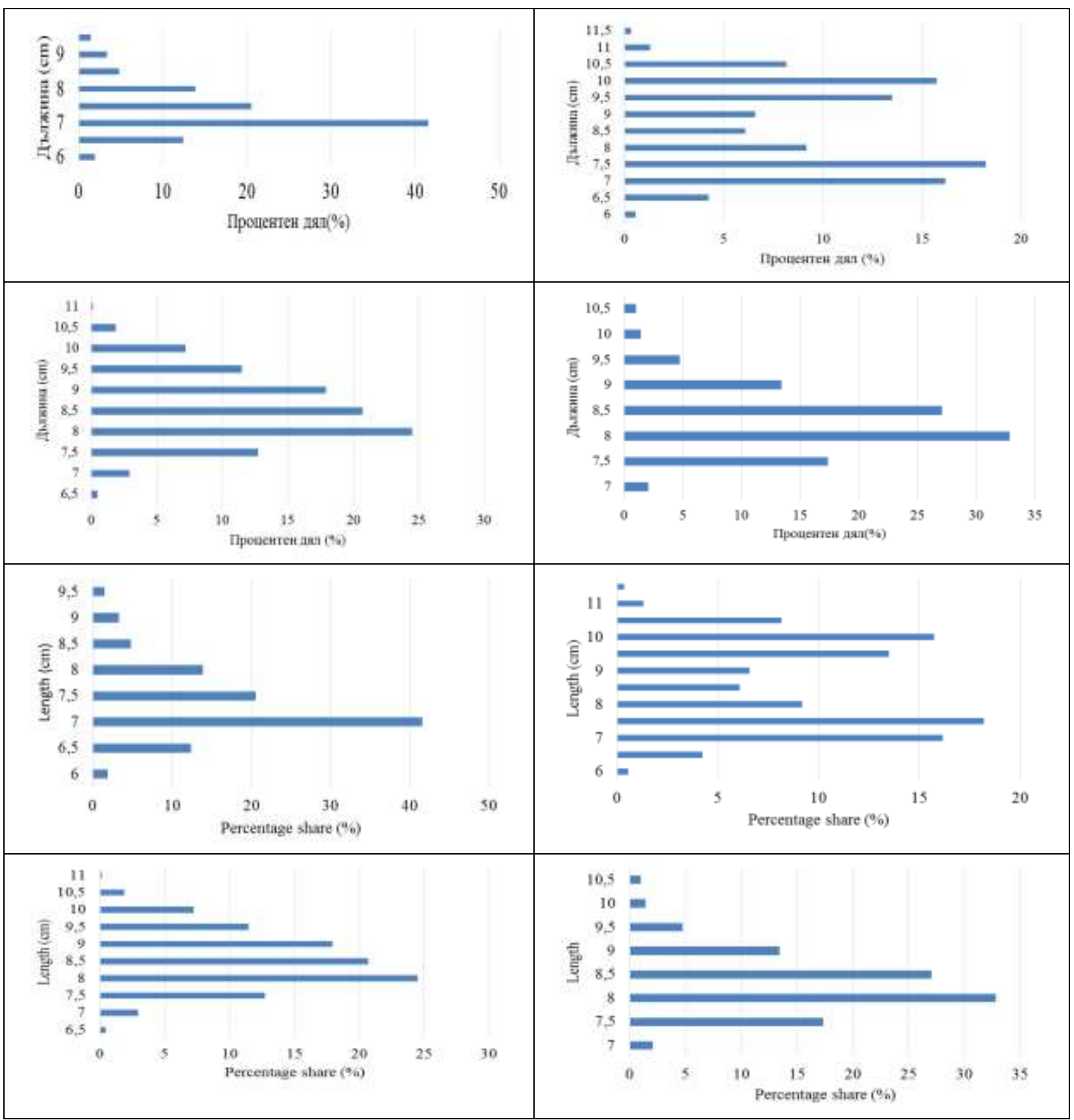

Project proposal № BG14MFOP001-3.003-0001 "Collection, management and use of data for the purposes of scientific analysis and implementation of the Common Fisheries Policy for the period 2017-2019", funded by the Maritime Affairs and Fisheries Program, co-financed by the European Union through the European Maritime 


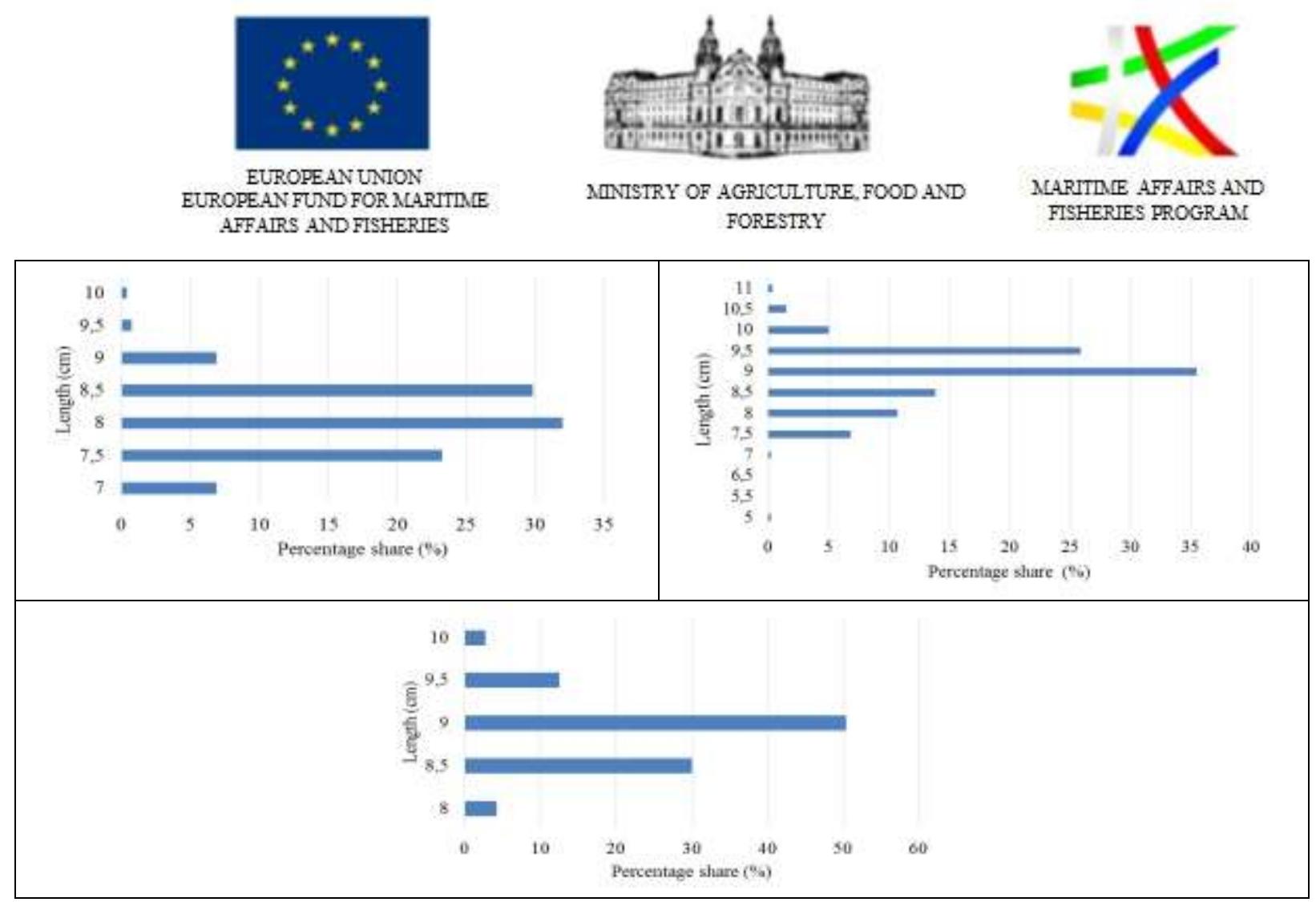

Fig. 3.2.3.1 Length structure of sprat landings, presented in the catches in the period February - December 2019

In February, the total length of sampled specimens varied in the range $6 \mathrm{~cm}$ to $9.5 \mathrm{~cm}$, length classes 7, 7.5 and $8 \mathrm{~cm}$ were most frequent in the catches, and the less frequent length class was $9.5 \mathrm{~cm}$. In March, the total length of sampled specimens varied in the range $6.5-11 \mathrm{~cm}$, with the biggest percentage share in the catches length structure were presented length classes $7,7.5,9.5$ and $10 \mathrm{~cm}$, and the smallest percentage share was registered for length class 11.5 $\mathrm{cm}$. In April, the total length of sampled specimens varied in the range $6.5-11 \mathrm{~cm}$, most frequent in the catches were length classes $8,8.5$ and $9 \mathrm{~cm}$, the less frequent class was $11 \mathrm{~cm}$. In May, most frequent in the catches' length structure were classes $8 \mathrm{~cm}$ and $8.5 \mathrm{~cm}$, less frequent specimens with total length of $10.5 \mathrm{~cm}$. In June, the biggest percentage shares in the samples were registered for the length classes 7,8 and $8.5 \mathrm{~cm}$, the smallest share was of the length class $10 \mathrm{~cm}$. In July, the total length of sampled specimens varied in the range $5-11$ $\mathrm{cm}$, most frequent in length structure of the catches were length classes $9 \mathrm{~cm}$ and $9.5 \mathrm{~cm}$, less frequent $-7 \mathrm{~cm}$ and $11 \mathrm{~cm}$. In August, the total length of sampled specimens varied in the range $8-10 \mathrm{~cm}$, most frequent in the length structure of the catches was class $9 \mathrm{~cm}$, less frequent - class $10 \mathrm{~cm}$. In September and October, the most present within the length structure of catches were classes 9, 9.5, 10 and $10.5 \mathrm{~cm}$ and less frequent were classes $11 \mathrm{~cm}$ and 11.5 $\mathrm{cm}$. Most frequent in the samples collected in November were classes $7.5,8$ and $8.5 \mathrm{~cm}$, less frequent $-6 \mathrm{~cm}$ and $11 \mathrm{~cm}$, in December most frequent $7 \mathrm{~cm}$ and $8 \mathrm{~cm}$ and less frequent $11.5 \mathrm{~cm}$ and $12 \mathrm{~cm}$.

Due to the high amount of the samples collected in 2019, the length structure of the catches represented the natural dynamics and seasonality of growth parameters of the studied species. In general, for the entire period of the research 2017-2019 most abundant and respectively most frequent in the catches were specimens with length from $7 \mathrm{~cm}$ to $10 \mathrm{~cm}$, those with total length below $7 \mathrm{~cm}$ were hardly presented in the catch composition due to the selectivity of the

Project proposal № BG14MFOP001-3.003-0001 "Collection, management and use of data for the purposes of scientific analysis and implementation of the Common Fisheries Policy for the period 2017-2019", funded by the Maritime Affairs and Fisheries Program, co-financed by the European Union through the European Maritime and Fisheries Fund 


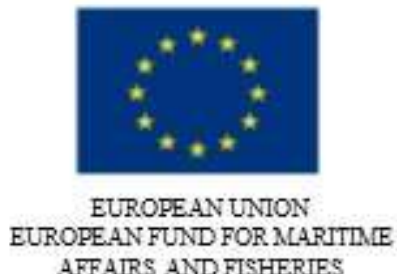

AFFAIRS AND FISHERIES

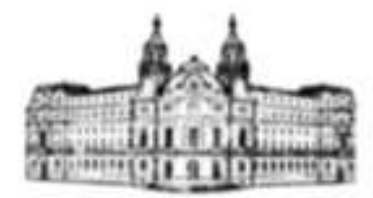

MINISTRY OF AGRICULTURE, FOOD AND FORESTRY
MLARITLIE AFFAIRS AND FISHERIES PROGRAM

fishing gears used. Thus, it can be further assumed that in the exploitation phase the specific total length varied within the range from $7 \mathrm{~cm}$ to $12 \mathrm{~cm}$.

Specimens with total length above $11 \mathrm{~cm}$ were rare in the catches due to the natural physiology and biology of the studied species.

\section{I.3.3 Age structure analysis of sprat in the period 2017-2019}

\section{I.3.3.1 Age structure analysis in 2017}

Three ichthyologists determined the age of sprat otoliths, and one of them read all otoliths twice. Specimens $(n=1250)$ were used for age determination. Indices of precision for age readings within and between readers are presented in Table 3.3.1.1. The test of symmetry $\left(\chi^{2}\right.$

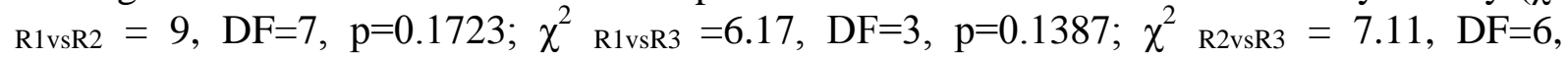
$\mathrm{P}=0.3021$ ) showed that age disagreement was due to simple random error and not to a systematic error between readers.

Table 3.3.1.1 Indices of precision for age readings of sprat, from the Bulgarian Black Sea waters, within and between readers

\begin{tabular}{|c|c|c|}
\hline \multirow[t]{2}{*}{ Index } & \multicolumn{2}{|c|}{ Index comparison } \\
\hline & Reader 1 & Between readers \\
\hline APE [\%] & 2.102 & 3.069 \\
\hline CV [\%] & 2.063 & 4.211 \\
\hline $\mathrm{D}[\%]$ & 1.623 & 2.34 \\
\hline
\end{tabular}

$\mathrm{APE}=$ average percentage error, $\mathrm{CV}=$ coefficient of variation, $\mathrm{D}=$ index of precision.

In November, the age distribution showed five age classes (0-4). 1-1+, 2-2+ and 3-3+ age groups were presented with almost equal shares in the landings. The oldest specimens in the samples belong to $4+$ years old, with a very low share in the landings. The recruitment share was detected to be $11.99 \%$.

\section{Age distribution of sprat - XI, 2017}

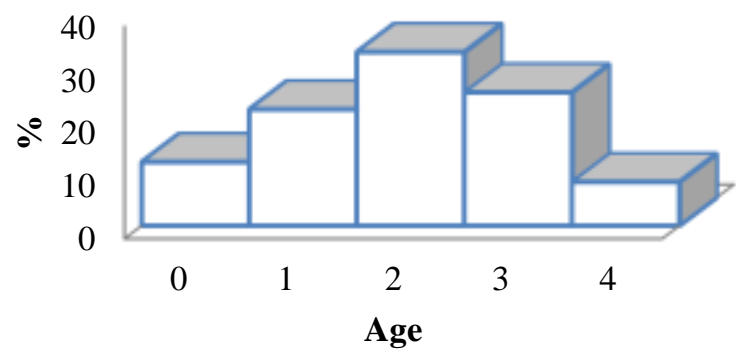

Fig. 3.3.1.2 Age distribution of sprat in November, 2017

Project proposal № BG14MFOP001-3.003-0001 "Collection, management and use of data for the purposes of scientific analysis and implementation of the Common Fisheries Policy for the period 2017-2019", funded by the Maritime Affairs and Fisheries Program, co-financed by the European Union through the European Maritime and Fisheries Fund 


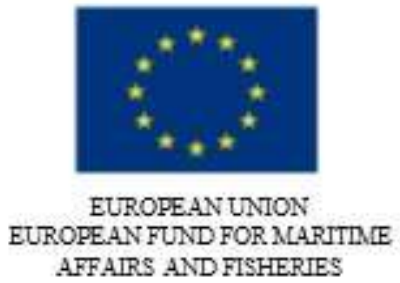

AFFAIRS AND FISHERIES

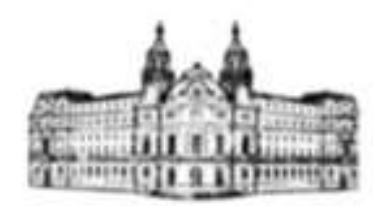

AINISTRY OF AGRICULTURE, FOOD AND FORESTRY
MLARITLIE AFFAIRS AND FISHERIES PROGRAM

\section{I.3.3.2 Age structure analysis in $\mathbf{2 0 1 8}$}

The same technology as the one described for age reading in 2017 was applied. The test of symmetry $(\chi 2 \mathrm{R} 1 \mathrm{vsR} 2=7, \mathrm{DF}=8, \mathrm{p}=0.242 ; \chi 2 \mathrm{R} 1 \mathrm{vsR} 3=5.70, \mathrm{DF}=2, \mathrm{p}=0.3314 ; \chi 2 \mathrm{R} 2 \mathrm{vsR} 3=$ $6.81, \mathrm{DF}=5, \mathrm{P}=0.2904$ ) showed that age disagreement was due to simple random error and not to a systematic difference between readers.

Table 3.3.2.1 Indices of precision for age readings of sprat, from the Bulgarian Black Sea waters, within and between readers

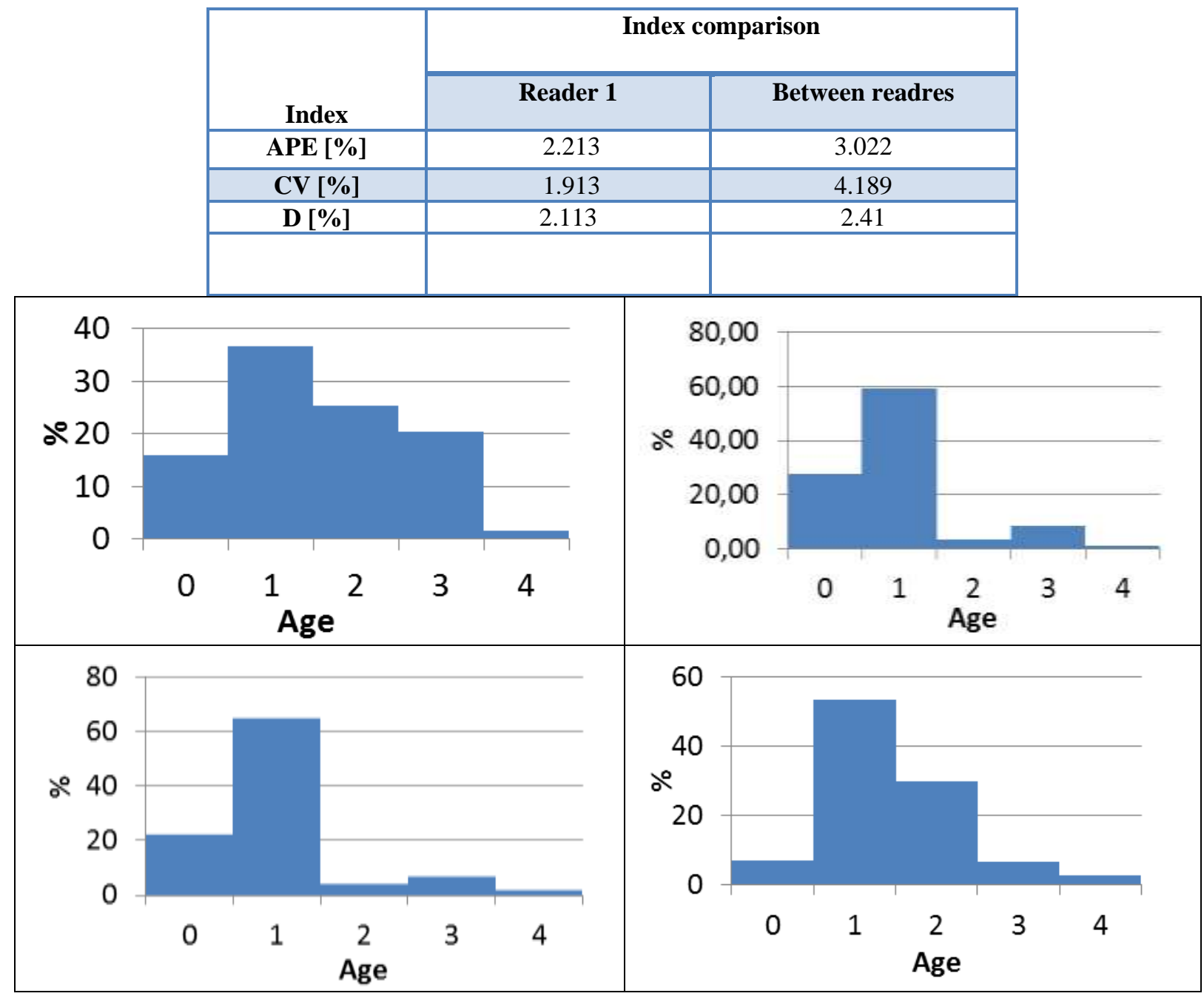

Project proposal № BG14MFOP001-3.003-0001 "Collection, management and use of data for the purposes of scientific analysis and implementation of the Common Fisheries Policy for the period 2017-2019", funded by the Maritime Affairs and Fisheries Program, co-financed by the European Union through the European Maritime and Fisheries Fund 


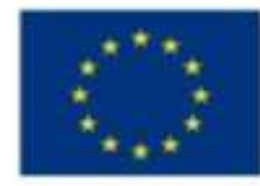

EUROPEAN UNTON EUROPEAN FUND FOR MLARITIIE AFFAIRS AND FISHERIES

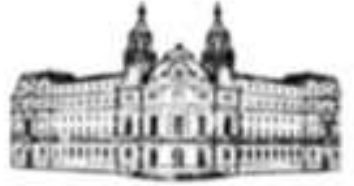

MINISTRY OF AGRICUITURE, FOOD AND FORESTRY

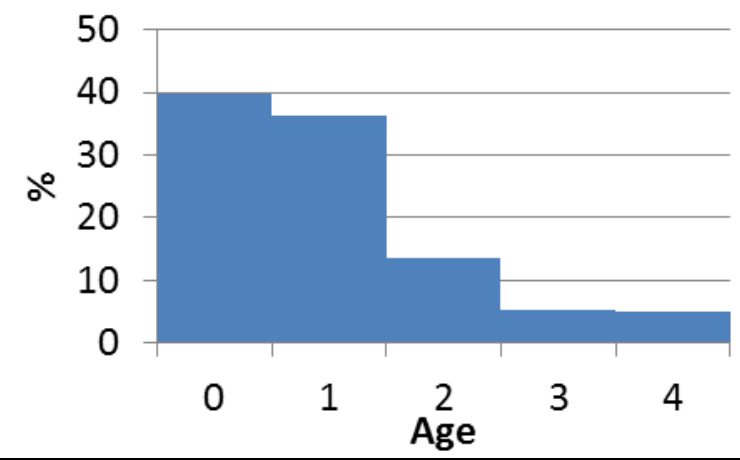

Fig. 3.3.2.1 Age distribution of sprat March - July 2018

In the majority of the samples collected during the studied period, the highest share was registered for age group 1-1+, with the exception of July samples where age group 0-0+ was most frequent. This is an indication for second annual recruitment of the stock which is considered in compliance with the concept for its seasonal dynamics, recruitment dynamics and sustainable development.

\section{I.3.3.3 Age structure analysis in 2019}

The same technology as the one described for age reading in 2017 was applied. Three readers determined the age of sprat otoliths, and one of them read all otoliths twice. Specimens $(\mathrm{n}=$ 1250) were used for age determination. Indices of precision for age readings within and between readers are presented in Table 3.3.3.1. The test of symmetry ( $\chi 2$ R1vsR $2=4, \mathrm{DF}=$, $\mathrm{p}=0.411 ; \chi 2 \mathrm{R} 1 \mathrm{vsR} 3=3.70, \mathrm{DF}=4, \mathrm{p}=0.2361 ; \chi 2 \mathrm{R} 2 \mathrm{vsR} 3=3.16, \mathrm{DF}=4, \mathrm{P}=0.2100$ ), showed that age disagreement was due to simple random error and not to a systematic difference between readers.

Table 3.3.3.1 Indices of precision for age readings of sprat from the Bulgarian Black Sea waters, within and between readers

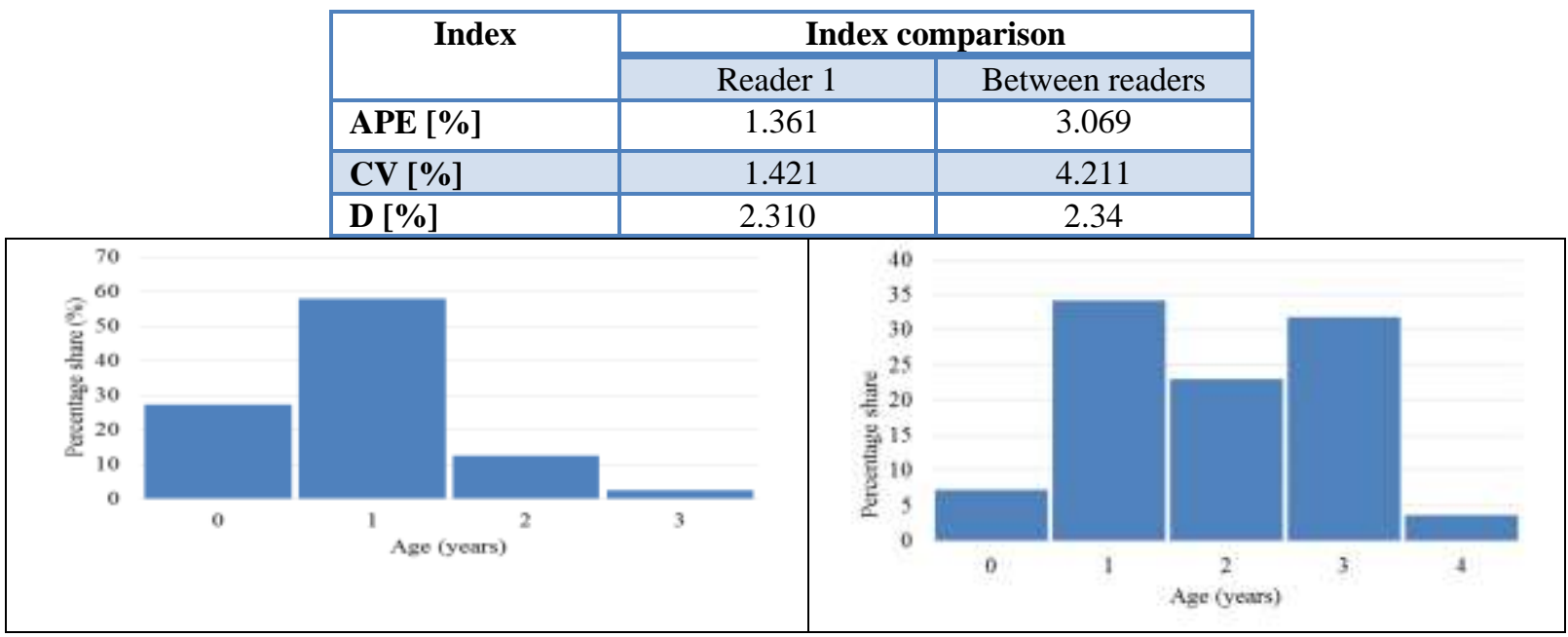

Project proposal № BG14MFOP001-3.003-0001 "Collection, management and use of data for the purposes of scientific analysis and implementation of the Common Fisheries Policy for the period 2017-2019", funded by the Maritime Affairs and Fisheries Program, co-financed by the European Union through the European Maritime and Fisheries Fund 


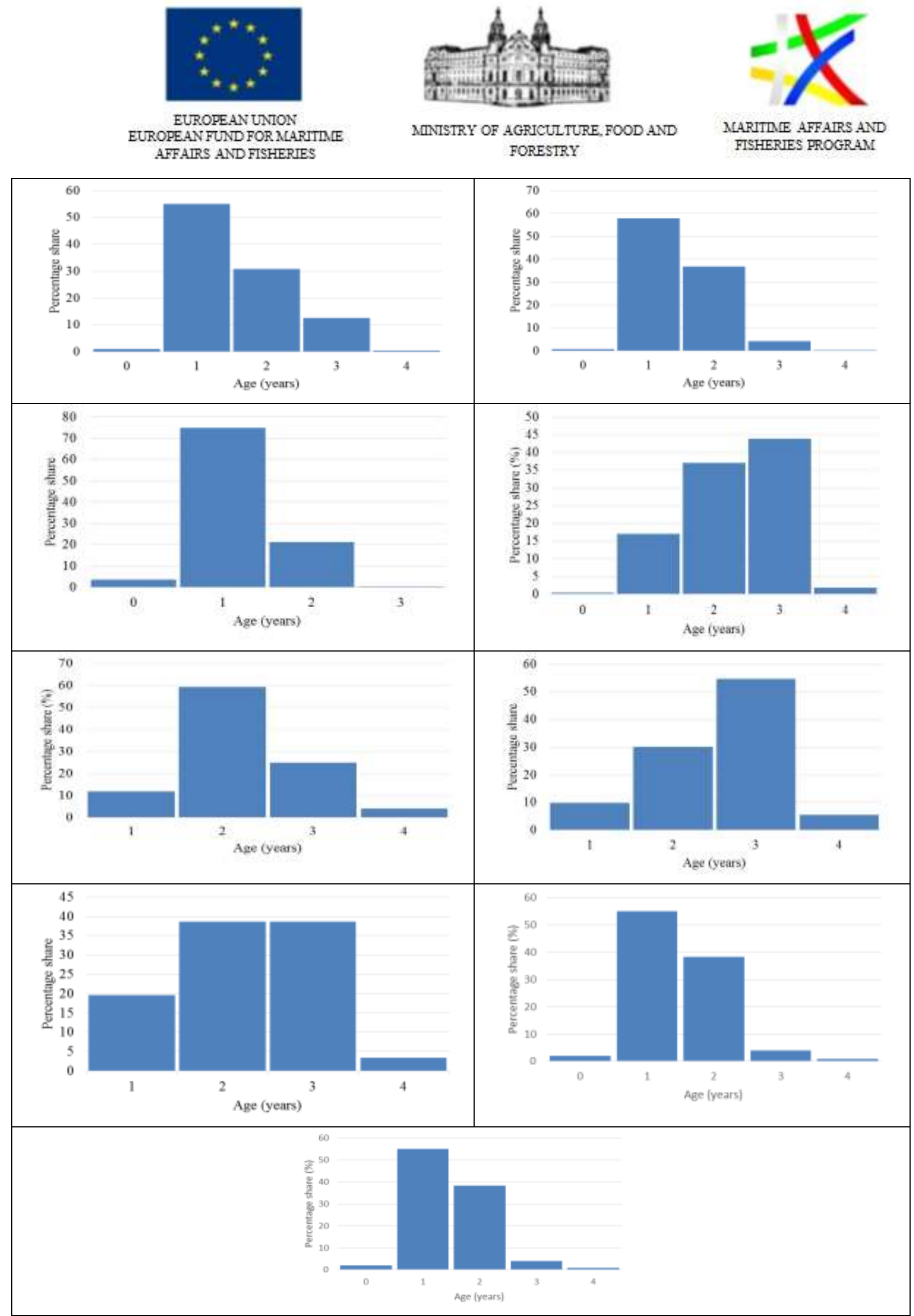

Fig. 3.3.3.1 Age structure of sprat from February to December 2019

Project proposal № BG14MFOP001-3.003-0001 "Collection, management and use of data for the purposes of scientific analysis and implementation of the Common Fisheries Policy for the period 2017-2019", funded by the Maritime Affairs and Fisheries Program, co-financed by the European Union through the European Maritime and Fisheries Fund 


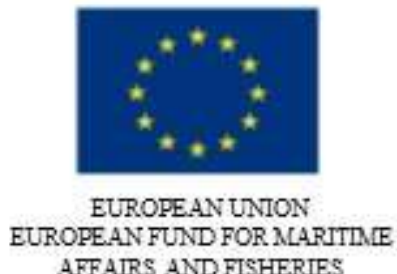

AFFAIRS AND FISHERIES

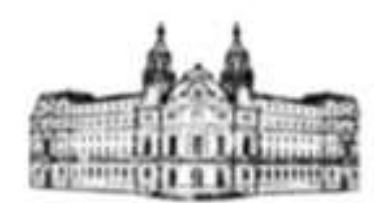

AINISTRY OF AGRICULTURE, FOOD AND FORESTRY

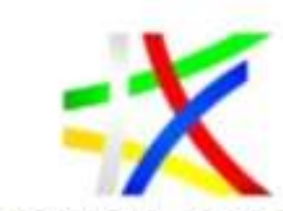

MCARITIE AFFAIRS AND FISHERIES PROGRAM

Age structure analysis in February showed that 1-1+age group was presented with $59 \%$ of the total number and 0+ age group - with $28 \%$ which showed that recruitment in February was high and the spawning processes in late 2018 were increased with comparatively high percentage. Age groups 2-2+ and 3-3+ were represented with $12 \%$ and $2 \%$, respectively. The oldest age groups were not presented in the catch. In March, the dynamics of age distribution showed decrease in the recruitment $(0+)$, still high share of 1-1+ age group, but significant increase of 2-2+ and especially of 3-3+ age group. 4-4+age olds were discovered in the catch as well. In April 2019, 1-1+age group was presented with 55\%, 2-2+ with 30\%. The presence of $0+$ and 4-4+ age groups was negligible. In May, the age structure observed was almost the same as the one observed in April, and the share of 3-3+even decreased. In June, the prevailing with over $70 \%$ share belong to $1-1+$ age group. The rest of age groups were presented with a low percentage. 4-4+old individuals were not presented in the catch. In July, the share of $1-1+$ decreased significantly, 2-2+ years old accounted for $37 \%$, and 3-3+ for 44\%. 4-4+ age group was represented with a low share. In August 2019, 2-2+olds showed almost $60 \%$ representation in the catch, the rest of the groups were with lower shares. In September, 3-3+ year old individuals were presented with 55\%, followed by 2-2+ with $30 \%$ share. The rest of the groups were presented with lower shares. In October 2019, 2-2+ and 3$3+$ old specimens showed equal share $36 \%$, similar to August and September, no recruitment of $0+$ was discovered in the catches. Still, the share of 1-1+ age group was high - about $20 \%$. The oldest groups were represented with a share around $3 \%$ in the catch. In November 2019, a high percentage of 1-1+ and 2-2 + age groups was registered. The appearance of recruitment $(0+)$ made an impression. 3-3+ and 4-4+ year olds were presented with very low percentage share in the catch. The one-year-old numbers raised to $55 \%$ in December's catches. The recruitment $(0+)$ increased compared to November, $2-2+$ decreased their percentage presence at the expense of 3-4 + individuals.

Due to the high amount of the samples collected in 2019, the age structure of the catches represented the natural dynamics and seasonality of growth parameters of the studied species.

\section{I.3.4 Sprat condition factor analysis 2017-2019}

\section{I.3.4.1 Fulton's condition factor of sprat in 2017}

In November 2017, the condition factor of sprat showed an increase in all age groups. The condition factor of age group $0-0+$ is usually estimated higher than the rest groups (Fig. 3.4.1.1)

Project proposal № BG14MFOP001-3.003-0001 "Collection, management and use of data for the purposes of scientific analysis and implementation of the Common Fisheries Policy for the period 2017-2019", funded by the Maritime Affairs and Fisheries Program, co-financed by the European Union through the European Maritime and Fisheries Fund 


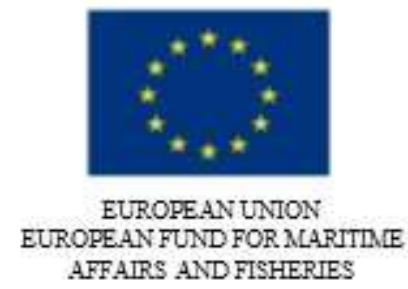

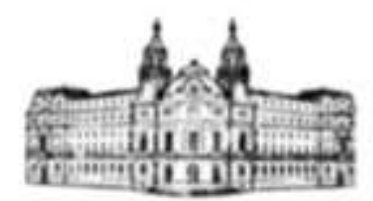

AINTSTRY OF AGRICUITURE, FOOD AND FORESTRY
MLARITLIE AFFAIRS AND FISHERIES PROGRAM

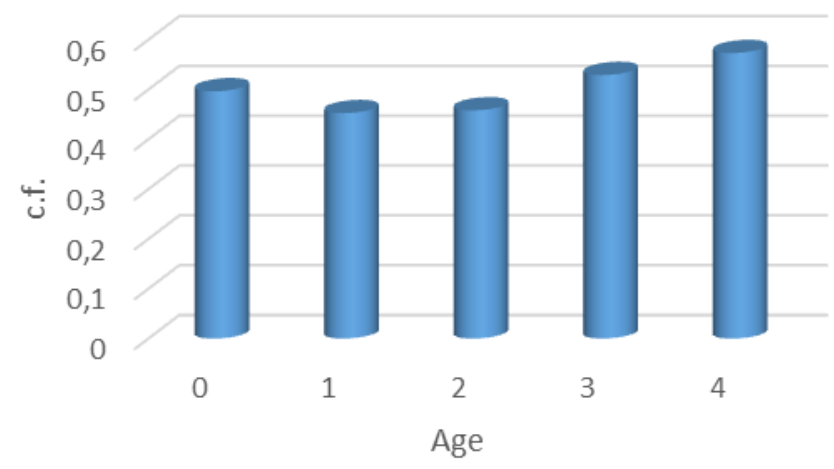

Fig. 3.4.1.1 Condition factor of sprat in November, 2017

\section{I.3.4.2 Fulton's condition factor of sprat in 2018}

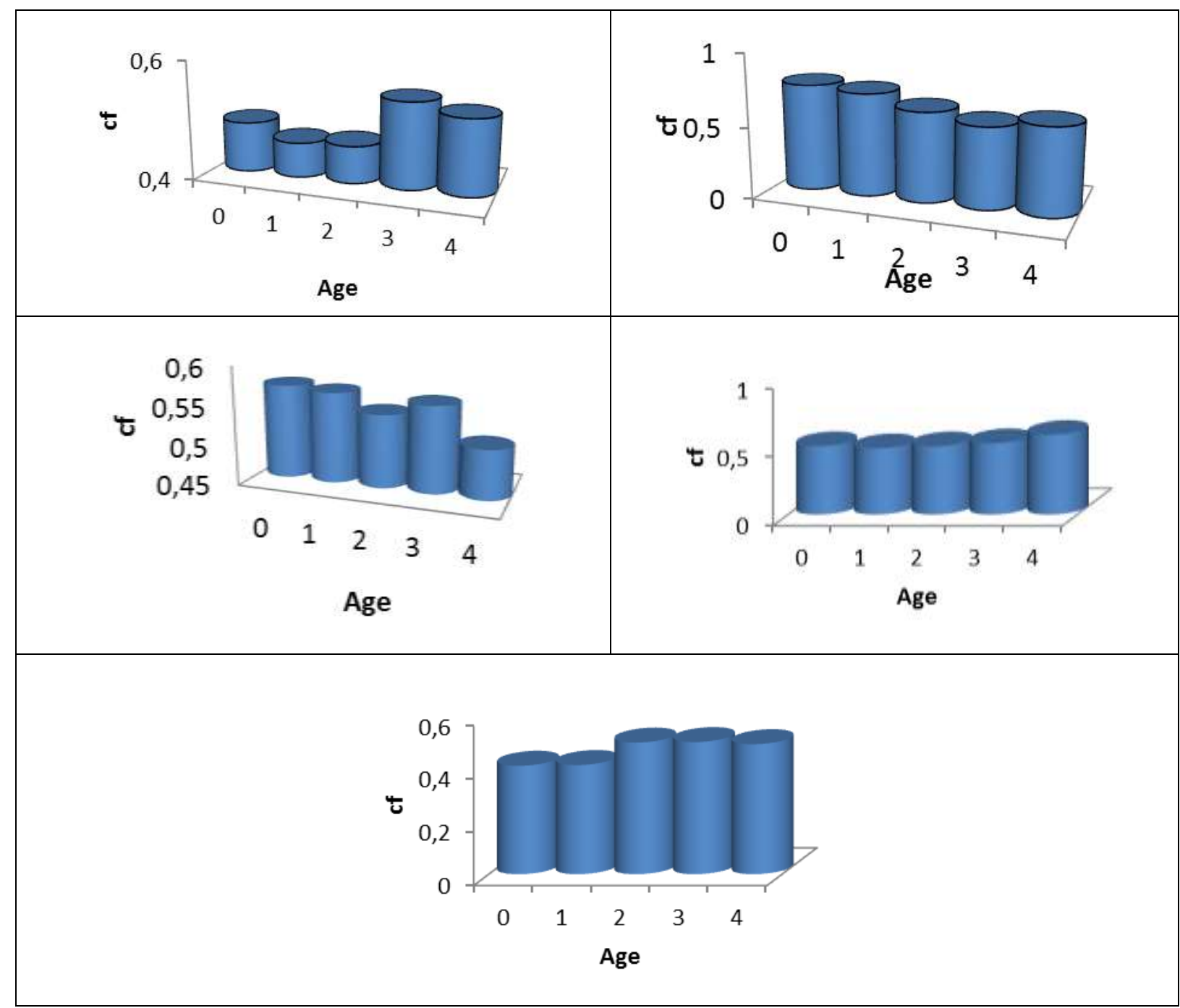

Fig. 3.4.2.1 Condition factor of sprat in the period March - July 2018

Project proposal № BG14MFOP001-3.003-0001 "Collection, management and use of data for the purposes of scientific analysis and implementation of the Common Fisheries Policy for the period 2017-2019", funded by the Maritime Affairs and Fisheries Program, co-financed by the European Union through the European Maritime 


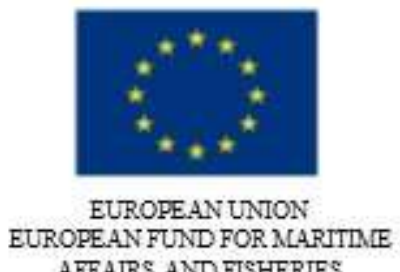

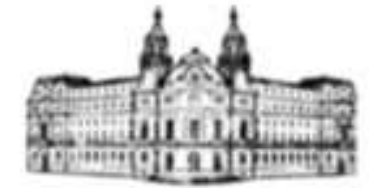

AINISTRY OF AGRICUITURE, FOOD AND FORESTRY

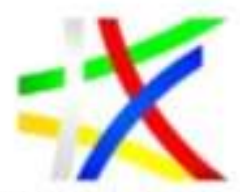

MLARITLE AFFAIRS AND FISHERIES PROGRAM

Fulton's condition factor variations were observed for the entire period of the research, most likely due to the natural variability of growth parameters as length and weight. From April to June the Fulton's condition factor decreased for all age groups with the exception of $0-0+$, which was compensated in July and the condition of age group $0-0+$ decreased as a result of the new recruitment to the stock and that specific pattern was expected to reappear in the annual dynamics of sprat growth parameters.

\section{I.3.4.3 Fulton's condition factor of sprat in 2019}

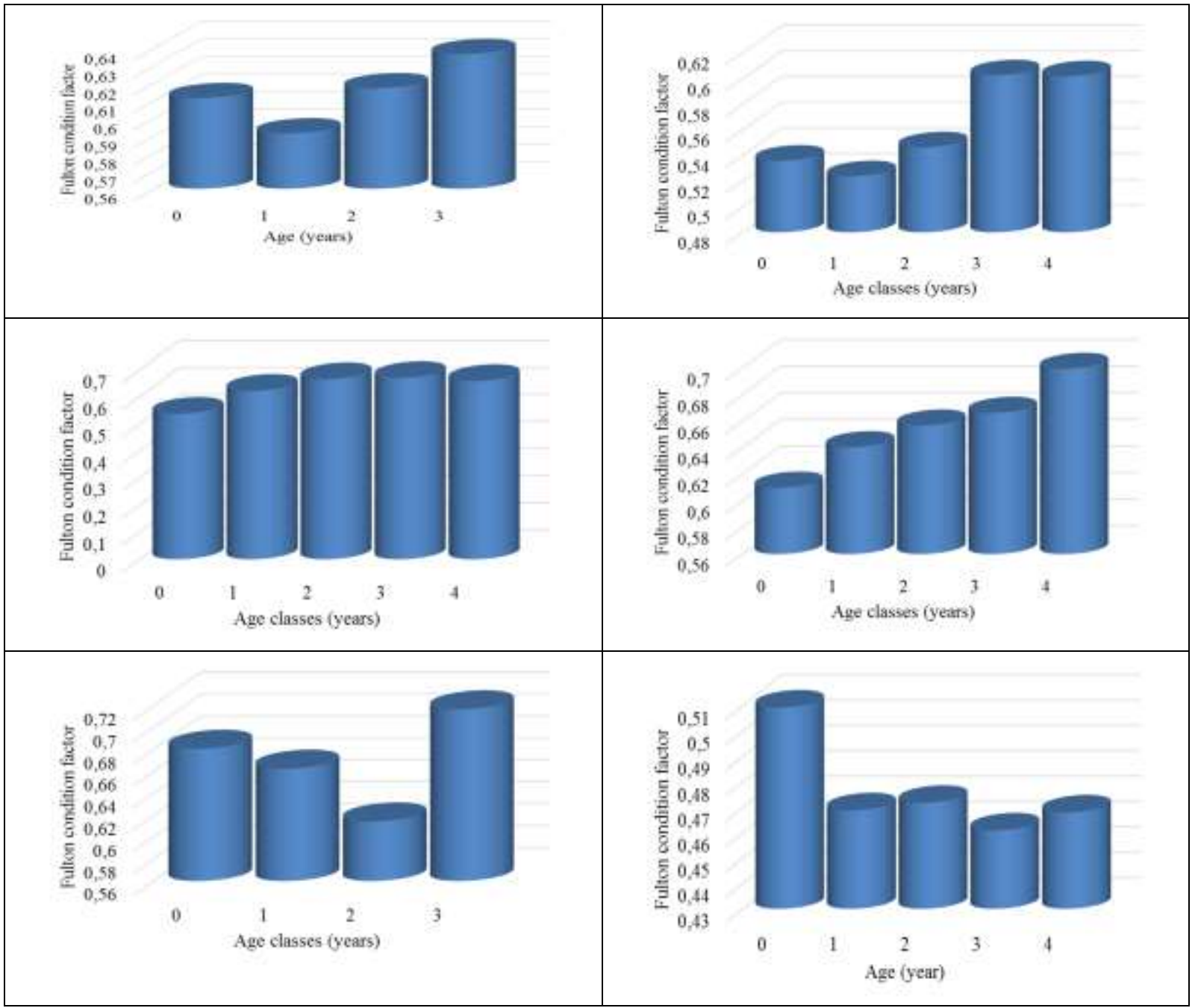

Project proposal № BG14MFOP001-3.003-0001 "Collection, management and use of data for the purposes of scientific analysis and implementation of the Common Fisheries Policy for the period 2017-2019", funded by the Maritime Affairs and Fisheries Program, co-financed by the European Union through the European Maritime and Fisheries Fund 


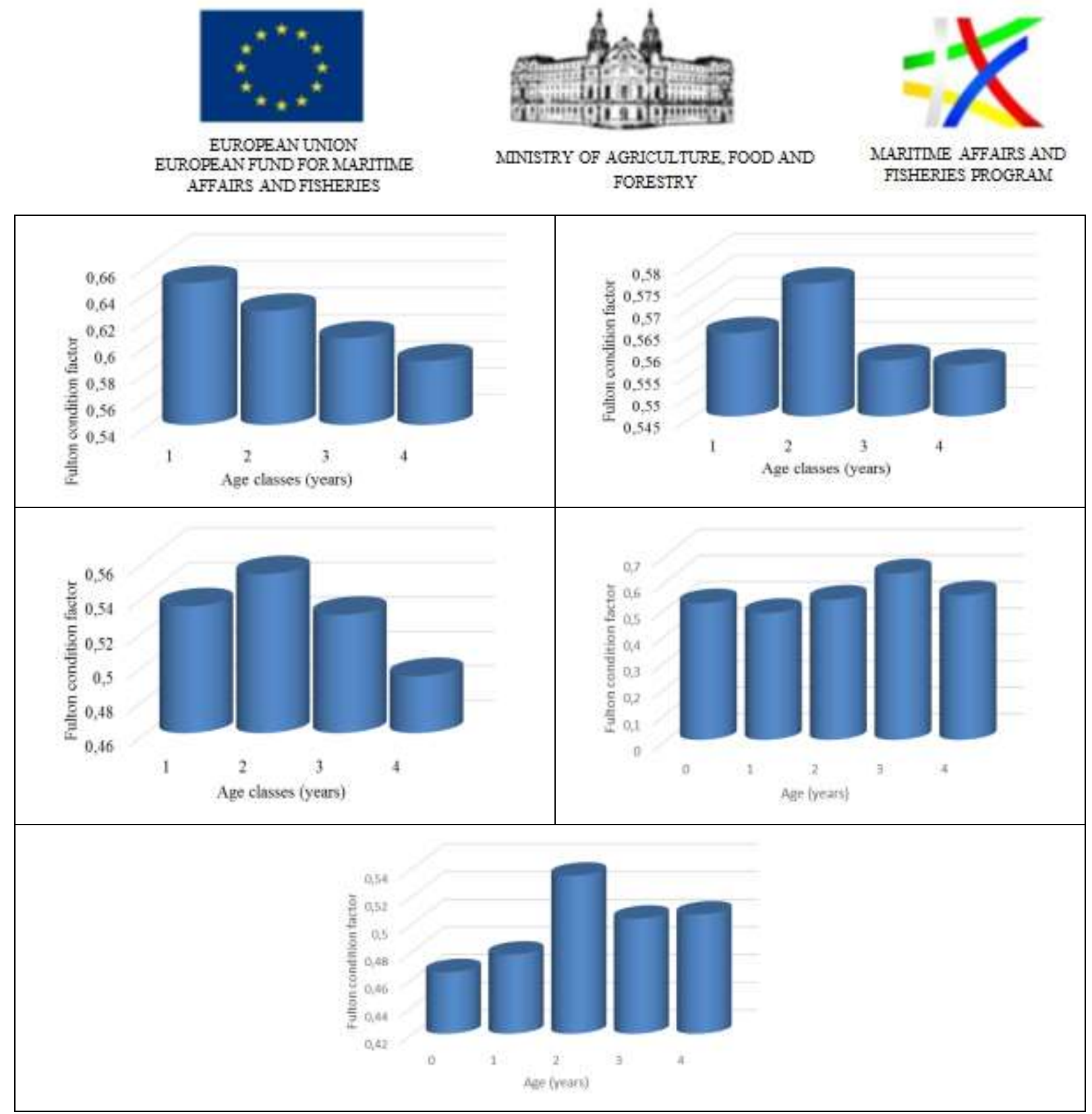

Фиг. 3.4.3.1 Fulton's condition factor in the period February - December 2019

In 2019, Fulton's condition factor of sprat again varied significantly as a result of growth parameters variability and species environment.

Project proposal № BG14MFOP001-3.003-0001 "Collection, management and use of data for the purposes of scientific analysis and implementation of the Common Fisheries Policy for the period 2017-2019", funded by the Maritime Affairs and Fisheries Program, co-financed by the European Union through the European Maritime and Fisheries Fund 


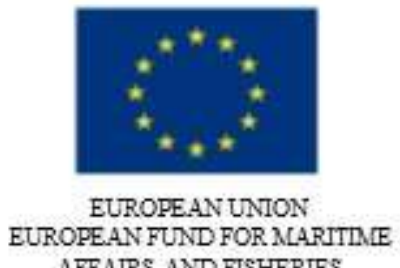

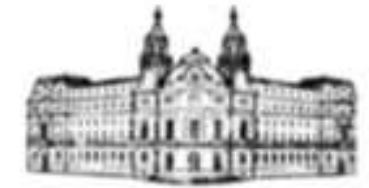

MINISTRY OF AGRICUITURE, FOOD AND FORESTRY

\section{I.3.5 Weight structure of sprat in the period 2018-2019}

\section{I.3.5.1 Weight structure of sprat in 2018}

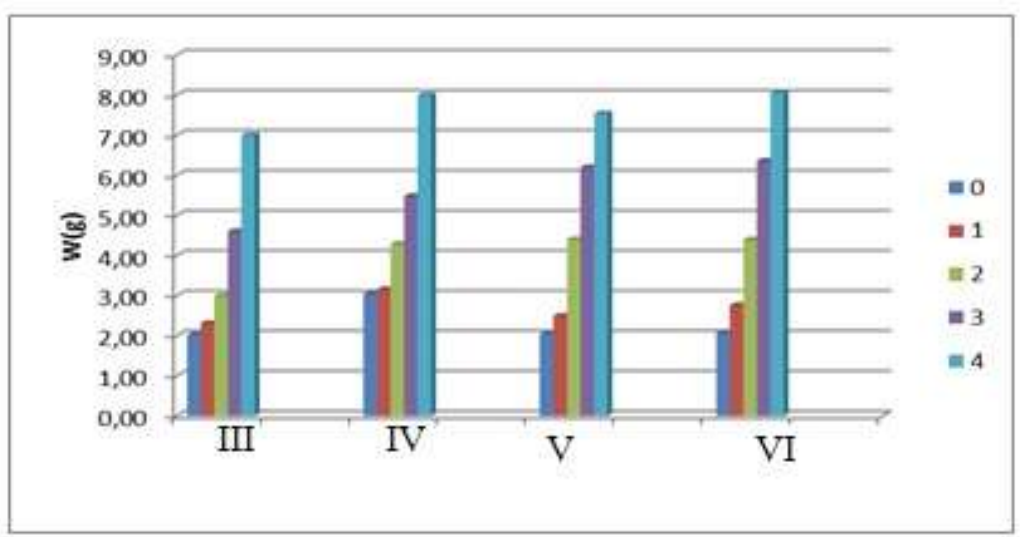

Fig. 3.5.1.1 Weight structure of sprat by age groups in 2018

It is evident that the mean weight of age groups $0-0+$ and 1-1+ tended to increase in April, however later in May and June it went down to the levels registered in March. Age group 2$2+$ showed an increase in the mean weight with $1 \mathrm{~g}$ from March to April and remained the same in May and June. Age group 3-3+ showed a sustainable increase in the mean weight for the entire period of the research and the mean weight of age group 4-4+ varied in a short range between $7 \mathrm{~g}$ and $8 \mathrm{~g}$.

\section{I.3.5.1 Weight structure of sprat in 2019}

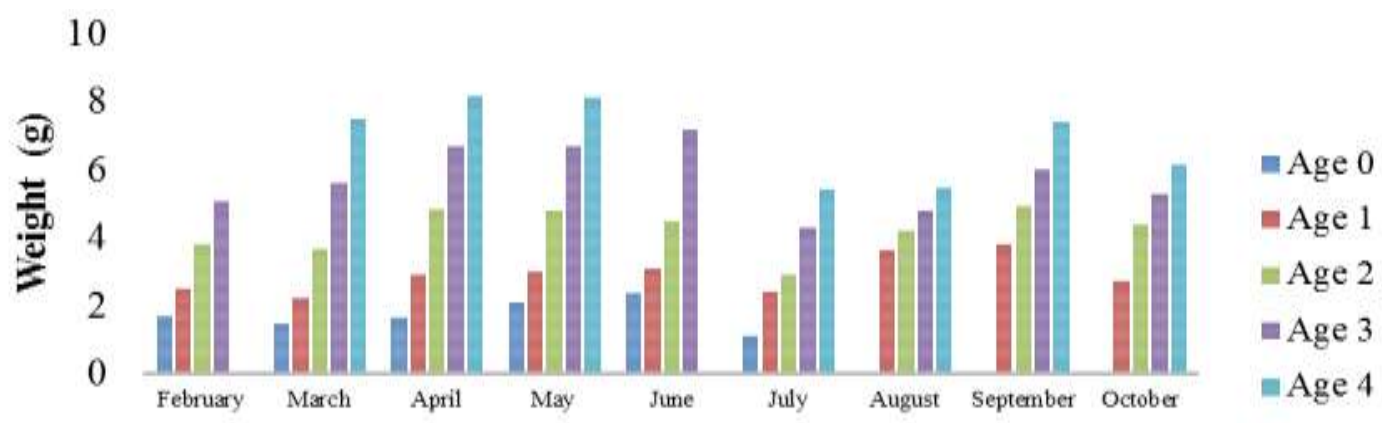

Project proposal № BG14MFOP001-3.003-0001 "Collection, management and use of data for the purposes of scientific analysis and implementation of the Common Fisheries Policy for the period 2017-2019", funded by the Maritime Affairs and Fisheries Program, co-financed by the European Union through the European Maritime and Fisheries Fund 


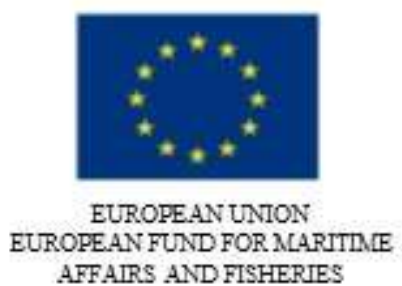

AFFAIRS AND FISHERIES

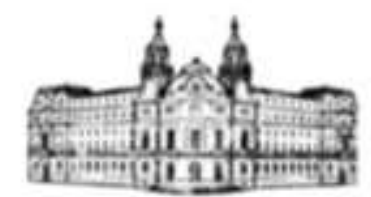

AINISTRY OF AGRICULTURE, FOOD AND FORESTRY
MLARITLIE AFFAIRS AND FISHERIES PROGRAM

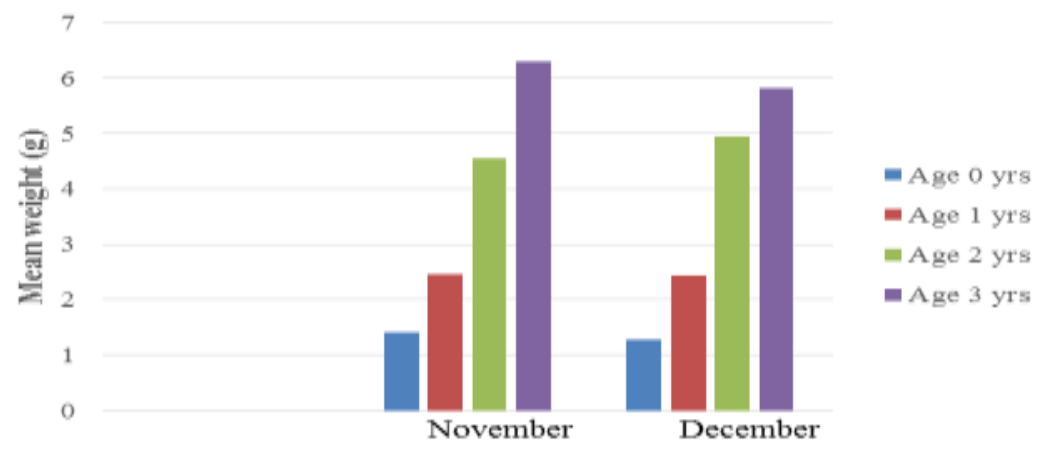

Fig. 3.5.1.1 Weight structure of sprat by age groups in 2019

As 2019 research covered longer period, the analysis of weight structure on almost annual basis showed the natural variability and seasonality of sprat weight. In the period September - February, a decrease in the mean weights by age groups was observed and in the period March - June, respectively, an increase of the mean weights of sprat by age groups.

\section{I.3.6 Length structure of sprat by age groups in the period 2018-2019}

Table 3.6.1 Length structure of sprat by age groups in 2018

\begin{tabular}{|r|r|c|r|r|r|}
\hline age & \multicolumn{1}{|c|}{ March } & \multicolumn{1}{|l|}{ April } & \multicolumn{1}{l|}{ May } & \multicolumn{1}{l|}{ June } & \multicolumn{1}{l|}{ July } \\
\hline \multicolumn{7}{|c|}{ Length, cm } \\
\hline $\mathbf{0}$ & 7,47 & 7,45 & 7,04 & 7,45 & 7,99 \\
\hline $\mathbf{1}$ & 7,95 & 7,91 & 7,63 & 8,19 & 8,33 \\
\hline $\mathbf{2}$ & 8,57 & 8,83 & 9,30 & 9,89 & 9,56 \\
\hline $\mathbf{3}$ & 9,43 & 9,91 & 10,34 & 10,66 & 10,03 \\
\hline $\mathbf{4}$ & 11,05 & 11,22 & 11,35 & 11,16 & 10,76 \\
\hline
\end{tabular}

Table 3.6.2 Age structure of sprat by age groups in 2019

\begin{tabular}{|c|c|c|c|c|c|c|c|c|c|c|c|c|}
\hline Age & February & March & April & May & June & July & August & September & October & November & December \\
\hline \multicolumn{7}{|c|}{ Length (cm) } \\
\hline $\mathbf{0}$ & 6.5 & 6.5 & 6.75 & 7 & 6 & $\mathrm{n} / \mathrm{a}$ & 7 & $\mathrm{n} / \mathrm{a}$ & & 6.5 & 6.5 \\
\hline $\mathbf{1}$ & 7.5 & 7.5 & 7.75 & 7.75 & 8 & 8.25 & 7.75 & 8.75 & 8.25 & 8 & 8 \\
\hline $\mathbf{2}$ & 8.5 & 8.75 & 9 & 9 & 8.5 & 8.75 & 9 & 9.5 & 9.5 & 9.5 & 9.75 \\
\hline $\mathbf{3}$ & 9.25 & 9.75 & 10 & 10 & 9.75 & 9.25 & 10 & 10.25 & 10.5 & 10 & 10.5 \\
\hline $\mathbf{4}$ & $\mathrm{n} / \mathrm{a}$ & 10.75 & 10.75 & 10.5 & 10.5 & 9.75 & $\mathrm{n} / \mathrm{a}$ & 11 & 11 & 11 & 11.5 \\
\hline
\end{tabular}

The data given in Tables 3.6.1 and 3.6.2 show a slight tendency for decrease of the total length of sprat by age groups. This observation cannot be applied as a solid base for specific

Project proposal № BG14MFOP001-3.003-0001 "Collection, management and use of data for the purposes of scientific analysis and implementation of the Common Fisheries Policy for the period 2017-2019", funded by the Maritime Affairs and Fisheries Program, co-financed by the European Union through the European Maritime 


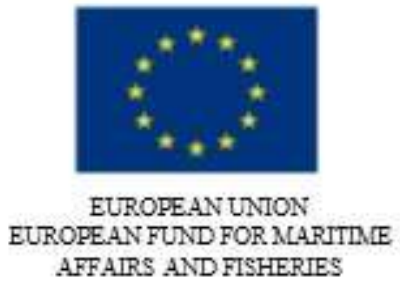

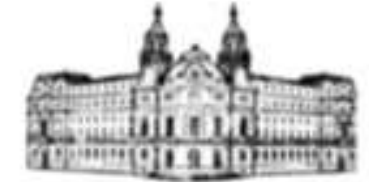

MINISTRY OF AGRICUITURE, FOOD AND FORESTRY
MLARITLE AFFAIRS AND FISHERIES PROGRAM

conclusions about the stock as a whole, since parameters such as length and weight are strongly dependent on the environment and food availability.

\section{I.3.7 Length-weight relationship of sprat in the period 2018-2019}

\section{I.3.7.1 LWR of sprat in 2018}

LWR of sprat in 2018 is well described by: $\mathrm{W}=0.084 * \mathrm{~L}^{2.8085}$

\section{I.3.7.1 LWR of sprat in 2019}

LWR model of the sampled specimens in the period February-October 2019 can be described as: $\mathrm{W}=0.0048 * \mathrm{~L}^{2.89}$

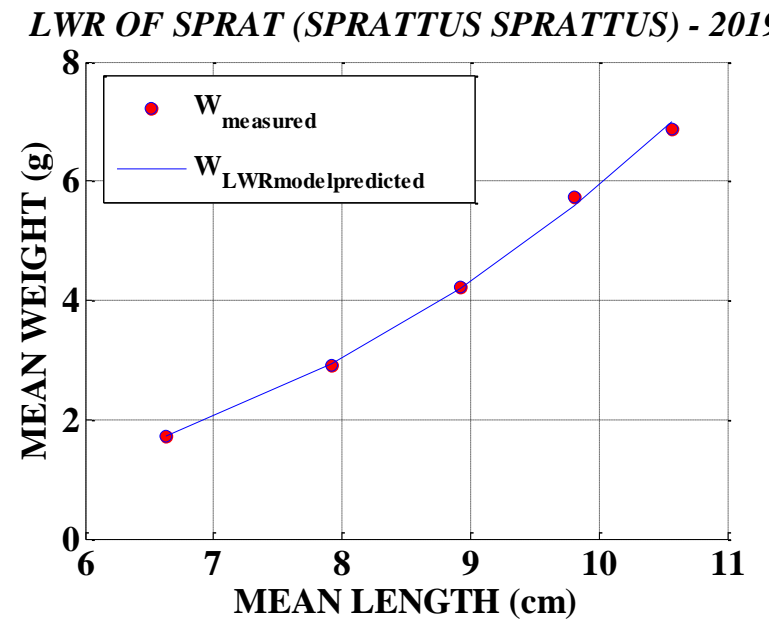

Fig. 3.7.1.1 LWR model of sprat in the period February-October 2019

LWR of the sampled specimens in November and December 2019 can be described as: $W=0.0031 * L^{3.2410}$.

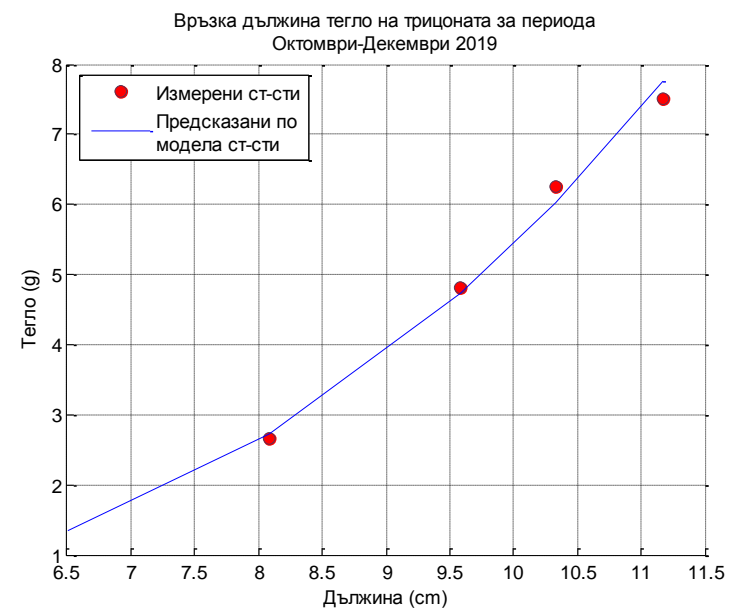

Fig. 3.7.1.2 LWR model of sprat in the period November-December 2019

Project proposal № BG14MFOP001-3.003-0001 "Collection, management and use of data for the purposes of scientific analysis and implementation of the Common Fisheries Policy for the period 2017-2019", funded by the Maritime Affairs and Fisheries Program, co-financed by the European Union through the European Maritime and Fisheries Fund 

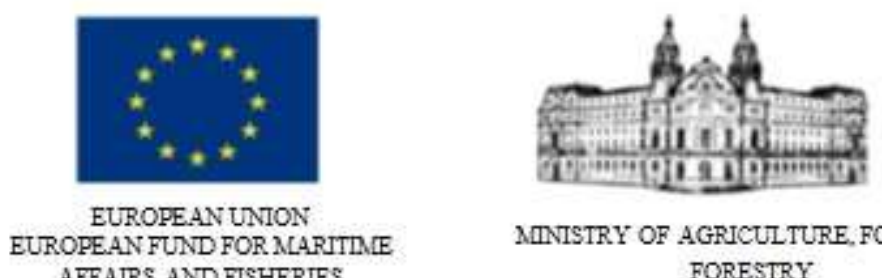

AFFAIRS AND FISHERIES

AINTSTRY OF AGRICUITURE, FOOD AND FORESTRY

Von Bertalanffy growth model parameters:

$L_{\text {asimpt }}=12.6154, \quad K=0.3715, \quad t_{0}=-1.7546 . \quad$ Model statistics $\quad-\quad \mathrm{R}=0.9573$; $F-$ statistics $=21.9446-$ Gulland and Holt method $\mathrm{R}=0.9981 ; F-$ statistics $=788.9312-$ von Bertalanffy method for estimations of $t_{0}$.

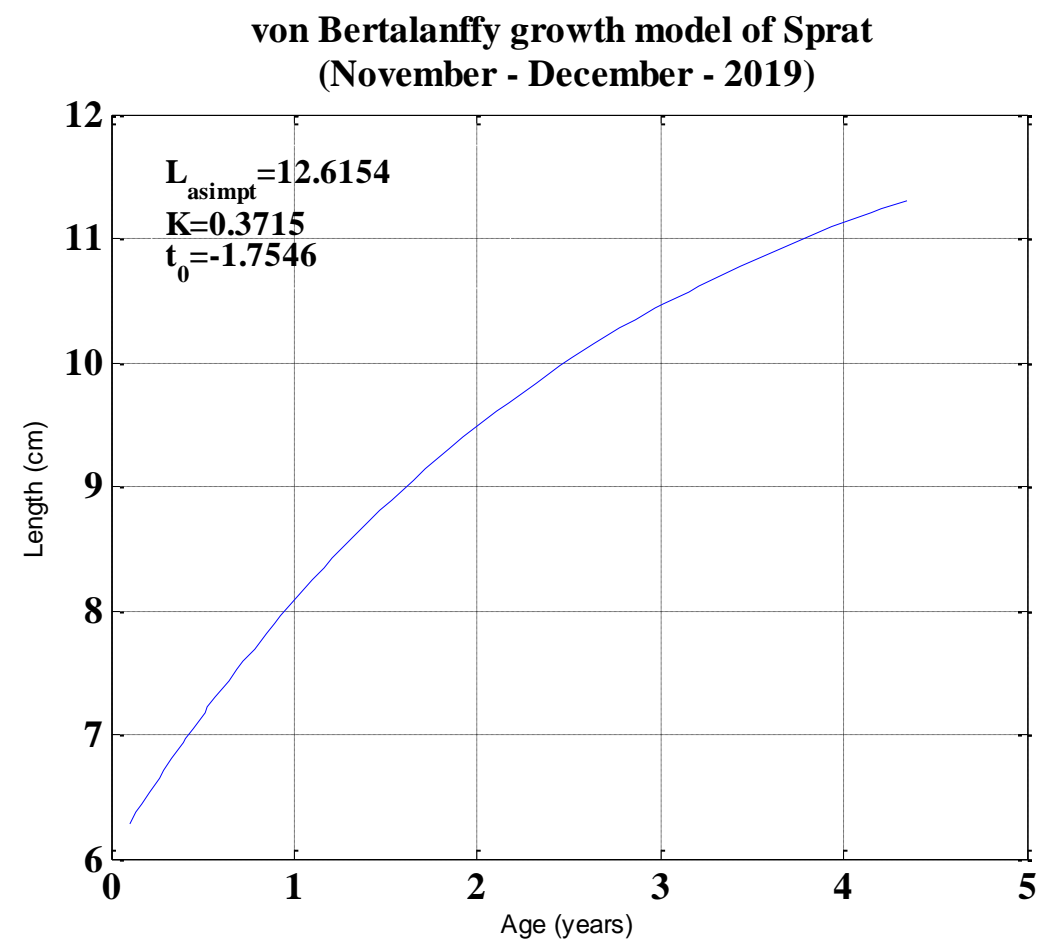

\section{I.3.8 Sex ratio of sprat in the period 2017-2019}

\section{I.3.8.1 Sex structure of sprat in 2017}

Female specimens ( $(+)$ were represented with $58 \%$, and male specimens $(\stackrel{\Im}{)}$ ) - with $42 \%$.

Project proposal № BG14MFOP001-3.003-0001 "Collection, management and use of data for the purposes of scientific analysis and implementation of the Common Fisheries Policy for the period 2017-2019", funded by the Maritime Affairs and Fisheries Program, co-financed by the European Union through the European Maritime and Fisheries Fund 


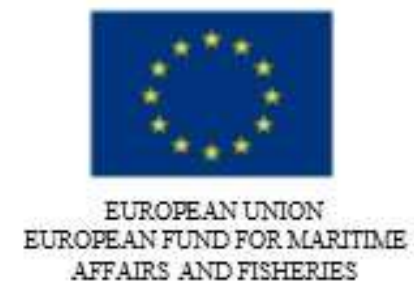

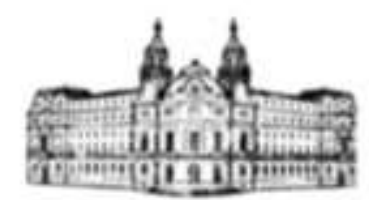

AMNISTRY OF AGRICUITURE, FOOD AND FORESTRY

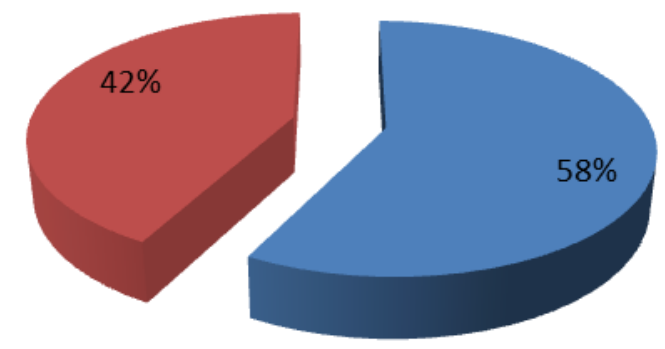

- Fem.n Male

Fig. 3.8.1.1 Sex ratio of sprat in 2017

\section{I.3.8.2 Sex structure of sprat in 2018}

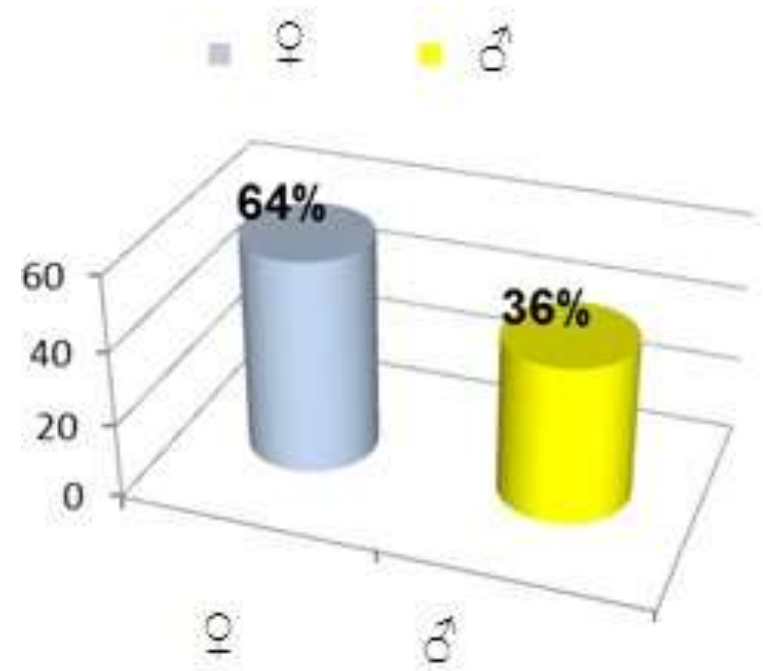

Fig. 3.8.2.1 Sex ratio of sprat in 2018

Project proposal № BG14MFOP001-3.003-0001 "Collection, management and use of data for the purposes of scientific analysis and implementation of the Common Fisheries Policy for the period 2017-2019", funded by the Maritime Affairs and Fisheries Program, co-financed by the European Union through the European Maritime and Fisheries Fund 


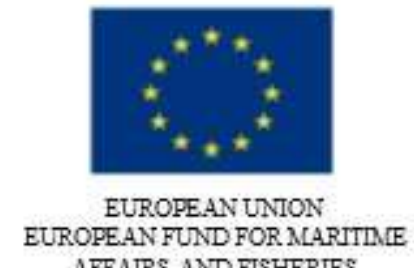

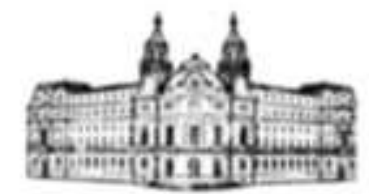

MINISTRY OF AGRICULTURE, FOOD AND FORESTRY
MLARITLE AFFAIRS AND FISHERIES PROGRAM

\section{I.3.8.3 Sex structure of sprat in 2019}

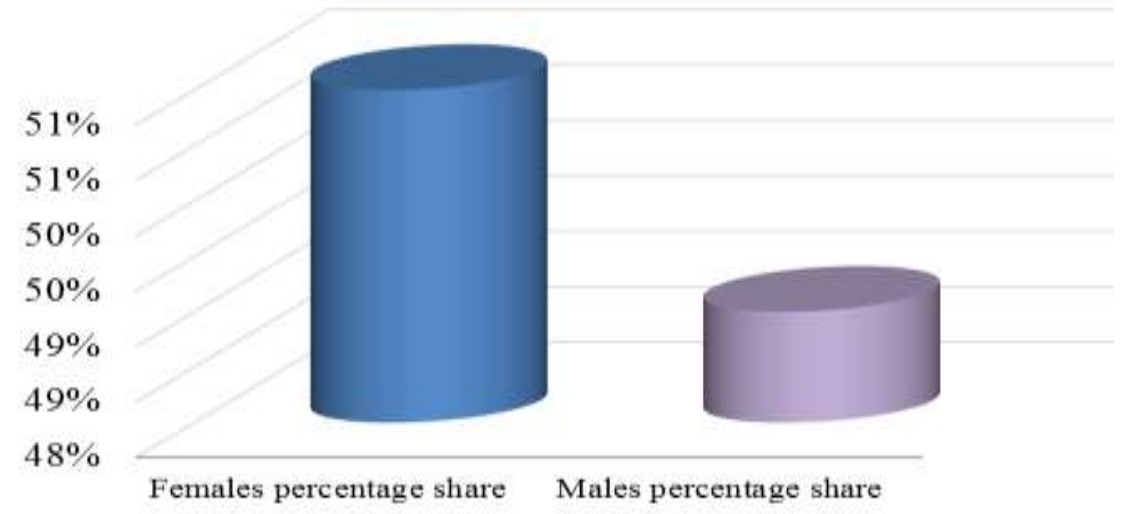

Fig. 3.8.3.1 Sex ratio of sprat in 2019

250 specimens were analyzed for determination of sex structure of sprat in 2019. The female specimens were presented with $51 \%$, and the male specimens $(\lesssim)$ with (49\%) (Fig. 3.8.3.1).

\section{I.3.9 Fertility of sprat in the period 2018-2019}

\section{I.3.9.1 Fertility of sprat in 2018}

Batch fecundity correlated with length $(\mathrm{cm})$ positively with determination $\left(\mathrm{R}^{2}=0.4751\right)$.

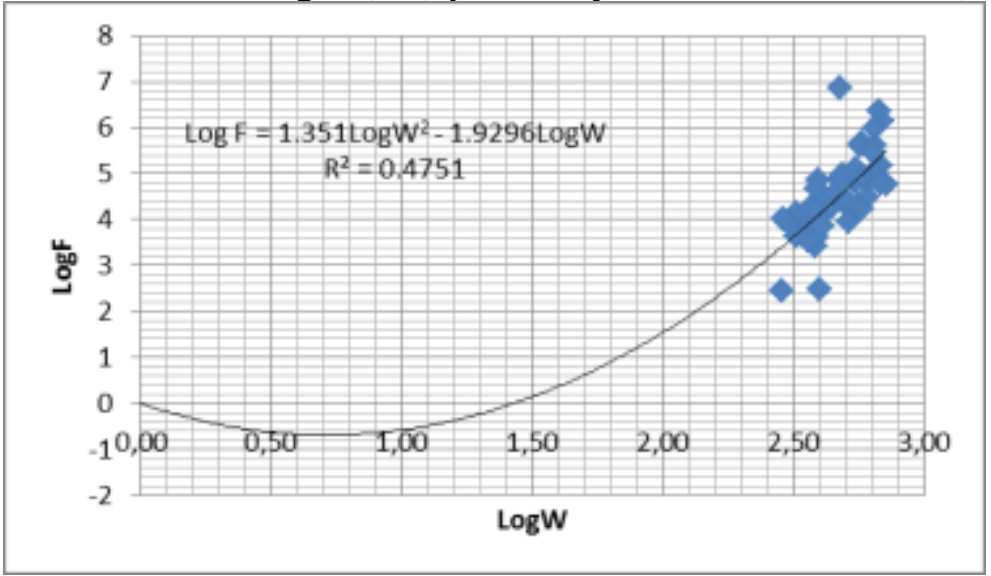

Fig. 3.9.1.1 Relation of LOG F and LOG L

Batch fecundity correlates with individual weight $(\mathrm{g})$ positively with good determination $\left(\mathrm{R}^{2}\right.$ $=0.4751$ ).

Project proposal № BG14MFOP001-3.003-0001 "Collection, management and use of data for the purposes of scientific analysis and implementation of the Common Fisheries Policy for the period 2017-2019", funded by the Maritime Affairs and Fisheries Program, co-financed by the European Union through the European Maritime and Fisheries Fund 


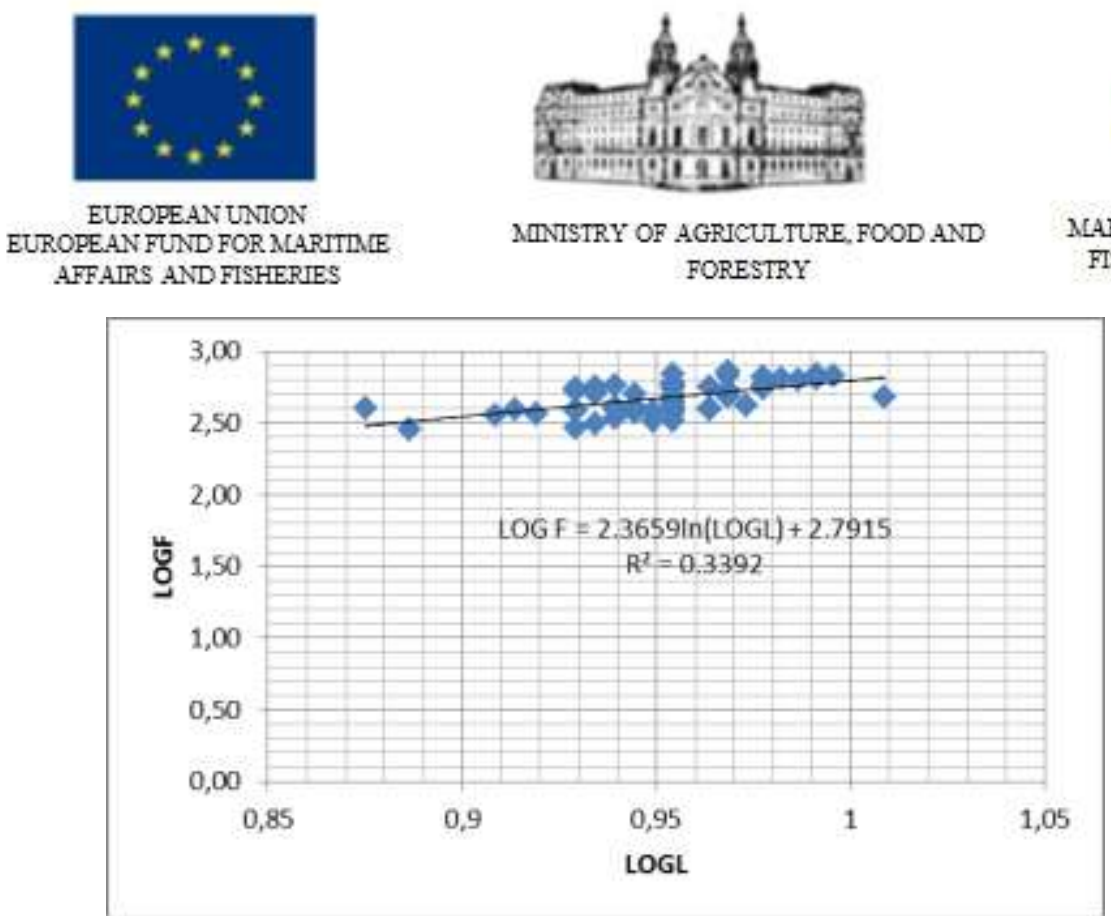

Fig. 3.9.1.2 Relation of LOG F and LOG W

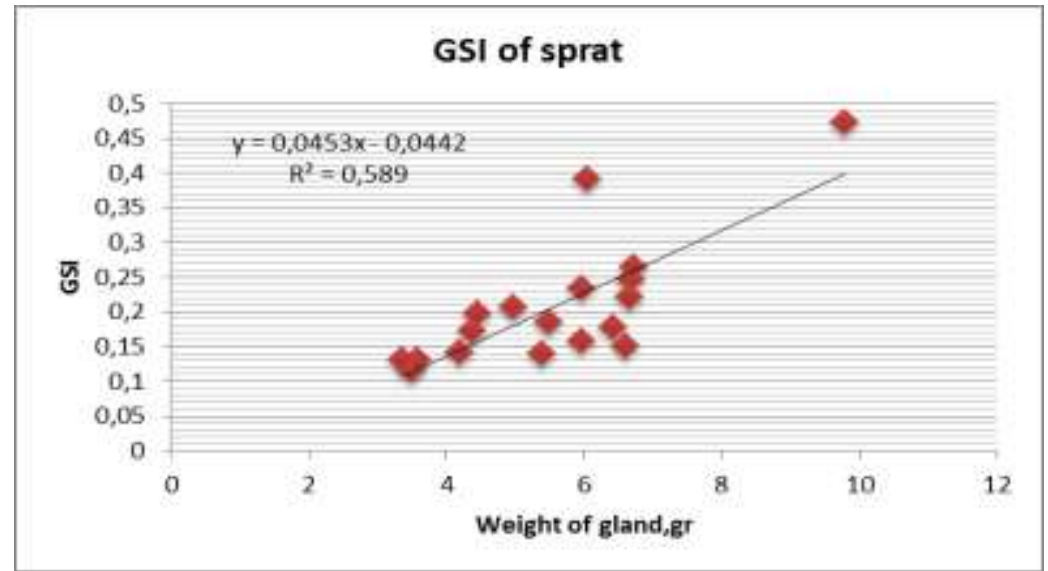

Fig. 3.9.1.3 Relation of GSI and gonads weight $(\mathrm{g})$

Very strong relation between GSI and weight of sprat $\left(\mathrm{R}^{2}=0.589\right)$ wae established. This fact clearly spoke that sprat was in active maturation .

\section{I.3.9.2 Fertility of sprat in 2019}

Fertility was determined on 500 specimens. The relation between body weight $(\mathrm{g})$ and glandule weight of males of sprat indicated linear negative trend with good coefficient of determination $\left(\mathrm{R}^{2}=0.43\right)$.

Project proposal № BG14MFOP001-3.003-0001 "Collection, management and use of data for the purposes of scientific analysis and implementation of the Common Fisheries Policy for the period 2017-2019", funded by the Maritime Affairs and Fisheries Program, co-financed by the European Union through the European Maritime and Fisheries Fund 


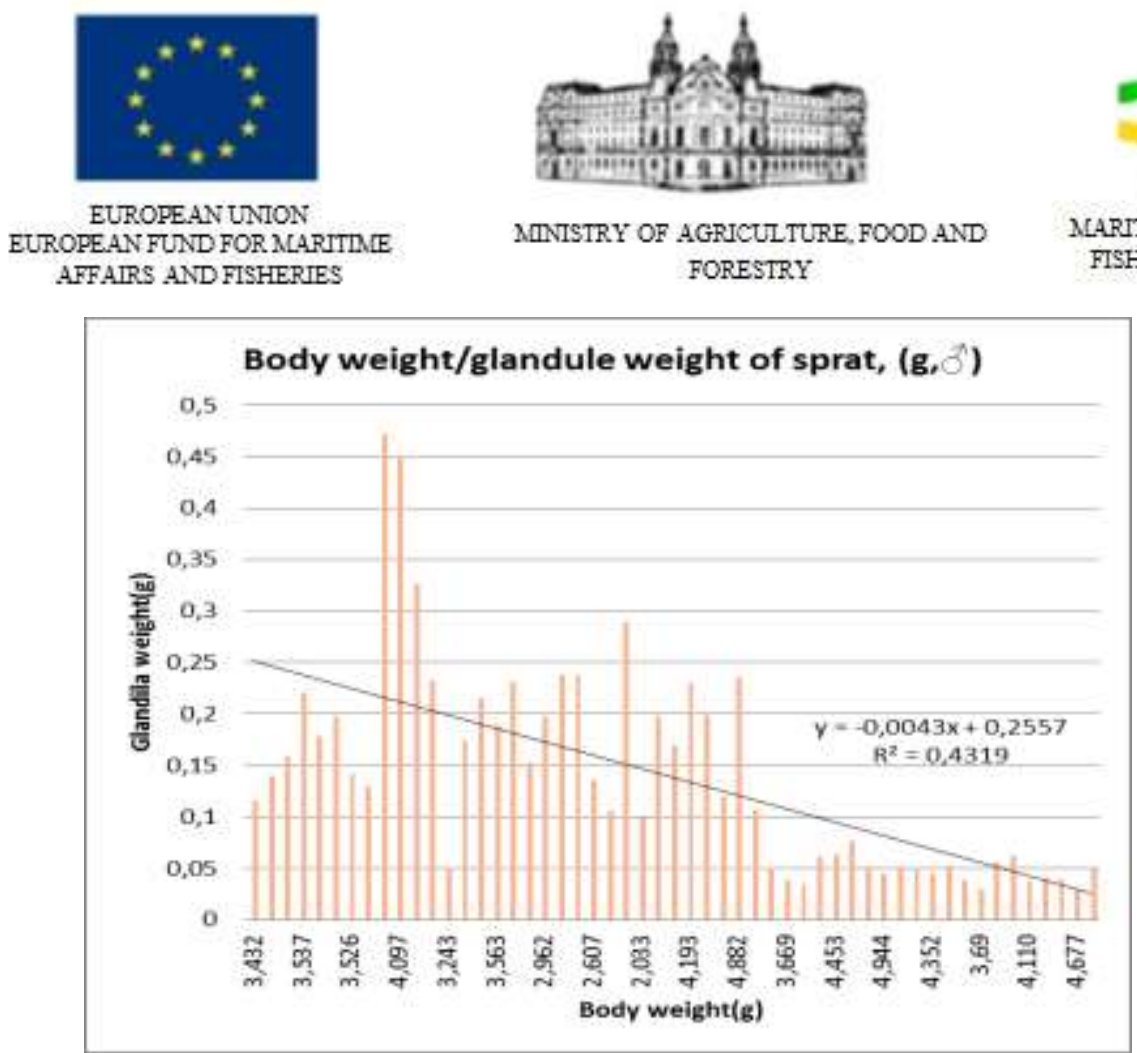

Fig. 3.9.2.1 Body weight/glandule weight of sprat $\widehat{\jmath}$

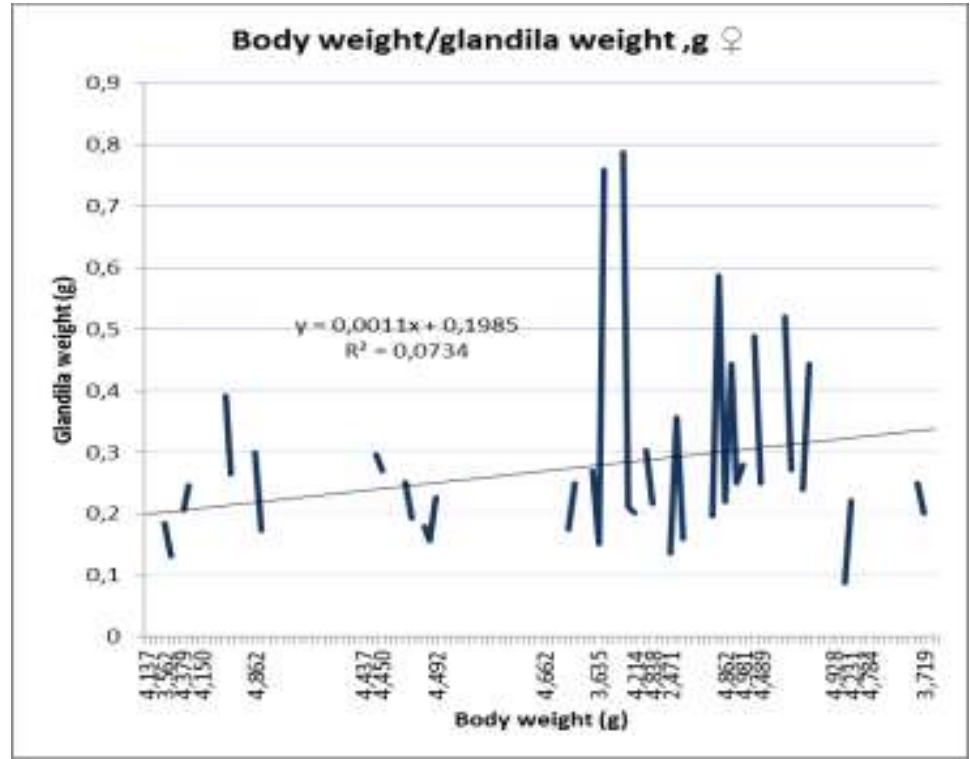

Fig. 3.9.2.2 Body weight/glandule weight of sprat $q$

There was a very weak linear relationship between individual weight and gland weight of the female individuals (June, 2019), which was a clear indication for the low contribution of female sex products as a ratio from the total sprat body weight. The individuals were not in active reproduction and the glands were in the developmental stages II-III, I-II, in many cases there were also non-sexually mature individuals.

Project proposal № BG14MFOP001-3.003-0001 "Collection, management and use of data for the purposes of scientific analysis and implementation of the Common Fisheries Policy for the period 2017-2019", funded by the Maritime Affairs and Fisheries Program, co-financed by the European Union through the European Maritime and Fisheries Fund 


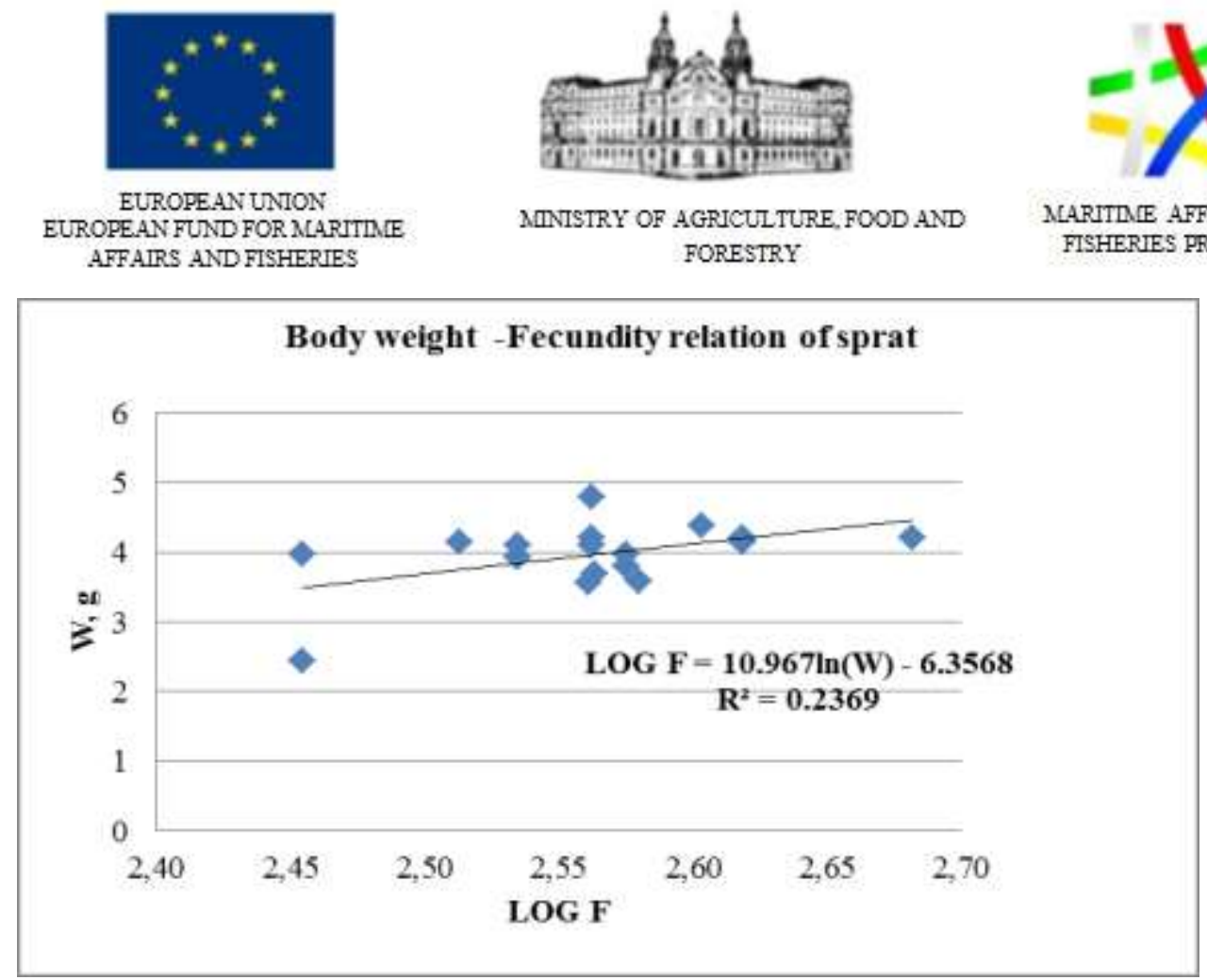

Fig. 3.9.2.3 Body weight-fecundity relation of sprat

The association of somatic weight with the fecundity of sprat in June 2019 was low deterministic $\left(\mathrm{R}^{2}=0.24\right)$, which was explained by the lack of mass spawning of sprat during the spring and summer seasons.

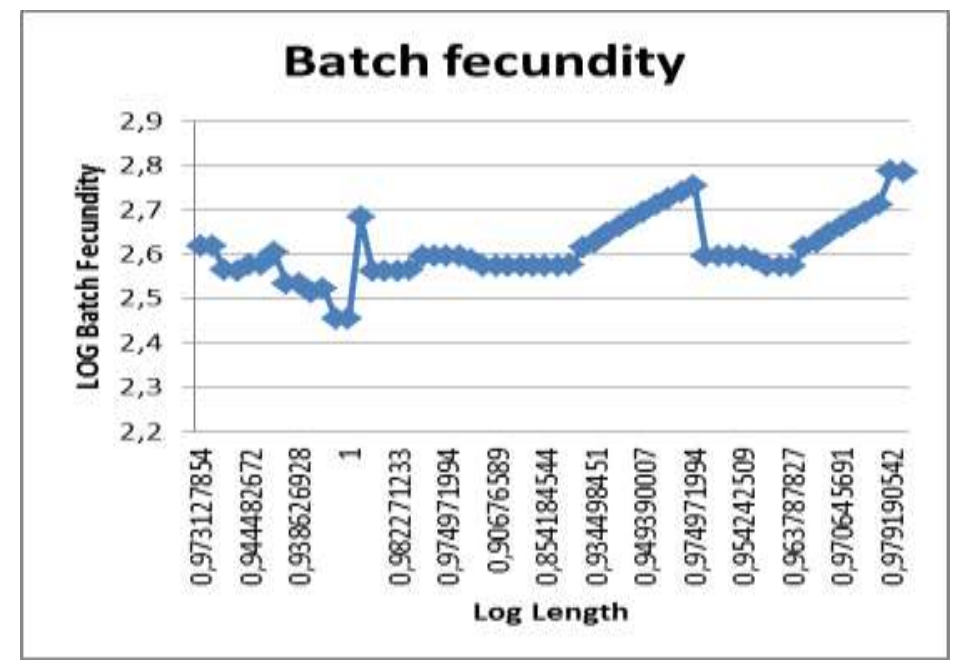

Fig. 3.9.2.4 Batch fecundity of sprat in October-December, 2019

The batch fecundity, in most of the cases, showed values above 2.5 (Log fecundity), corresponding to the Log individual weights ( $\mathrm{g}$ ) from 0.85 to 1 .

Project proposal № BG14MFOP001-3.003-0001 "Collection, management and use of data for the purposes of scientific analysis and implementation of the Common Fisheries Policy for the period 2017-2019", funded by the Maritime Affairs and Fisheries Program, co-financed by the European Union through the European Maritime and Fisheries Fund 


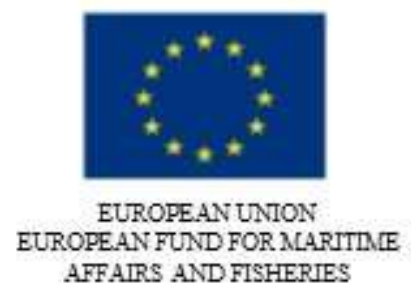

AFFAIRS AND FISHERIES

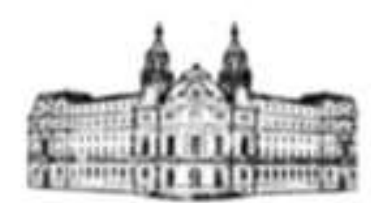

AINISTRY OF AGRICULTURE, FOOD AND FORESTRY
MLARITLIE AFFAIRS AND FISHERIES PROGRAM

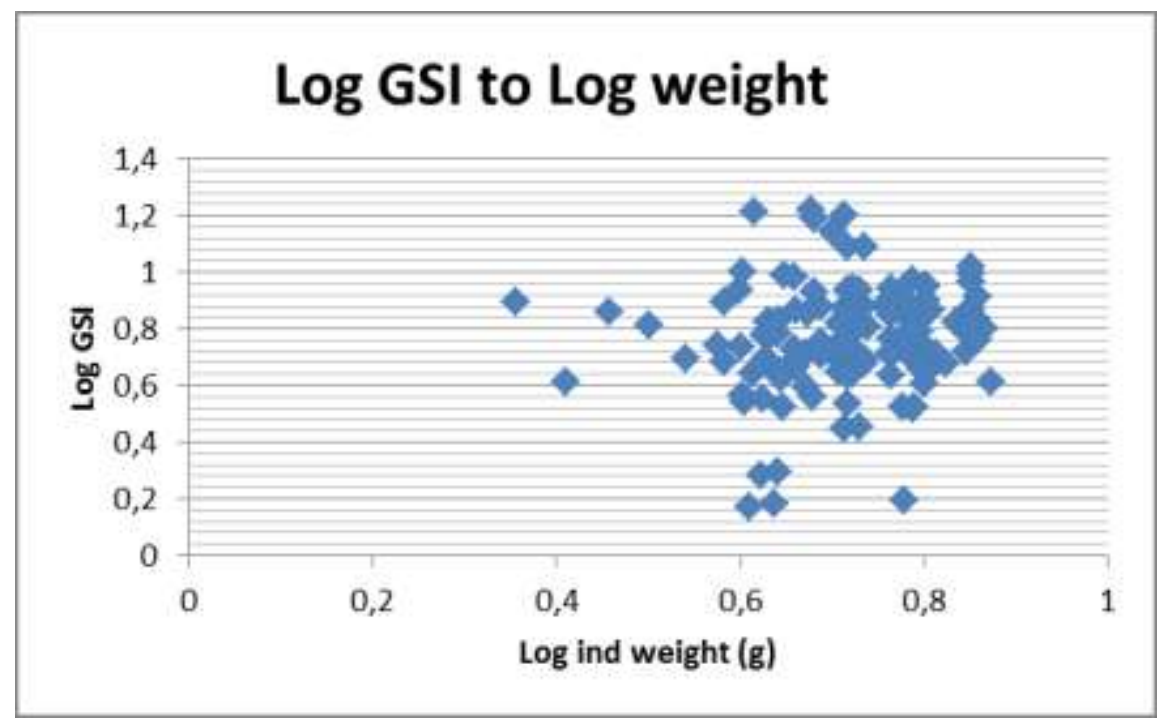

Fig. 3.9.2.5 Gonadosomatic index vs individual weights of sprat

GSI as a measure of sexual maturity showed that sprat in the period Octobre-December 2019 was in relatively good maturity (females), which corresponded to the active maturation season of the species.

\section{I.3.10 Sexual Maturity}

1000 specimens were used for sexual maturity determination. Most of the individuals were in III - IV stage of gonads.

\section{I.3.11 Catch numbers and biomass of sprat by age and length in the period 2017-2019}

\section{I.3.11.1 Analysis of the abundance and biomass of sprat by age and length in 2017}

Monthly catches (in tons) together with mean weights of sprat were used to derive the monthly catch numbers. The share (\%) by age groups and catch numbers were used to create catch-at-age matrix for selected months by age groups.

Project proposal № BG14MFOP001-3.003-0001 "Collection, management and use of data for the purposes of scientific analysis and implementation of the Common Fisheries Policy for the period 2017-2019", funded by the Maritime Affairs and Fisheries Program, co-financed by the European Union through the European Maritime and Fisheries Fund 


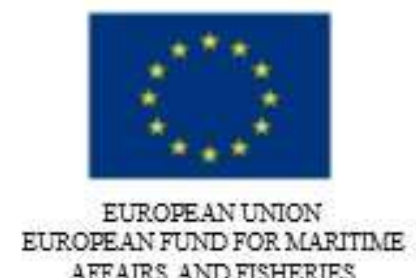

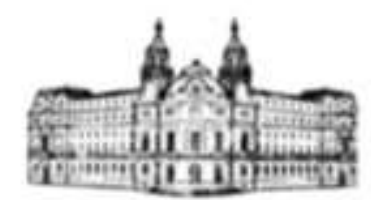

MINISTRY OF AGRICULTURE, FOOD AND FORESTRY
MLARITLIE AFFAIRS AND FISHERIES PROGRAM

Table 3.11.1.1 Catch-at-age $\left(10^{-3}\right)$ matrix and biomass $(\mathrm{kg})$ of sprat by months

\begin{tabular}{|c|c|}
\hline Catch-at-age & \\
\hline $\left.\mathbf{( 1 0}^{-\mathbf{3}}\right)$ & \\
\hline & \\
\hline Age groups & November \\
\hline $\mathbf{0}$ & 10748.596 \\
\hline $\mathbf{1}$ & 19642.680 \\
\hline $\mathbf{2}$ & 29331.555 \\
\hline $\mathbf{3}$ & 22519.065 \\
\hline $\mathbf{4}$ & 7380.198 \\
\hline$\sum$ & 89622.094 \\
\hline Biomass $\mathbf{( k g )}$ & November \\
\hline Age groups & 19052540.471 \\
\hline $\mathbf{0}$ & 38231614.583 \\
\hline $\mathbf{1}$ & 82932884.849 \\
\hline $\mathbf{2}$ & 112380647.320 \\
\hline $\mathbf{3}$ & \\
\hline
\end{tabular}

Monthly catches (in tons) together with mean weights of sprat were used to derive the monthly catch numbers. The share (\%) by length groups and catch numbers were used to create catch at length matrix for selected months by age groups.

Table 3.11.1.2 Catch-at-length $\left(10^{-3}\right)$ matrix and biomass $(\mathrm{kg})$ of sprat by months

\begin{tabular}{|c|c|}
\hline $\begin{array}{c}\text { Catch-at-length } \\
\text { (millions) }\end{array}$ & November \\
\hline $\begin{array}{c}\text { Length group (cm) } \\
6.5\end{array}$ & 67.601 \\
\hline 7.0 & 231.266 \\
\hline 7.5 & 435.848 \\
\hline 8.0 & 351.347 \\
\hline 8.5 & 209.919 \\
\hline 9.0 & 120.970 \\
\hline 9.5 & 185.013 \\
\hline 10.0 & 184.124 \\
\hline 10.5 & 273.072 \\
\hline 11.0 & 47.143 \\
\hline$\sum$ & 2106.302 \\
\hline Biomass (kg) & \\
\hline
\end{tabular}

Project proposal № BG14MFOP001-3.003-0001 "Collection, management and use of data for the purposes of scientific analysis and implementation of the Common Fisheries Policy for the period 2017-2019", funded by the Maritime Affairs and Fisheries Program, co-financed by the European Union through the European Maritime and Fisheries Fund 


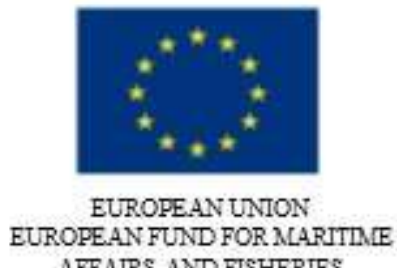
EUROPEAN FUND FOR NLARUTL

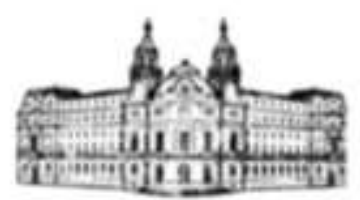

AINISTRY OF AGRICULTURE, FOOD AND FORESTRY

\begin{tabular}{|c|c|}
\hline Length group (cm) & November \\
\hline 6.5 & 0.995 \\
\hline 7.0 & 4.053 \\
\hline 7.5 & 8.377 \\
\hline 8.0 & 7.437 \\
\hline 8.5 & 4.659 \\
\hline 9.0 & 4.839 \\
\hline 9.5 & 8.696 \\
\hline 10.0 & 10.390 \\
\hline 10.5 & 18.179 \\
\hline 11.0 & 3.536 \\
\hline$\Sigma$ & 71.16 \\
\hline
\end{tabular}

\section{I.3.11.2 Analysis of the abundance and biomass of sprat by age and length in 2018}

Monthly catches (in tons) together with mean weights of sprat were used to derive the monthly catch numbers. The share (\%) by age groups and catch numbers were used to create catch-at-age matrix for selected months by age groups .

Table 3.11.2.1 Catch-at-age $\left(10^{-3}\right)$ matrix and biomass $(\mathrm{kg})$ of sprat by months

\begin{tabular}{|c|c|c|c|c|c|}
\hline $\begin{array}{c}\text { Catch-at-age } \\
\left(10^{-3}\right)\end{array}$ & & & & & \\
\hline Age groups & March & April & May & June & July \\
\hline $\mathbf{0}$ & 14528.38008 & 55806.40413 & 36.39010924 & 12.37333333 & 82.28474 \\
\hline $\mathbf{1}$ & 33349.23609 & 118955.7562 & 104.9119107 & 95.20592593 & 75.31146 \\
\hline $\mathbf{2}$ & 23113.33195 & 6608.653121 & 6.968318791 & 53.27407407 & 27.89313 \\
\hline $\mathbf{3}$ & 18490.66556 & 16888.7802 & 11.22673583 & 11.68592593 & 11.15725 \\
\hline $\mathbf{4}$ & 1320.761826 & 2202.884374 & 2.709901752 & 5.155555556 & 10.45992 \\
\hline & & & & & \\
\hline Biomass (kg) & & & & & \\
\hline Age groups & March & April & May & June & July \\
\hline $\mathbf{0}$ & 29440053.58 & 169493005.9 & 74157.43811 & 25650.45333 & 172536.5 \\
\hline $\mathbf{1}$ & 76946282.26 & 375555843.9 & 262115.6487 & 262976.1898 & 182622 \\
\hline $\mathbf{2}$ & 69209184.72 & 28329093.05 & 30667.35984 & 233947.3421 & 122176.3 \\
\hline $\mathbf{3}$ & 85093146.66 & 92601916.12 & 69592.81092 & 74360.49847 & 56052.41 \\
\hline $\mathbf{4}$ & 9245332.779 & 17623074.99 & 20424.14238 & 41529.51634 & 64258.81 \\
\hline$\Sigma$ & 269934000 & 68357705 & 456957.4 & 638464 & 597646 \\
\hline
\end{tabular}

Monthly catches (in tons) together with mean weights of sprat were used to derive the monthly catch numbers. The share $(\%)$ by length groups and catch numbers were used to create catch-at-length matrix for selected months by age groups (Table 3.11.2.2).

Project proposal № BG14MFOP001-3.003-0001 "Collection, management and use of data for the purposes of scientific analysis and implementation of the Common Fisheries Policy for the period 2017-2019", funded by the Maritime Affairs and Fisheries Program, co-financed by the European Union through the European Maritime and Fisheries Fund 


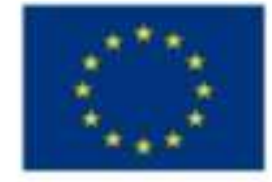

EUROPEAN UNTON EUROPEAN FUND FOR MLARITIE AFFAIRS AND FISHERIES

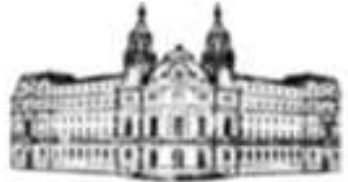

AINISTRY OF AGRICUITURE, FOOD AND FORESTRY
MLARITLIE AFFAIRS AND FISHERIES PROGRAM

Table 3.11.2.2 Catch-at-length $\left(10^{-3}\right)$ matrix and biomass $(\mathrm{kg})$ of sprat by months

\begin{tabular}{|c|c|c|c|c|c|}
\hline $\begin{array}{c}\text { Catch-at-length } \\
\text { (millions) }\end{array}$ & & & & & \\
\hline $\begin{array}{l}\text { Length group } \\
\text { (cm) }\end{array}$ & March & April & May & June & July \\
\hline 6.5 & & 1,51 & 18,9271 & & \\
\hline 7.0 & 0.022949 & 71.50 & 52.50743 & 8.992089 & \\
\hline 7.5 & 0.076498 & 57.95 & 82.42445 & 95.64313 & 33.13253 \\
\hline 8.0 & 0.196981 & 39.13 & 56.17074 & 80.11134 & 66.26505 \\
\hline 8.5 & 0.072673 & 12.04 & 11.60048 & 46.59537 & 48.59437 \\
\hline 9.0 & 0.080322 & 4.52 & 6.105515 & 51.50014 & 25.76974 \\
\hline 9.5 & 0.034424 & 6.02 & 5.494964 & 20.43657 & 13.98929 \\
\hline 10.0 & 0.030599 & 5.27 & 6.716067 & 58.85731 & 16.19812 \\
\hline 10.5 & 0.003825 & 5.27 & 10.98993 & 40.87313 & 8.83534 \\
\hline 11.0 & 0.00765 & 2.26 & 3.052758 & 13.89686 & 5.890227 \\
\hline 11.5 & & & 0.610552 & 5.722238 & \\
\hline 12.0 & & & 1,221103 & & \\
\hline Biomass (kg) & March & April & May & June & July \\
\hline \multicolumn{6}{|l|}{$\begin{array}{c}\text { Length group } \\
(\mathrm{cm})\end{array}$} \\
\hline 6.5 & & 0.03 & 0.252071 & 0.169051 & \\
\hline 7.0 & 0.000428 & 1.47 & 1.173988 & 1.912045 & \\
\hline 7.5 & 0.001494 & 2.08 & 2.050298 & 1.999187 & 0.61868 \\
\hline 8.0 & 0.004689 & 1.56 & 1.426039 & 1.284234 & 1.259752 \\
\hline 8.5 & 0.001758 & 0.49 & 0.35473 & 1.814767 & 1.281357 \\
\hline 9.0 & 0.003181 & 0.19 & 0.231643 & 0.904114 & 0.826242 \\
\hline 9.5 & 0.001711 & 0.30 & 0.264125 & 3.178049 & 0.637387 \\
\hline 10.0 & 0.001589 & 0.29 & 0.376466 & 2.334837 & 0.807746 \\
\hline 10.5 & 0.000249 & 0.33 & 0.713124 & 1.167745 & 0.041596 \\
\hline 11.0 & 0.000535 & 0.18 & 0.211007 & 0.421157 & 0.39759 \\
\hline 11.5 & & & 0.04341 & & \\
\hline 12.0 & & & 0.109899 & & \\
\hline
\end{tabular}

\section{I.3.11.3 Analysis of the abundance and biomass of sprat by age and length in} 2019

Table 3.11.3.1 Catch at age $\left(10^{-3}\right)$ matrix and biomass $(\mathrm{kg})$ of sprat by months

\begin{tabular}{|c|c|c|c|c|c|c|c|c|}
\hline \multirow{2}{*}{$\begin{array}{l}\text { Age } \\
\text { groups }\end{array}$} & \multicolumn{5}{|c|}{ Catch-at-Age $* 10^{-3}$ (in thousands) } & \multirow[b]{2}{*}{ July } & \multirow[b]{2}{*}{ August } & \multirow[b]{2}{*}{ September } \\
\hline & February & March & April & May & June & & & \\
\hline $\mathbf{0}$ & 5001.91 & 8783.20 & 13448.56 & 17015.22 & 12766.92 & 17303.05 & 9284.91 & 6043.47 \\
\hline 1 & 32599.35 & 57243.52 & 87649.42 & 110894.71 & 83206.95 & 112770.62 & 60513.34 & 39387.61 \\
\hline 2 & 16297.36 & 28617.69 & 43818.48 & 55439.47 & 41597.56 & 56377.30 & 30252.37 & 19691.01 \\
\hline 3 & 8604.66 & 15109.53 & 23135.22 & 29270.86 & 21962.62 & 29766.01 & 15972.60 & 10396.43 \\
\hline 4 & 608.61 & 1068.69 & 1636.35 & 2070.32 & 1553.41 & 2105.34 & 1129.74 & 735.34 \\
\hline & & & \multicolumn{6}{|c|}{ Biomass (kg) } \\
\hline
\end{tabular}

Project proposal № BG14MFOP001-3.003-0001 "Collection, management and use of data for the purposes of scientific analysis and implementation of the Common Fisheries Policy for the period 2017-2019", funded by the Maritime Affairs and Fisheries Program, co-financed by the European Union through the European Maritime and Fisheries Fund 


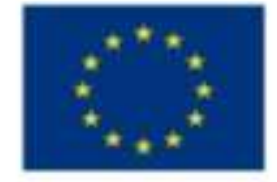

EUROPEAN UNTON EUROPEAN FUND FOR MAARTIME AFFAIRS AND FISHERIES

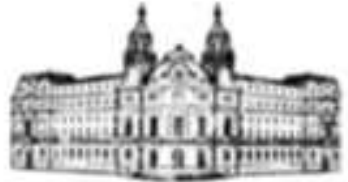

MINTSTRY OF AGRICUITURE, FOOD AND FORESTRY
MLARITLIE AFFAIRS AND FISHERIES PROGRAM

\begin{tabular}{|c|c|c|c|c|c|c|c|c|}
\hline groups & February & March & April & May & June & July & August & September \\
\hline $\mathbf{0}$ & 8.45 & 14.84 & 22.73 & 28.76 & 21.58 & 29.24 & 15.69 & 10.21 \\
\hline $\mathbf{1}$ & 85.52 & 150.17 & 229.93 & 290.91 & 218.28 & 295.84 & 158.75 & 103.33 \\
\hline $\mathbf{2}$ & 66.98 & 117.62 & 180.09 & 227.86 & 170.97 & 231.71 & 124.34 & 80.93 \\
\hline $\mathbf{3}$ & 48.79 & 85.67 & 131.18 & 165.97 & 124.53 & 168.77 & 90.56 & 58.95 \\
\hline $\mathbf{4}$ & 4.25 & 7.46 & 11.42 & 14.45 & 10.84 & 14.70 & 7.89 & 5.13 \\
\hline
\end{tabular}

Table 3.11.3.2 Catch at length $\left(10^{-3}\right)$ matrix and biomass $(\mathrm{kg})$ of sprat by months

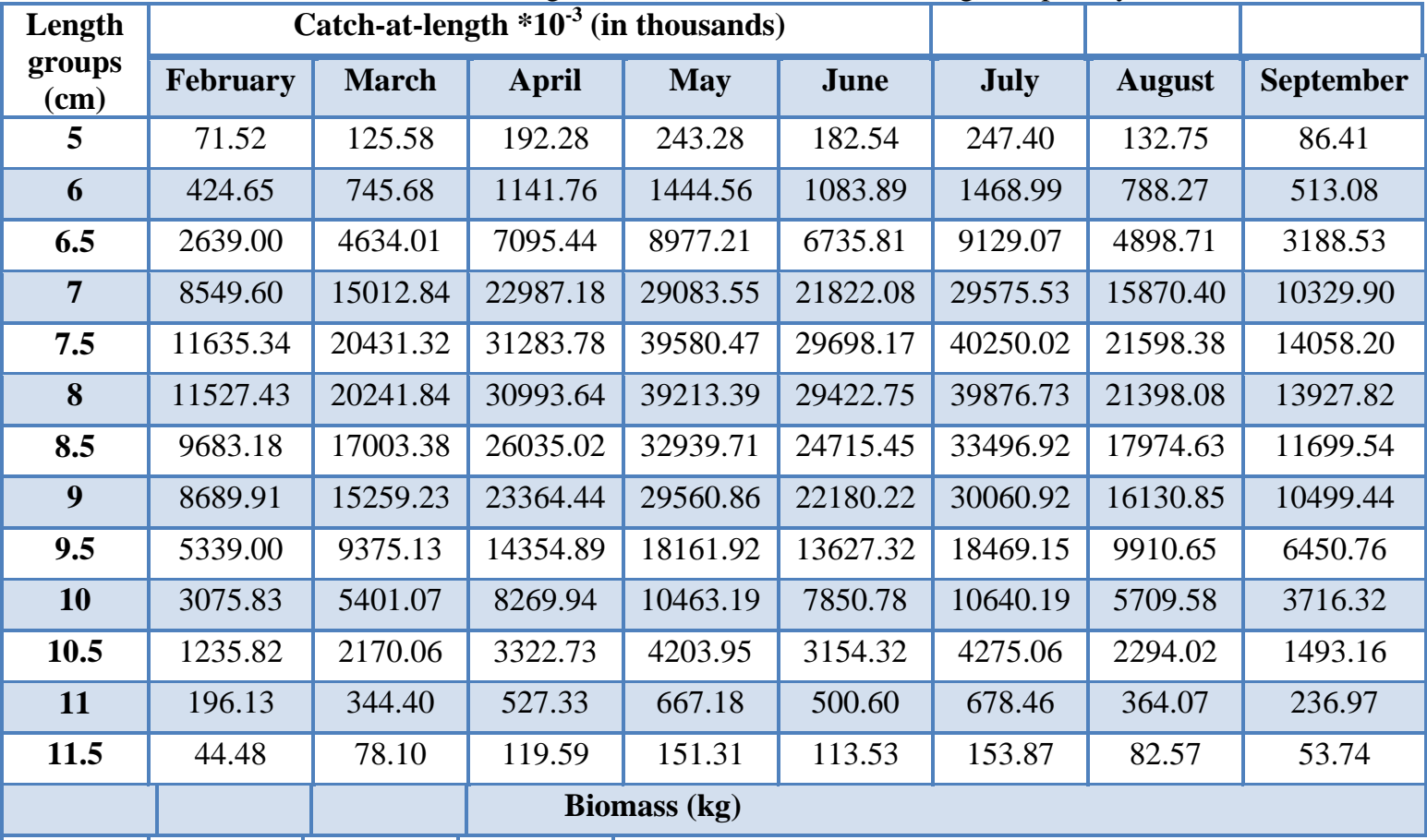

\begin{tabular}{|c|c|c|c|c|c|c|c|c|}
\hline \multirow{2}{*}{$\begin{array}{l}\text { Length } \\
\text { groups } \\
(\mathrm{cm})\end{array}$} & \multirow[b]{2}{*}{ February } & \multirow[b]{2}{*}{ March } & \multirow[b]{2}{*}{ April } & \multirow[b]{2}{*}{ May } & \multirow[b]{2}{*}{ June } & \multirow[b]{2}{*}{ July } & \multirow[b]{2}{*}{ August } & \multirow[b]{2}{*}{ September } \\
\hline & & & & & & & & \\
\hline 5 & 0.04 & 0.08 & 0.12 & 0.15 & 0.11 & 0.15 & 0.08 & 0.05 \\
\hline 6 & 0.51 & 0.90 & 1.38 & 1.75 & 1.31 & 1.78 & 0.96 & 0.62 \\
\hline 6.5 & 4.03 & 7.08 & 10.84 & 13.72 & 10.30 & 13.95 & 7.49 & 4.87 \\
\hline 7 & 16.78 & 29.46 & 45.11 & 57.07 & 42.82 & 58.04 & 31.14 & 20.27 \\
\hline 7.5 & 28.23 & 49.58 & 75.91 & 96.05 & 72.07 & 97.67 & 52.41 & 34.11 \\
\hline 8 & 34.63 & 60.81 & 93.10 & 117.80 & 88.39 & 119.79 & 64.28 & 41.84 \\
\hline 8.5 & 35.49 & 62.31 & 95.41 & 120.72 & 90.58 & 122.76 & 65.87 & 42.88 \\
\hline 9 & 38.49 & 67.59 & 103.49 & 130.93 & 98.24 & 133.15 & 71.45 & 46.50 \\
\hline 9.5 & 26.60 & 46.72 & 71.53 & 90.50 & 67.90 & 92.03 & 49.38 & 32.14 \\
\hline 10 & 18.75 & 32.93 & 50.42 & 63.79 & 47.86 & 64.87 & 34.81 & 22.66 \\
\hline 10.5 & 8.58 & 15.07 & 23.07 & 29.19 & 21.90 & 29.69 & 15.93 & 10.37 \\
\hline 11 & 1.46 & 2.56 & 3.92 & 4.96 & 3.72 & 5.05 & 2.71 & 1.76 \\
\hline 11.5 & 0.39 & 0.68 & 1.04 & 1.31 & 0.99 & 1.34 & 0.72 & 0.47 \\
\hline
\end{tabular}

Project proposal № BG14MFOP001-3.003-0001 "Collection, management and use of data for the purposes of scientific analysis and implementation of the Common Fisheries Policy for the period 2017-2019", funded by the Maritime Affairs and Fisheries Program, co-financed by the European Union through the European Maritime 


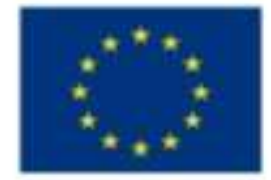

EUROPEAN UNTON EUROPEAN FUND FOR MLARITIIE AFFAIRS AND FISHERIES

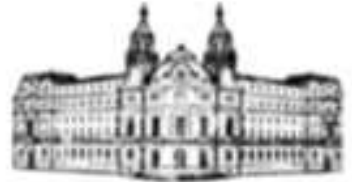

AINISTRY OF AGRICULTURE, FOOD AND FORESTRY
MLARITLIE AFFAIRS AND FISHERIES PROGRAM

Table 3.11.3.3 Catch $\left(10^{-3}\right)$ and biomass $(\mathrm{kg})$ by size and age of sprat (October-December, 2019)

\begin{tabular}{|c|c|c|c|c|c|c|}
\hline & \multicolumn{3}{|c|}{ catch-at-length in numbers $* 10-3$} & \multicolumn{3}{|c|}{ Biomass (kg) } \\
\hline Length $(\mathrm{cm})$ & October & November & December & October & November & December \\
\hline 6.5 & 7329.89224 & 1058.713831 & 882.9344028 & 9990.643123 & 1443.026952 & 1203.43959 \\
\hline 7 & 16246.1986 & 2346.56589 & 1956.96296 & 29971.92937 & 4329.080855 & 3610.31877 \\
\hline 7.5 & 17900.3107 & 2585.482288 & 2156.211805 & 35772.94796 & 5166.967472 & 4309.09015 \\
\hline 8 & 17121.1807 & 2472.946425 & 2062.360395 & 49308.65799 & 7122.036245 & 5939.55669 \\
\hline 8.5 & 11726.0681 & 1693.687997 & 1412.483106 & 38673.45725 & 5585.910781 & 4658.47584 \\
\hline 9 & 9172.81418 & 1324.901503 & 1104.926641 & 35772.94796 & 5166.967472 & 4309.09015 \\
\hline 9.5 & 8836.58309 & 1276.337008 & 1064.425363 & 44152.19703 & 6377.248141 & 5318.42658 \\
\hline 10 & 8390.77711 & 1211.945755 & 1010.725061 & 48664.10037 & 7028.937732 & 5861.91543 \\
\hline 10.5 & 4253.28169 & 614.3348367 & 512.3361444 & 29649.65056 & 4282.531599 & 3571.49814 \\
\hline 11 & 2345.5978 & 338.7930885 & 282.5428974 & 17403.05576 & 2513.659851 & 2096.31413 \\
\hline 11.5 & 522.295667 & 75.43925996 & 62.9139962 & 4511.903346 & 651.6895911 & 543.488848 \\
\hline \multirow[t]{2}{*}{12} & 334.916706 & 48.37464693 & 40.34295081 & 2900.509294 & 418.9433086 & 349.38568 \\
\hline & \multicolumn{3}{|c|}{ catch-at-age in numbers $* 10-3$} & \multicolumn{3}{|c|}{ Biomass (kg) } \\
\hline Age (years) & October & November & December & October & November & December \\
\hline $\mathbf{0 +}$ & 26244.1631 & 3790.65033 & 3161.284463 & 34677.2 & 5008.7 & 4177.1 \\
\hline 1 & 38024.4201 & 5492.165251 & 4580.294981 & 98483.248 & 14224.708 & 11862.964 \\
\hline 2 & 24812.1345 & 3583.811207 & 2988.787069 & 115128.304 & 16628.884 & 13867.972 \\
\hline 3 & 11168.1804 & 1613.10789 & 1345.281804 & 69354.4 & 10017.4 & 8354.2 \\
\hline 4 & 3931.01862 & 567.7878543 & 473.5174089 & 29128.848 & 4207.308 & 3508.764 \\
\hline
\end{tabular}

\section{I.3.12 Coefficient of variation of length}

Table 3.12.1. Coefficient of variation of length

\begin{tabular}{|c|c|c|c|c|c|c|c|c|c|c|c|}
\hline & $\begin{array}{l}\text { Febr } \\
\text { uary }\end{array}$ & March & April & May & June & July & $\begin{array}{c}\text { Augu } \\
\text { st }\end{array}$ & $\begin{array}{c}\text { Septemb } \\
\text { er }\end{array}$ & October & $\begin{array}{c}\text { Novemb } \\
\text { er }\end{array}$ & $\begin{array}{c}\text { Decembe } \\
\mathbf{r}\end{array}$ \\
\hline $\begin{array}{l}\text { Coefficient } \\
\text { of variation } \\
\text { (CV) }\end{array}$ & na & $\mathrm{CV}=0.18$ & $\mathrm{CV}=0.18$ & na & na & na & na & $\mathrm{CV}=0.11$ & $\mathrm{CV}=0.14$ & $\mathrm{CV}=0.15$ & $\mathrm{CV}=0.14$ \\
\hline 1 sample & & $\mathrm{CV}=0.22$ & $\mathrm{CV}=0.22$ & & & & & $\mathrm{CV}=0.21$ & $\mathrm{CV}=0.22$ & $\mathrm{CV}=0.20$ & $\mathrm{CV}=0.23$ \\
\hline 2 sample & & $\mathrm{CV}=0.20$ & $\mathrm{CV}=0.16$ & & & & & & & & \\
\hline
\end{tabular}

\section{I.3.13 Conclusions and recommendations}

Sprat is a fast growing species with highly cycling nature of its recruitment and parental stock biomass dependent on the anthropogenic impacts different from fishing, as well as of fishing press and dynamics in the environmental factors. Therefore, the continuity of the study of the dynamics of population parameters is of great importance. In the studied months the observed length, weight and age structure were stable. The condition factor was expected to rise due to the beginning of the spawning period and gonad maturation in the next months. Linearly and by weight, the sprat grew well, as in October-December the condition was high, which was associated with the active ripening of sex products. The majority of samples studied were with

Project proposal № BG14MFOP001-3.003-0001 "Collection, management and use of data for the purposes of scientific analysis and implementation of the Common Fisheries Policy for the period 2017-2019", funded by the Maritime Affairs and Fisheries Program, co-financed by the European Union through the European Maritime and Fisheries Fund 


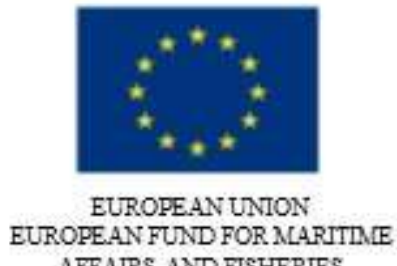

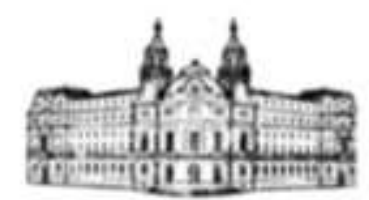

AINTSTRY OF AGRICUITURE, FOOD AND FORESTRY
MLARITLE AFFAIRS AND FISHERIES PROGRAM

developed gonads, the stages of sexually maturation showed readiness for the porational disposal of sexual products during the active breeding season of the species. It prevails 1-1+ age, with the senior age groups presented with a small percentage in the catches. New indicators as lipid content, otoliths chemistry should be introduced when biological characteristics are studied.

Project proposal № BG14MFOP001-3.003-0001 "Collection, management and use of data for the purposes of scientific analysis and implementation of the Common Fisheries Policy for the period 2017-2019", funded by the Maritime Affairs and Fisheries Program, co-financed by the European Union through the European Maritime and Fisheries Fund 


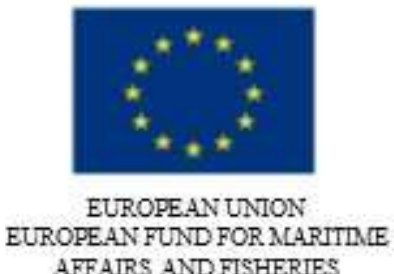

AFFAIRS AND FISHERIES

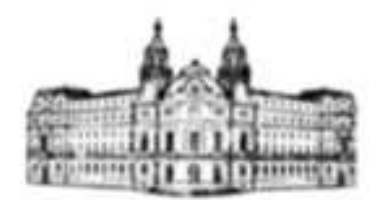

AINTSTRY OF AGRICULTURE, FOOD AND FORESTRY

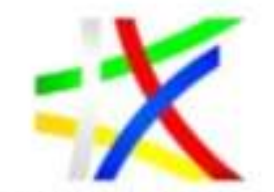

MCARITIE AFFAIRS AND FISHERIES PROGRAM

\section{Biological monitoring of horse mackerel (Trachurus mediterraneus) landings}

\section{II.1 Objectives}

Horse mackerel (Trachurus mediterraneus) is of significant importance to the commercial fishing sector of Bulgara. Information on the age of individual fish species significantly enhances the quality of studies on population characteristics such as growth, recruitment, mortality, and reproduction, and it is often a prerequisite for more detailed studies on life history strategies and stock assessment. Multiannual biological monitoring on the landings provides the so called "Fishery dependent" information. The aim of this study was to collect and analyze the dynamics in length and weight, as well as to determinate the condition of horse mackerel species. The condition factor is also a useful index for monitoring of feeding intensity, age, and growth rates in fish. It is strongly influenced by both biotic and abiotic environmental conditions and can be used as an index to assess the status of the aquatic ecosystem in which fish live. Biological information on a given species collected each month, analyzed and compared to previous periods could be used for estimation of growth parameters. These indicators are very important for the species. The purpose was to define the age of horse mackerel, as one of the important indicators for the assessment of fishing reserves. Reliable and informative long-term data are crucial for the assessment of fish stocks, fisheries management and the decision-making process in general.

\section{II.2 Sampling}

\section{II.2.1 Geographic area coverage}

Data of the present analysis were collected from landing ports on the Bulgarian Black Sea coast. Information about the size of the catches was also collected.

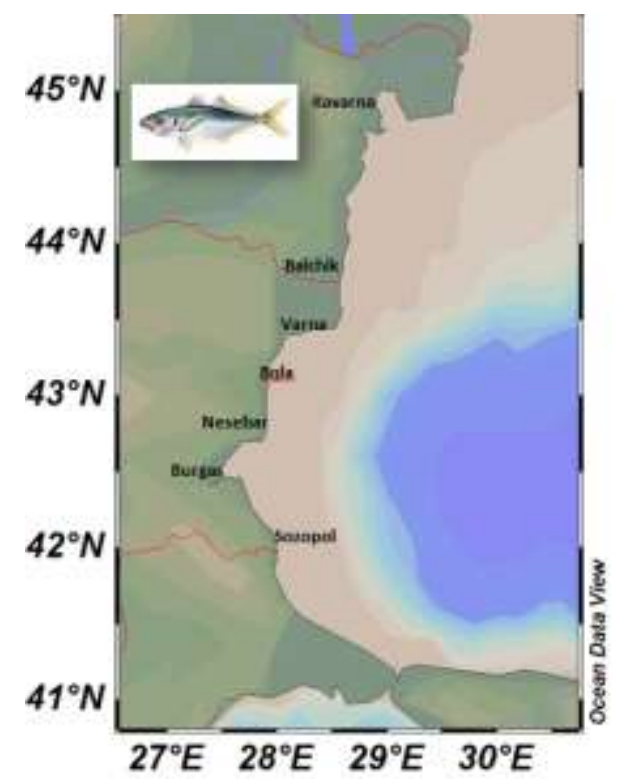

Fig. 2.1.1 Map of the ports for sampling of horse mackerel during the period 2017-2019

Project proposal № BG14MFOP001-3.003-0001 "Collection, management and use of data for the purposes of scientific analysis and implementation of the Common Fisheries Policy for the period 2017-2019", funded by the Maritime Affairs and Fisheries Program, co-financed by the European Union through the European Maritime and Fisheries Fund 


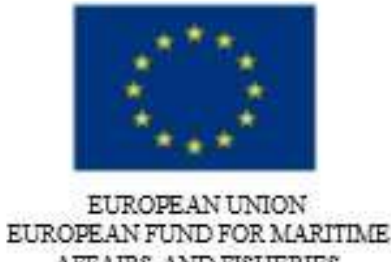

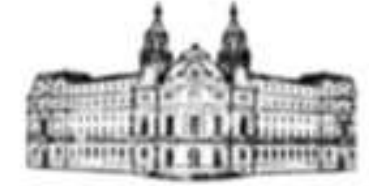

MINTSTRY OF AGRICUITURE, FOOD AND FORESTRY
MLARITIE AFFAIRS AND FISHERIES PROGRAM

In 2017, 5 samples were collected, containing 1734 specimens.

In 2018, 19 samples were collected, containing 2674 specimens.

In 2019, 11 samples were collected, containing 1500 specimens.

\section{II.2.1.2 Sampling period}

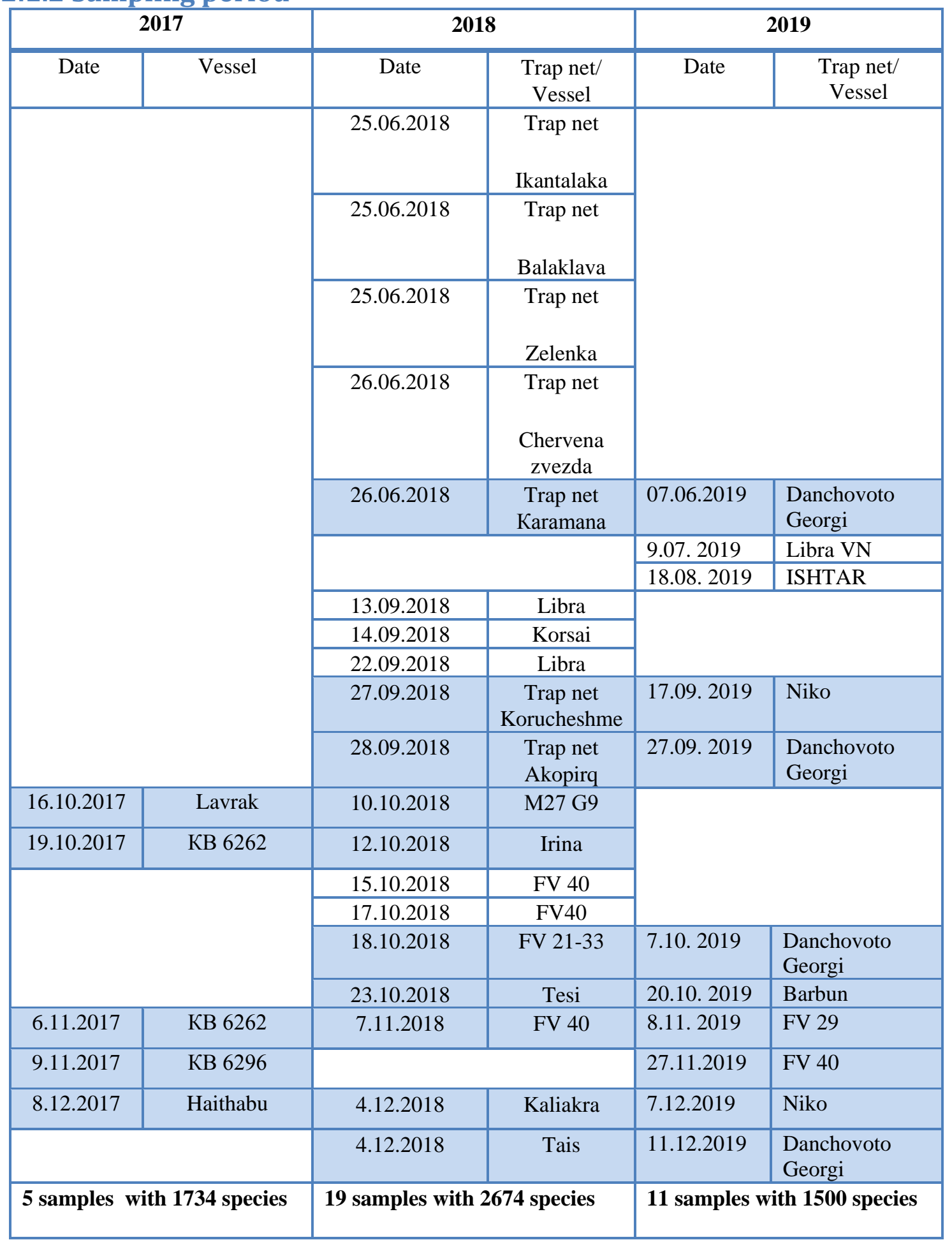

Project proposal № BG14MFOP001-3.003-0001 "Collection, management and use of data for the purposes of scientific analysis and implementation of the Common Fisheries Policy for the period 2017-2019", funded by the Maritime Affairs and Fisheries Program, co-financed by the European Union through the European Maritime and Fisheries Fund 


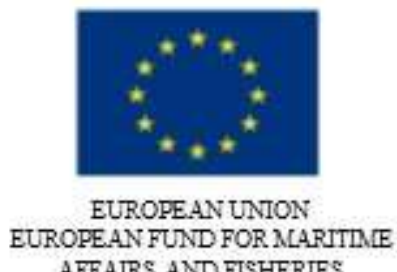

AFFAIRS AND FISHERIES

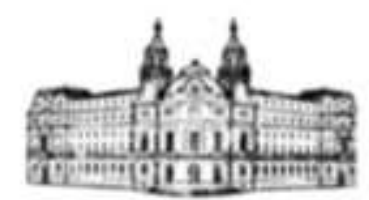

AINISTRY OF AGRICULTURE, FOOD AND FORESTRY

\section{II.2.1.3 Statistical analysis of data}

Refer to the methodology used for sprat stock analysis.

\section{II.3 Results}

\section{3.1 Catch statistics in the period 2017-2019}

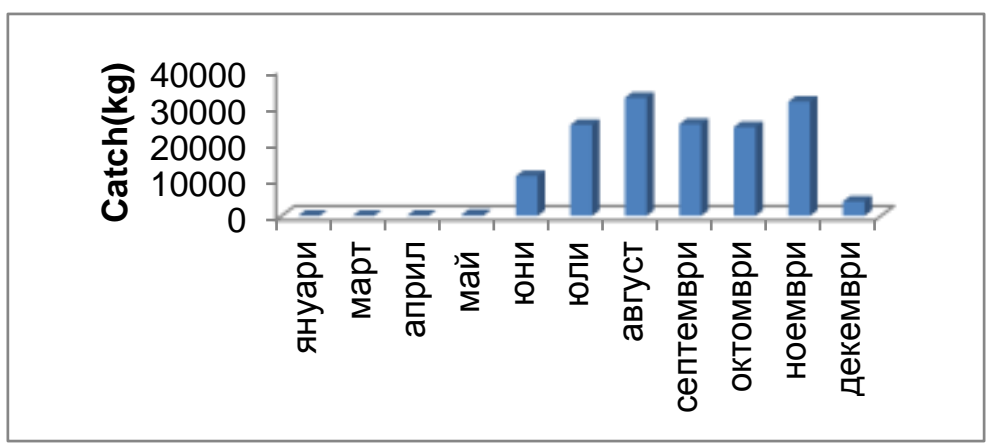

Fig. 3.1.1 Landing statistics in 2017
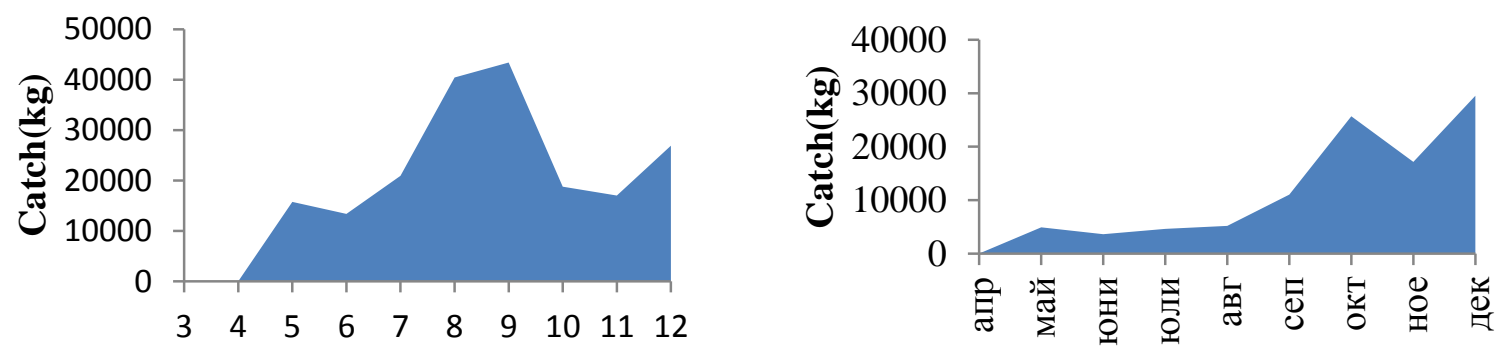

Fig. 3.1.2 Landings statistics in 2018 (left) and 2019 (right)

The statistics collected and the graphical interpretations show that in 2017 the highest quantity and intensity of the catches was registered in August, in 2018 in the period August-September and in 2019 - in December.

\section{II.3.2 Size structure in the period 2017-2019}

\section{II.3.2.1 Size structure analysis for 2017}

Dimensional characteristics of horse mackerel are shown on Fig. 3.2.1. The catches from the Bulgarian Black Sea waters during the period October-November 2017 and the size of the composition are represented by individuals with a body length from $9.5 \mathrm{~cm}$ to $16.0 \mathrm{~cm}$.

Project proposal № BG14MFOP001-3.003-0001 "Collection, management and use of data for the purposes of scientific analysis and implementation of the Common Fisheries Policy for the period 2017-2019", funded by the Maritime Affairs and Fisheries Program, co-financed by the European Union through the European Maritime and Fisheries Fund 


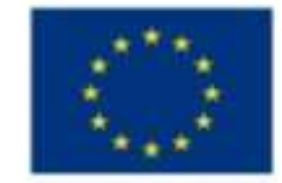

EUROPEAN UNTON EUROPEAN FUND FOR MLARITIIE AFFAIRS AND FISHERIES

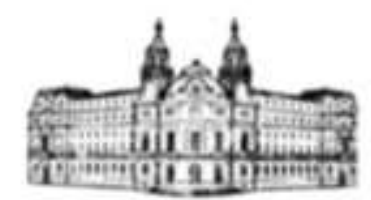

AINTSTRY OF AGRICUITURE, FOOD AND FORESTRY
MLARITLE AFFAIRS AND FISHERIES PROGRAM

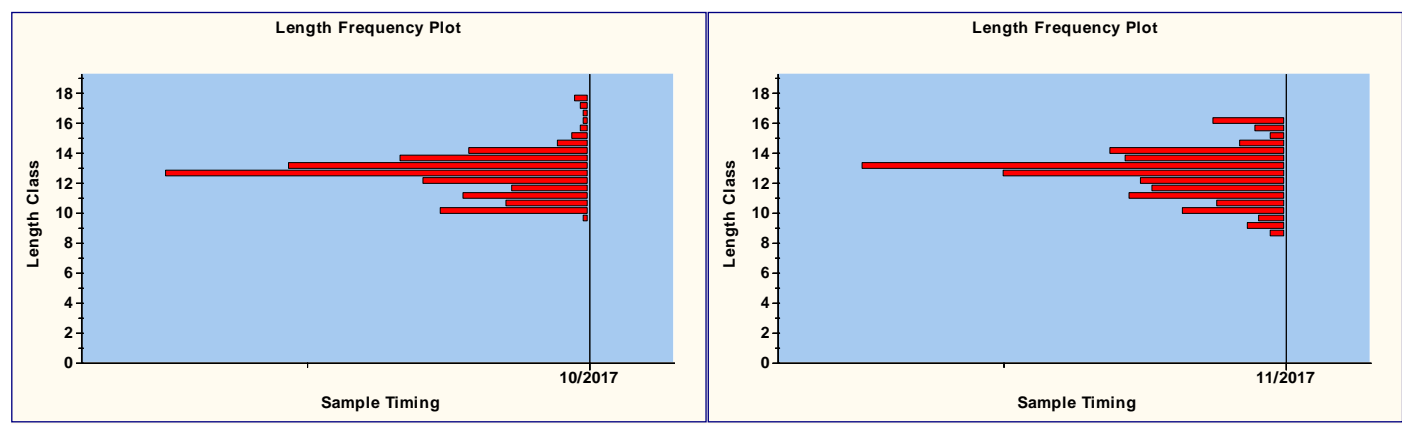

(a)

(b)

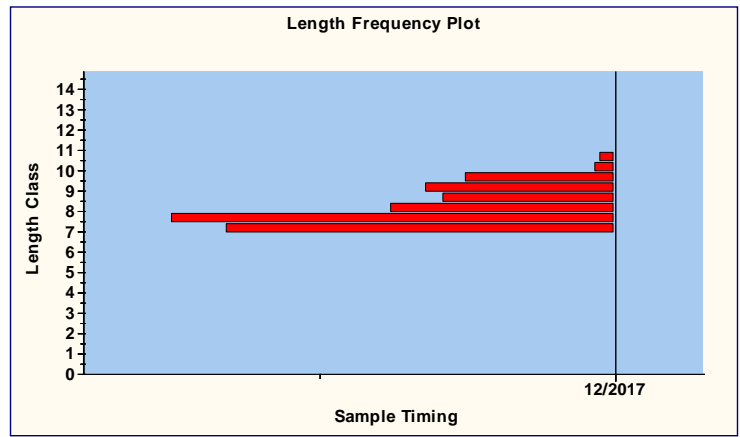

(c)

Fig. 3.2.1 Frequency of horse mackerel length from landings in October (a), November (b), December (c), 2017

\section{II.3.2.2 Size structure analysis for 2018}

In the catches from the Bulgarian Black Sea waters in 2018, the size composition is represented by individuals with a body length from $7.0 \mathrm{~cm}$ to $18.0 \mathrm{~cm}$.

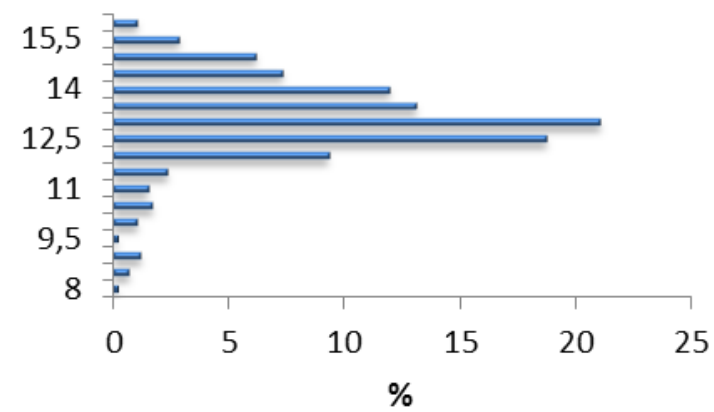

(a)

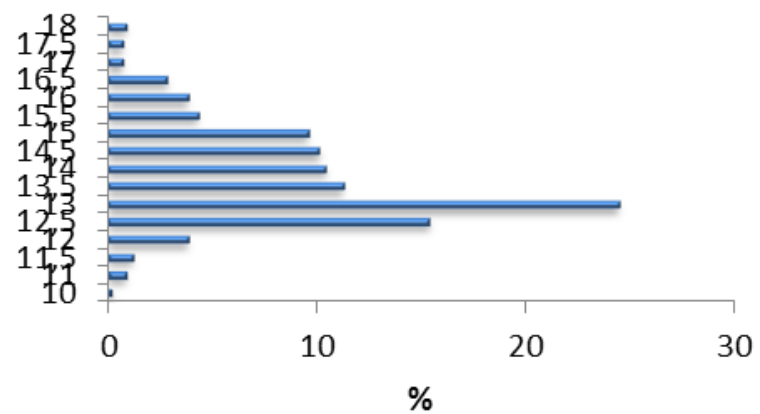

(b)

Project proposal № BG14MFOP001-3.003-0001 "Collection, management and use of data for the purposes of scientific analysis and implementation of the Common Fisheries Policy for the period 2017-2019", funded by the Maritime Affairs and Fisheries Program, co-financed by the European Union through the European Maritime 


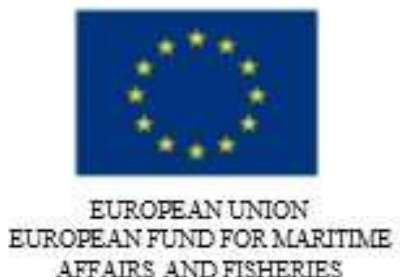

AFFAIRS AND FISHERIES

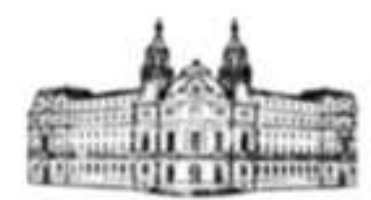

MINISTRY OF AGRICULTURE, FOOD AND FORESTRY
MLARITLIE AFFAIRS AND FISHERIES PROGRAM

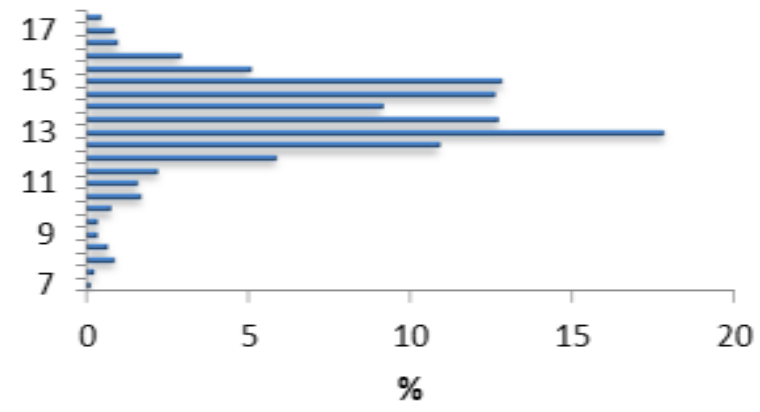

(c)

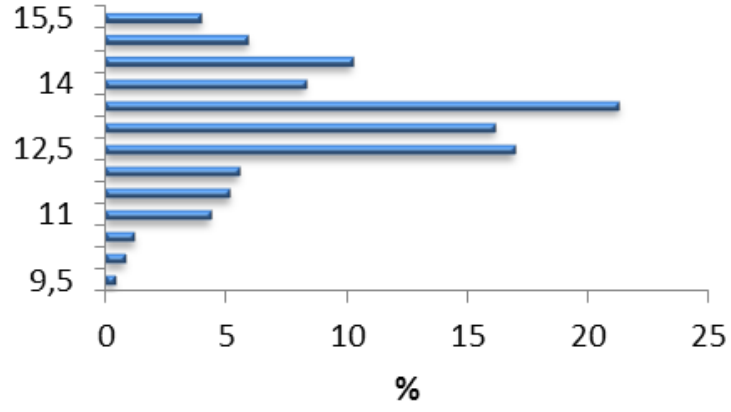

(d)

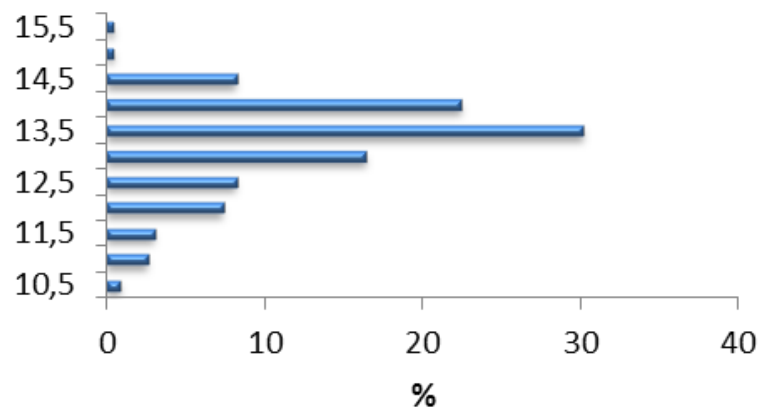

(e)

Fig. 3.2.2 Frequency of horse mackerel length on landings in June (a), September (b), October (c), November (d) December (e), 2018

\section{II.3.2.3 Size structure analysis for 2019}

The catches from the Bulgarian Black Sea waters in 2019 were dominated by a single-modal structure. In June and August the maximum was $12.5 \mathrm{~cm}$ and in July, September and December $-13.0 \mathrm{~cm}$. In November, the proportion of 9-10 $\mathrm{cm}$ increased, which was mainly due to the new $0+$ species.

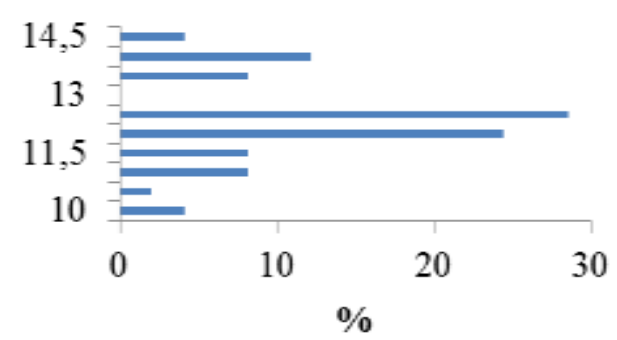

(a)

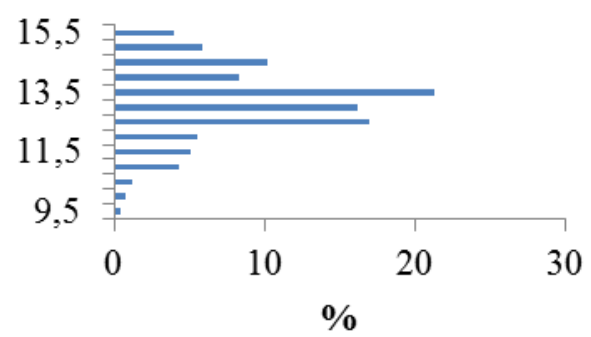

(b)

Project proposal № BG14MFOP001-3.003-0001 "Collection, management and use of data for the purposes of scientific analysis and implementation of the Common Fisheries Policy for the period 2017-2019", funded by the Maritime Affairs and Fisheries Program, co-financed by the European Union through the European Maritime 


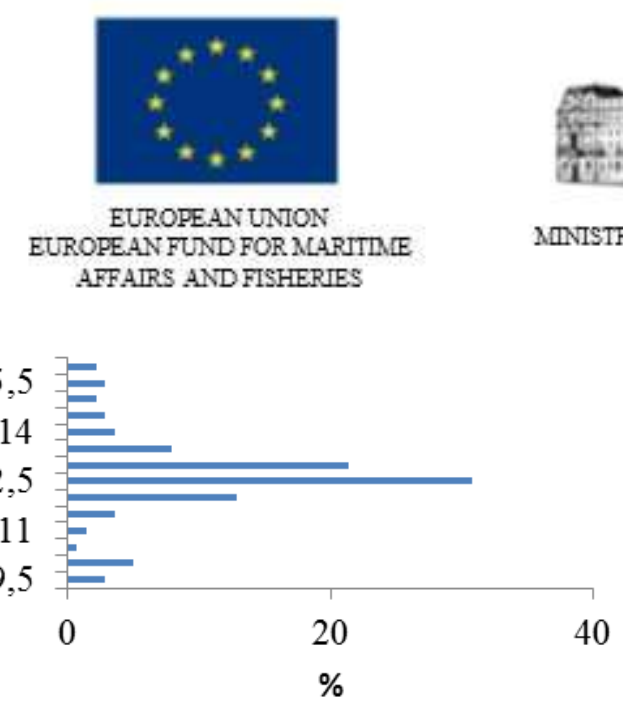

(c)

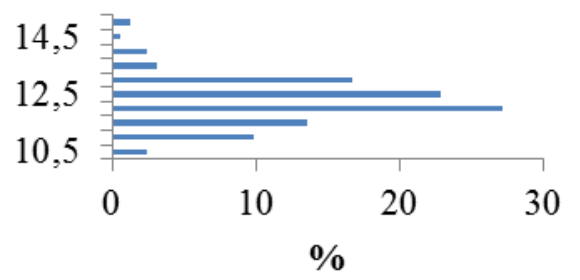

(e)

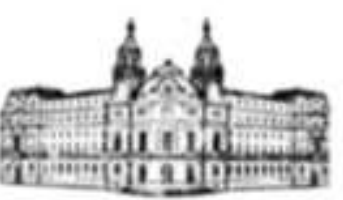

INISTRY OF AGRICUITURE, FOOD AND FORESTRY

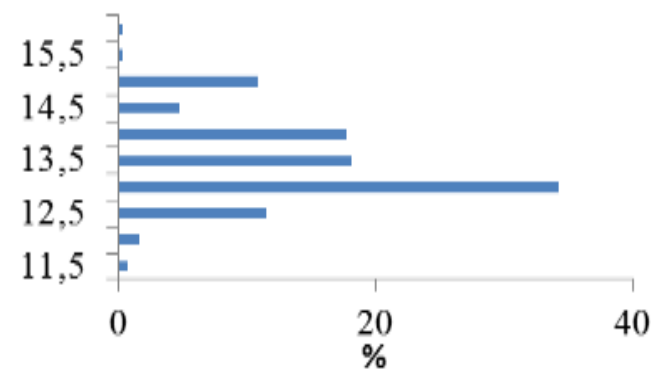

(d)

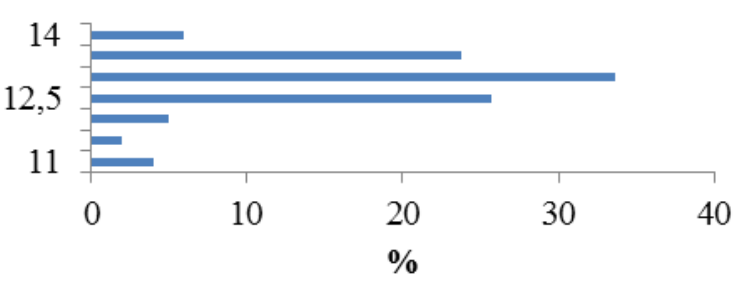

(g)

Fig. 3.2.3.1 Frequency of horse mackerel length from landing in June (a), July (b), August (c), September (d),

October (f), November (f), December (g), 2019

\section{II.3.1 Age structure of landings}

The age structure of horse mackerel during the period 2017-2019 was characterized by 7 age classes. The most indicative of the biological state of the species was the age composition during the spring season (May-June), which most closely reflected the real qualitative composition of the catches of the species in the Bulgarian Black Sea waters. A larger share had the three-year-olds (age 3) in June $2019-46.94 \%$ and to some extent in $2018-22.22 \%$. The four-year-olds were well represented during the said period with a percentage varying between 18.37\% (June, 2019) and 39.30\% (June, 2018). In June 2019, it should be noted that the 5th and 6th age group were missing. From data on the average age of the species, there was a decrease in the participation of young age groups (annuals) ranging between $2.32 \%$ (June, 2018) and 6.12\% (June, 2019). On Fig. 3.1 .1 is presented the range of variation of the percentage composition in the different age classes in June.

Project proposal № BG14MFOP001-3.003-0001 "Collection, management and use of data for the purposes of scientific analysis and implementation of the Common Fisheries Policy for the period 2017-2019", funded by the Maritime Affairs and Fisheries Program, co-financed by the European Union through the European Maritime and Fisheries Fund 


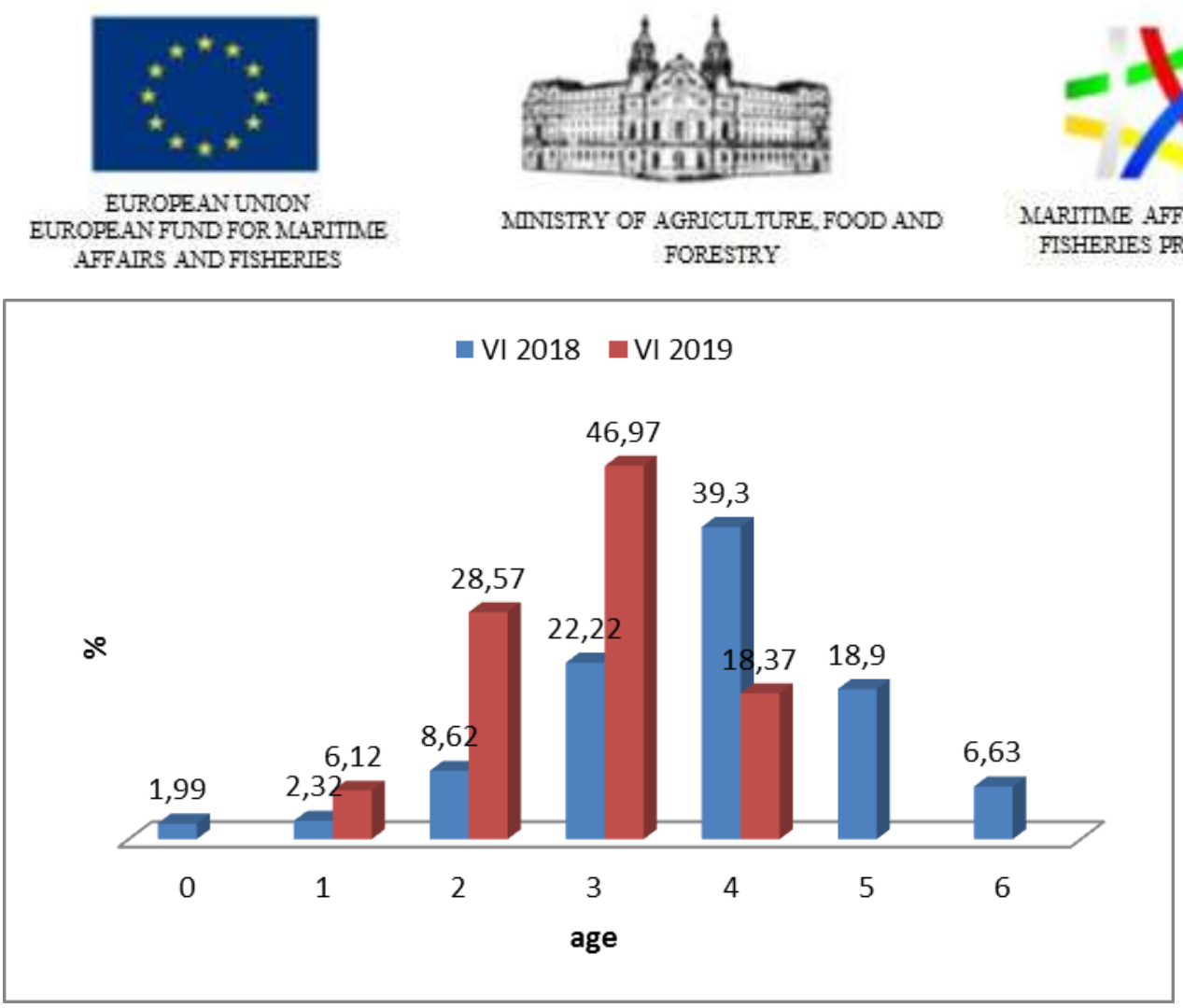

Fig. 3.1.1 Variation of the percentage participation of horse mackerel by age groups in June 2018, 2019 Note: For June, 2017 no comparative analysis data were available.

In a multiannual plan, that age distribution remained below normal for the species due to the low participation of senior age groups (5-6 years old). In July 2019, the expected participation of the one-year old increased (13.39\%) and the proportion of senior ages (3-4 years old) showed significant participation. During the month of July there was a significant participation of second age groups (Fig. 3.1.2).

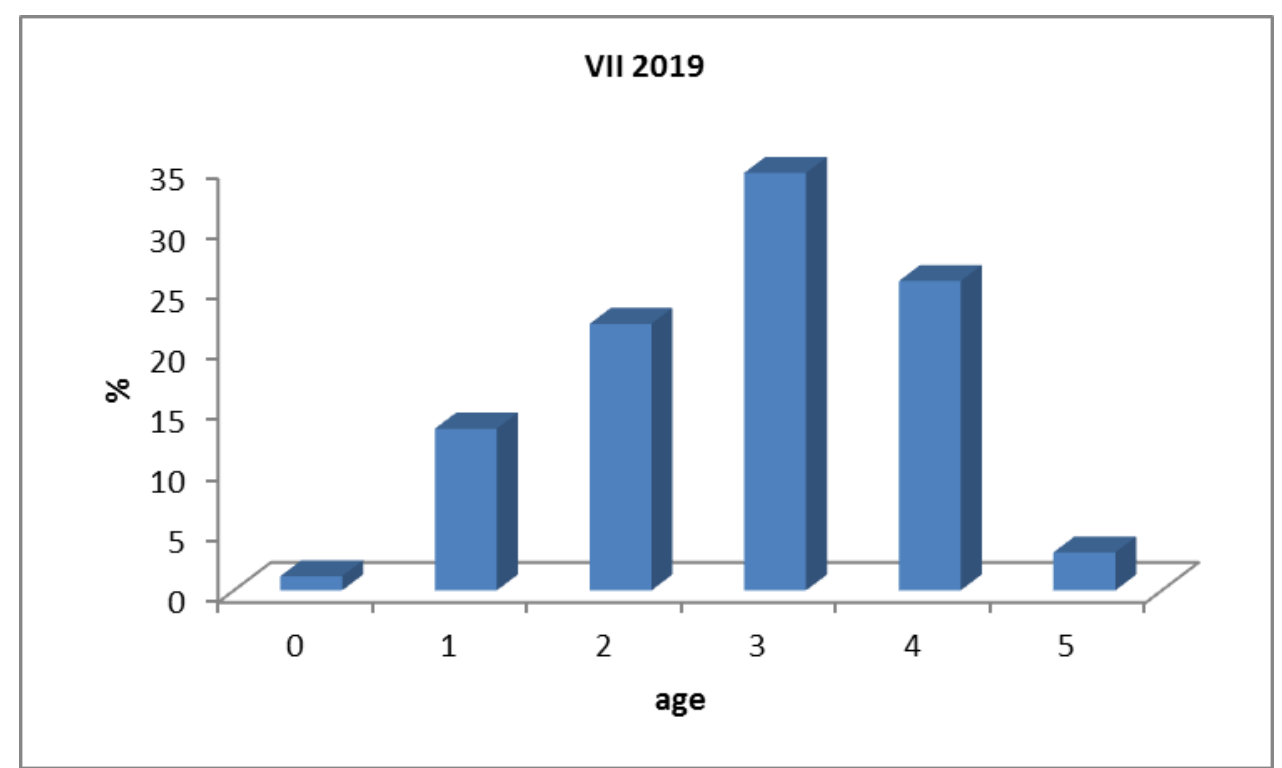

Fig. 3.1.2 Variation in the percentage participation of horse mackerel by age groups in July 2019 Note: For July 2017 and 2018 there were no comparative analysis data available.

Project proposal № BG14MFOP001-3.003-0001 "Collection, management and use of data for the purposes of scientific analysis and implementation of the Common Fisheries Policy for the period 2017-2019", funded by the Maritime Affairs and Fisheries Program, co-financed by the European Union through the European Maritime and Fisheries Fund 


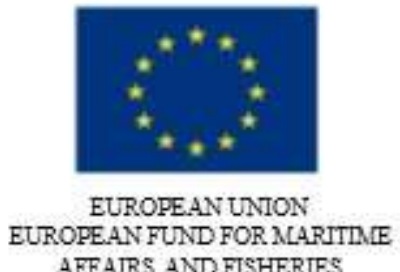

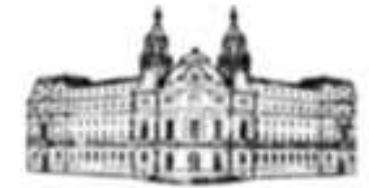

AINISTRY OF AGRICUITURE, FOOD AND FORESTRY
MLARITLE AFFAIRS AND FISHERIES PROGRAM

In the autumn season of the accounting period 2017-2019, four year olds had a significant share in the catches, reaching 54.29\% (September, 2018) and 36.83\% (September, 2019).

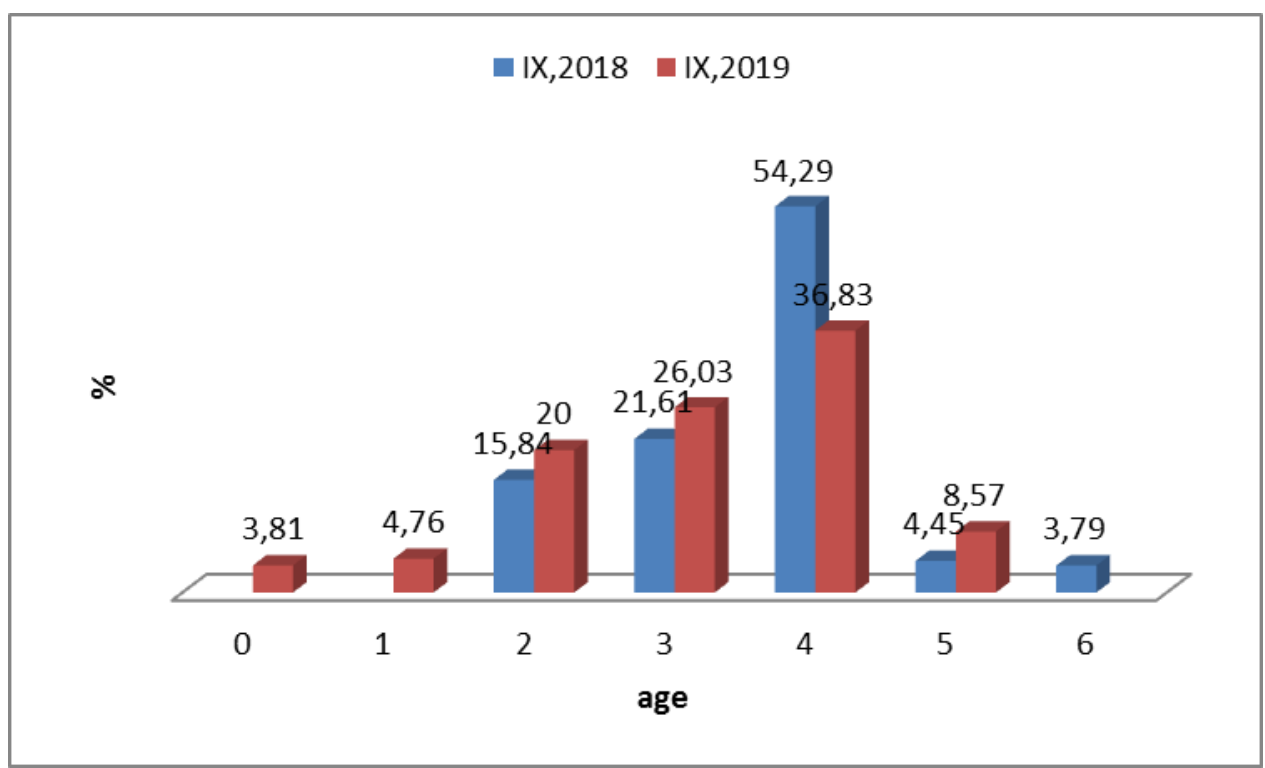

Fig. 3.1.3 Variation in the percentage participation of horse mackerel by age groups in September 2018-2019 Note: For September, 2017 no comparative analysis data were available.

\section{II.3.4 Condition factor}

During the spring migration along our coast in June, the values of $K=0.804-0.828$ (Fig. 3.4.1). The values of Fulton's condition factor of horse mackerel in June showde high values for all age groups.

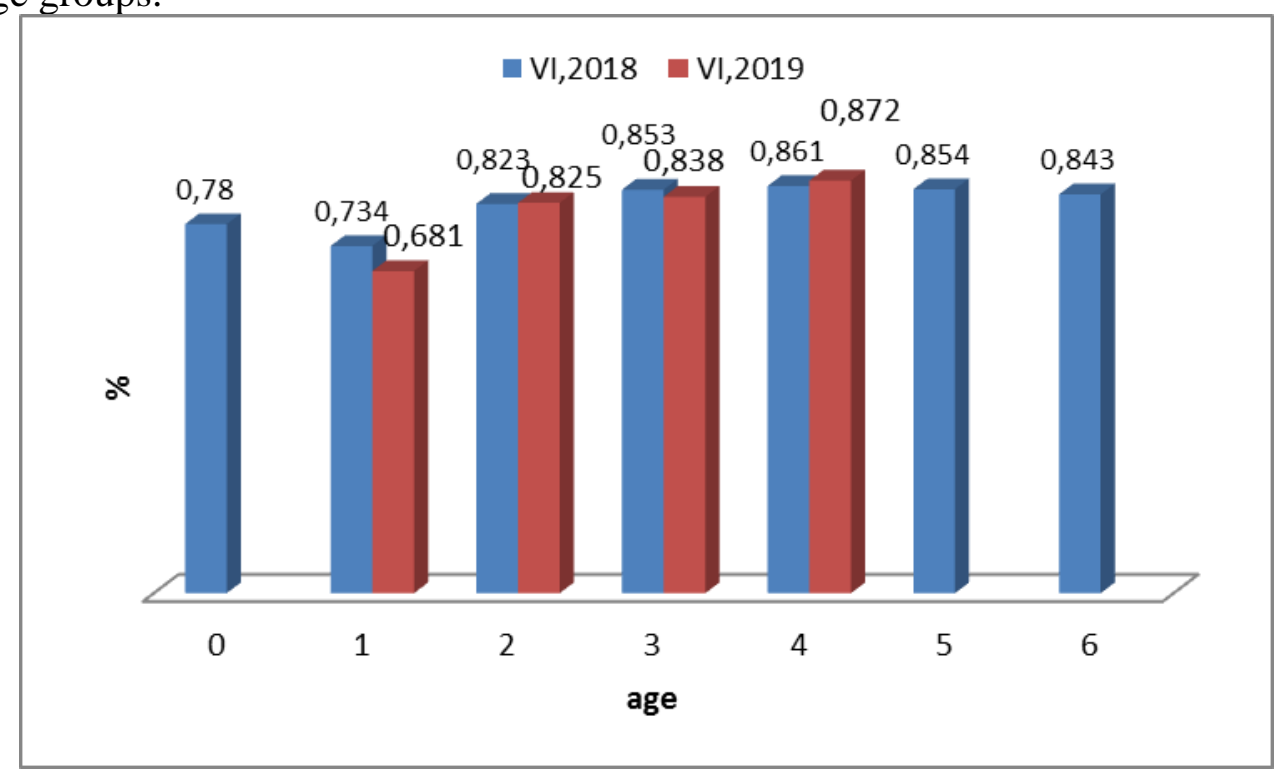

Fig. 3.4.1 Condition factor by age groups in June 2018 and 2019

Note: For June, 2017 no comparative analysis data were available.

Project proposal № BG14MFOP001-3.003-0001 "Collection, management and use of data for the purposes of scientific analysis and implementation of the Common Fisheries Policy for the period 2017-2019", funded by the Maritime Affairs and Fisheries Program, co-financed by the European Union through the European Maritime and Fisheries Fund 


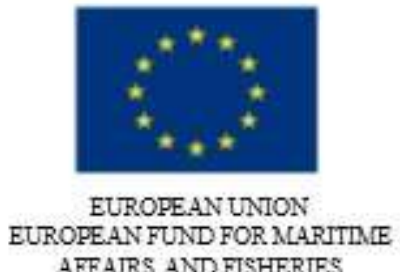

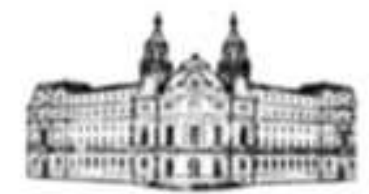

AINTSTRY OF AGRICULTURE, FOOD AND FORESTRY

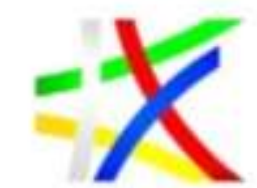

MLARITLE AFFAIRS AND FISHERIES PROGRAM

High values of $\mathrm{K}$ were also observed in the next month July when the species in parallel with reproduction were actively nourished.

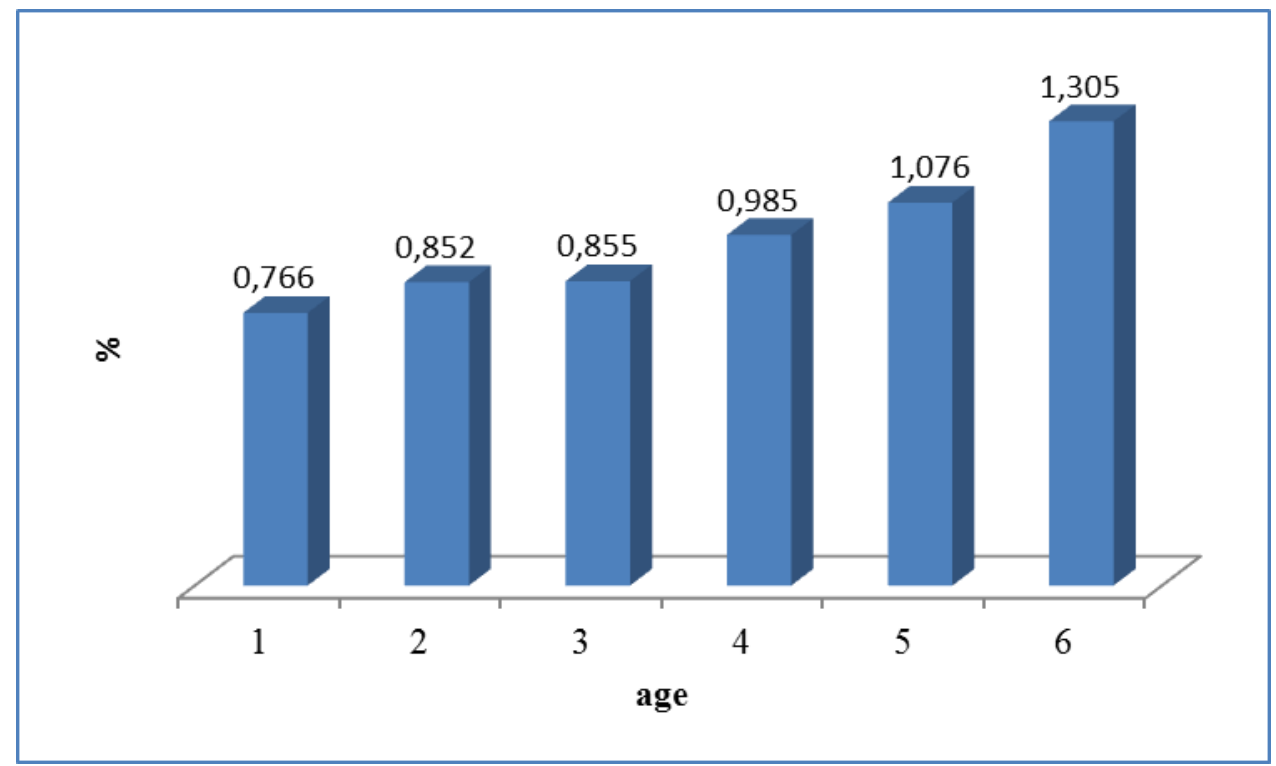

Fig. 3.4.2 Condition factor by age groups in July 2019

Note: For July, 2017 and 2018 no comparative analysis data were available.

The autumn months are usually characterized by a significant increase in the Fulton's condition factor. For those reasons, the autumn condition factor reached 0.954 (September, 2019). In September of the reporting period, the condition factor was relatively high compared to the previous months.

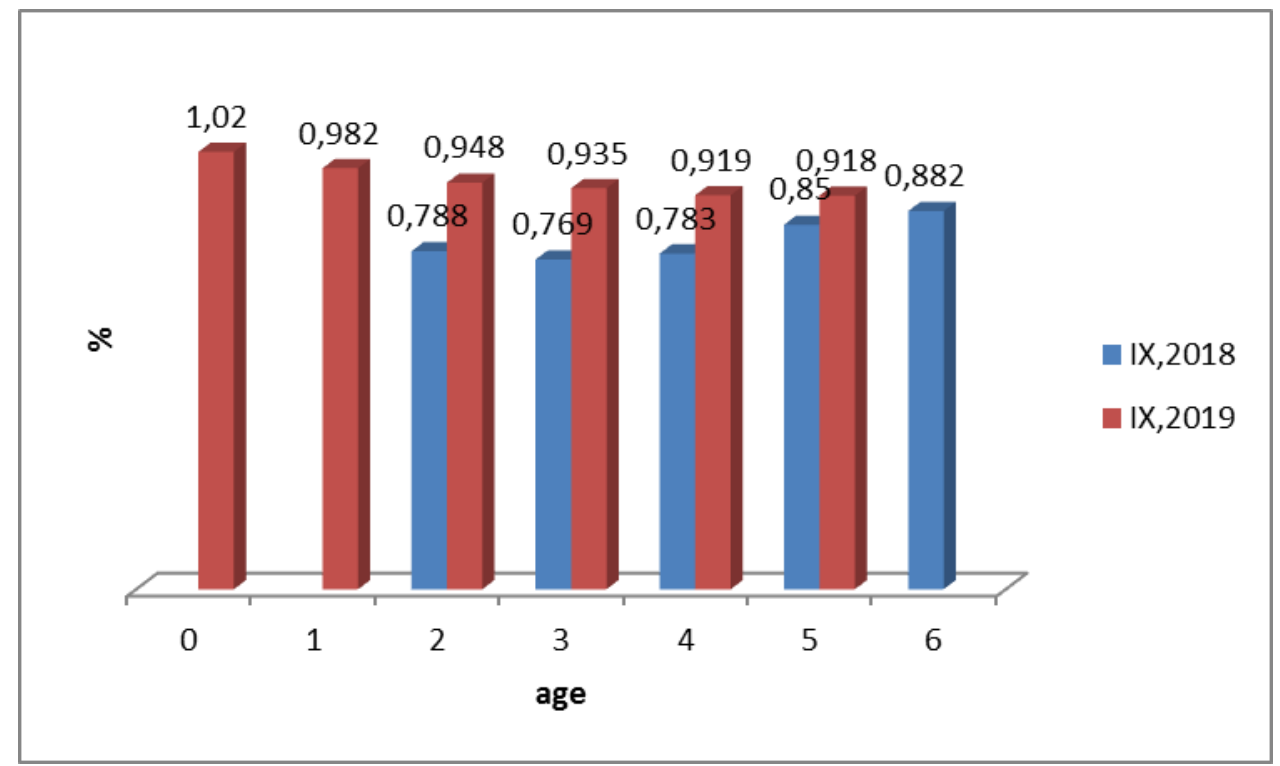

Fig. 3.4.3. Condition factor by age groups in September 2018 and 2019 Note: For September, 2018 no comparative analysis data were available.

Project proposal № BG14MFOP001-3.003-0001 "Collection, management and use of data for the purposes of scientific analysis and implementation of the Common Fisheries Policy for the period 2017-2019", funded by the Maritime Affairs and Fisheries Program, co-financed by the European Union through the European Maritime and Fisheries Fund 


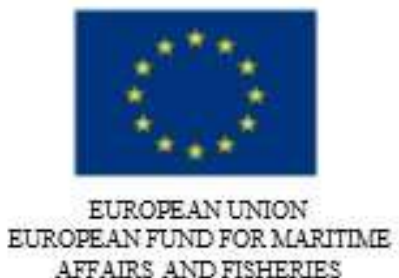

AFFAIRS AND FISHERIES

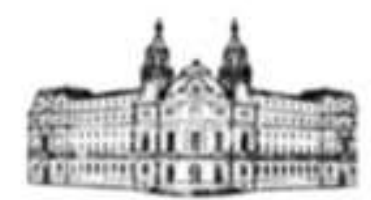

MINISTRY OF AGRICULTURE, FOOD AND FORESTRY
MLARITLIE AFFAIRS AND FISHERIES PROGRAM

In October, the species reached a good level of $\mathrm{K}$, the condition factor showed a relatively good value in 2018 and 2019 with averages 0.839 and 0.844 , respectively.

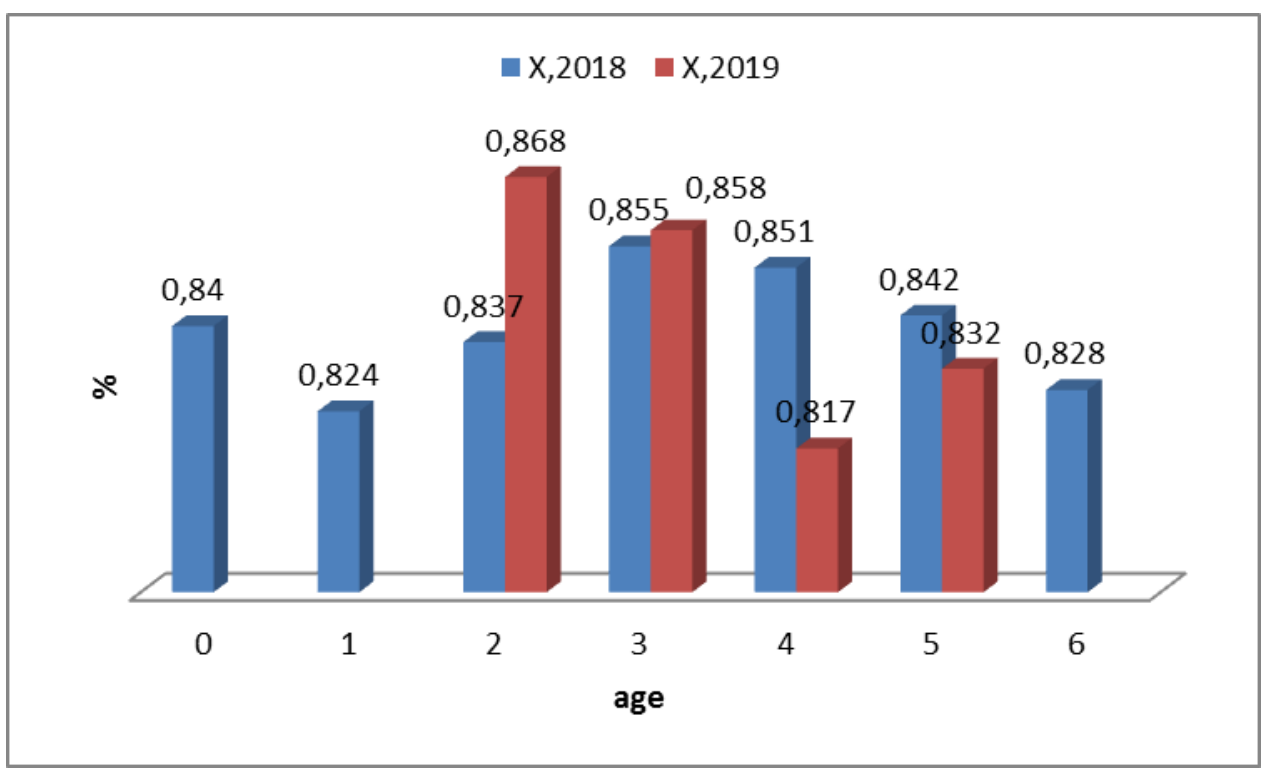

Fig. 3.4.4 Fig. 41. Condition factor by age groups in October, 2018 and 2019 Note: For October, 2017 no comparative analysis data were available.

\section{II.3.5 Weight structure}

In June, the weight structure referred to the average multiannual data showed a similar picture (Fig. 3.5.1).

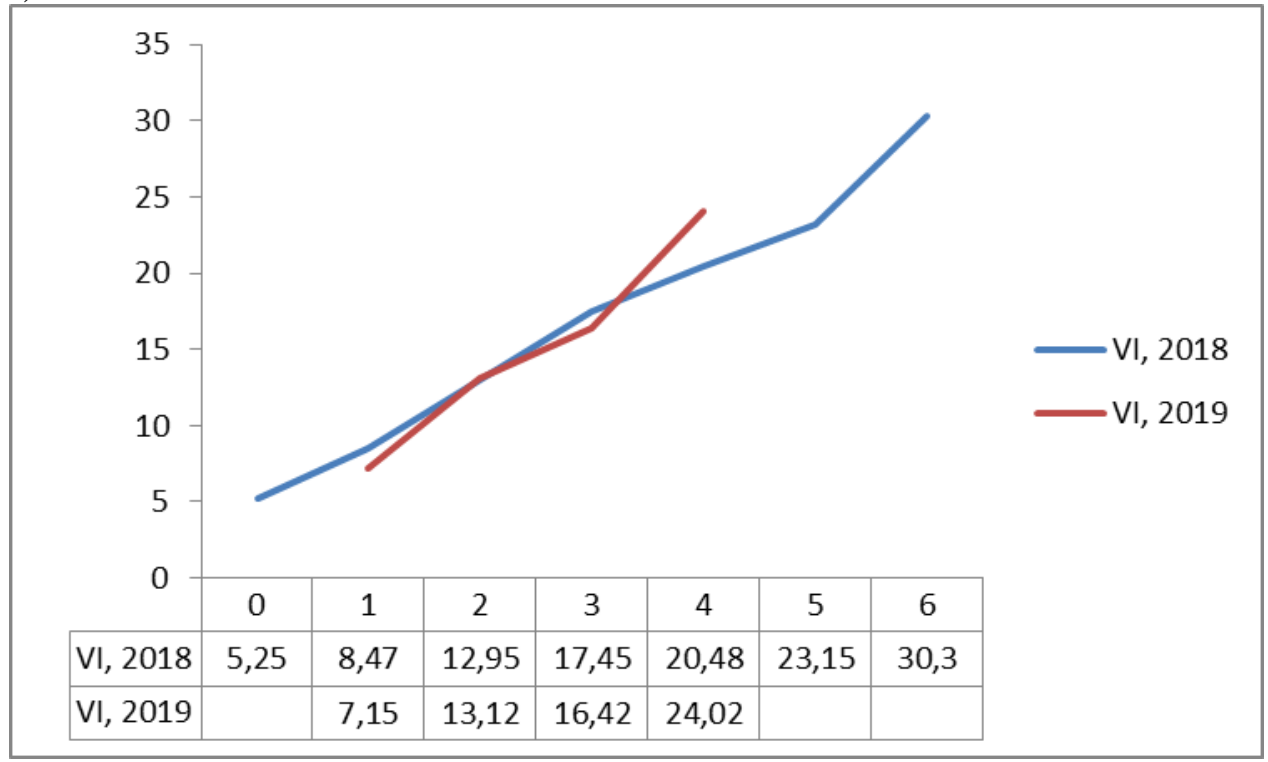

Fig. 3.5.1 Variation of average weights by age groups in June, 2018 and 2019 Note: For July, 2017 no comparative analysis data were available.

Project proposal № BG14MFOP001-3.003-0001 "Collection, management and use of data for the purposes of scientific analysis and implementation of the Common Fisheries Policy for the period 2017-2019", funded by the Maritime Affairs and Fisheries Program, co-financed by the European Union through the European Maritime and Fisheries Fund 


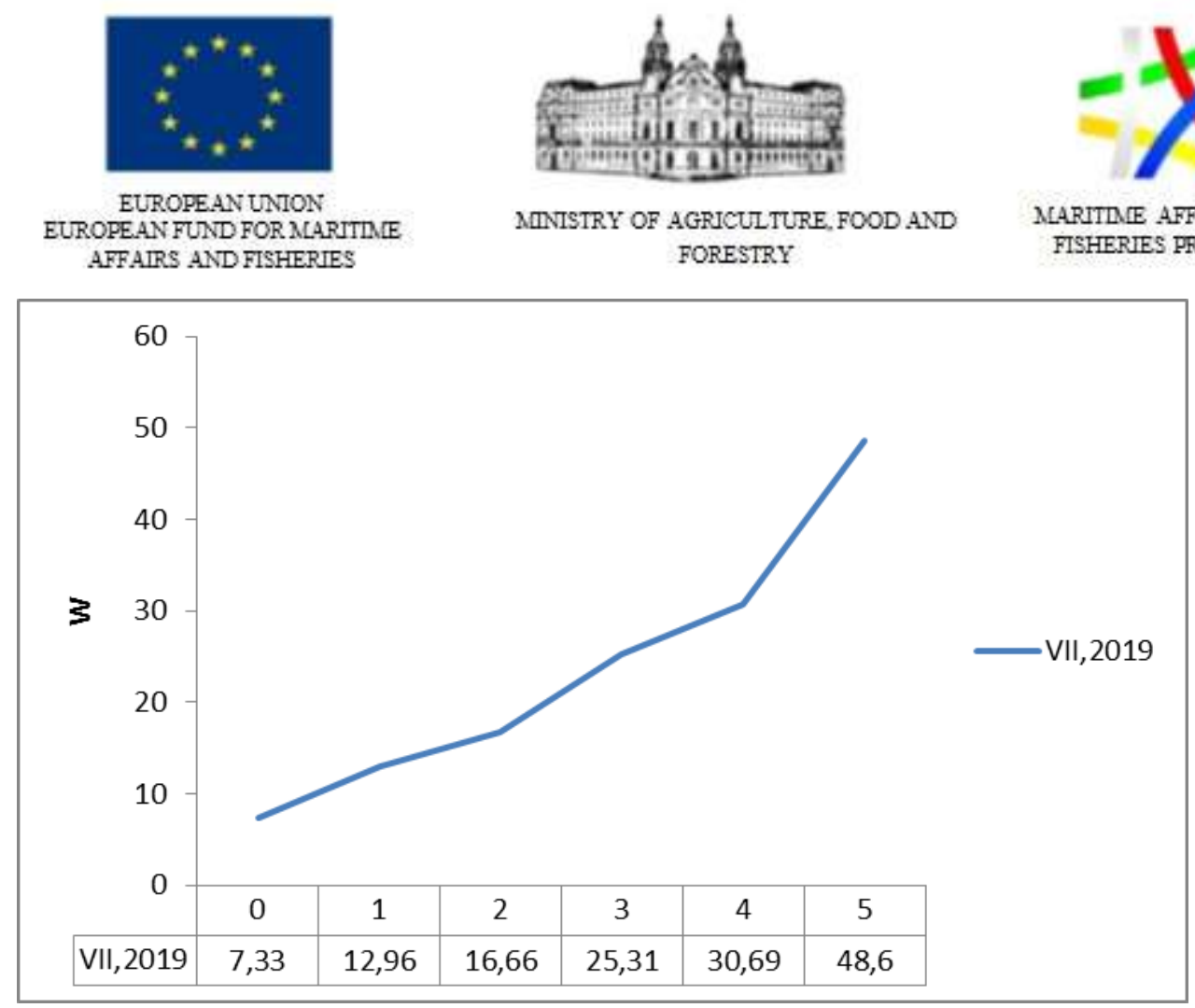

Fig. 3.5.2 Variation of average weights by age groups in July 2019

Note: For July, 2017 and 2018 no comparative analysis data were available.

After the completion of the breeding process during the autumn migration, horse mackerel continued its increased nurture and accumulation of reserve fats in preparation for the winter period. In September 2018 and 2019, the weight increase of the age of 2+ had a good rate and amounted in the optimum range 14.28-19.35g. In October, the weight increase of age 2+, lagged behind the norm with a deviation of $7.1 \mathrm{~g}$.

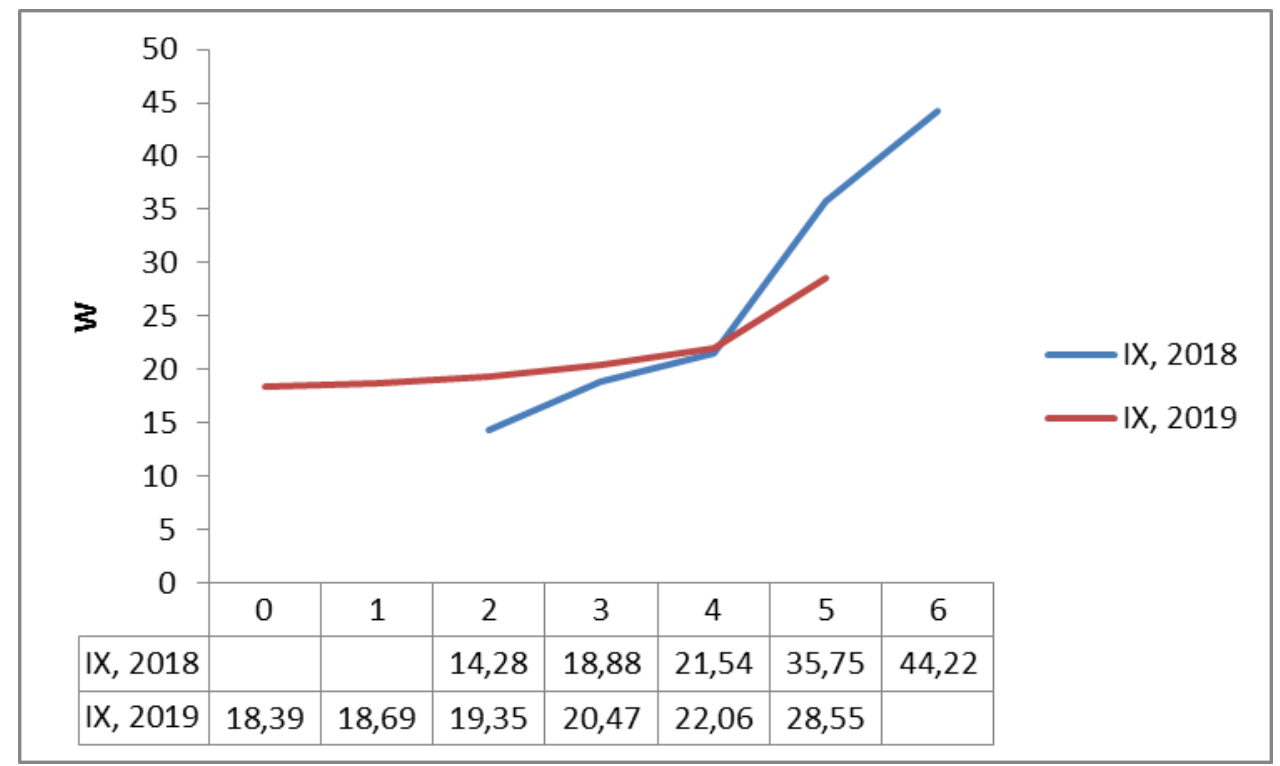

Fig. 3.5.3 Variation of average weights by age groups in September 2018 and 2019 Note: For September, 2017 no comparative analysis data were available.

Project proposal № BG14MFOP001-3.003-0001 "Collection, management and use of data for the purposes of scientific analysis and implementation of the Common Fisheries Policy for the period 2017-2019", funded by the Maritime Affairs and Fisheries Program, co-financed by the European Union through the European Maritime and Fisheries Fund 


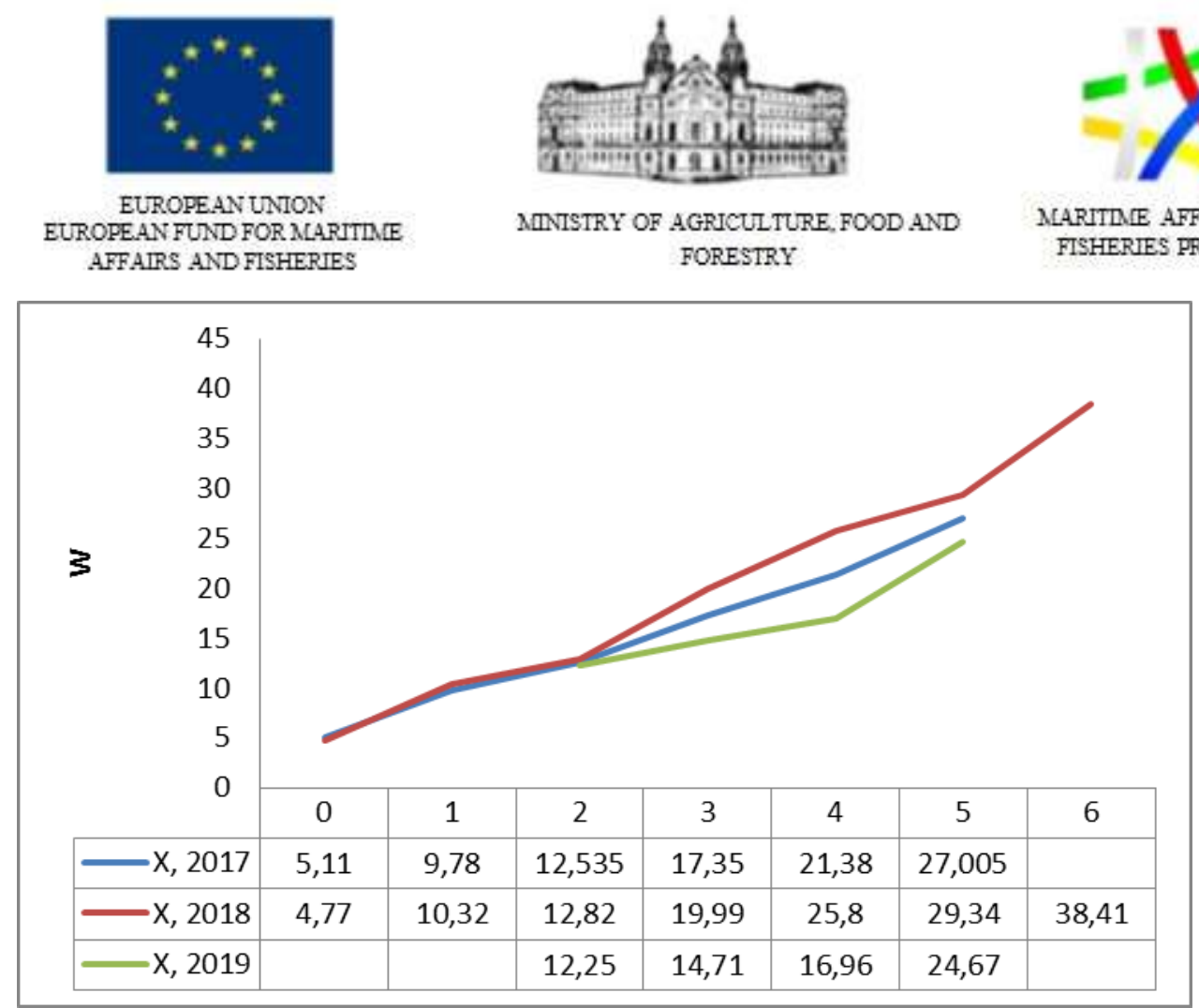

Fig. 3.5.4 Variation of average weights by age groups in October 2017 and 2019

\section{II.3.6 Size structure}

In June of the reporting period, the average linear dimensions of age 1+ showed values within the average multiannual data of $10.17-10.21 \mathrm{~cm}$. This was an indication of a good increase in replenishment.

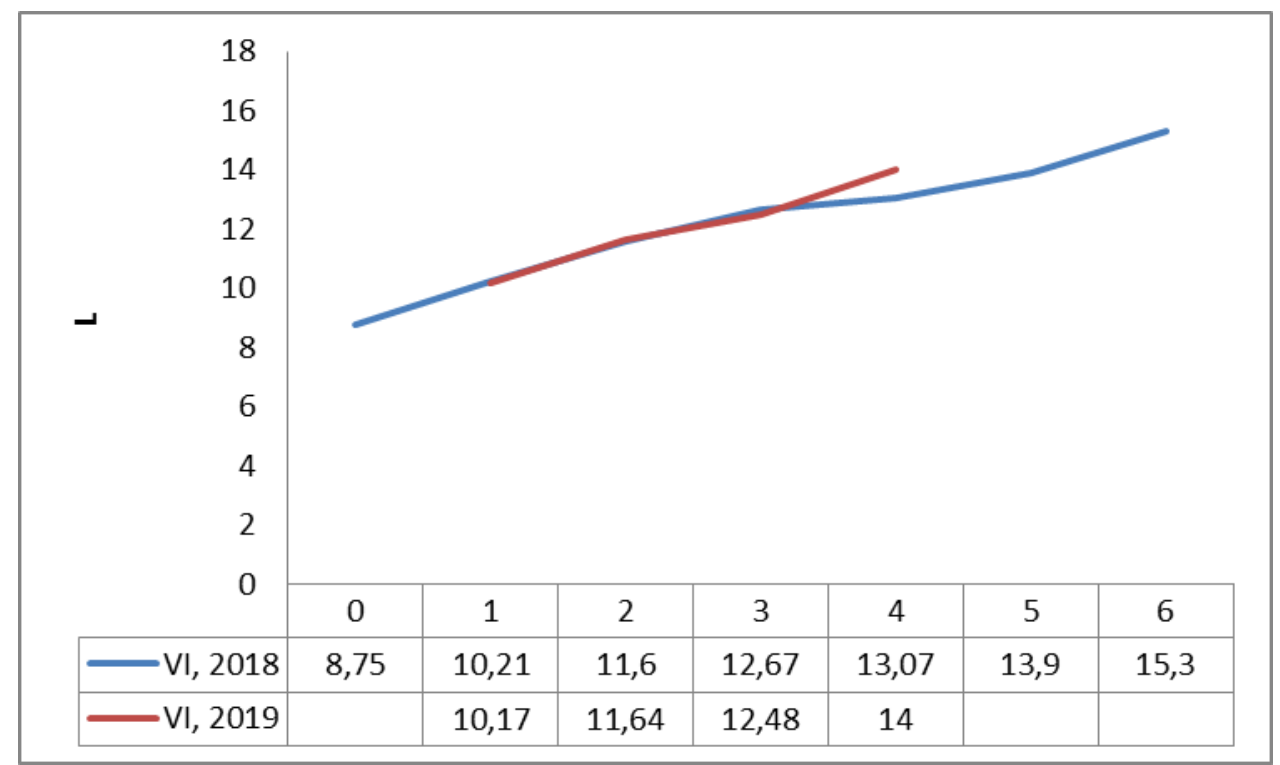

Fig. 3.6. 1 Variation of average lengths by age groups in June, 2018 and 2019 Note: For June, 2017 no comparative analysis data were available.

Project proposal № BG14MFOP001-3.003-0001 "Collection, management and use of data for the purposes of scientific analysis and implementation of the Common Fisheries Policy for the period 2017-2019", funded by the Maritime Affairs and Fisheries Program, co-financed by the European Union through the European Maritime and Fisheries Fund 


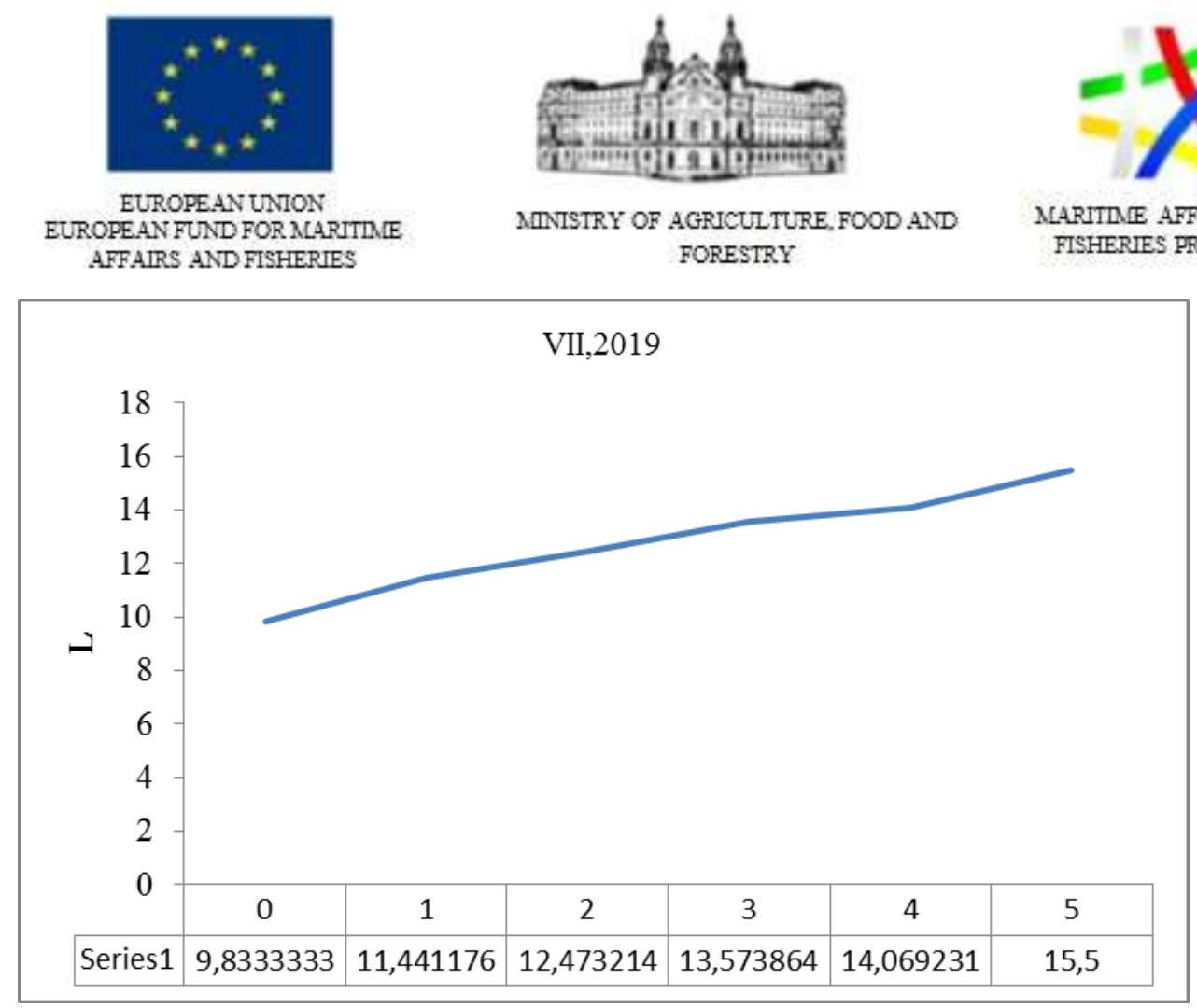

Fig. 3.6. 2 Variation of the average lengths by age groups in July 2019

Note: For July, 2017 and 2018 no comparative analysis data were available.

The rise in the autumn months increased in relation to further nurture.

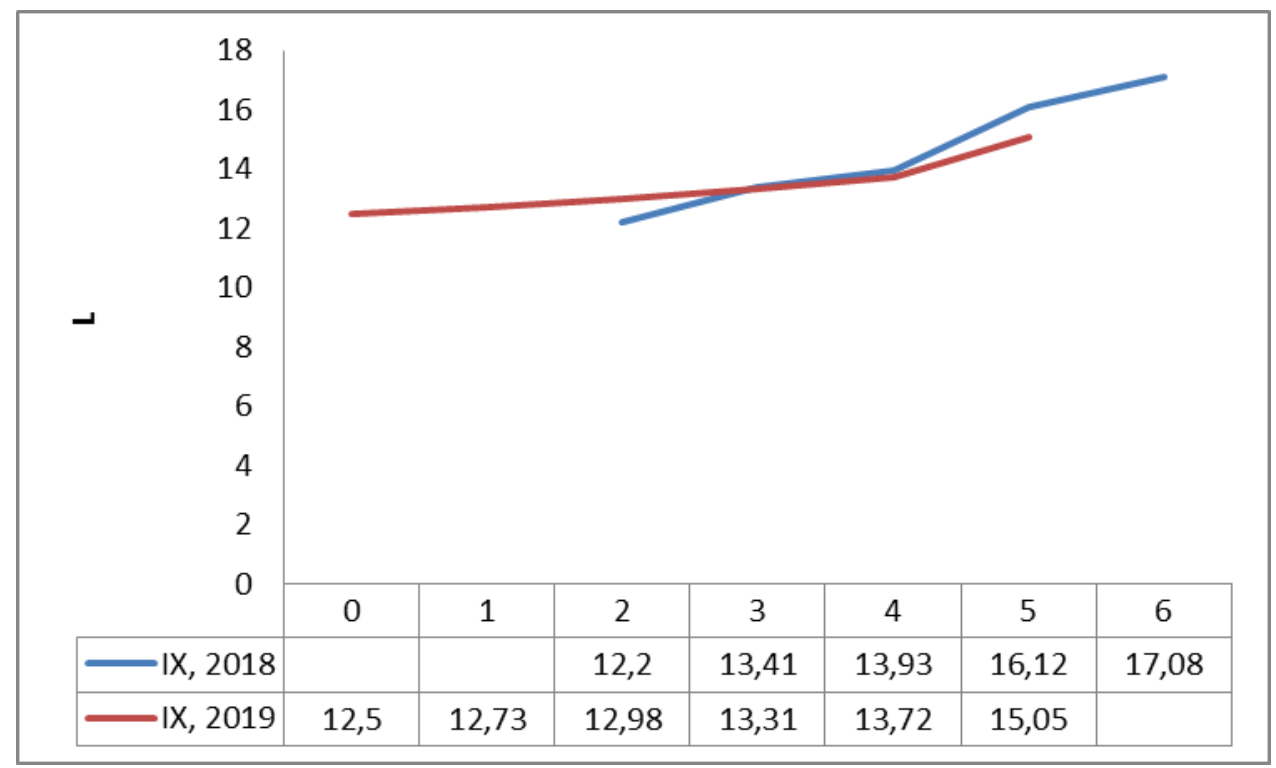

Fig. 3.6.3 Variation of average lengths by age groups in September, 2019 Note: For September, 2017 no comparative analysis data were available.

Project proposal № BG14MFOP001-3.003-0001 "Collection, management and use of data for the purposes of scientific analysis and implementation of the Common Fisheries Policy for the period 2017-2019", funded by the Maritime Affairs and Fisheries Program, co-financed by the European Union through the European Maritime and Fisheries Fund 


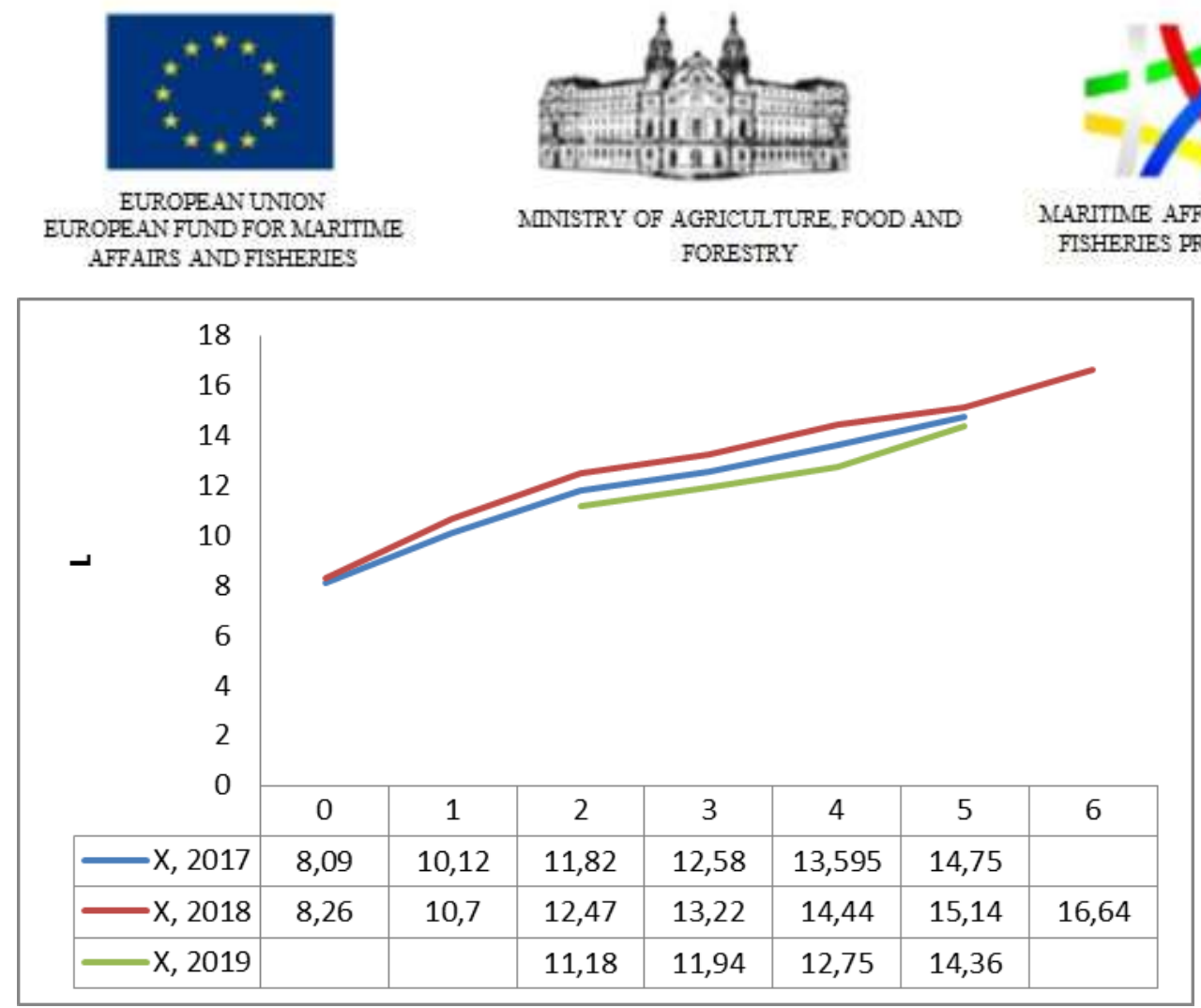

Fig. 3.6.4 Varying average lengths by age groups in October 2017 and 2019

\section{II.3.7 Length- weight relationship}

During the period 2018-2019, the growth of horse mackerel was algometric $(n \neq 3)$, i.e. not the same in terms of linear and weight growth.

The interrelationship between the size (L) and the weight (W) of the specimens studied is described by the equation:

$$
\begin{aligned}
& \text { for } 2018: \mathrm{W}=0.065 * \mathrm{~L}^{3.1169} \\
& \text { for } 2019: \mathrm{W}=0.078 * \mathrm{~L}^{3.2412}
\end{aligned}
$$

\section{II.3.8 Sex ratio}

Males $(\circlearrowleft)$ prevailed by $64 \%$, followed by female $(+)$ specimens with $36 \%$ in 2018 . Females (ㅇ) prevailed by $56 \%$, followed by male ( ${ }^{\Uparrow}$ ) specimens with $44 \%$ in 2019 (Fig. 3.8.1).
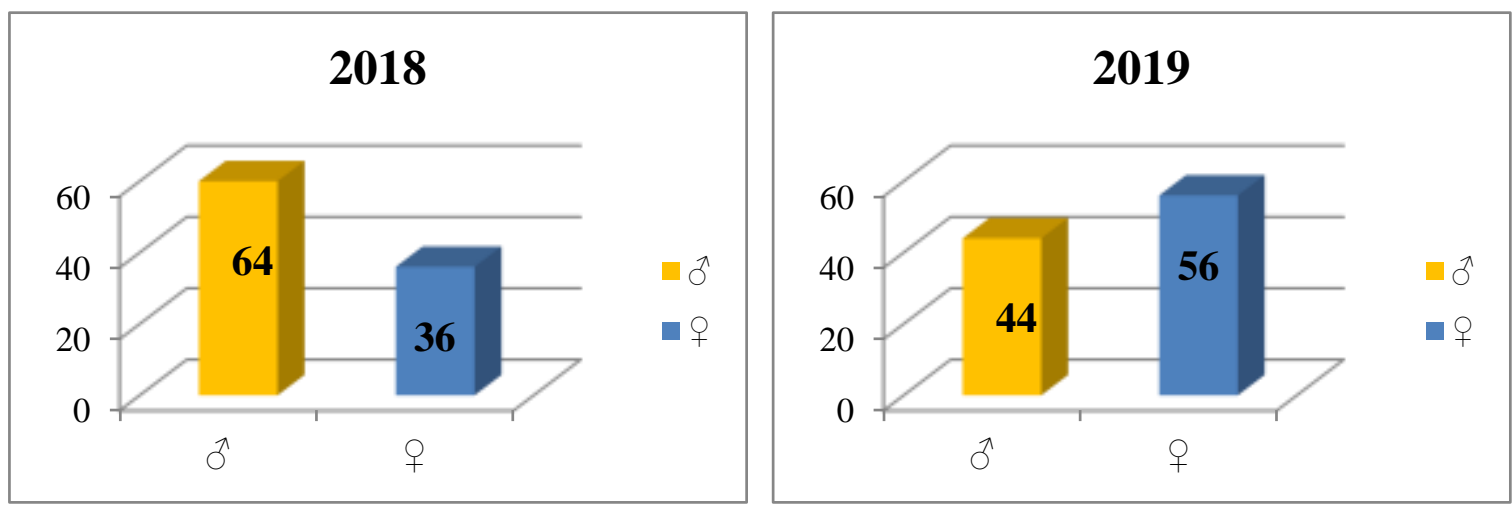

Fig. 3.8.1 Sex ratio of horse mackerel in 2018 and 2019

Project proposal № BG14MFOP001-3.003-0001 "Collection, management and use of data for the purposes of scientific analysis and implementation of the Common Fisheries Policy for the period 2017-2019", funded by the Maritime Affairs and Fisheries Program, co-financed by the European Union through the European Maritime and Fisheries Fund 


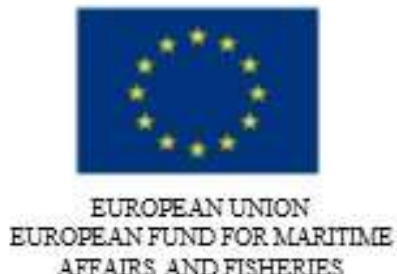

AFFAIRS AND FISHERIES

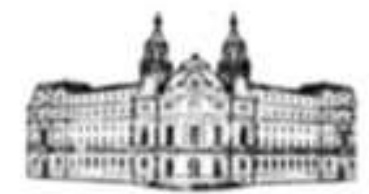

AINISTRY OF AGRICULTURE, FOOD AND FORESTRY

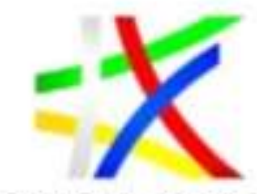

MCARITLE AFFAIRS AND FISHERIES PROGRAM

\section{II.3.9 Fertility}

The dependence between weight and fertility of horse mackerel during the spring-summer season of 2019 showed a relatively strong dependence $\left(\mathrm{R}^{2}=0.9\right)$ on the gonadosomatic index and the weight of the gland (ovarias).

\section{II.3.10 Sexual maturity}

All investigated specimens showed VI-VII degree of maturation and only $10 \%$ were in III-IV degree. Horse mackerel is a summer-breeding species. The beginning of the active breed of horse mackerel was registered in June-August. In June, there was a mass of mature sexual products in more than $40 \%$ of the female species.

\section{III.3.11 Catch numbers and biomass by age and length}

\section{II.3.11.1 Catch numbers and biomass by age and length in 2017}

Monthly catches (in tons) together with mean weights of horse mackerel were used to derive the monthly catch numbers. The share $(\%)$ by age groups and catch numbers were used to create catch-at-age matrix for selected months by age groups (Table 3.11.1).

Table 3.11.1 Catch-at-age $\left(10^{-3}\right)$ matrix and biomass $(\mathrm{kg})$ of horse mackerel for selected months

\begin{tabular}{|c|c|c|c|}
\hline \multicolumn{4}{|c|}{ Catch-at-age $\left(10^{-3}\right)$} \\
\hline Age groups & October & November & December \\
\hline 0 & 0.085 & 0.080 & 0.107 \\
\hline 1 & 0.138 & 0.239 & 0.095 \\
\hline 2 & 0.201 & 0.995 & 0.071 \\
\hline 3 & 0.480 & 0.863 & 0.033 \\
\hline 4 & 0.427 & 0.013 & 0.004 \\
\hline 5 & 0.042 & 0.066 & \\
\hline$\sum$ & 1.373 & 2.256 & 0.310 \\
\hline \multicolumn{4}{|c|}{ Biomass (kg) } \\
\hline Age groups & October & November & December \\
\hline 0 & 761.868 & 535.379 & 528.641 \\
\hline 1 & 1444.803 & 2296.697 & 1107.651 \\
\hline 2 & 2980.395 & 12589.129 & 1293.794 \\
\hline 3 & 9231.934 & 13974.726 & 900.177 \\
\hline 4 & 8782.003 & 262.340 & 110.023 \\
\hline 5 & 1156.528 & 1689.397 & \\
\hline$\sum$ & 24357.530 & 31347.669 & 3940.286 \\
\hline
\end{tabular}

Project proposal № BG14MFOP001-3.003-0001 "Collection, management and use of data for the purposes of scientific analysis and implementation of the Common Fisheries Policy for the period 2017-2019", funded by the Maritime Affairs and Fisheries Program, co-financed by the European Union through the European Maritime 

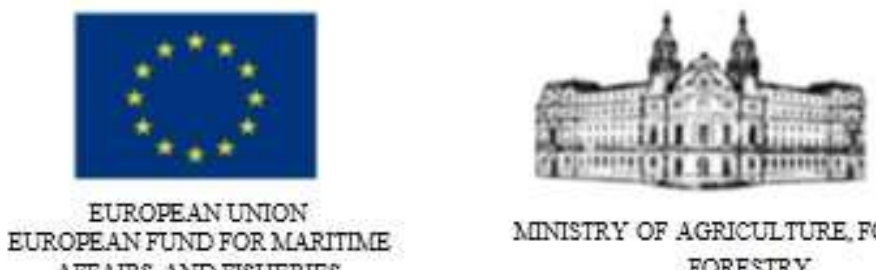
AFFATRS AND

AINISTRY OF AGRICULTURE, FOOD AND FORESTRY
MLARITLE AFFAIRS AND FISHERIES PROGRAM

Table 3.11.2 Catch-at-length $\left(10^{-3}\right)$ matrix and biomass $(\mathrm{kg})$ of horse mackerel for selected months

\begin{tabular}{|c|c|c|c|}
\hline \multicolumn{4}{|c|}{ Catch-at-length (millions) } \\
\hline Length group (cm) & October & November & December \\
\hline 7.0 & & & 66.847 \\
\hline 7.5 & & & 76.274 \\
\hline 8.0 & & & 38.566 \\
\hline 8.5 & & 1.760 & 29.567 \\
\hline 9.0 & & 4.399 & 32.567 \\
\hline 9.5 & 0.464 & 3.079 & 25.710 \\
\hline 10.0 & 12.052 & 11.877 & 3.428 \\
\hline 10.5 & 6.721 & 7.918 & 2.571 \\
\hline 11.0 & 10.198 & 18.036 & \\
\hline 11.5 & 6.258 & 15.396 & \\
\hline 12.0 & 13.443 & 16.716 & \\
\hline 12.5 & 34.302 & 32.552 & \\
\hline 13.0 & 24.336 & 48.828 & \\
\hline 13.5 & 15.297 & 18.475 & \\
\hline 14.0 & 9.734 & 20.235 & \\
\hline 14.5 & 2.549 & 5.279 & \\
\hline 15.0 & 1.391 & 1.760 & \\
\hline 15.5 & 0.695 & 3.519 & \\
\hline 16.0 & 0.464 & 8.358 & \\
\hline$\sum$ & 137.903 & 218.186 & 275.531 \\
\hline \multicolumn{4}{|c|}{ Biomass (kg) } \\
\hline Length group $(\mathrm{cm})$ & October & November & December \\
\hline 7.0 & & & 467.931 \\
\hline 7.5 & & & 305.098 \\
\hline 8.0 & & & 159.084 \\
\hline 8.5 & & 8.358 & 152.763 \\
\hline 9.0 & & 24.194 & 195.400 \\
\hline 9.5 & 3.639 & 16.320 & 171.403 \\
\hline 10.0 & 107.799 & 93.829 & 27.425 \\
\hline 10.5 & 69.169 & 71.262 & 22.711 \\
\hline 11.0 & 125.842 & 173.141 & \\
\hline
\end{tabular}

Project proposal № BG14MFOP001-3.003-0001 "Collection, management and use of data for the purposes of scientific analysis and implementation of the Common Fisheries Policy for the period 2017-2019", funded by the Maritime Affairs and Fisheries Program, co-financed by the European Union through the European Maritime and Fisheries Fund 


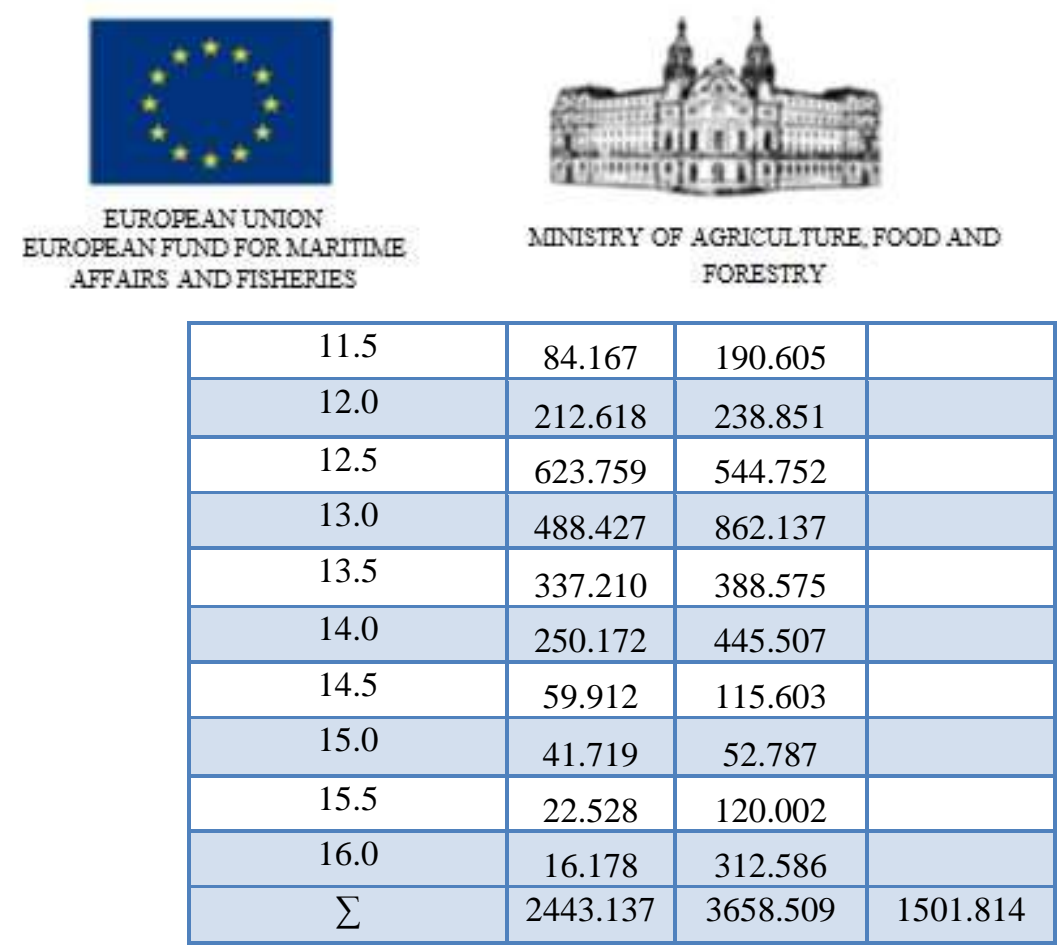

\section{II.3.11.2 Catch numbers and biomass by age and length in 2018}

Table 3.11.2.1 Catch-at-age $\left(10^{-3}\right)$ matrix and biomass $(\mathrm{kg})$ of horse mackerel for selected months

\begin{tabular}{|c|c|c|c|c|c|}
\hline \multicolumn{6}{|c|}{ Catch-at-age $\left(10{ }^{-3}\right)$} \\
\hline Age groups & June & September & October & November & December \\
\hline $\mathbf{0}$ & 0.013492 & & 0.019155 & 0.011757 & \\
\hline $\mathbf{1}$ & 0.01574 & & 0.024628 & 0.133248 & \\
\hline $\mathbf{2}$ & 0.058464 & 0.322836 & 0.197023 & 0.219467 & 0.059789 \\
\hline $\mathbf{3}$ & 0.150656 & 0.440537 & 0.28094 & 0.344876 & 0.472333 \\
\hline $\mathbf{4}$ & 0.266459 & 1.106386 & 0.218002 & 0.254738 & 0.843024 \\
\hline $\mathbf{5}$ & 0.12817 & 0.090798 & 0.130437 & 0.031352 & 0.011958 \\
\hline $\mathbf{6}$ & 0.044972 & 0.077346 & 0.021891 & & \\
\hline & & Biomass $(\mathbf{k g})$ & & \\
\hline Age groups & June & September & October & November & December \\
\hline $\mathbf{0}$ & 70.83093 & & 91.36645 & 107.2288 & \\
\hline $\mathbf{1}$ & 133.2705 & & 254.1462 & 1567.755 & \\
\hline $\mathbf{2}$ & 757.3383 & 4608.551 & 2525.698 & 3416.665 & 636.4962 \\
\hline $\mathbf{3}$ & 2629.095 & 8317.135 & 5617.14 & 6025.603 & 9175.015 \\
\hline $\mathbf{4}$ & 5457.677 & 23826.61 & 5624.544 & 5183.143 & 16740.77 \\
\hline $\mathbf{5}$ & 2966.837 & 3245.761 & 3827.618 & 700.5693 & 361.7232 \\
\hline $\mathbf{6}$ & 1362.451 & 3420.046 & 840.7871 & & \\
\hline $\mathbf{2}$ & 13377.5 & 43418.1 & 18781.3 & 17000.96 & 26914 \\
\hline & & & & \\
\hline & & & & \\
\hline
\end{tabular}

Table 3.11.2 Catch-at-length $\left(10^{-3}\right)$ matrix and biomass $(\mathrm{kg})$ of horse mackerel for selected months

Project proposal № BG14MFOP001-3.003-0001 "Collection, management and use of data for the purposes of scientific analysis and implementation of the Common Fisheries Policy for the period 2017-2019", funded by the Maritime Affairs and Fisheries Program, co-financed by the European Union through the European Maritime and Fisheries Fund 


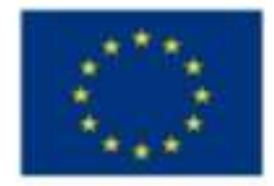

EUROPEAN UNTON EUROPE.AN FUND FOR MLARITIVE AFFAIRS AND FISHERIES

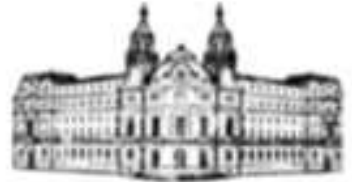

AINISTRY OF AGRICULTURE, FOOD AND FORESTRY
MLARITLIE AFFAIRS AND FISHERIES PROGRAM

\begin{tabular}{|c|c|c|c|c|c|}
\hline \multicolumn{6}{|c|}{ Catch-at-length (millions) } \\
\hline $\begin{array}{l}\text { Length group } \\
\text { (cm) }\end{array}$ & June & September & October & November & December \\
\hline 7.0 & & & 1.183084486 & & \\
\hline 7.5 & & & 2.366168971 & & \\
\hline 8.0 & 1.157564243 & & 9.464675885 & & \\
\hline 8.5 & 4.630256972 & & 7.098506914 & & \\
\hline 9.0 & 8.1029497 & & 3.549253457 & & \\
\hline 9.5 & 1.157564243 & & 3.549253457 & 1.100616166 & \\
\hline 10.0 & 6.945385457 & 0.80488404 & 8.281591399 & 2.201232332 & \\
\hline 10.5 & 11.57564243 & & 18.92935177 & 3.301848498 & 2.050916 \\
\hline 11.0 & 10.41807819 & 4.024420198 & 17.74626728 & 12.10677782 & 6.152749 \\
\hline 11.5 & 16.2058994 & 5.634188277 & 24.8447742 & 14.30801016 & 7.178208 \\
\hline 12.0 & 64.8235976 & 18.51233291 & 67.43581568 & 15.40862632 & 17.43279 \\
\hline 12.5 & 130.8047594 & 74.85421568 & 125.4069555 & 47.32649513 & 19.48371 \\
\hline 13.0 & 147.0106589 & 119.1228379 & 205.8567005 & 45.1252628 & 38.96741 \\
\hline 13.5 & 91.44757519 & 54.73211469 & 146.7024762 & 59.43327296 & 71.78208 \\
\hline 14.0 & 83.34462549 & 50.70769449 & 105.2945192 & 23.11293948 & 53.32383 \\
\hline 14.5 & 50.93282669 & 49.09792642 & 145.5193917 & 28.61602031 & 19.48371 \\
\hline 15.0 & 42.82987699 & 46.6832743 & 147.8855607 & 16.50924249 & 1.025458 \\
\hline 15.5 & 19.67859213 & 20.92698503 & 57.9711398 & 11.00616166 & 1.025458 \\
\hline 16.0 & 6.945385457 & 18.51233291 & 33.1263656 & & \\
\hline 16.5 & & 13.68302867 & 10.64776037 & & \\
\hline 17.0 & & 3.219536158 & 9.464675885 & & \\
\hline 17.5 & & 3.219536158 & 4.732337943 & & \\
\hline 18.0 & & 4.024420198 & & & \\
\hline \multicolumn{6}{|c|}{ Biomass (kg) } \\
\hline $\begin{array}{l}\text { Length group } \\
\text { (cm) }\end{array}$ & June & September & October & November & December \\
\hline 7.0 & & & 0.041408 & & \\
\hline 7.5 & & & 0.189294 & & \\
\hline 8.0 & 0.046303 & & 3.123343 & & \\
\hline 8.5 & 0.219937 & & 2.200537 & & \\
\hline 9.0 & 0.463026 & & 0.638866 & & \\
\hline 9.5 & 0.061351 & & 0.638866 & 0.066037 & \\
\hline 10.0 & 0.574152 & 0.096586 & 1.490686 & 0.176099 & \\
\hline
\end{tabular}

Project proposal № BG14MFOP001-3.003-0001 "Collection, management and use of data for the purposes of scientific analysis and implementation of the Common Fisheries Policy for the period 2017-2019", funded by the Maritime Affairs and Fisheries Program, co-financed by the European Union through the European Maritime and Fisheries Fund 


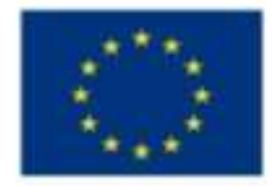

EUROPEAN UNTON EUROPEAN FUND FOR MLARITIIE AFFAIRS AND FISHERIES

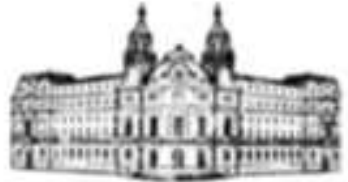

AINISTRY OF AGRICULTURE, FOOD AND FORESTRY
MLARITLIE AFFAIRS AND FISHERIES PROGRAM

\begin{tabular}{|l|c|c|c|c|c|}
\hline $\mathbf{1 0 . 5}$ & 1.052331 & & 28.58332 & 0.308173 & 0.174327902 \\
\hline $\mathbf{1 1 . 0}$ & 1.125152 & 0.321954 & 25.73209 & 1.210678 & 0.662446027 \\
\hline & 2.013004 & 1.054398 & 69.56537 & 2.003121 & 0.892148674 \\
\hline $\mathbf{1 2 . 0}$ & 9.355434 & 2.495141 & 552.9737 & 2.520411 & 2.440590626 \\
\hline $\mathbf{1 2 . 5}$ & 18.87793 & 10.94642 & 2095.55 & 7.741262 & 3.408623211 \\
\hline $\mathbf{1 3 . 0}$ & 27.68199 & 19.89673 & 6964.132 & 7.381204 & 7.219226054 \\
\hline $\mathbf{1 3 . 5}$ & 19.30586 & 10.30252 & 3789.325 & 9.721585 & 14.10005089 \\
\hline $\mathbf{1 4 . 0}$ & 19.79551 & 11.26033 & 2269.097 & 3.780617 & 12.01837065 \\
\hline $\mathbf{1 4 . 5}$ & 13.24138 & 11.87204 & 4628.972 & 4.680763 & 4.624816691 \\
\hline $\mathbf{1 5 . 0}$ & 12.0734 & 11.28817 & 5313.528 & 2.70044 & 0.29225560 \\
\hline $\mathbf{1 5 . 5}$ & 6.137406 & 6.414926 & 877.1033 & 1.800294 & 0.328146639 \\
\hline $\mathbf{1 6 . 0}$ & 2.516545 & 6.406877 & 308.0752 & & \\
\hline $\mathbf{1 6 . 5}$ & & 5.336381 & 36.52182 & & \\
\hline $\mathbf{1 7 . 0}$ & & 1.400498 & 30.66555 & & \\
\hline $\mathbf{1 7 . 5}$ & & 1.577573 & 8.612855 & & \\
\hline $\mathbf{1 8 . 0}$ & & 2.068552 & & & \\
\hline
\end{tabular}

\section{II.3.11.3 Catch numbers and biomass by age and length in 2019}

Table 3.11.1 Catch-at-age $\left(10^{-3}\right)$ matrix and biomass $(\mathrm{kg})$ of horse mackerel for selected months

\begin{tabular}{|c|c|c|c|c|c|c|}
\hline \multicolumn{7}{|c|}{ Catch-at-Age $* 10^{-3}$ (in thousands) } \\
\hline Age groups & July & August & September & October & November & December \\
\hline $\mathbf{0}$ & 0.512690114 & 3.697709 & 12.082121 & 26.5790012 & 18.6999961 & 33.8425495 \\
\hline 1 & 1.512435836 & 10.90824 & 35.642258 & 78.4080536 & 55.1649884 & 99.8355211 \\
\hline 2 & 3.87081036 & 27.9177 & 91.220016 & 200.671459 & 141.18497 & 255.511249 \\
\hline 3 & 6.664971482 & 48.07021 & 157.06758 & 345.527016 & 243.099949 & 439.953144 \\
\hline 4 & 5.690860265 & 41.04456 & 134.11155 & 295.026914 & 207.569956 & 375.6523 \\
\hline 5 & 0.974111217 & 7.025646 & 22.956031 & 50.5001023 & 35.5299925 & 64.3008441 \\
\hline 6 & 0.17944154 & 1.294198 & 4.2287425 & 9.30265043 & 6.54499862 & 11.8448923 \\
\hline$\sum$ & 19.41 & 139.96 & 457.31 & 1006.015 & 707.794851 & 1280.9405 \\
\hline \multicolumn{7}{|c|}{ Biomass (kg) } \\
\hline Age groups & July & August & September & October & November & December \\
\hline $\mathbf{0}$ & 6.658598731 & 48.024 & 156.92 & 345.1966383 & 242.86751 & 439.5325 \\
\hline 1 & 19.22368186 & 138.648 & 453.03 & 996.5986274 & 701.1697 & 1268.951 \\
\hline
\end{tabular}

Project proposal № BG14MFOP001-3.003-0001 "Collection, management and use of data for the purposes of scientific analysis and implementation of the Common Fisheries Policy for the period 2017-2019", funded by the Maritime Affairs and Fisheries Program, co-financed by the European Union through the European Maritime and Fisheries Fund 


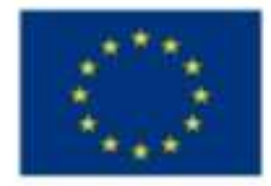

EUROPEAN UNTON EUROPE.AN FUND FOR MLARITME AFFAIRS AND FISHERIES

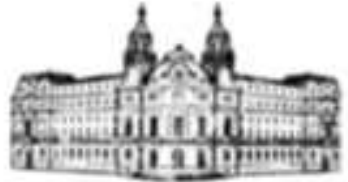

AINISTRY OF AGRICUITURE, FOOD AND FORESTRY
MLARITLIE AFFAIRS ANT FISHERIES PROGRAM

\begin{tabular}{|c|c|c|c|c|c|c|}
\hline $\mathbf{2}$ & 63.5451284 & 458.311 & 1497.51 & 3294.321462 & 2317.762 & 4194.598 \\
\hline $\mathbf{3}$ & 121.3042539 & 874.891 & 2858.67 & 6288.683602 & 4424.4837 & 8007.264 \\
\hline $\mathbf{4}$ & 125.1928225 & 902.936 & 2950.31 & 6490.275688 & 4566.3164 & 8263.948 \\
\hline $\mathbf{5}$ & 30.05749018 & 216.786 & 708.34 & 1558.247461 & 1096.3249 & 1984.088 \\
\hline $\mathbf{6}$ & 6.129684093 & 44.210 & 144.45 & 317.7765216 & 223.57573 & 404.619 \\
\hline$\Sigma$ & 372.11 & 2683.81 & 8769.23 & 19291.1 & 13572.5 & 24563.0 \\
\hline
\end{tabular}

Table 3.11.2 Catch-at-length $\left(10^{-3}\right)$ matrix and biomass $(\mathrm{kg})$ of horse mackerel for selected months

\begin{tabular}{|c|c|c|c|c|c|c|}
\hline \multicolumn{7}{|c|}{ Catch-at-length $* 10^{-3}$ (in thousands) } \\
\hline $\begin{array}{c}\text { Length } \\
\text { groups (cm) }\end{array}$ & July & August & September & October & November & December \\
\hline 9.5 & 0.128173 & 0.924427134 & 3.020530345 & 6.644750308 & 4.674999018 & 8.460637382 \\
\hline 10.0 & 0.28198 & 2.033739695 & 6.645166759 & 14.61845068 & 10.28499784 & 18.61340224 \\
\hline 10.5 & 0.128173 & 0.924427134 & 3.020530345 & 6.644750308 & 4.674999018 & 8.460637382 \\
\hline 11.0 & 0.435787 & 3.143052256 & 10.26980317 & 22.59215105 & 15.89499666 & 28.7661671 \\
\hline 11.5 & 0.615228 & 4.437250244 & 14.49854566 & 31.89480148 & 22.43999528 & 40.61105943 \\
\hline 12.0 & 1.256091 & 9.059385916 & 29.60119738 & 65.11855301 & 45.81499037 & 82.91424635 \\
\hline 12.5 & 3.486293 & 25.14441805 & 82.15842538 & 180.7372084 & 127.1599733 & 230.1293368 \\
\hline 13.0 & 4.588577 & 33.09449141 & 108.1349863 & 237.882061 & 167.3649648 & 302.8908183 \\
\hline 13.5 & 3.229948 & 23.29556378 & 76.11736469 & 167.4477078 & 117.8099752 & 213.208062 \\
\hline 14.0 & 2.230202 & 16.08503214 & 52.557228 & 115.6186554 & 81.34498291 & 147.2150905 \\
\hline 14.5 & 1.204822 & 8.689615062 & 28.39298524 & 62.46065289 & 43.94499077 & 79.52999139 \\
\hline 15.0 & 1.332994 & 9.614042196 & 31.41351559 & 69.1054032 & 48.61998978 & 87.99062878 \\
\hline 15.5 & 0.384518 & 2.773281403 & 9.061591035 & 19.93425092 & 14.02499705 & 25.38191215 \\
\hline 16.0 & 0.102538 & 0.739541707 & 2.416424276 & 5.315800246 & 3.739999214 & 6.768509906 \\
\hline$\sum$ & 19.41 & 139.96 & 457.31 & 1006.015 & 707.794851 & 1280.9405 \\
\hline \multicolumn{7}{|c|}{ Biomass (kg) } \\
\hline $\begin{array}{c}\text { Length } \\
\text { groups (cm) }\end{array}$ & July & August & September & October & November & December \\
\hline & & & & & & \\
\hline 9.5 & 0.852347 & 6.147440443 & 20.08652679 & 44.18758955 & 31.08874347 & 56.3 \\
\hline 10.0 & 2.167483 & 15.63267913 & 51.07918182 & 112.3671575 & 79.05735005 & 143.1 \\
\hline 10.5 & 1.096018 & 7.904879139 & 25.82889059 & 56.81999819 & 39.97643604 & 72.3 \\
\hline 11.0 & 4.457734 & 32.15080537 & 105.0515283 & 231.0988784 & 162.59257 & 294.3 \\
\hline 11.5 & 8.575896 & 61.85249513 & 202.1006648 & 444.5935983 & 312.7995093 & 566.1 \\
\hline
\end{tabular}

Project proposal № BG14MFOP001-3.003-0001 "Collection, management and use of data for the purposes of scientific analysis and implementation of the Common Fisheries Policy for the period 2017-2019", funded by the Maritime Affairs and Fisheries Program, co-financed by the European Union through the European Maritime and Fisheries Fund 


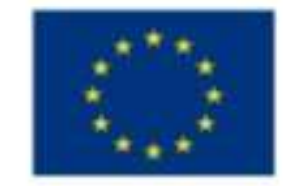

EUROPEAN UNTON EUROPEAN FUND FOR MLARITIIE AFFAIRS AND FISHERIES

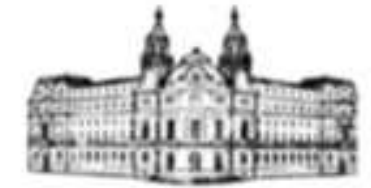

MINTSTRY OF AGRICUITURE, FOOD AND FORESTRY
MLARITLE AFFAIRS AND FISHERIES PROGRAM

\begin{tabular}{|c|c|c|c|c|c|c|}
\hline $\mathbf{1 2 . 0}$ & 19.59325 & 141.3136581 & 461.736979 & 1015.757693 & 714.6493089 & 1293.3 \\
\hline $\mathbf{1 2 . 5}$ & 59.10469 & 426.2846332 & 1392.868753 & 3064.119218 & 2155.800244 & 3901.5 \\
\hline $\mathbf{1 3 . 0}$ & 64.28774 & 463.6666772 & 1515.013154 & 3332.820059 & 2344.848155 & 4243.6 \\
\hline $\mathbf{1 3 . 5}$ & 69.28965 & 499.7423225 & 1632.888947 & 3592.130551 & 2527.289367 & 4573.8 \\
\hline $\mathbf{1 4 . 0}$ & 53.71134 & 387.3858305 & 1265.768402 & 2784.515968 & 1959.081803 & 3545.5 \\
\hline $\mathbf{1 4 . 5}$ & 33.8097 & 243.8479063 & 796.7637178 & 1752.770327 & 1233.183969 & 2231.8 \\
\hline $\mathbf{1 5 . 0}$ & 36.91404 & 266.2375789 & 869.9211177 & 1913.70652 & 1346.412685 & 2436.7 \\
\hline $\mathbf{1 5 . 5}$ & 14.5604 & 105.0149225 & 343.1322472 & 754.8436349 & 531.0798884 & 961.1 \\
\hline $\mathbf{1 6 . 0}$ & 3.691369 & 26.62350147 & 86.99127393 & 191.3688089 & 134.6399717 & 243.7 \\
\hline$\sum$ & 372.11 & 2683.81 & 8769.23 & 19291.1 & 13572.5 & 24563.0 \\
\hline
\end{tabular}

\section{II.3.12 Coefficient of variation of length}

The coefficient of variation (Table 3.12.1) showed a relatively low degree of standard deviation around the average. The variability in the range of 0.07-0.14 could be rated as low. This means that the random sample of horse mackerel in the tested months was conducted according to the variation statistics and correctly reflected the general condition at that time of the year.

Table 3.12.1 Length coefficient of variation in horse mackerel samples

\begin{tabular}{|c|c|c|c|c|c|c|c|}
\hline $\begin{array}{c}\text { coefficient of } \\
\text { variation }(\mathbf{C V})\end{array}$ & June & July & August & September & October & November & December \\
\hline 1 sample & na & na & na & $\mathrm{CV}=0.09$ & $\mathrm{CV}=0.07$ & $\mathrm{CV}=0.13$ & $\mathrm{CV}=0.12$ \\
\hline 2 sample & & & & $\mathrm{CV}=0.07$ & $\mathrm{CV}=0.12$ & $\mathrm{CV}=0.11$ & $\mathrm{CV}=0.14$ \\
\hline
\end{tabular}

\section{III.Conclusions and recommendations}

- The age structure was composed of 7 age groups.

- The linear and weight dimensions reached high values. The values of $\mathrm{K}$ coefficient showed good physiological status during the spring-summer period of 2018-2019. In the autumn months, a similar picture was recorded when comparing the two periods.

- The dynamics of the gomadosomaticic index during propagation and spawning showed a characteristic rapid maturation of the sexual products, and the correlation between weight and fertility of horse mackerel during the spring-summer season showed a relatively strong dependence on the gonadosomatic index and the weight of the gland.

- The main age groups were three and four-year-olds, which were high-number generations.

- During the period 2018-2019, the growth of horse mackerel was allometric.

- In 2018, males prevailed by $64 \%$, followed by female specimens with $36 \%$. In 2019 , females prevailed by $56 \%$, followed by males with $44 \%$.

Project proposal № BG14MFOP001-3.003-0001 "Collection, management and use of data for the purposes of scientific analysis and implementation of the Common Fisheries Policy for the period 2017-2019", funded by the Maritime Affairs and Fisheries Program, co-financed by the European Union through the European Maritime and Fisheries Fund 


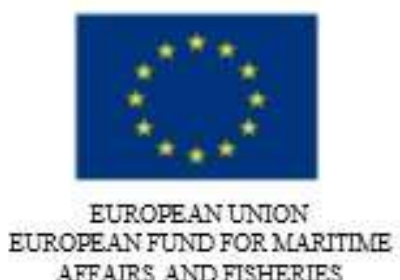

AFFAIRS AND FISHERIES

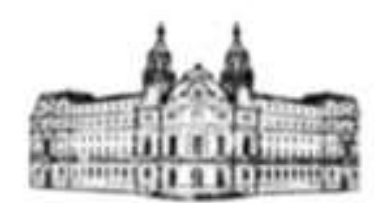

AINISTRY OF AGRICULTURE, FOOD AND FORESTRY

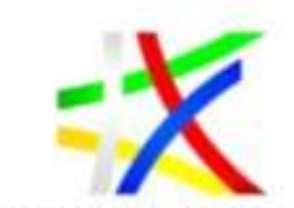

MLARITLE AFFAIRS AND FISHERIES PROGRAM

\section{Biological monitoring of whiting (Merlangius merlangus) landings}

\section{III.1 Objectives}

Several species, which are not targeted by the fishery, are also caught as bycatch. The role that these fish species as prey, competitors, predators, and herbivores make them potential key members of communities and key determinants on how other populations fare. One of the species caught as bycatch during several fisheries operations in the Bulgarian Black Sea waters was whiting. The whiting (Merlangius merlangus euxinus) is bento-pelagic or demersal fish belonging to the Gadidae family. In the Black Sea, whiting is one of the most abundant demersal fish and appears a key species of the ecosystem of the basin (Bradova and Prodanov, 2003; Popescu, 2010). Besides being an important resource to man, whiting is also an important part of the Black Sea ecosystem. As a large predator, whiting influences other fish and shellfish populations, notably the commercially important stocks of sprat, anchovy, horse mackerel and shrimp (Mazlum and Bilgin, 2014). Multiannual biological monitoring on the landings provides the so called "Fishery dependant" information. The aim of this study was to collect and analyze dynamics in length, weight and age distribution as well as to determine the condition of the whiting. Biological information on a given species collected each month, analyzed and compared to previous periods could be used for estimation of growth parameters. Bycatch and discarding are currently one of the most important topics in fisheries management, both from economic and environmental points of view. The omission of discard data from the stock assessment process may result in underestimation of fishing mortality and can lead to biased assessments, hampering achievement of sustainable resource use. Knowledge of the impacts of bycatch and discarding on the community and ecosystem levels becomes increasingly necessary in the context of the multispecies and ecosystem-based approaches to fisheries management. Collecting bycatch data is critical to effective fisheries management. Determination of growth parameters is an important part of studying the biology of fishes. Incorporation of these parameters into analytic models for fish stock assessment gives valuable insight into the levels of exploitation and directions for management. However, information on such species is also essential to assess the ecosystem condition and therefore manage fisheries properly.

\section{2 Sampling}

\section{2.1.1 Geographic area coverage}

Data of the present analysis were collected from the Bulgarian Black Sea waters.

Project proposal № BG14MFOP001-3.003-0001 "Collection, management and use of data for the purposes of scientific analysis and implementation of the Common Fisheries Policy for the period 2017-2019", funded by the Maritime Affairs and Fisheries Program, co-financed by the European Union through the European Maritime and Fisheries Fund 


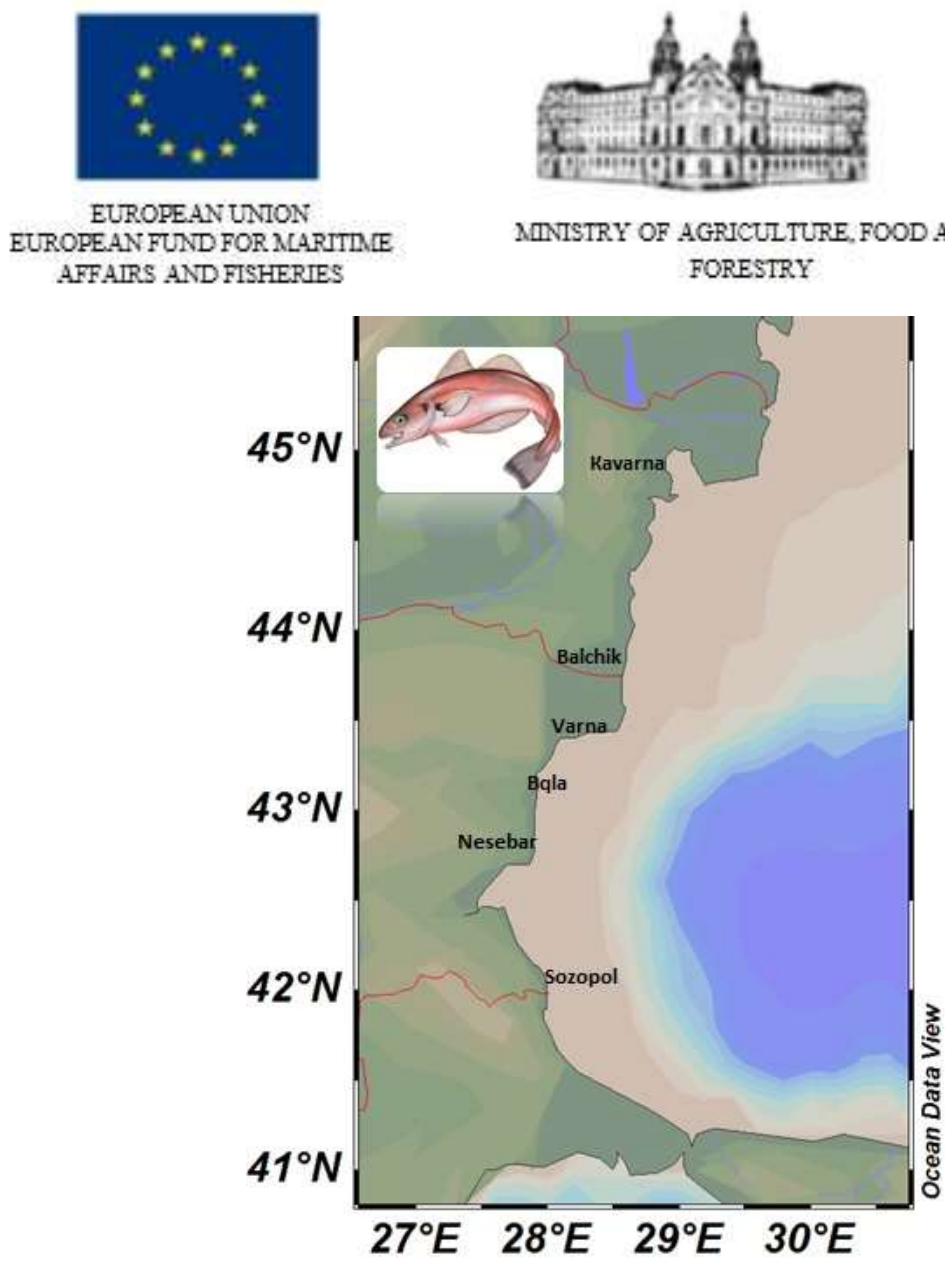

Fig. 2.1.1 Map of the ports for collection of samples of whiting during the period 2017-2019

In 2017, 3 samples were collected, containing 1857 specimens.

In 2018, 4 samples were collected, containing 650 specimens.

In 2019, 8 samples were collected, containing 838 specimens.

\begin{tabular}{|c|c|c|c|c|c|}
\hline \multicolumn{2}{|r|}{2017} & \multicolumn{2}{|c|}{2018} & \multicolumn{2}{|c|}{2019} \\
\hline Date & Vessel & \multicolumn{2}{|r|}{ Vessel } & \multirow{2}{*}{$\begin{array}{c}\text { Date } \\
10.03 .2019\end{array}$} & Vessel \\
\hline & & & & & Burevestnik \\
\hline & & & & 21.06 .2019 & ISHTAR \\
\hline & & 17.07.2018 & Niko & 3.07 .2019 & ISHTAR \\
\hline & & & & 18.08.2019 & Biola \\
\hline & & & & 27.09 .2019 & Ciklama \\
\hline & & 10.10 .2018 & Kaliakra & 14.10. 2019 & Ciklama \\
\hline & & 12.10 .2018 & Irina & & \\
\hline & & 23.10 .2018 & Tesi & & \\
\hline 1.11.2017 & Haithabu & & & 11.11 .2019 & ISHTAR \\
\hline 4.11.2017 & Haithabu & & & & \\
\hline 9.12.2017 & Haithabu & & & 5.12 .2019 & ISHTAR \\
\hline 3 samples & vith 1857 spe & 4 sample & 650 species & 8 samples & 838 species \\
\hline
\end{tabular}

Project proposal № BG14MFOP001-3.003-0001 "Collection, management and use of data for the purposes of scientific analysis and implementation of the Common Fisheries Policy for the period 2017-2019", funded by the Maritime Affairs and Fisheries Program, co-financed by the European Union through the European Maritime and Fisheries Fund 

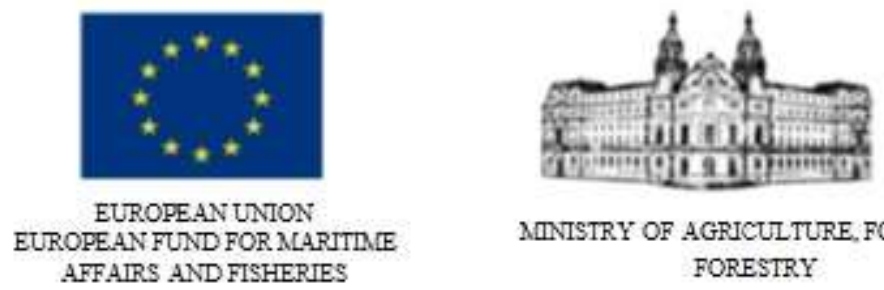

AMNISTRY OF AGRICULTURE, FOOD AND FORESTRY

\section{2.1.3 Statistical analysis of data}

Refer to the methodology used for sprat stock analysis.

\section{III.3 Results}

\section{3.1 Landings statistics in the period 2017-2019}

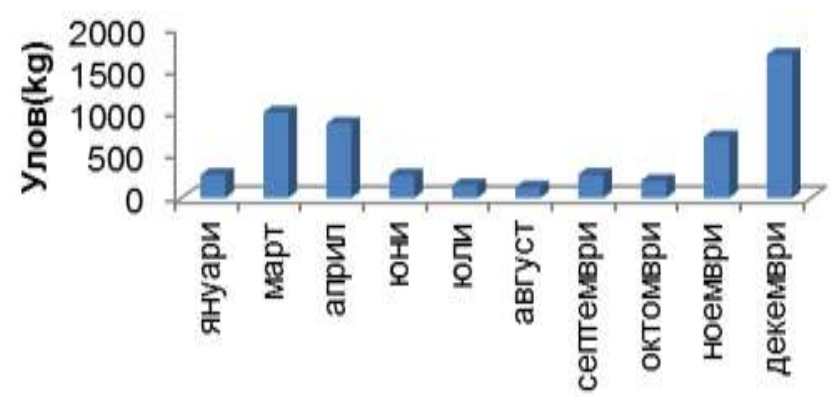

Фиг. 3.1.1 Landings statistics for 2017
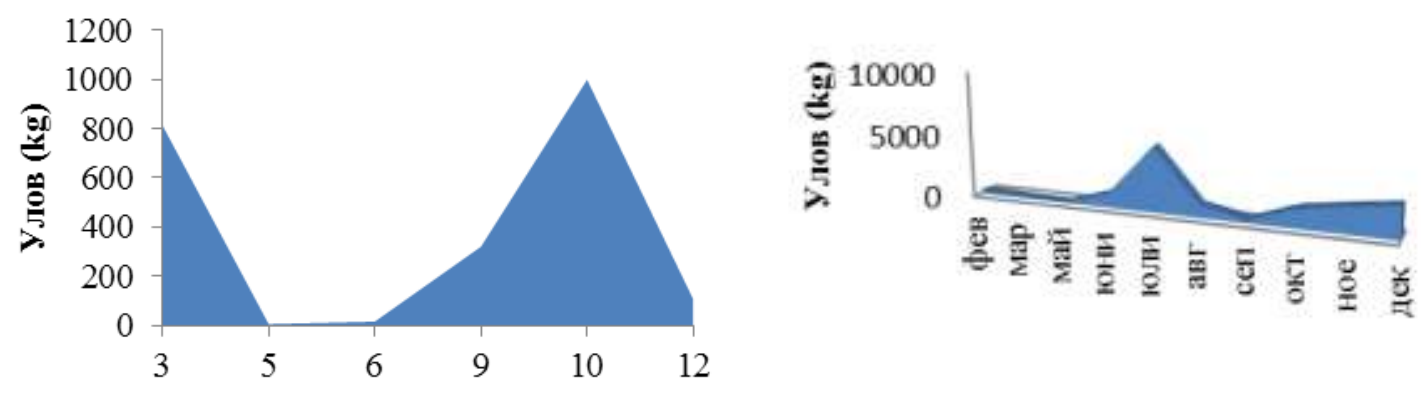

Fig. 3.1.2 Statistics of whiting landings in 2018 (left) and in 2019 (right)

From the collected statistics and graphical interpretations, it is evident that in 2017 the largest quantity and intensity of catches was recorded in December, 2018 - in October and 2019 - in July.

\section{3.2 Size structure in the period 2017-2019}

\section{3.2.1 Analysis of the size structure for 2017}

In the catches from the Bulgarian Black Sea water area in November 2017, the size composition was represented by individuals with a body length from $7.0 \mathrm{~cm}$ to $20.5 \mathrm{~cm}$.

Project proposal № BG14MFOP001-3.003-0001 "Collection, management and use of data for the purposes of scientific analysis and implementation of the Common Fisheries Policy for the period 2017-2019", funded by the Maritime Affairs and Fisheries Program, co-financed by the European Union through the European Maritime and Fisheries Fund 


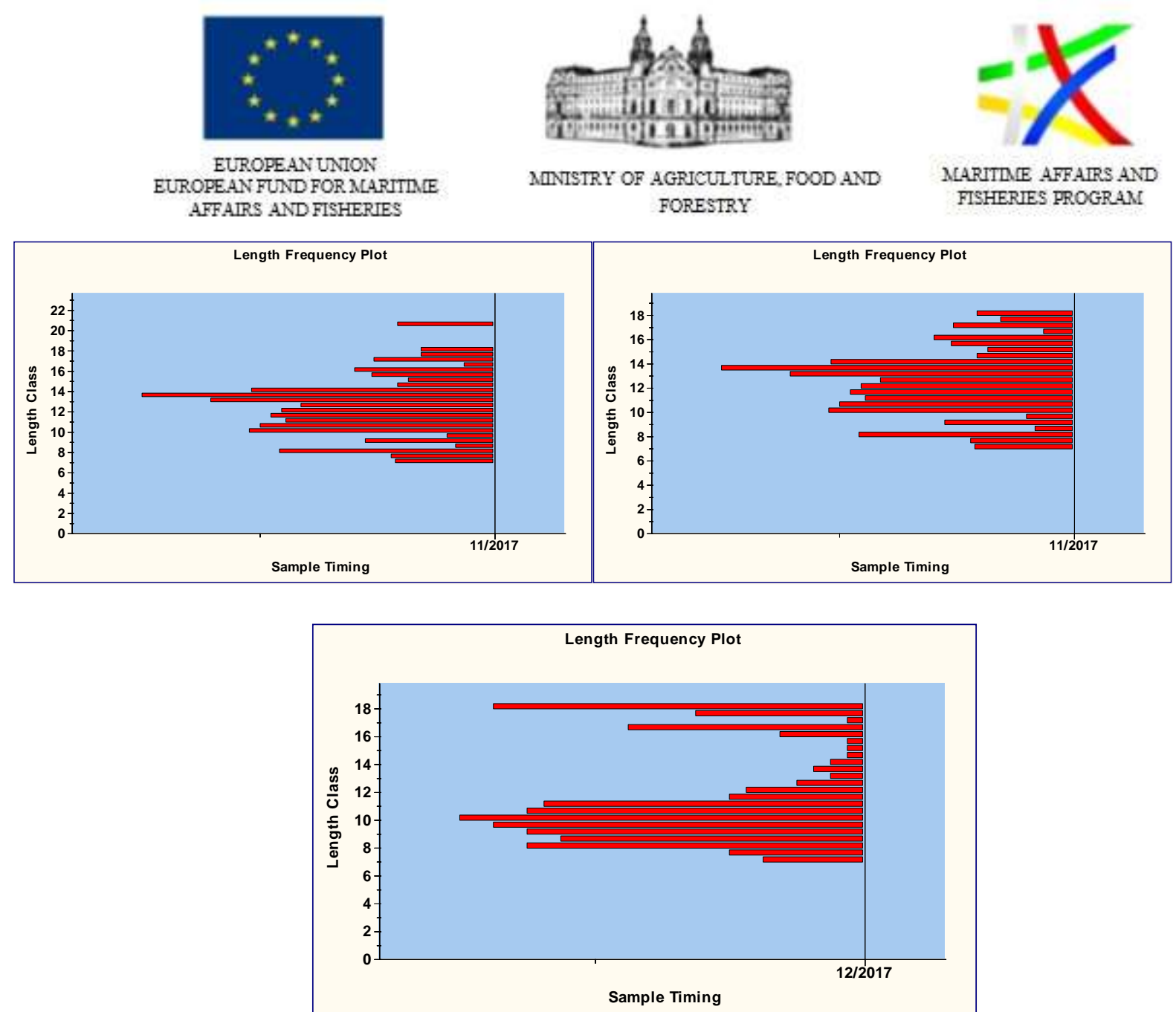

Fig. 3.2.1 Frequency of whiting length from landings in November- December 2017

\section{3.2.2 Analysis of the size structure for 2018}

In the catches from the Bulgarian Black Sea water area in October 2018, the size composition was resented by individuals with a body length from $7.5 \mathrm{~cm}$ to $17.5 \mathrm{~cm}$.
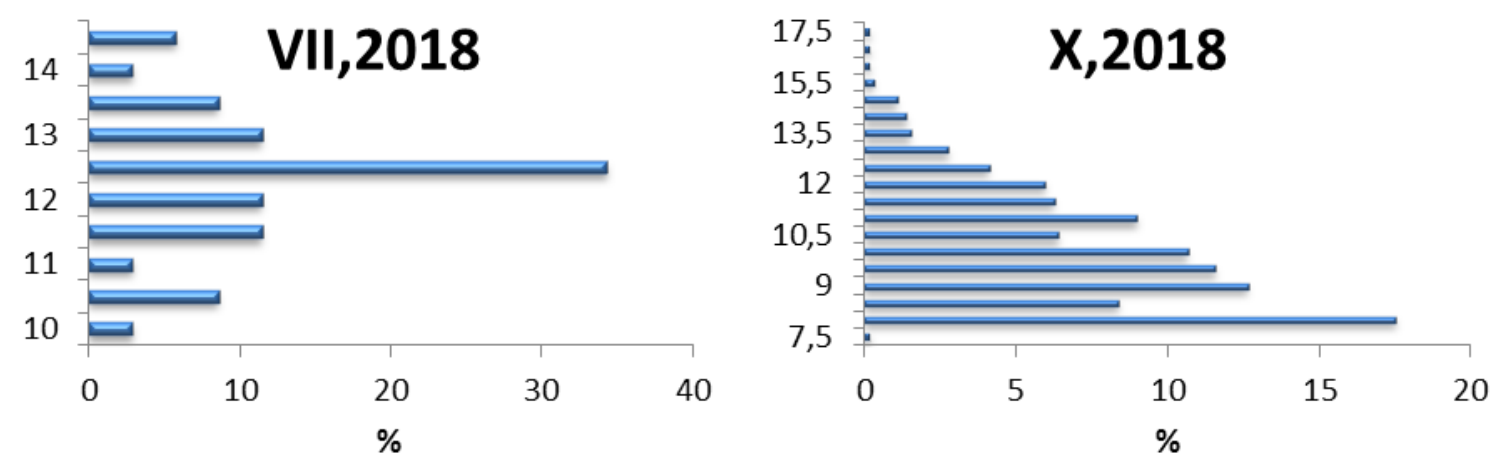

Fig. 3.2.2.1 Frequency of whiting length from landings in 2018

Project proposal № BG14MFOP001-3.003-0001 "Collection, management and use of data for the purposes of scientific analysis and implementation of the Common Fisheries Policy for the period 2017-2019", funded by the Maritime Affairs and Fisheries Program, co-financed by the European Union through the European Maritime and Fisheries Fund 


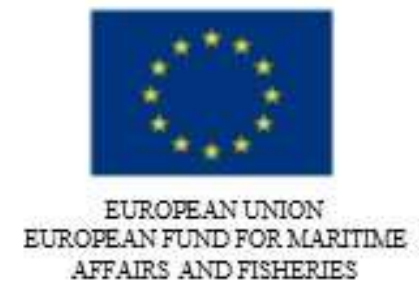

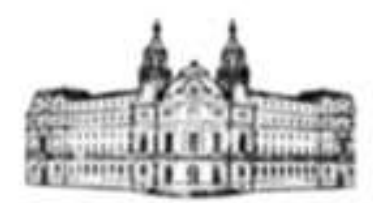

AINTSTRY OF AGRICULTURE, FOOD AND FORESTRY
MLARITLE AFFAIRS ANT FISHERIES PROGRAM

\section{3.2.3 Analysis of the size structure for 2019}

In the catches from the Bulgarian Black Sea water area in 2019 , the size composition was represented by individuals with a body length from $8.0 \mathrm{~cm}$ to $20.0 \mathrm{~cm}$.

\section{III,2019}

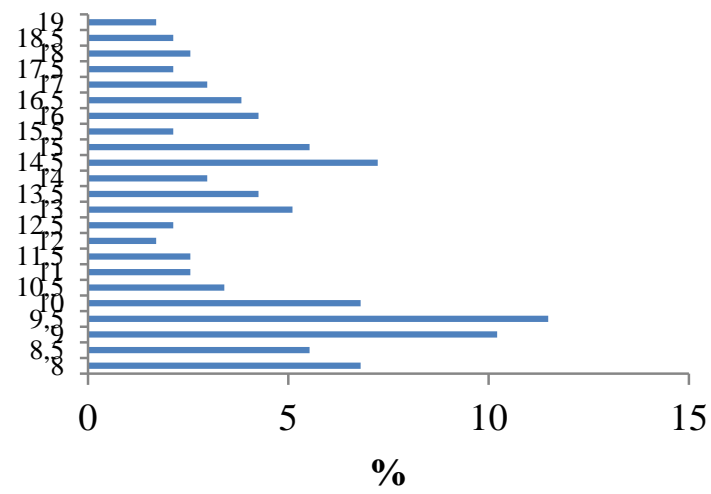

VII,2019

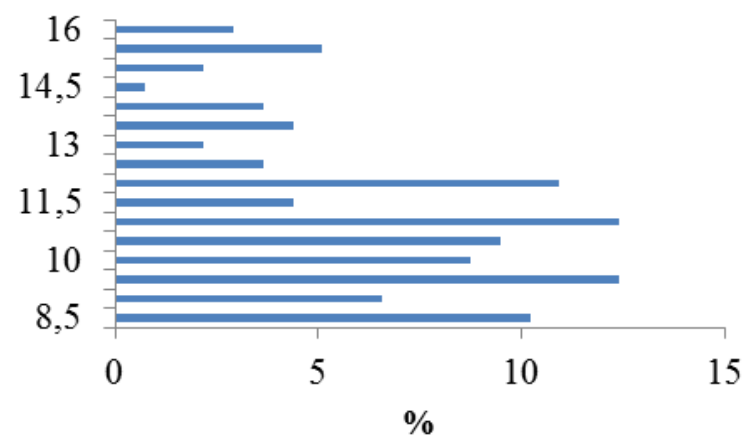

IX,2019

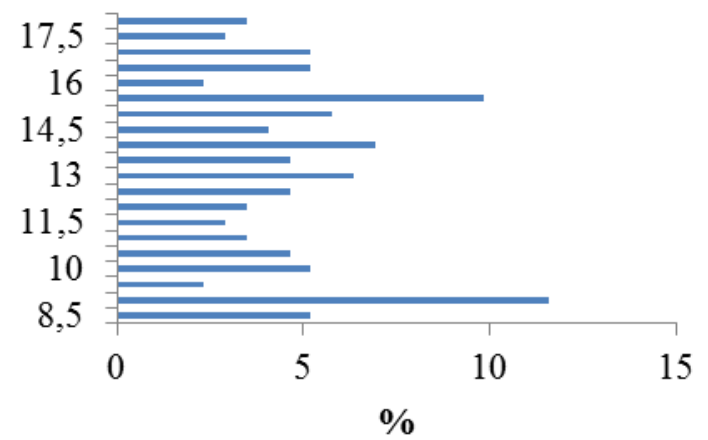

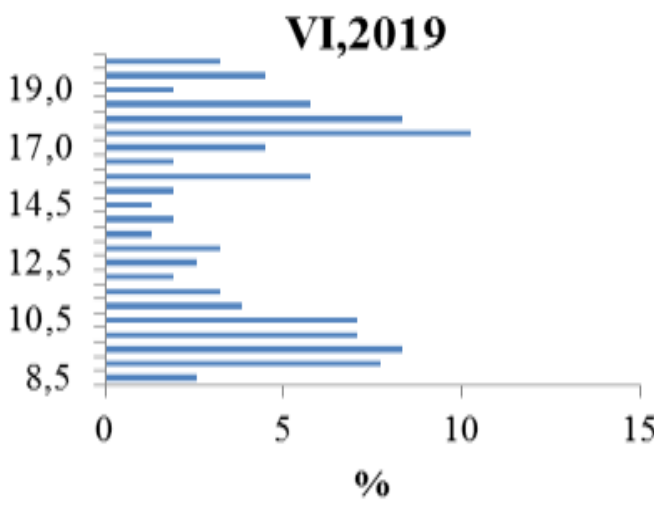

VIII,2019

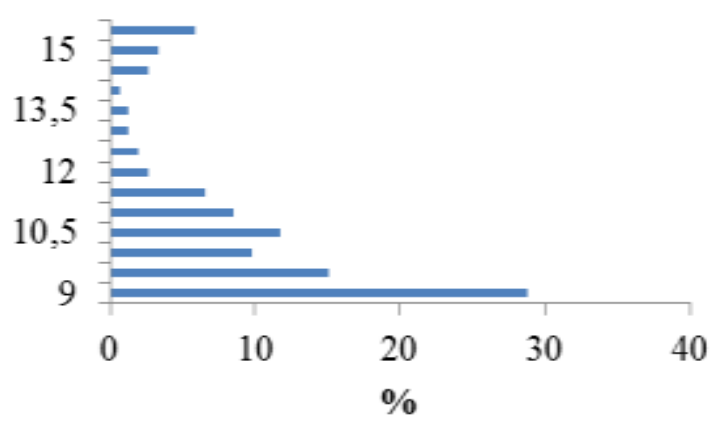

$\mathbf{X , 2 0 1 9}$

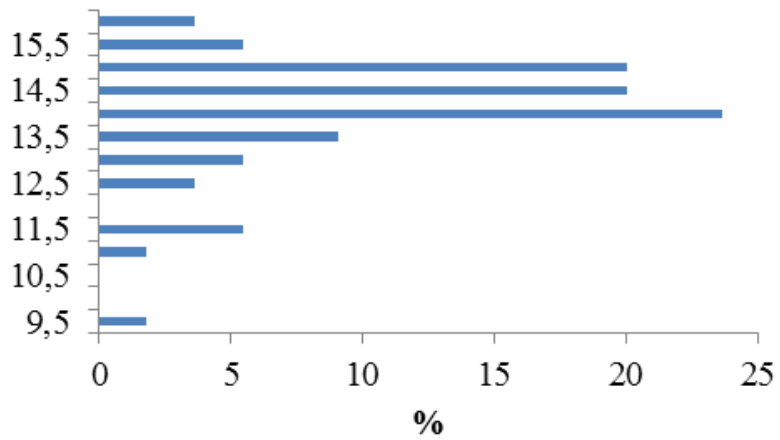

Project proposal № BG14MFOP001-3.003-0001 "Collection, management and use of data for the purposes of scientific analysis and implementation of the Common Fisheries Policy for the period 2017-2019", funded by the Maritime Affairs and Fisheries Program, co-financed by the European Union through the European Maritime 


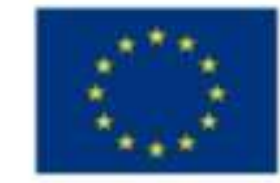

EUROPEAN UNTON EUROPEAN FUND FOR MLARITIIE AFFAIRS AND FISHERIES

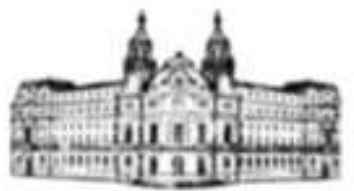

AINTSTRY OF AGRICULTURE, FOOD AND FORESTRY

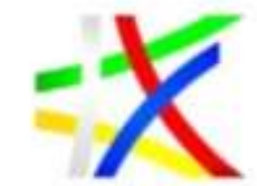

MLARITLE AFFAIRS AND FISHERIES PROGRAM
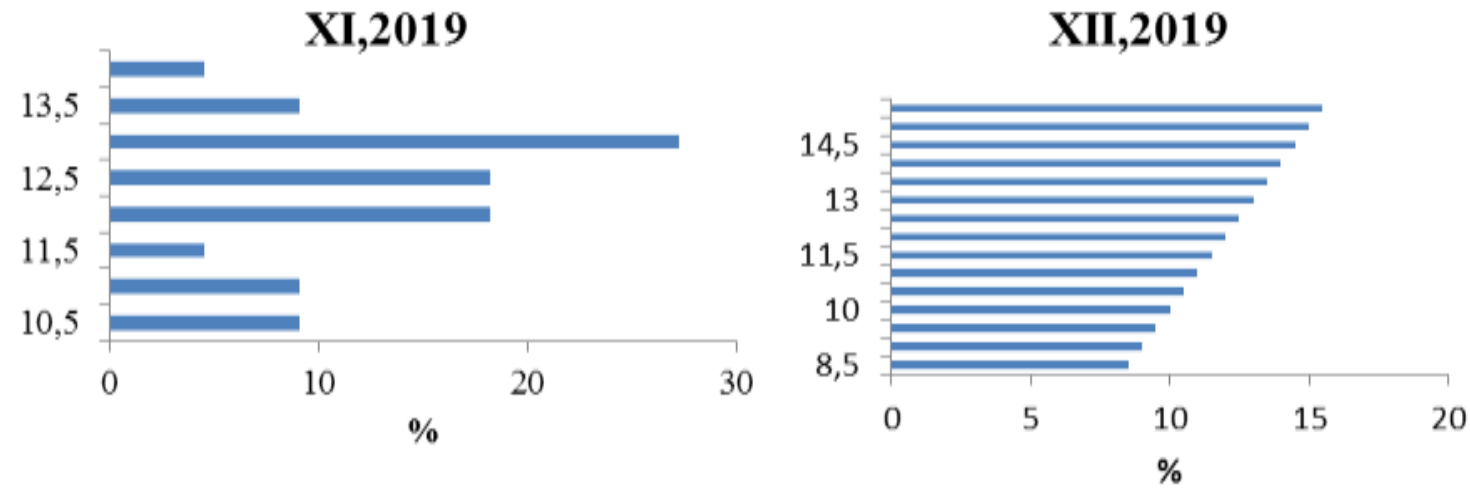

Fig. 3.2.3.1 Frequency of whiting length from landings in 2019

\section{III.3.3 Age structure of whiting}

The age structure of whiting during the period 2017-2019 was characterized by 7 age classes. The one-year-olds had the highest participation rate in July 2019, total of 57.66\%. Three and four-year-old fish had the lowest percentage of participation. With a relatively high participation rate in July 2018 was the three-year-old fish $(34.45 \%)$. The winter months (November-December) of the period 2017-2019 were characterized by the absence in the catches of the most senior age group - six-year olds.

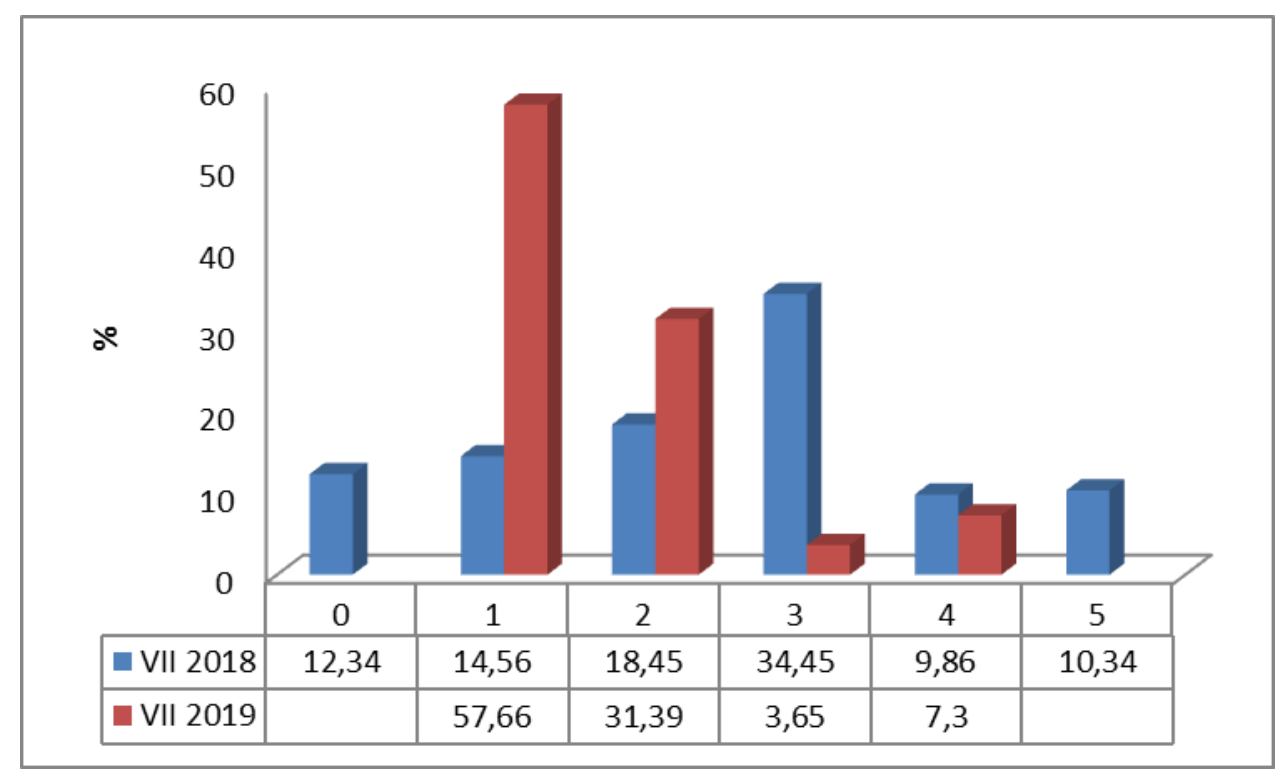

Fig. 3.3.1 Variation of the percentage of whiting per age group in July 2018 and 2019 Note: For July 2017, no comparative analysis data were available.

The age structure of whiting in October 2018 and 2019 was represented by a significant participation of the three-year-old fish. In October $2019-38.19 \%$ and $29-37 \%$ in 2018 . The senior age classes (six years) were present with a small percentage in the catches $-0.46 \%$ in

Project proposal № BG14MFOP001-3.003-0001 "Collection, management and use of data for the purposes of scientific analysis and implementation of the Common Fisheries Policy for the period 2017-2019", funded by the

Maritime Affairs and Fisheries Program, co-financed by the European Union through the European Maritime and Fisheries Fund 


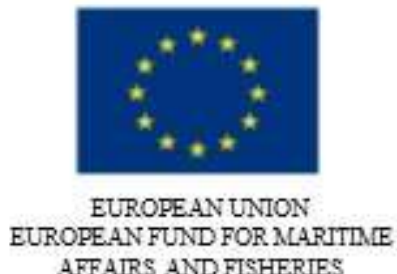

AFFAIRS AND FISHERIES

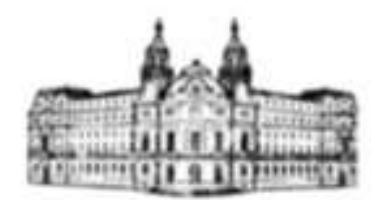

AINISTRY OF AGRICULTURE, FOOD AND FORESTRY

2018 and completely absent in 2019. In November, there was an increased presence of fish aged $2+$, which reached $36.36 \%$ and $41.27 \%$. In October and November, the new generation of zero-year fish was presented in the catches in the range of $8.31 \%-9.09 \%-12.63 \%$. In December of the research period, the filling $(0+)$ was well represented in the catches.

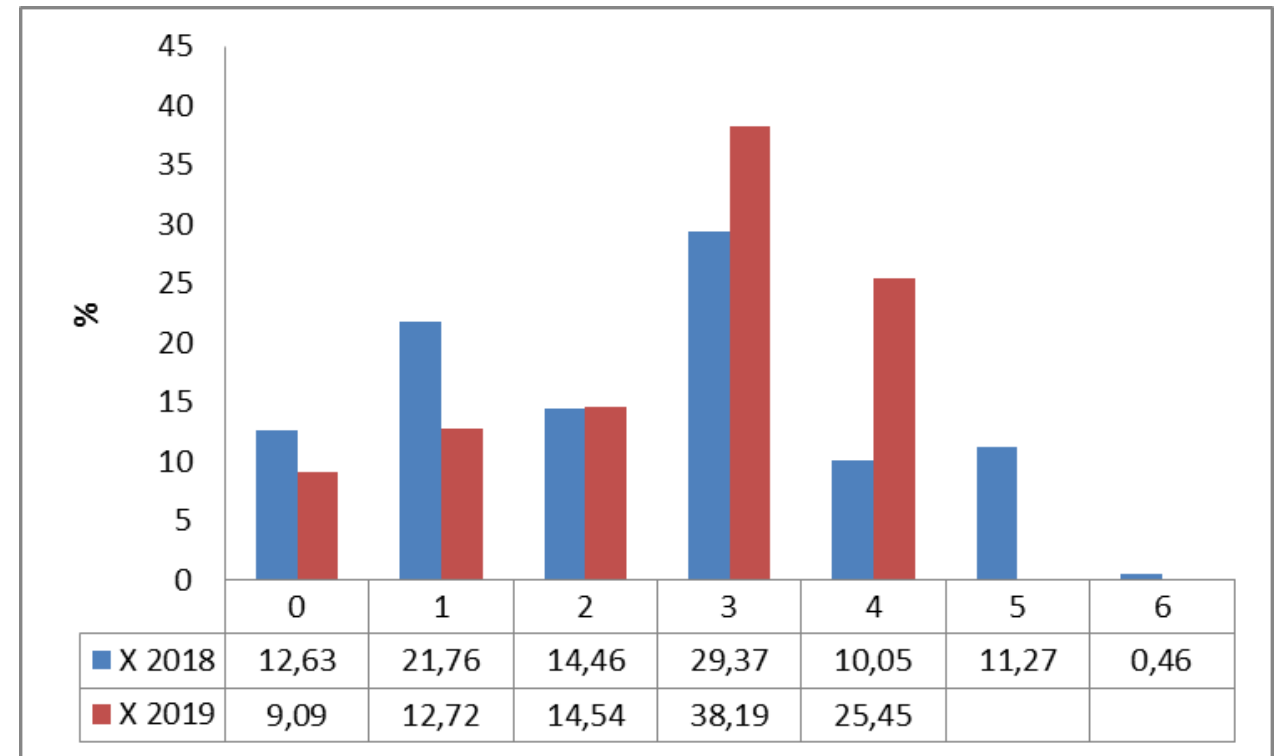

Fig. 3.3.2 Variation of the percentage of whiting per age group in October 2018 and 2019 Note: For October 2017, no comparative analysis data were available.

One and two-year-old fish participated with a high percentage in the catches from November and December of the period 2017-2019.

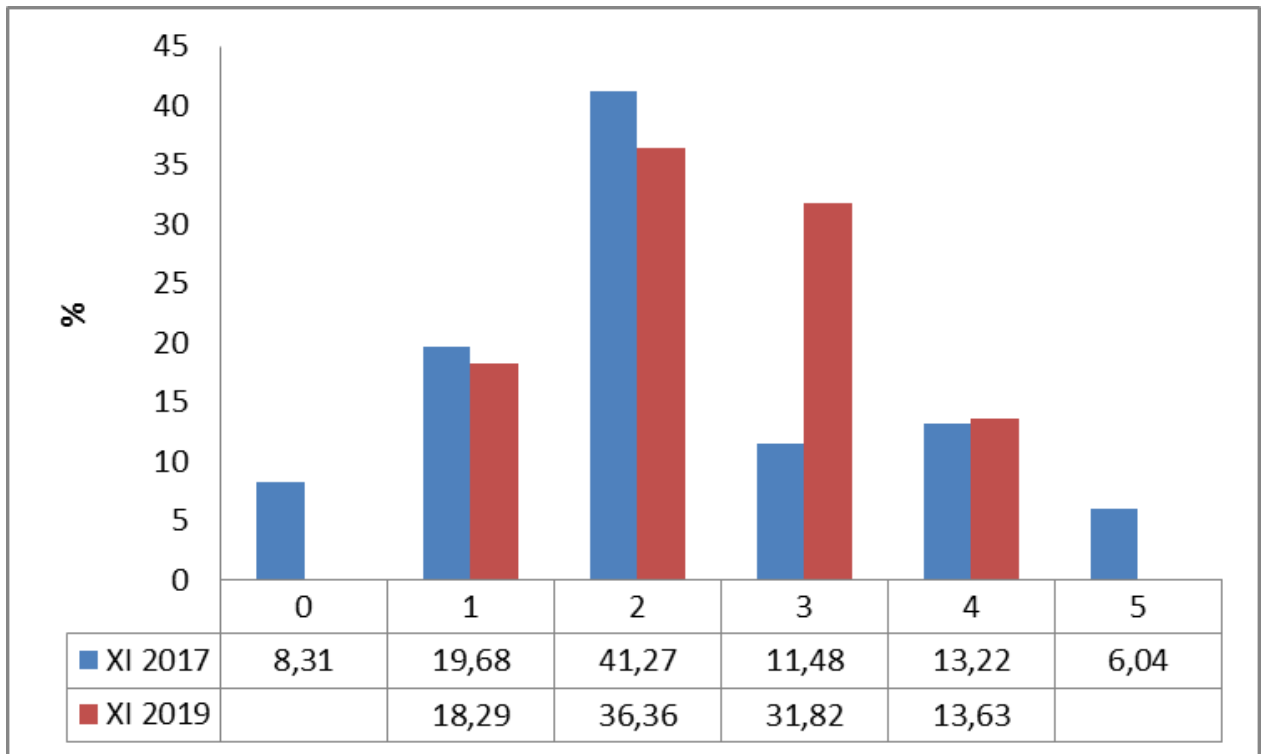

Fig. 3.3.3. Variation of the percentage of whiting per age groups in November 2017and 2019 Note: For November, 2018 no comparative analysis data were available.

Project proposal № BG14MFOP001-3.003-0001 "Collection, management and use of data for the purposes of scientific analysis and implementation of the Common Fisheries Policy for the period 2017-2019", funded by the Maritime Affairs and Fisheries Program, co-financed by the European Union through the European Maritime and Fisheries Fund 

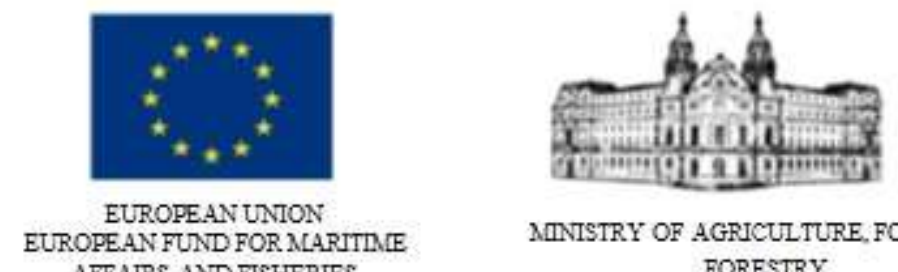

EUROPEAN FUND FOR MLARITIIE

MINISTRY OF AGRICUITURE, FOOD AND FORESTRY

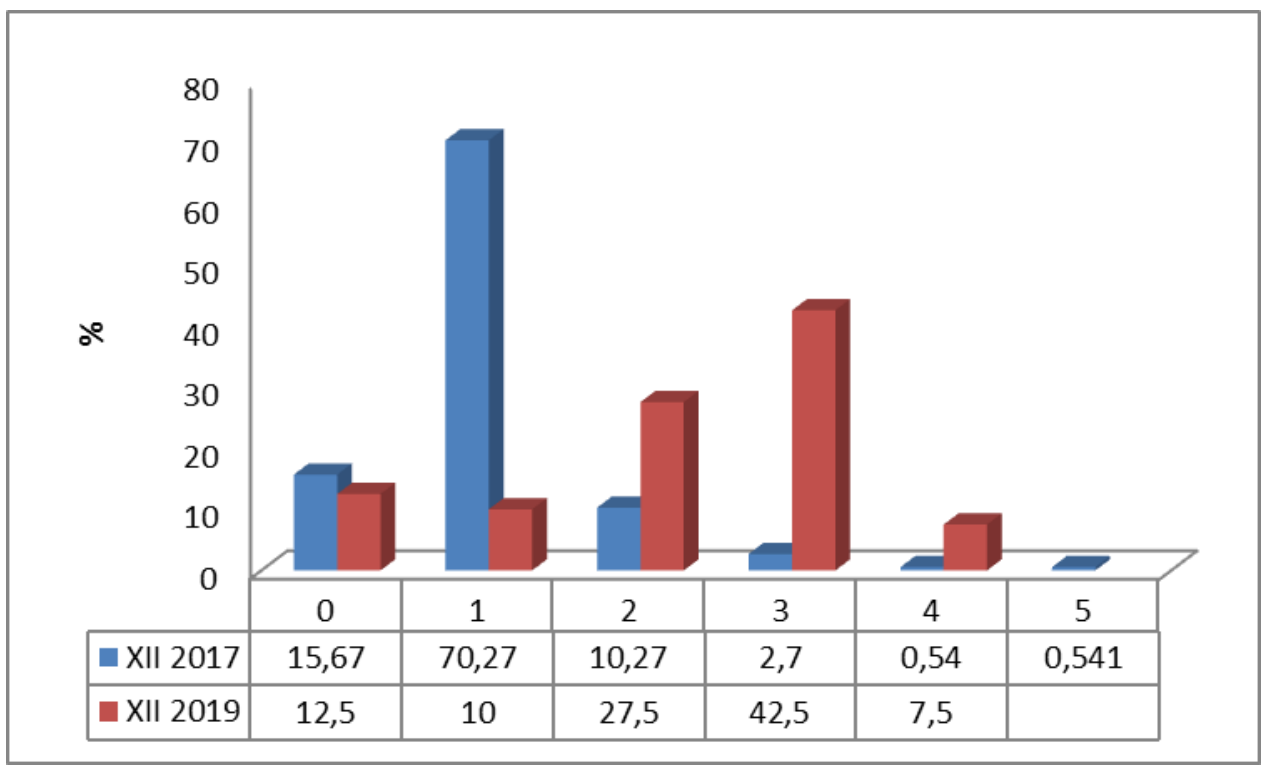

Fig. 3.3.4 Variation of the percentage of whiting by age groups in December 2017 and 2019 Note: For December 2018, no comparative analysis data were available.

\section{III.3.4 Condition factor}

The average values of the Fulton's condition factor of whiting during the research period ranged widely. The highest averages of $\mathrm{K}$ in July belong to $1+$ and $2+$ age fish. The values of the Fulton's condition facor were the highest in November 2017 and 2019. The lowest Fulton's condition factor was registered for individuals of age 1+ (1.08) in November 2019.

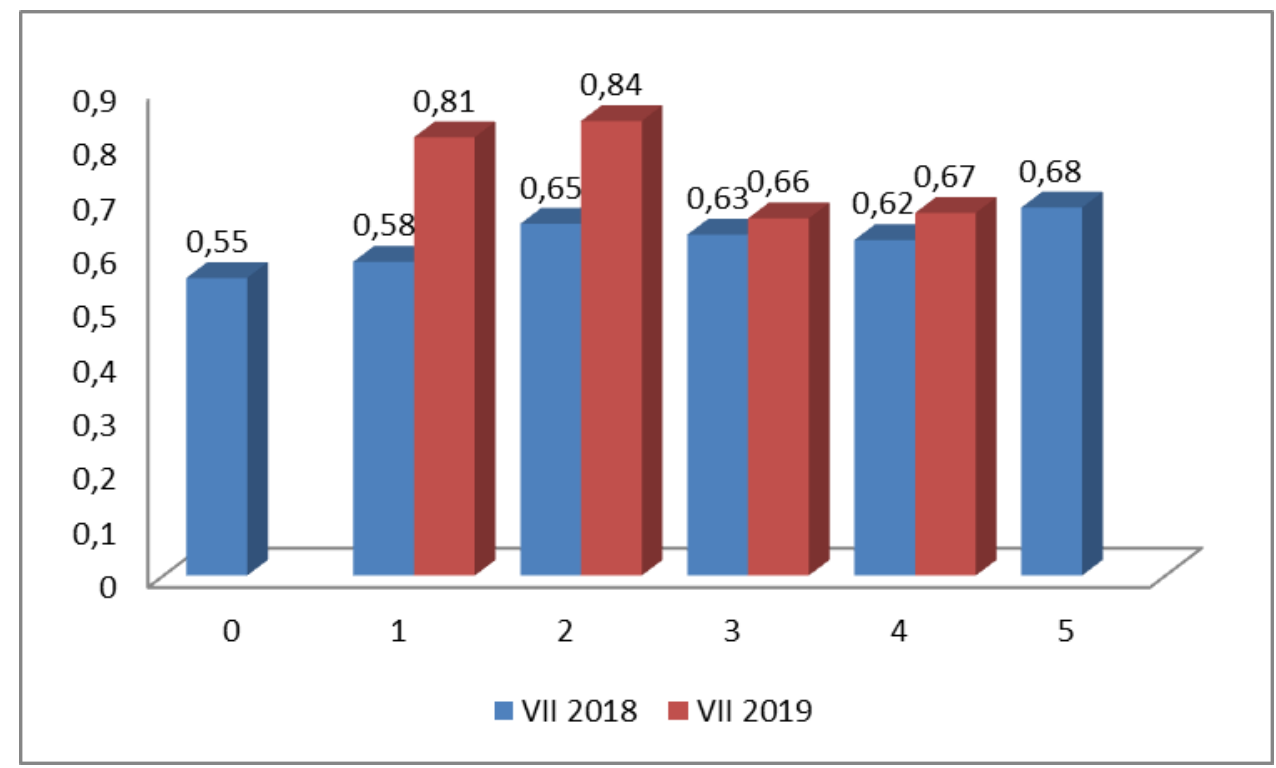

Fig. 3.4.1 Condition factor by age groups in July 2018 and 2019

Note: For July, 2017 there was no comparative analysis data available.

Project proposal № BG14MFOP001-3.003-0001 "Collection, management and use of data for the purposes of scientific analysis and implementation of the Common Fisheries Policy for the period 2017-2019", funded by the Maritime Affairs and Fisheries Program, co-financed by the European Union through the European Maritime and Fisheries Fund 


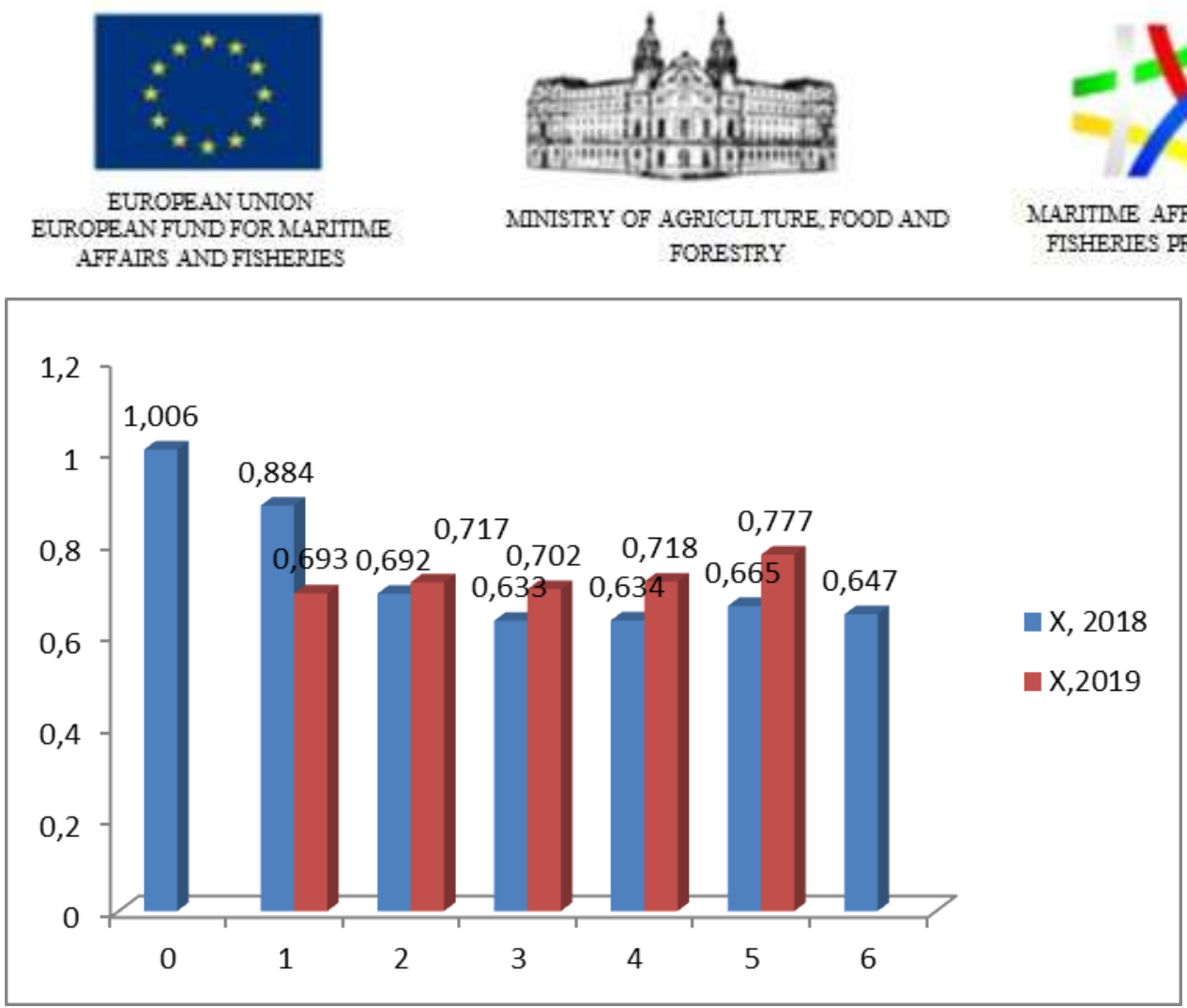

Fig. 3.4.2 Condition factor by age groups in October 2018 and 2019

Note: For October, 2017 no comparative analysis data were available.

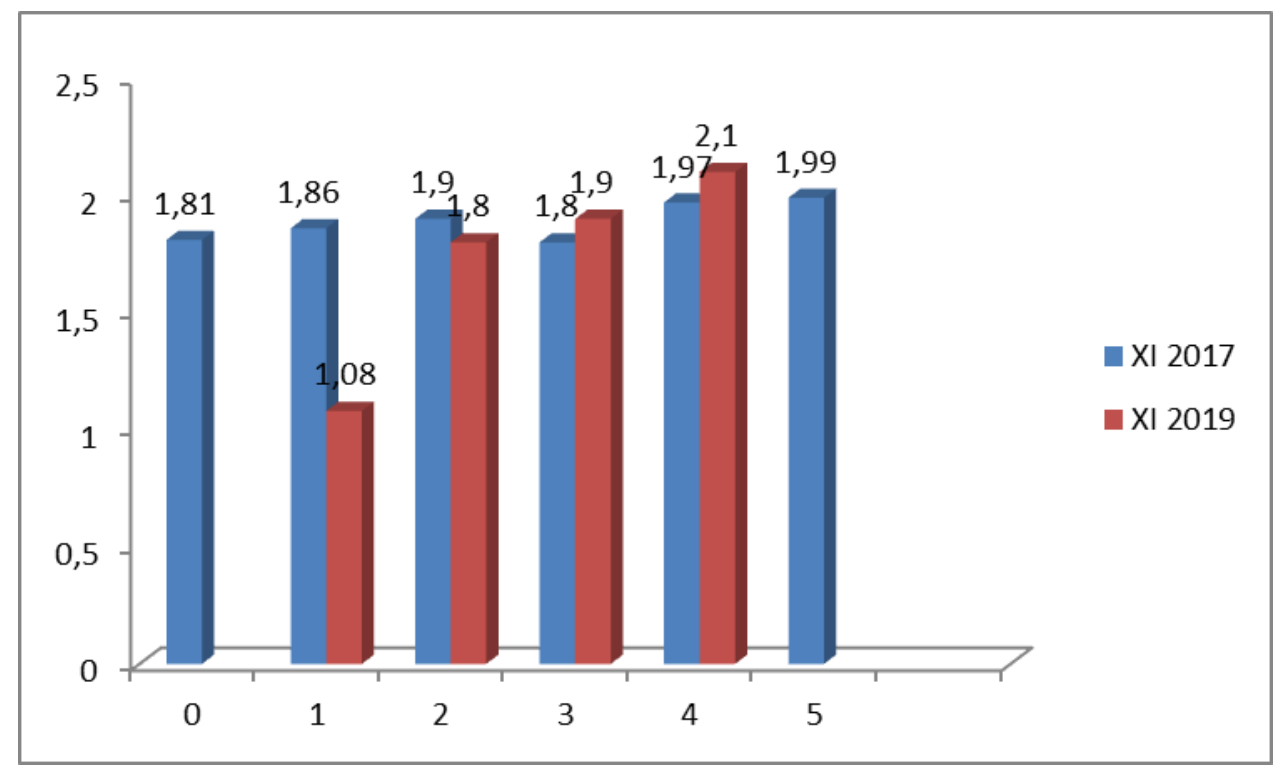

Fig. 3.4.3 Condition factor by age groups in November 2017 and 2019 Note: For November, 2018 no comparative analysis data were available.

\section{III.3.5 Weight structure of whiting}

In July, the weight increase relative to the average annual data showed varying values.

Project proposal № BG14MFOP001-3.003-0001 "Collection, management and use of data for the purposes of scientific analysis and implementation of the Common Fisheries Policy for the period 2017-2019", funded by the Maritime Affairs and Fisheries Program, co-financed by the European Union through the European Maritime and Fisheries Fund 


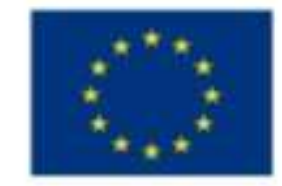

EUROPEAN UNTON EUROPEAN FUND FOR MLARITIIE AFFAIRS AND FISHERIES

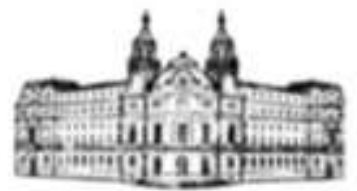

MINISTRY OF AGRICULTURE, FOOD AND FORESTRY
MLARITLE AFFAIRS AND FISHERIES PROGRAM

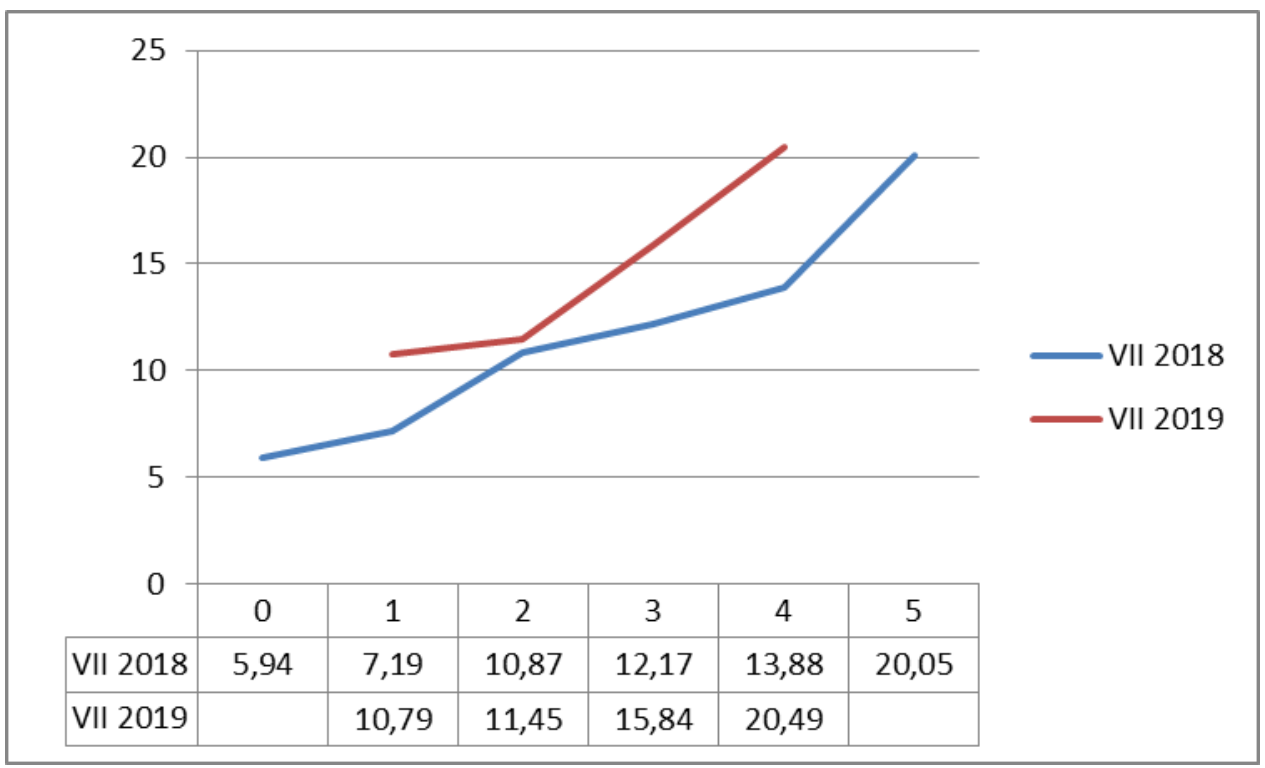

Fig. 3.5.1 Variation of the average weights by age groups in July 2018 and 2019

In October, 2018 at age $1+$ the weight increase was below the norm with $2.65 \mathrm{~g}$, at $2+-$ with $8.58 \mathrm{~g}$, and for age classes $3+, 4+$ and $5+-$ with 10-12.0 g.

During that period, despite the active nurture of the species, the weight increase was not restored in its previous traditional values.

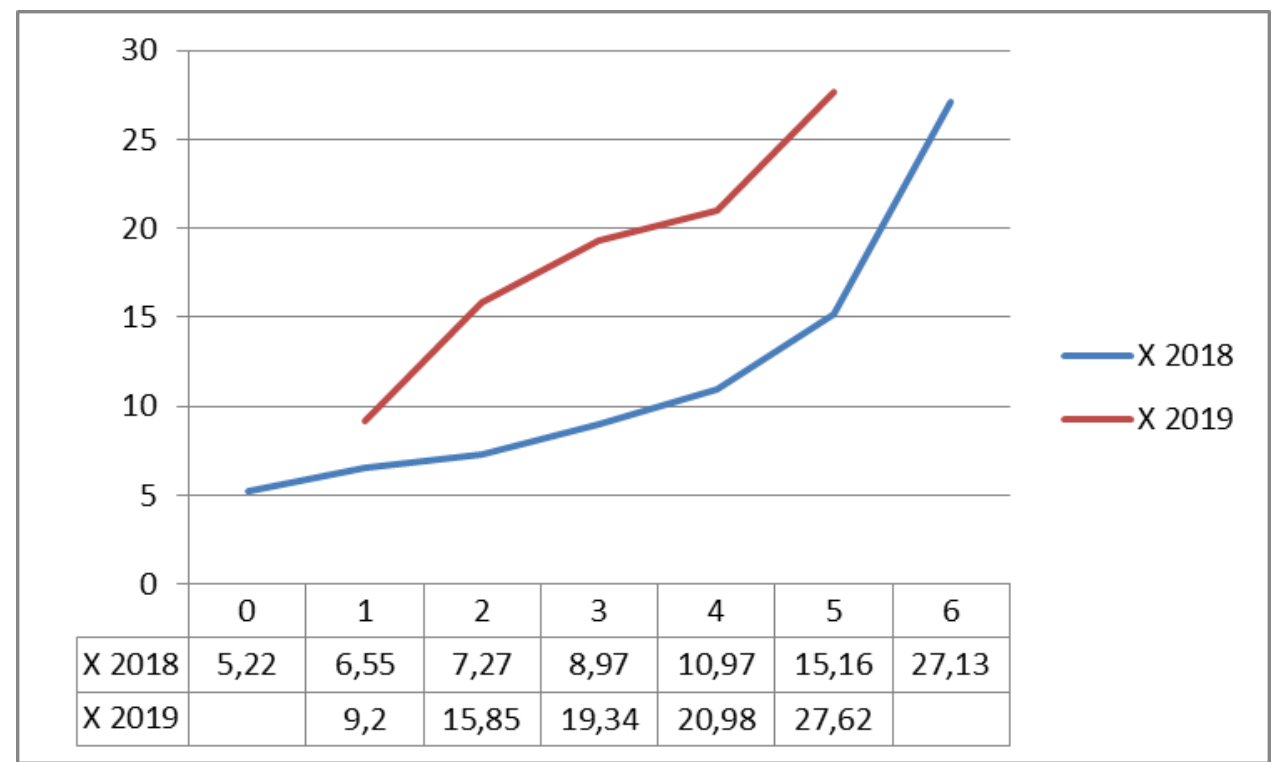

Fig. 3.5.2 Variation of the average weights by age groups in October 2018 and 2019

\section{3.6 Size structure}

In July of the reporting period, the average linear dimensions of age $3+$ and 4+ showed values within the average multiannual data of $10.4-11.0 \mathrm{~cm}$.

Project proposal № BG14MFOP001-3.003-0001 "Collection, management and use of data for the purposes of scientific analysis and implementation of the Common Fisheries Policy for the period 2017-2019", funded by the Maritime Affairs and Fisheries Program, co-financed by the European Union through the European Maritime 


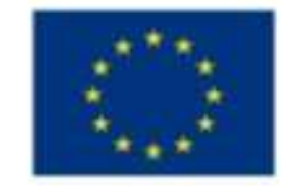

EUROPEAN UNTON EUROPEAN FUND FOR MLARITIIE AFFAIRS AND FISHERIES

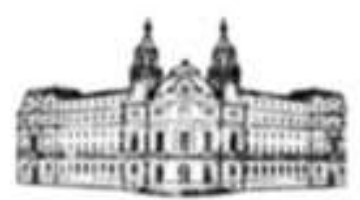

MINISTRY OF AGRICULTURE, FOOD AND FORESTRY
MLARITLIE AFFAIRS AND FISHERIES PROGRAM

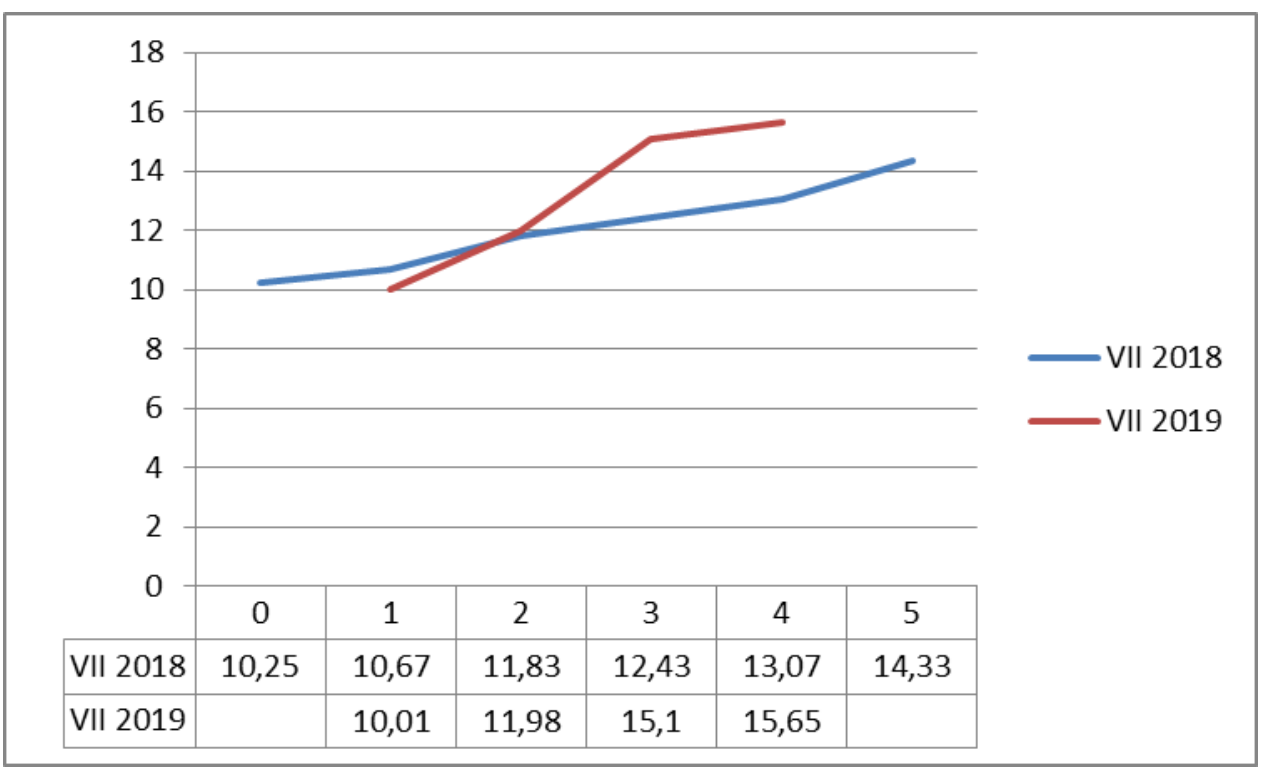

Fig. 3.6.1 Variation of the average lengths by age groups in 2018 and 2019

The rate of linear increase in October 2018 accounted for a reduction in values. In October 2018, the average weights were 2.0-2.5 g lower at ages 1+, 3+; for 4 and 2 year old, the annual lags were $3.7 \mathrm{~g}$.

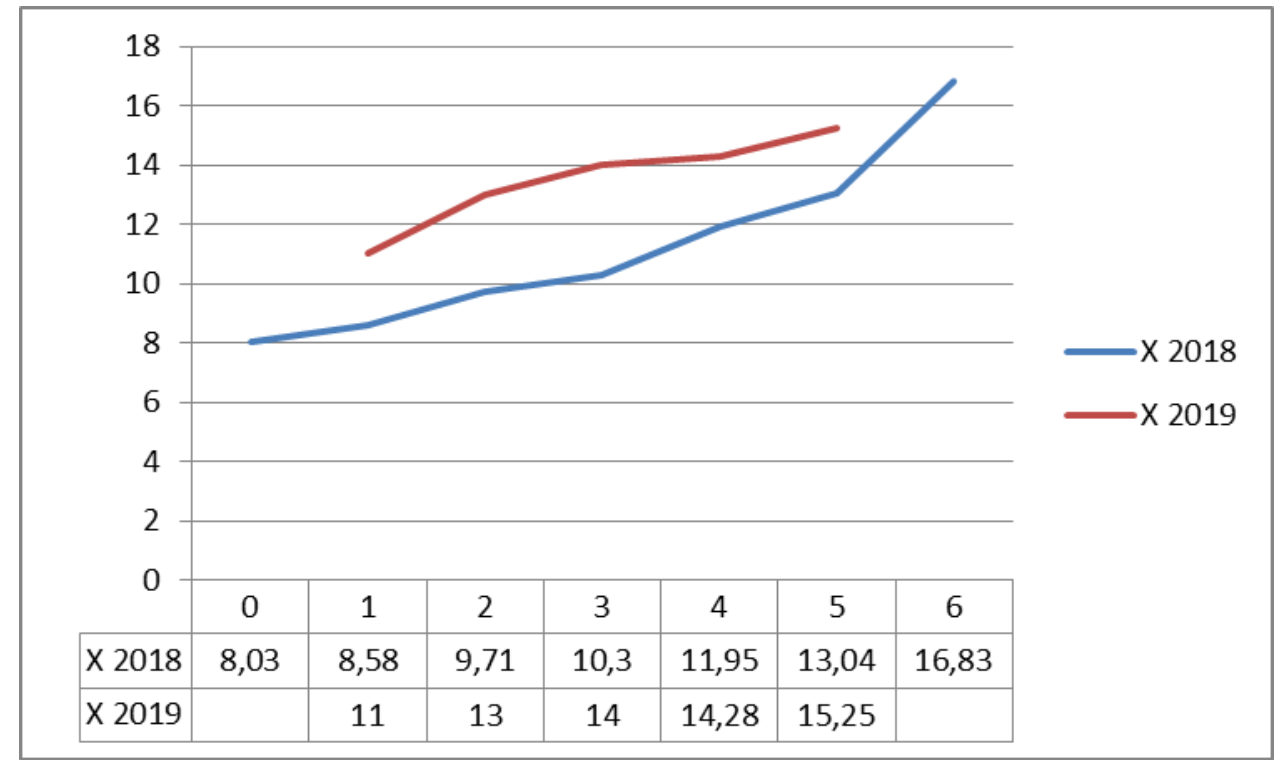

Fig. 3.6.2 Variation of the average lengths by age groups in October 2018 and 2019

Project proposal № BG14MFOP001-3.003-0001 "Collection, management and use of data for the purposes of scientific analysis and implementation of the Common Fisheries Policy for the period 2017-2019", funded by the Maritime Affairs and Fisheries Program, co-financed by the European Union through the European Maritime and Fisheries Fund 


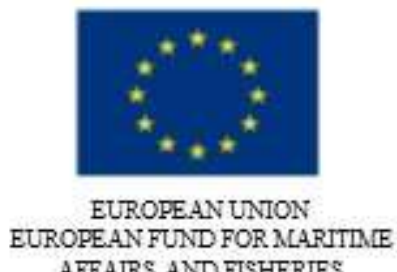

AFFAIRS AND FISHERIES

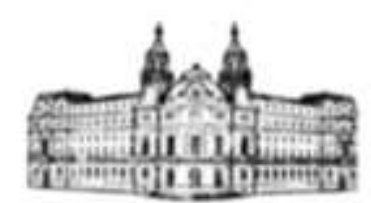

AINISTRY OF AGRICULTURE, FOOD AND FORESTRY

\section{III.3.7 Length- weight relationship}

It follows from the analysis made that the increase of the whiting was allometric in the period 2017-2019. The interrelation between the size (L) and the weight (W) of the specimens sampled is described by the equation:

$$
\begin{aligned}
& \mathrm{W}=0.0562 * \mathrm{~L}^{2.1704}-2018 \\
& \mathrm{~W}=0.0452 * \mathrm{~L}^{2.371}-2019
\end{aligned}
$$

\section{III.3.8 Sex ratio}

In 2017-2019, male (ð) fish showed greater participation in the catches than female (†) specimens.

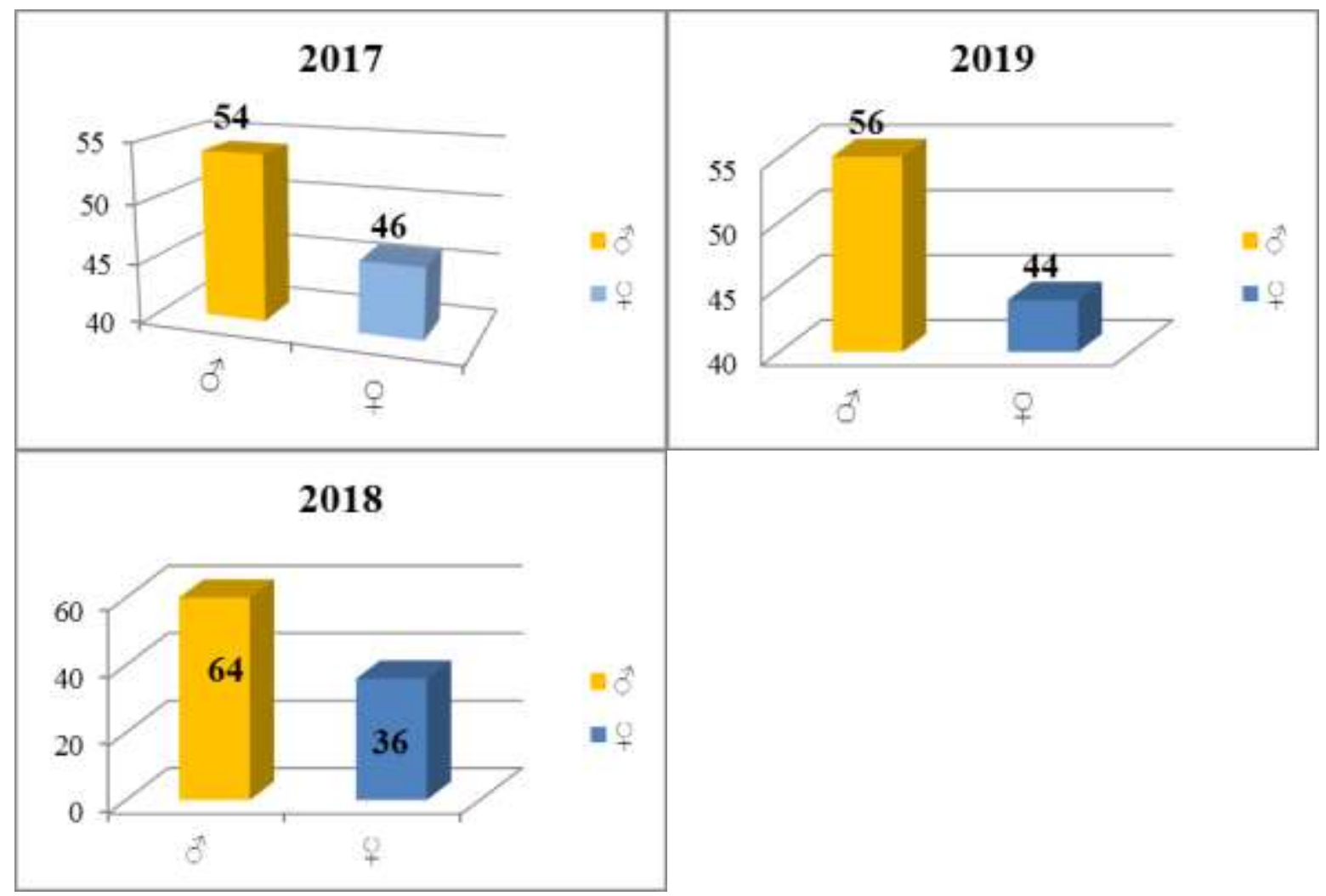

Fig. 3.8.1 Gender ratio of whiting in the period 2017-2019

\section{III.3.9 Fertility}

During the period considered, the whiting showed that the GSI was heavily dependent on the weight of the gonads, which was associated with the high percentage of maturation of females in late spring and summer and the breeding process of the whiting. In total, the dynamics of the GSI was extremely high, which testified to a very rapid process of maturation of the

Project proposal № BG14MFOP001-3.003-0001 "Collection, management and use of data for the purposes of scientific analysis and implementation of the Common Fisheries Policy for the period 2017-2019", funded by the Maritime Affairs and Fisheries Program, co-financed by the European Union through the European Maritime and Fisheries Fund 


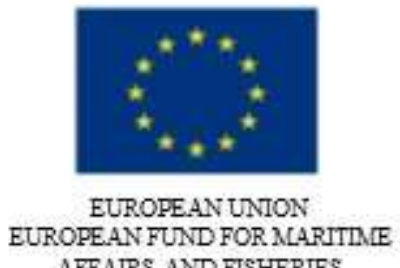

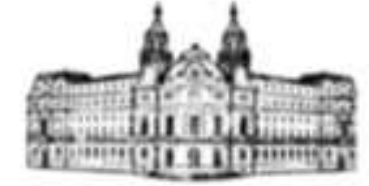

MINISTRY OF AGRICUITURE, FOOD AND FORESTRY
MLARITLE AFFAIRS AND FISHERIES PROGRAM

gonads, simultaneously with the active nurture, before the inclusion of the species in the breeding process.

\section{III.3.10 Sexual maturity}

In 2019, an active ripening of the sex products was observed and in excess of $80 \%$ as the degree of maturity was IV-VI.

\section{III.3.11 Catch numbers and biomass by age and length}

\section{III.3.11.1 Catch numbers and biomass by age and length for 2017}

Monthly catches (in tons) together with mean weights of the whiting were used to derive the monthly catch numbers. The shares $(\%)$ by age groups and catch numbers were used to create catch-at-age matrix for selected months by age groups.

Table 3.11.1 Catch-at-age $\left(10^{-3}\right)$ matrix and biomass $(\mathrm{kg})$ of whiting for selected months

\begin{tabular}{|c|c|c|}
\hline \multicolumn{3}{|c|}{ Catch-at-age(10-3) } \\
\hline Age groups & November & December \\
\hline 0 & 4.157 & 38.862 \\
\hline 1 & 9.839 & 174.210 \\
\hline 2 & 20.634 & 25.462 \\
\hline 3 & 5.742 & 6.700 \\
\hline 4 & 6.609 & 1.340 \\
\hline 5 & 3.020 & 1.340 \\
\hline$\sum$ & 50.000 & 247.915 \\
\hline & Biomass (kg) & December \\
\hline Age groups & November & 103755.666 \\
\hline 0 & 12557.496 & 1011659.621 \\
\hline 1 & 66811.330 & 306007.185 \\
\hline 2 & 228653.478 & 142182.450 \\
\hline 3 & 137388.927 & 52129.098 \\
\hline 4 & 176977.857 & 66065.926 \\
\hline 5 & 96419.511 & 1681799.946 \\
\hline$\sum$ & 718808.599 & \\
\hline & & \\
\hline & &
\end{tabular}

Project proposal № BG14MFOP001-3.003-0001 "Collection, management and use of data for the purposes of scientific analysis and implementation of the Common Fisheries Policy for the period 2017-2019", funded by the Maritime Affairs and Fisheries Program, co-financed by the European Union through the European Maritime and Fisheries Fund 


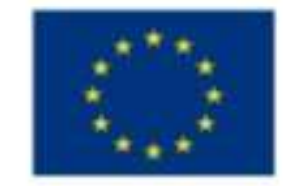

EUROPEAN UNTON EUROPEAN FUND FOR MLARITIE AFFAIRS AND FISHERIES

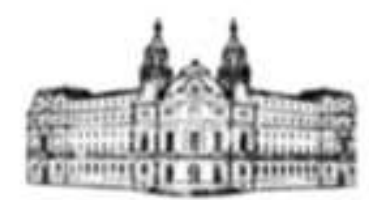

AINTSTRY OF AGRICUITURE, FOOD AND FORESTRY
MLARITLE AFFAIRS AND FISHERIES PROGRAM

Table 3.11.2 Catch-at-length $\left(10^{-3}\right)$ matrix and biomass $(\mathrm{kg})$ of whiting for selected months

\begin{tabular}{|c|c|c|}
\hline \multicolumn{3}{|c|}{ Catch-at-length (millions) } \\
\hline TL,cm & November & December \\
\hline 7 & 1.890 & 3.090 \\
\hline 7.5 & 1.972 & 4.120 \\
\hline 8 & 4.109 & 10.300 \\
\hline 8.5 & 0.740 & 9.270 \\
\hline 9 & 2.465 & 10.300 \\
\hline 9.5 & 0.904 & 11.330 \\
\hline 10 & 4.684 & 12.360 \\
\hline 10.5 & 4.479 & 10.300 \\
\hline 11 & 3.985 & 9.785 \\
\hline 11.5 & 4.273 & 4.120 \\
\hline 12 & 4.068 & 3.605 \\
\hline 12.5 & 3.698 & 2.060 \\
\hline 13 & 5.424 & 1.030 \\
\hline 13.5 & 6.738 & \\
\hline 14 & 4.643 & 1.545 \\
\hline 14.5 & 1.849 & 1.030 \\
\hline 15 & 1.643 & \\
\hline 15.5 & 2.342 & \\
\hline 16 & 2.671 & \\
\hline 16.5 & 0.575 & \\
\hline 17 & 2.301 & 0.515 \\
\hline 18 & 1.397 & 0.515 \\
\hline 20.5 & 1.849 & \\
\hline$\sum$ & 68.698 & 95.274 \\
\hline \multicolumn{3}{|c|}{ Biomass (kg) } \\
\hline TL,cm & November & December \\
\hline 7 & 0.0463 & 0.061 \\
\hline 7.5 & 0.0588 & 0.102 \\
\hline 8 & 0.0290 & 0.315 \\
\hline 8.5 & 0.0323 & 0.320 \\
\hline 9 & 0.1270 & 0.417 \\
\hline 9.5 & 0.0543 & 0.619 \\
\hline 10 & 0.3356 & 0.818 \\
\hline 10.5 & 0.3746 & 0.652 \\
\hline 11 & 0.3658 & 0.878 \\
\hline
\end{tabular}

Project proposal № BG14MFOP001-3.003-0001 "Collection, management and use of data for the purposes of scientific analysis and implementation of the Common Fisheries Policy for the period 2017-2019", funded by the Maritime Affairs and Fisheries Program, co-financed by the European Union through the European Maritime and Fisheries Fund 


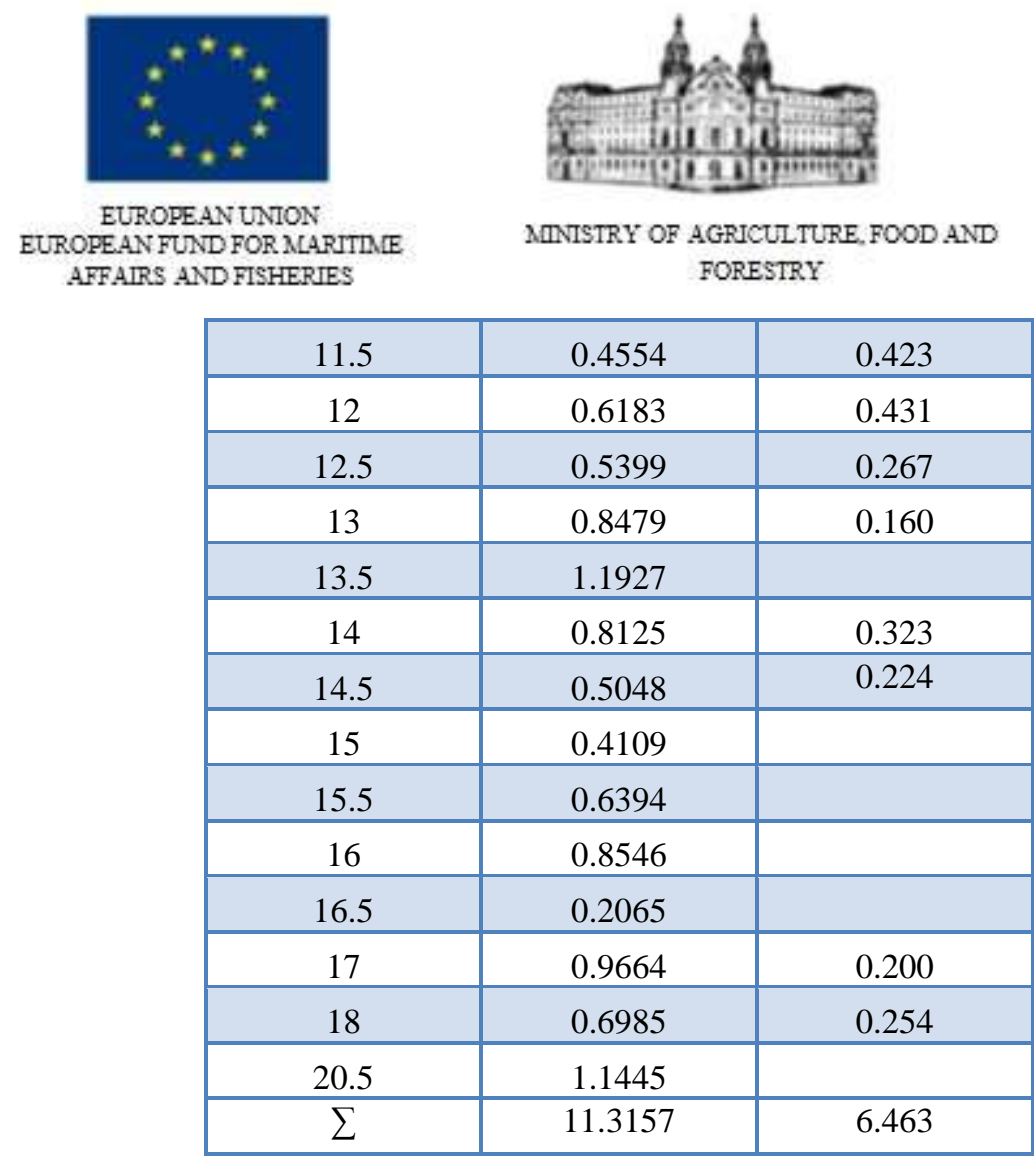

\section{III.3.11.2 Catch numbers and biomass by age and length in 2018}

Table 3.11.2.1 Catch-at-age $\left(10^{-3}\right)$ matrix and biomass $(\mathrm{kg})$ of whiting for selected months

\begin{tabular}{|c|c|}
\hline \multicolumn{2}{|c|}{ Catch-at-age $\left(10^{-3}\right)$} \\
\hline Age groups & October \\
\hline $\mathbf{0}$ & 0.014521 \\
\hline $\mathbf{1}$ & 0.025018 \\
\hline $\mathbf{3}$ & 0.01662 \\
\hline $\mathbf{4}$ & 0.033765 \\
\hline $\mathbf{5}$ & 0.011547 \\
\hline $\mathbf{6}$ & 0.012946 \\
\hline \multicolumn{2}{|c|}{ Biomass (kg) } \\
\hline Age groups & 0.000525 \\
\hline $\mathbf{0}$ & $\mathbf{O c t o b e r}$ \\
\hline $\mathbf{1}$ & 75.77106 \\
\hline $\mathbf{2}$ & 163.7887 \\
\hline $\mathbf{3}$ & 120.8688 \\
\hline $\mathbf{4}$ & 302.8879 \\
\hline $\mathbf{5}$ & 126.6477 \\
\hline $\mathbf{6}$ & 196.2847 \\
\hline$\sum$ & 14.24098 \\
\hline
\end{tabular}

Project proposal № BG14MFOP001-3.003-0001 "Collection, management and use of data for the purposes of scientific analysis and implementation of the Common Fisheries Policy for the period 2017-2019", funded by the Maritime Affairs and Fisheries Program, co-financed by the European Union through the European Maritime and Fisheries Fund 


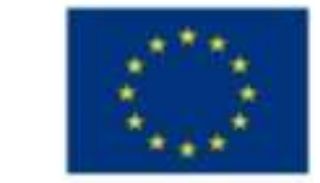

EUROPEAN UNTON EUROPEAN FUND FOR MLARITIIE AFFAIRS AND FISHERIES

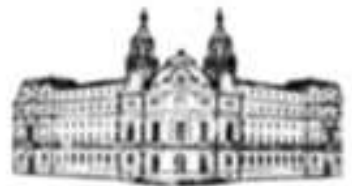

AINISTRY OF AGRICULTURE, FOOD AND FORESTRY
MLARITLE AFFAIRS AND FISHERIES PROGRAM

Table 3.11.2.2 Catch-at-length $\left(10^{-3}\right)$ matrix and biomass $(\mathrm{kg})$ of whiting for selected months

\begin{tabular}{|c|c|c|}
\hline \multicolumn{3}{|c|}{ Catch-at-length (millions) } \\
\hline Length group (cm) & July & October \\
\hline 7.5 & & 0.452106 \\
\hline 8 & & 51.99218 \\
\hline 8.5 & & 24.86583 \\
\hline 9 & & 37.52479 \\
\hline 9.5 & & 34.36005 \\
\hline 10 & 0.995016 & 31.64741 \\
\hline 10.5 & 2.985049 & 18.98845 \\
\hline 11 & 0.995016 & 26.67425 \\
\hline 11.5 & 3.980065 & 18.53634 \\
\hline 12 & 3.980065 & 17.63213 \\
\hline 12.5 & 11.94019 & 12.20686 \\
\hline 13 & 3.980065 & 8.137907 \\
\hline 13.5 & 2.985049 & 4.521059 \\
\hline 14 & 0.995016 & 4.068953 \\
\hline 14.5 & 1.990032 & \\
\hline 15 & & 3.164741 \\
\hline 15.5 & & 0.904212 \\
\hline 16 & & 0.452106 \\
\hline 17 & & 0.452106 \\
\hline 17.5 & & 0.452106 \\
\hline \multicolumn{3}{|c|}{ Biomass (kg) } \\
\hline Length group (cm) & July & October \\
\hline 7.5 & & 0.020797 \\
\hline 8 & & 2.703593 \\
\hline 8.5 & & 1.36762 \\
\hline 9 & & 2.176438 \\
\hline 9.5 & & 2.061603 \\
\hline 10 & 0.053731 & 1.993787 \\
\hline 10.5 & 0.19361 & 1.241483 \\
\hline 11 & 0.085661 & 2.172821 \\
\hline 11.5 & 0.395011 & 1.711673 \\
\hline 12 & 0.420136 & 2.00509 \\
\hline 12.5 & 1.522375 & 1.515007 \\
\hline 13 & 0.521786 & 1.146993 \\
\hline 13.5 & 0.452145 & 0.796159 \\
\hline
\end{tabular}

Project proposal № BG14MFOP001-3.003-0001 "Collection, management and use of data for the purposes of scientific analysis and implementation of the Common Fisheries Policy for the period 2017-2019", funded by the Maritime Affairs and Fisheries Program, co-financed by the European Union through the European Maritime and Fisheries Fund 


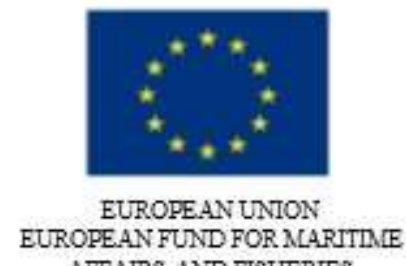

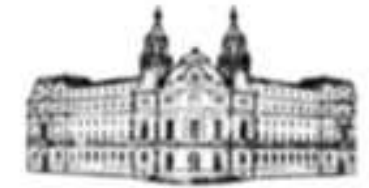

AINTSTRY OF AGRICUITURE, FOOD AND FORESTRY
MLARITLE AFFAIRS AND FISHERIES PROGRAM

\begin{tabular}{|c|l|l|}
\hline $\mathbf{1 4}$ & 0.206685 & 0.768128 \\
\hline $\mathbf{1 4 . 5}$ & 0.391867 & \\
\hline $\mathbf{1 5}$ & & 0.729247 \\
\hline $\mathbf{1 5 . 5}$ & & 0.254988 \\
\hline $\mathbf{1 6}$ & & 0.121616 \\
\hline $\mathbf{1 7}$ & & 0.121164 \\
\hline $\mathbf{1 7 . 5}$ & & 0.179486 \\
\hline
\end{tabular}

\section{III.3.11.3 Catch numbers and biomass by age and length in 2019}

Table 3.11.3.1 Catch-at-age $\left(10^{-3}\right)$ matrix and biomass $(\mathrm{kg})$ of whiting for selected months

\begin{tabular}{|c|c|c|c|c|c|}
\hline \multicolumn{7}{|c|}{ Catch-at-Age *10-3 (in thousands) } \\
\hline Age groups & March & June & July & August & September \\
\hline $\mathbf{0}$ & 0.087269 & 2.891894 & 3.600791 & 2.01408875 & 0.739608194 \\
\hline $\mathbf{1}$ & 0.86022 & 28.50581 & 35.49352 & 19.85316054 & 7.290423628 \\
\hline $\mathbf{2}$ & 0.583453 & 19.33437 & 24.07386 & 13.46562193 & 4.944809069 \\
\hline $\mathbf{3}$ & 0.149603 & 4.957532 & 6.172785 & 3.452723572 & 1.267899761 \\
\hline $\mathbf{4}$ & 0.29422 & 9.749813 & 12.13981 & 6.790356357 & 2.493536197 \\
\hline $\mathbf{5}$ & 0.114696 & 3.800774 & 4.732469 & 2.647088072 & 0.972056484 \\
\hline$\Sigma$ & 2.09 & 69.24 & 86.21 & 48.22 & 17.71 \\
\hline \multicolumn{7}{|c|}{ Biomass } & $(\mathbf{k g})$ & & \\
\hline Age groups & March & June & July & August & September \\
\hline $\mathbf{0}$ & 0.397505725 & 13.17248 & 16.40148 & 9.174106 & 3.36889 \\
\hline $\mathbf{1}$ & 7.089897645 & 234.9438 & 292.5362 & 163.629 & 60.0874 \\
\hline $\mathbf{2}$ & 7.736626268 & 256.375 & 319.2209 & 178.555 & 65.56847 \\
\hline $\mathbf{3}$ & 3.992892955 & 132.3158 & 164.7507 & 92.15269 & 33.84006 \\
\hline $\mathbf{4}$ & 9.764860824 & 323.5863 & 402.9079 & 225.365 & 82.75791 \\
\hline $\mathbf{5}$ & 5.135361022 & 170.1747 & 211.8901 & 118.5199 & 43.52256 \\
\hline$\sum$ & 34.12 & 1130.57 & 1407.71 & 787.40 & 289.15 \\
\hline
\end{tabular}

\begin{tabular}{|c|c|c|c|}
\hline Age groups & October & November & December \\
\hline $\mathbf{0}$ & 2.920812567 & 0.005251474 & 2.863742454 \\
\hline $\mathbf{1}$ & 28.79086673 & 0.05176453 & 28.22831848 \\
\hline $\mathbf{2}$ & 19.52771831 & 0.035109855 & 19.14616384 \\
\hline $\mathbf{3}$ & 5.007107258 & 0.009002527 & 4.909272778 \\
\hline $\mathbf{4}$ & 9.847310941 & 0.01770497 & 9.654903131 \\
\hline $\mathbf{5}$ & 3.838782231 & 0.006901937 & 3.763775797 \\
\hline$\sum$ & 69.93259804 & 0.125735294 & 68.56617647 \\
\hline Age groups & October & November & December \\
\hline $\mathbf{0}$ & 13.3042 & 0.02392 & 13.04425 \\
\hline $\mathbf{1}$ & 237.2933 & 0.426641 & 232.6568 \\
\hline
\end{tabular}

Project proposal № BG14MFOP001-3.003-0001 "Collection, management and use of data for the purposes of scientific analysis and implementation of the Common Fisheries Policy for the period 2017-2019", funded by the Maritime Affairs and Fisheries Program, co-financed by the European Union through the European Maritime and Fisheries Fund 

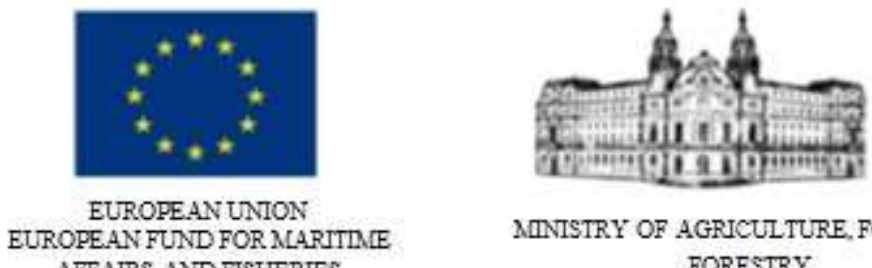

MINISTRY OF AGRICUITURE, FOOD AND FORESTRY

\begin{tabular}{|c|c|c|c|}
\hline $\mathbf{2}$ & 258.9388 & 0.465559 & 253.8793 \\
\hline $\mathbf{3}$ & 133.639 & 0.240276 & 131.0278 \\
\hline $\mathbf{4}$ & 326.8222 & 0.58761 & 320.4363 \\
\hline $\mathbf{5}$ & 171.8765 & 0.309025 & 168.5182 \\
\hline$\sum$ & 1141.874 & 2.053032 & 1119.563 \\
\hline
\end{tabular}

Table 3.11.3.2 Catch-at-length $\left(10^{-3}\right)$ matrix and biomass $(\mathrm{kg})$ of whiting for selected months.

\begin{tabular}{|c|c|c|c|c|c|}
\hline \multicolumn{6}{|c|}{ Catch-at-length $* 10^{-3}$ (in thousands) } \\
\hline $\begin{array}{c}\text { Length } \\
\text { group } \\
\text { (cm) }\end{array}$ & March & June & July & August & September \\
\hline 8 & 0.039894 & 1.322008517 & 1.646076 & 0.920726 & 0.338107 \\
\hline 8.5 & 0.089762 & 2.974519163 & 3.703671 & 2.071634 & 0.76074 \\
\hline 9 & 0.319154 & 10.57606814 & 13.16861 & 7.36581 & 2.704853 \\
\hline 9.5 & 0.191991 & 6.362165988 & 7.921741 & 4.430995 & 1.627138 \\
\hline 10 & 0.122176 & 4.048651083 & 5.041108 & 2.819724 & 1.035451 \\
\hline 10.5 & 0.127163 & 4.213902148 & 5.246868 & 2.934815 & 1.077715 \\
\hline 11 & 0.114696 & 3.800774486 & 4.732469 & 2.647088 & 0.972056 \\
\hline 11.5 & 0.079788 & 2.644017034 & 3.292152 & 1.841453 & 0.676213 \\
\hline 12 & 0.079788 & 2.644017034 & 3.292152 & 1.841453 & 0.676213 \\
\hline 12.5 & 0.057348 & 1.900387243 & 2.366234 & 1.323544 & 0.486028 \\
\hline 13 & 0.082282 & 2.726642566 & 3.395032 & 1.898998 & 0.697345 \\
\hline 13.5 & 0.069815 & 2.313514905 & 2.880633 & 1.611271 & 0.591687 \\
\hline 14 & 0.069815 & 2.313514905 & 2.880633 & 1.611271 & 0.591687 \\
\hline 14.5 & 0.077295 & 2.561391502 & 3.189272 & 1.783907 & 0.655082 \\
\hline 15 & 0.084775 & 2.809268099 & 3.497912 & 1.956543 & 0.718477 \\
\hline 15.5 & 0.117189 & 3.883400019 & 4.835349 & 2.704633 & 0.993188 \\
\hline 16 & 0.052361 & 1.735136179 & 2.160475 & 1.208453 & 0.443765 \\
\hline 16.5 & 0.047374 & 1.569885114 & 1.954715 & 1.093362 & 0.401502 \\
\hline 17 & 0.057348 & 1.900387243 & 2.366234 & 1.323544 & 0.486028 \\
\hline 17.5 & 0.064828 & 2.14826384 & 2.674874 & 1.49618 & 0.549423 \\
\hline 18 & 0.062335 & 2.065638308 & 2.571994 & 1.438635 & 0.528292 \\
\hline 18.5 & 0.034907 & 1.156757452 & 1.440317 & 0.805636 & 0.295843 \\
\hline 19 & 0.017454 & 0.578378726 & 0.720158 & 0.402818 & 0.147922 \\
\hline 19.5 & 0.017454 & 0.578378726 & 0.720158 & 0.402818 & 0.147922 \\
\hline 20 & 0.012467 & 0.413127662 & 0.514399 & 0.287727 & 0.105658 \\
\hline$\Sigma$ & 2.09 & 69.24 & 86.21 & 48.22 & 17.71 \\
\hline
\end{tabular}

Project proposal № BG14MFOP001-3.003-0001 "Collection, management and use of data for the purposes of scientific analysis and implementation of the Common Fisheries Policy for the period 2017-2019", funded by the Maritime Affairs and Fisheries Program, co-financed by the European Union through the European Maritime and Fisheries Fund 


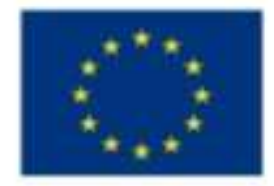

EUROPEAN UNTON EUROPEAN FUND FOR MLARITIIE AFFAIRS AND FISHERIES

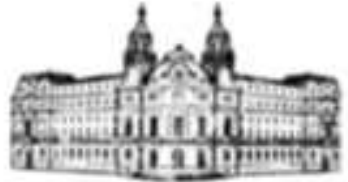

MINISTRY OF AGRICUITURE, FOOD AND FORESTRY
MLARITLIE AFFAIRS AND FISHERIES PROGRAN

\begin{tabular}{|c|c|c|c|c|c|}
\hline $\begin{array}{c}\text { Length } \\
\text { group } \\
\text { (cm) }\end{array}$ & March & June & July & August & September \\
\hline $\mathbf{8}$ & 0.173193 & 5.739241 & 7.146117 & 3.997153 & 1.467824 \\
\hline $\mathbf{8 . 5}$ & 0.411168 & 13.6252 & 16.96519 & 9.489412 & 3.484676 \\
\hline $\mathbf{9}$ & 1.617823 & 53.61116 & 66.75301 & 37.33804 & 13.71117 \\
\hline $\mathbf{9 . 5}$ & 1.113063 & 36.8845 & 45.92609 & 25.68858 & 9.433291 \\
\hline $\mathbf{1 0}$ & 0.945523 & 31.33257 & 39.01321 & 21.82189 & 8.013374 \\
\hline $\mathbf{1 0 . 5}$ & 1.144523 & 37.92702 & 47.22417 & 26.41466 & 9.699918 \\
\hline $\mathbf{1 1}$ & 1.175041 & 38.93831 & 48.48337 & 27.11898 & 9.95856 \\
\hline $\mathbf{1 1 . 5}$ & 0.916547 & 30.37238 & 37.81764 & 21.15315 & 7.767803 \\
\hline $\mathbf{1 2}$ & 1.090276 & 36.12939 & 44.98589 & 25.16268 & 9.240172 \\
\hline $\mathbf{1 2 . 5}$ & 0.806026 & 26.70994 & 33.25742 & 18.60241 & 6.831127 \\
\hline $\mathbf{1 3}$ & 1.289288 & 42.72422 & 53.19732 & 29.75572 & 10.92681 \\
\hline $\mathbf{1 3 . 5}$ & 1.173158 & 38.87592 & 48.40568 & 27.07553 & 9.942602 \\
\hline $\mathbf{1 4}$ & 1.287054 & 42.65017 & 53.10513 & 29.70415 & 10.90788 \\
\hline $\mathbf{1 4 . 5}$ & 1.56909 & 51.99625 & 64.74223 & 36.21332 & 13.29816 \\
\hline $\mathbf{1 5}$ & 1.968552 & 65.23355 & 81.22442 & 45.43257 & 16.68362 \\
\hline $\mathbf{1 5 . 5}$ & 2.966355 & 98.29856 & 122.3948 & 68.46103 & 25.14007 \\
\hline $\mathbf{1 6}$ & 1.458259 & 48.32354 & 60.16923 & 33.65542 & 12.35885 \\
\hline $\mathbf{1 6 . 5}$ & 1.5373 & 50.94277 & 63.43051 & 35.47961 & 13.02873 \\
\hline $\mathbf{1 7}$ & 2.041588 & 67.65379 & 84.23794 & 47.11817 & 17.30261 \\
\hline $\mathbf{1 7 . 5}$ & 2.486159 & 82.38592 & 102.5814 & 57.37851 & 21.07038 \\
\hline $\mathbf{1 8}$ & 2.786363 & 92.33403 & 114.9681 & 64.30698 & 23.61463 \\
\hline $\mathbf{1 8 . 5}$ & 1.640651 & 54.3676 & 67.69488 & 37.86487 & 13.90463 \\
\hline $\mathbf{1 9}$ & 0.89782 & 29.7518 & 37.04494 & 20.72095 & 7.609089 \\
\hline $\mathbf{1 9 . 5}$ & 0.940756 & 31.17461 & 38.81653 & 21.71188 & 7.972976 \\
\hline $\mathbf{2 0}$ & 0.681568 & 22.58569 & 28.12218 & 15.73003 & 5.77634 \\
\hline$\sum$ & $\mathbf{3 4 . 1 2}$ & $\mathbf{1 1 3 0 . 5 7}$ & $\mathbf{1 4 0 7 . 7 1}$ & $\mathbf{7 8 7 . 4 0}$ & $\mathbf{2 8 9 . 1 5}$ \\
\hline & & & & & \\
\hline
\end{tabular}

\begin{tabular}{|c|c|c|c|}
\hline \multicolumn{4}{|c|}{ Catch-at-length $* \mathbf{1 0}^{-3}$ (in thousands) } \\
\hline $\begin{array}{c}\text { Length } \\
\text { group } \\
\text { (cm) }\end{array}$ & October & November & December \\
\hline $\mathbf{8}$ & 1.335228602 & 0.002400674 & 1.309139408 \\
\hline $\mathbf{8 . 5}$ & 3.004264355 & 0.005401516 & 2.945563667 \\
\hline $\mathbf{9}$ & 10.68182882 & 0.019205391 & 10.47311526 \\
\hline $\mathbf{9 . 5}$ & 6.425787648 & 0.011553243 & 6.300233399 \\
\hline $\mathbf{1 0}$ & 4.089137594 & 0.007352064 & 4.009239436 \\
\hline $\mathbf{1 0 . 5}$ & 4.256041169 & 0.007652148 & 4.172881862 \\
\hline
\end{tabular}

Project proposal № BG14MFOP001-3.003-0001 "Collection, management and use of data for the purposes of scientific analysis and implementation of the Common Fisheries Policy for the period 2017-2019", funded by the Maritime Affairs and Fisheries Program, co-financed by the European Union through the European Maritime and Fisheries Fund 


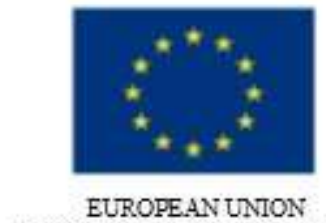

EUROPEAN FUND FOR MLARITIE AFFAIRS AND FISHERIES

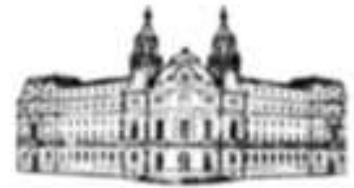

AINISTRY OF AGRICULTURE, FOOD AND FORESTRY
MLARITLE AFFAIRS AND FISHERIES PROGRAM

\begin{tabular}{|c|c|c|c|}
\hline 11 & 3.838782231 & 0.006901937 & 3.763775797 \\
\hline 11.5 & 2.670457204 & 0.004801348 & 2.618278815 \\
\hline 12 & 2.670457204 & 0.004801348 & 2.618278815 \\
\hline 12.5 & 1.919391116 & 0.003450969 & 1.881887898 \\
\hline 13 & 2.753908992 & 0.00495139 & 2.700100028 \\
\hline 13.5 & 2.336650054 & 0.004201179 & 2.290993963 \\
\hline 14 & 2.336650054 & 0.004201179 & 2.290993963 \\
\hline 14.5 & 2.587005417 & 0.004651306 & 2.536457602 \\
\hline 15 & 2.83736078 & 0.005101432 & 2.781921241 \\
\hline 15.5 & 3.922234019 & 0.00705198 & 3.84559701 \\
\hline 16 & 1.75248754 & 0.003150884 & 1.718245472 \\
\hline 16.5 & 1.585583965 & 0.0028508 & 1.554603046 \\
\hline 17 & 1.919391116 & 0.003450969 & 1.881887898 \\
\hline 17.5 & 2.169746479 & 0.003901095 & 2.127351537 \\
\hline 18 & 2.086294691 & 0.003751053 & 2.045530324 \\
\hline 18.5 & 1.168325027 & 0.00210059 & 1.145496982 \\
\hline 19 & 0.584162513 & 0.001050295 & 0.572748491 \\
\hline 19.5 & 0.584162513 & 0.001050295 & 0.572748491 \\
\hline 20 & 0.417258938 & 0.000750211 & 0.409106065 \\
\hline$\Sigma$ & 69.93259804 & 0.125735294 & 68.56617647 \\
\hline $\begin{array}{c}\text { Length } \\
\text { group } \\
\text { (cm) }\end{array}$ & October & November & December \\
\hline 8 & 5.796634 & 0.010422 & 5.683373 \\
\hline 8.5 & 13.76146 & 0.024742 & 13.49257 \\
\hline 9 & 54.14727 & 0.097354 & 53.08928 \\
\hline 9.5 & 37.25334 & 0.06698 & 36.52544 \\
\hline 10 & 31.64589 & 0.056898 & 31.02756 \\
\hline 10.5 & 38.30629 & 0.068873 & 37.55781 \\
\hline 11 & 39.3277 & 0.070709 & 38.55927 \\
\hline 11.5 & 30.6761 & 0.055154 & 30.07672 \\
\hline 12 & 36.49069 & 0.065608 & 35.77769 \\
\hline 12.5 & 26.97704 & 0.048503 & 26.44993 \\
\hline 13 & 43.15146 & 0.077584 & 42.30832 \\
\hline 13.5 & 39.26468 & 0.070596 & 38.49748 \\
\hline 14 & 43.07667 & 0.07745 & 42.23499 \\
\hline 14.5 & 52.51621 & 0.094422 & 51.49009 \\
\hline 15 & 65.88588 & 0.11846 & 64.59853 \\
\hline 15.5 & 99.28155 & 0.178503 & 97.34167 \\
\hline 16 & 48.80678 & 0.087752 & 47.85314 \\
\hline
\end{tabular}

Project proposal № BG14MFOP001-3.003-0001 "Collection, management and use of data for the purposes of scientific analysis and implementation of the Common Fisheries Policy for the period 2017-2019", funded by the Maritime Affairs and Fisheries Program, co-financed by the European Union through the European Maritime and Fisheries Fund 


$\begin{aligned} & \mid * \\
& \text { EUROPEAN UNION }\end{aligned}$
EURREAN FUND FOR MLARITIE
AFFAIRS AND FISHERIES
\begin{tabular}{|c|c|c|c|}
\hline $\mathbf{1 6 . 5}$ & 51.4522 & 0.092508 & 50.44687 \\
\hline $\mathbf{1 7}$ & 68.33032 & 0.122854 & 66.99521 \\
\hline $\mathbf{1 7 . 5}$ & 83.20978 & 0.149607 & 81.58393 \\
\hline $\mathbf{1 8}$ & 93.25737 & 0.167672 & 91.43521 \\
\hline $\mathbf{1 8 . 5}$ & 54.91128 & 0.098728 & 53.83836 \\
\hline $\mathbf{1 9}$ & 30.04932 & 0.054027 & 29.46218 \\
\hline $\mathbf{1 9 . 5}$ & 31.48636 & 0.056611 & 30.87114 \\
\hline $\mathbf{2 0}$ & 22.81155 & 0.041014 & 22.36583 \\
\hline$\sum$ & 1141.874 & 2.053032 & 1119.563 \\
\hline
\end{tabular}

\section{Conclusions and recommendations}

- The age structure of whiting during the period 2017-2019 was characterized by 7 age classes. The year-olds had the highest participation rate in July 2019 (total of 57.66\%). Three and four-year-old individuals had the lowest percentage of participation.

- The average values of the Fulton's condition factor of whiting during the investigation period ranged widely.

- In July 2018-2019, the weight increase relative to the average annual data showed varying values.

- The linear increase rate in October 2018 accounted for a reduction in values.

- It follows from the analysis that the increase in the period 2017-2019 of whiting was allometric.

- In 2017-2019, males (ð) showed greater participation in the catches than females (ㅇ).

- During the period considered, the whiting showed that the GSI was heavily dependent on the weight of the gonads which was associated with the high percentage of maturation of females in late spring and summer and the whiting breeding process.

- An active maturation of sex products was observed, as in over of $80 \%$ the degree of maturity was IV-VI.

Project proposal № BG14MFOP001-3.003-0001 "Collection, management and use of data for the purposes of scientific analysis and implementation of the Common Fisheries Policy for the period 2017-2019", funded by the Maritime Affairs and Fisheries Program, co-financed by the European Union through the European Maritime and Fisheries Fund 


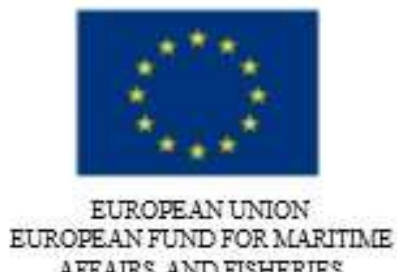

AFFAIRS AND FISHERIES

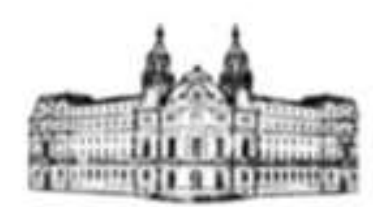

AINISTRY OF AGRICULTURE, FOOD AND FORESTRY

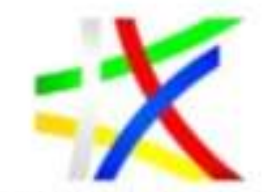

MCARITLE AFFAIRS AND FISHERIES PROGRAM

\section{Biological monitoring of red mullet (Mullus Barbatus)}

\section{IV.1 Objectives}

Red mullet is one of the most important fish species fished and consumed traditionally in the Black Sea countries. Multiannual biological monitoring on the landings provides the so called "Fishery dependant" information. The aim of this study was to collect and analyze dynamics in length, weight and age distribution as well as to determine the condition of the red mullet species using the so-called condition factor. The condition factor is also a useful index for monitoring of feeding intensity, age and growth rates in fish. It is strongly influenced by both biotic and abiotic environmental conditions and can be used as an index to assess the status of the aquatic ecosystem in which fish live. Biological information on species collected each month, analyzed and compared to previous periods could be used for estimation of the growth parameters. These indicators are very important for the species. Reliable and informative long-term data are crucial for the assessment of fish stocks, fisheries management and the decision-making process in general.

\section{IV.2 Sampling in the period 2017-2019}

\section{IV.2.1 Geographic area of coverage}

For the entire period of the research, samples were collected directly from landings at the designated Bulgarian fishing ports (Fig. 2.1.1).

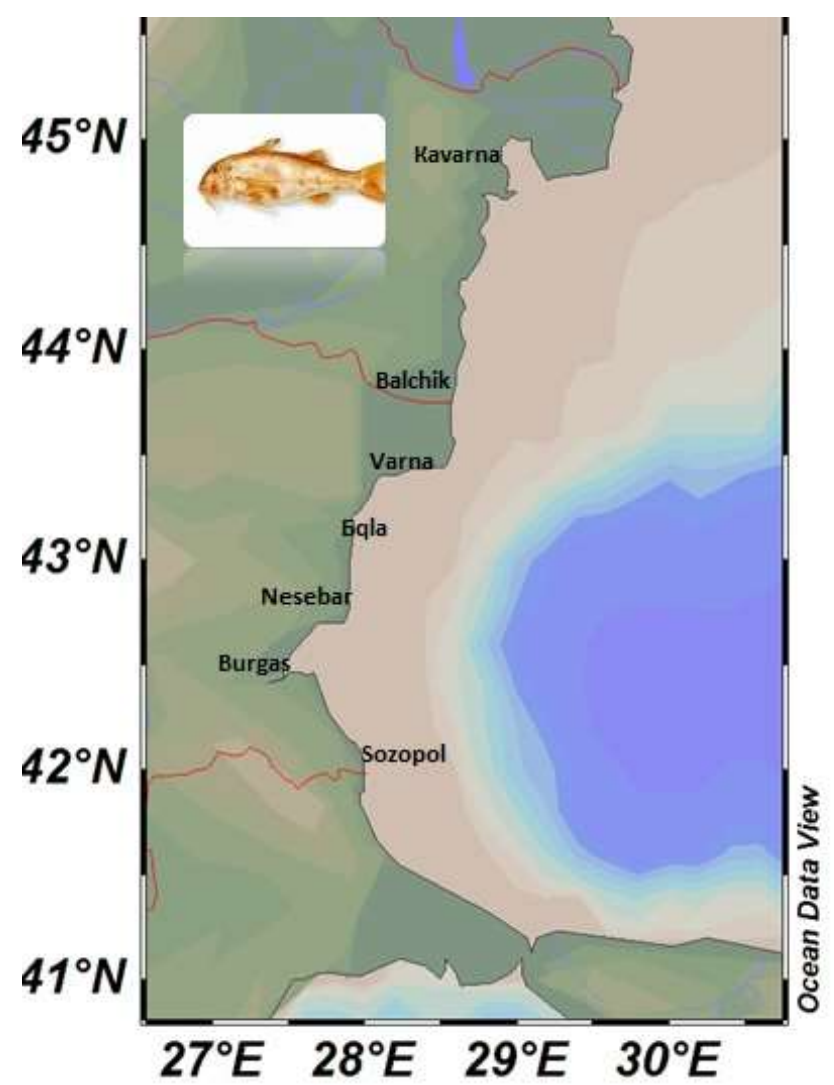

Fig. 2.1.1 Sampling ports along the Bulgarian Black Sea coast (2017-2019)

Project proposal № BG14MFOP001-3.003-0001 "Collection, management and use of data for the purposes of scientific analysis and implementation of the Common Fisheries Policy for the period 2017-2019", funded by the Maritime Affairs and Fisheries Program, co-financed by the European Union through the European Maritime 


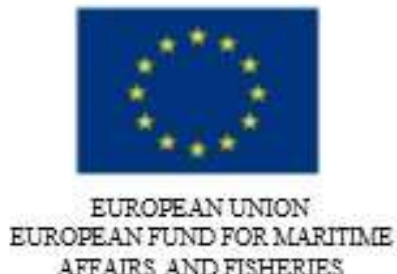

AFFAIRS AND FISHERIES

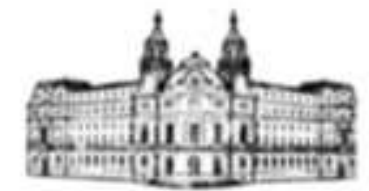

AINISTRY OF AGRICULTURE, FOOD AND FORESTRY
MLARITLIE AFFAIRS AND FISHERIES PROGRAM

\section{IV.2.2 Samples description}

In October-November 2017, 3194 specimens were collected and processed for analysis of the population dynamics of red mullet along the Bulgarian Black Sea coast.

In 2018, 500 specimens were collected processed.

In 2019, 16 samples (2027 specimens) were collected and processed.

Information about the size and structure of the catches was also collected and recorded.

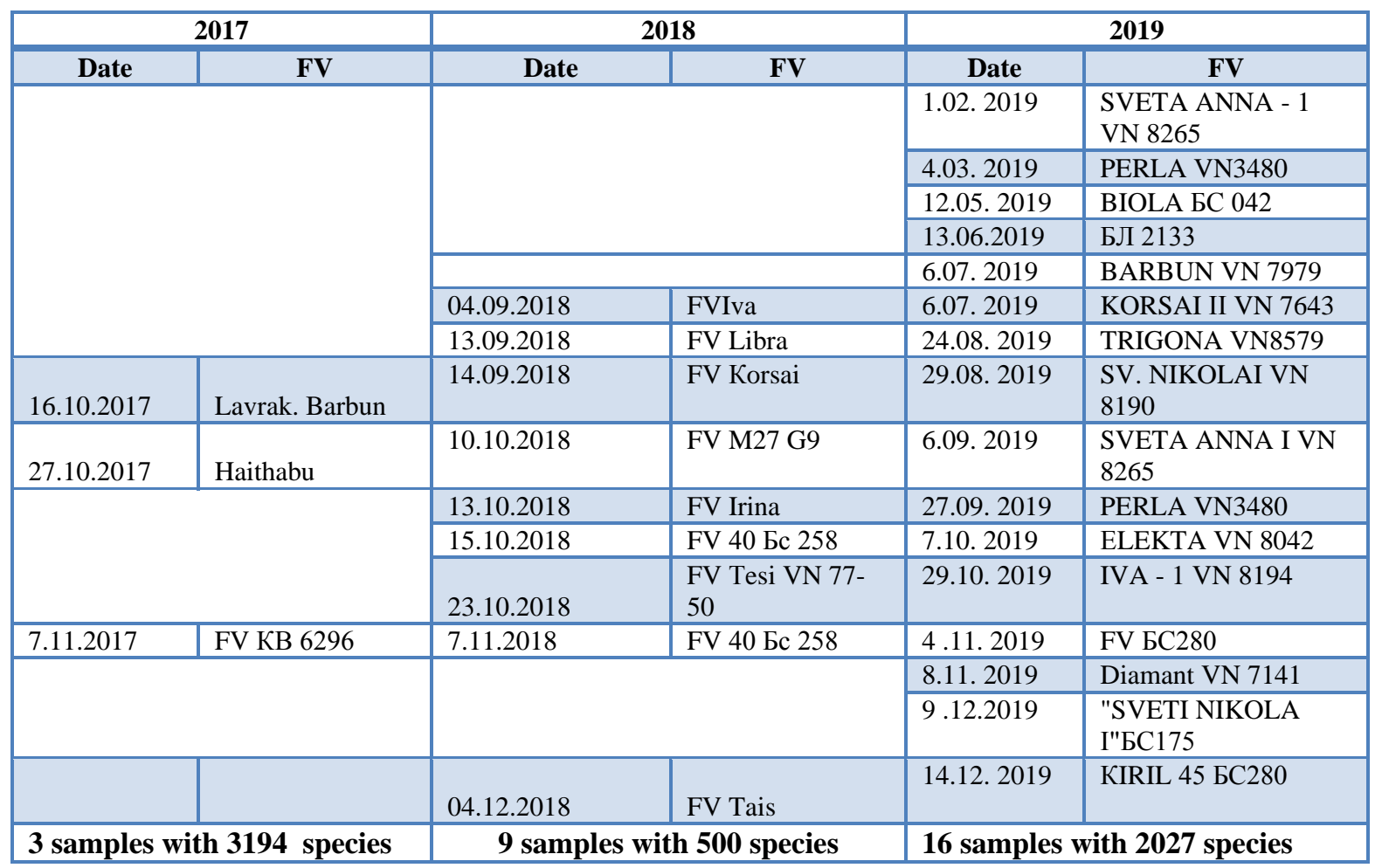

\section{IV.2.3 Statistical analysis}

Refer to the methodology used for sprat stock analysis.

\section{IV.3 Results}

\section{IV.3.1 Landings in 2017-2019}

The official statistics of red mulled landings in 2017 is presented in Fig. 3.1.1. The highest fishing intensity and the biggest catches were registered in November $(172527.2 \mathrm{~kg})$. The lowest fishing intensity and respectively the smallest catches of red mullet were registered in May (152 kg) (Fig. 3.1.1).

The official red mullet landing statistics in 2018 is presented in Fig. 3.1.2 (left). The highest fishing intensity and the biggest catches were registered in September $(200490.4 \mathrm{~kg})$. The lowest fishing intensity and respectively the smallest catches of red mullet were registered in April (3 kg) (Fig. 3.1.2, left).

Project proposal № BG14MFOP001-3.003-0001 "Collection, management and use of data for the purposes of scientific analysis and implementation of the Common Fisheries Policy for the period 2017-2019", funded by the Maritime Affairs and Fisheries Program, co-financed by the European Union through the European Maritime 


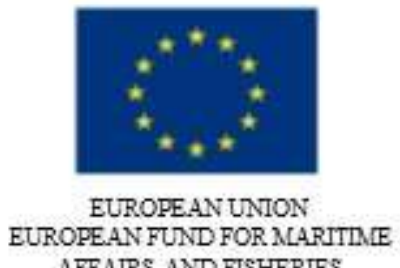

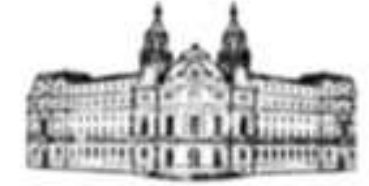

MINISTRY OF AGRICUITURE, FOOD AND FORESTRY

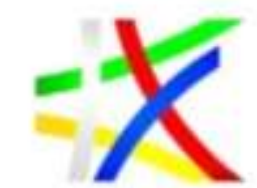

MLARITLE AFFAIRS AND FISHERIES PROGRAM

The official red mullet landing statistics in 2019 is presented in Fig. 3.1.2 (right). The highest fishing intensity and the biggest catches were registered in November $(15794.1 \mathrm{~kg})$. The lowest fishing intensity and respectively the smallest catches of red mullet were registered in August (14194 kg) (Fig. 3.1.2, right).

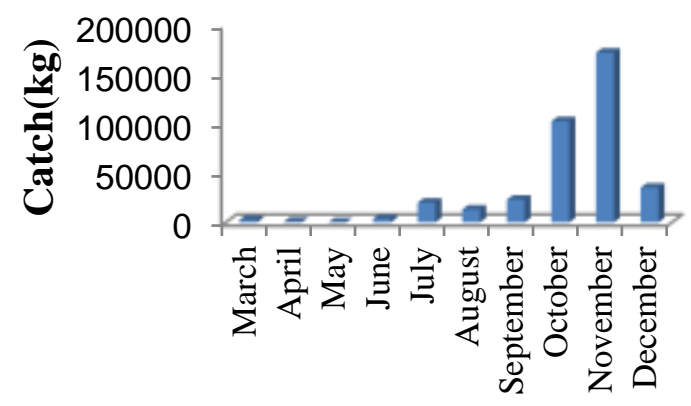

Fig. 3.1.1 Red mullet landings in 2017
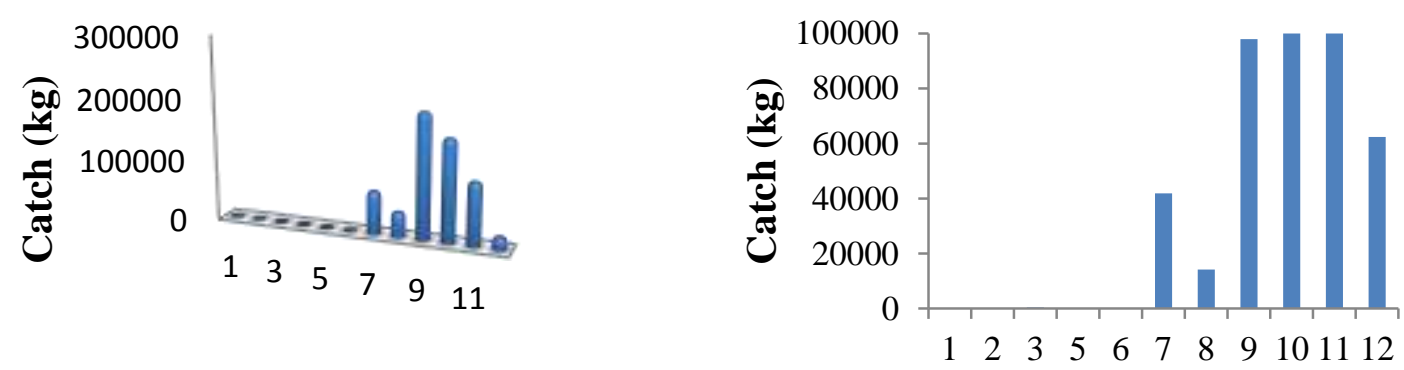

Fig. 3.1.2 Red mullet landings in 2018 (left) and 2019 (right)

\section{IV.3.2 Length structure of red mullet in the period 2017-2019}

\section{IV.3.2.1 Length structure analysis for 2017}

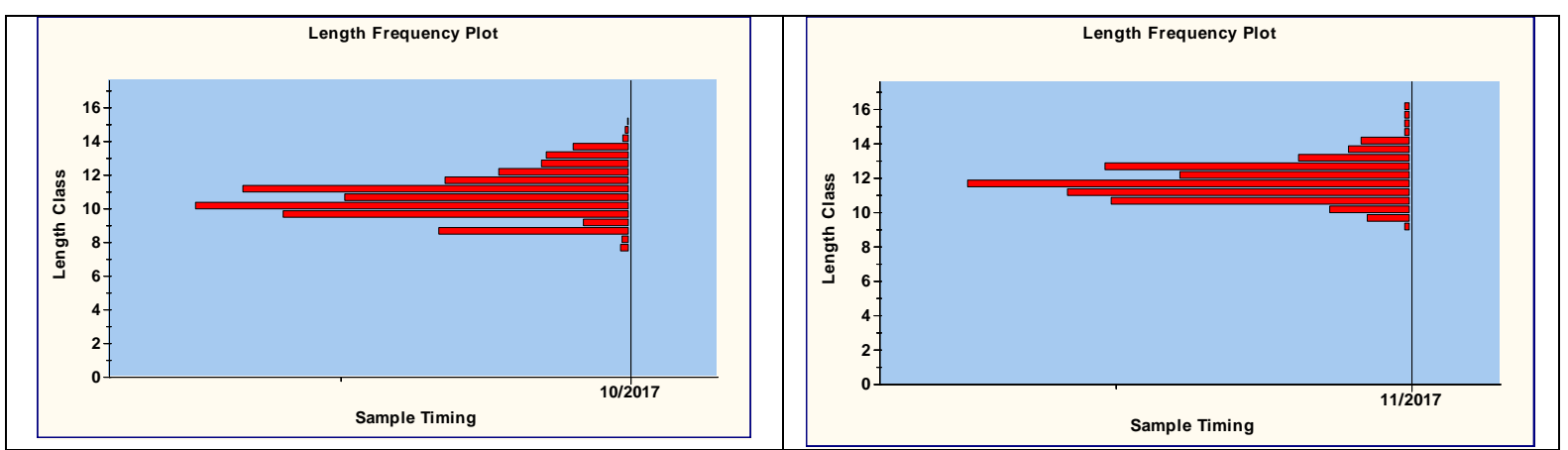

Fig. 3.2.1.1 Length structure of red mullet presented in catches in October-November, 2017

Project proposal № BG14MFOP001-3.003-0001 "Collection, management and use of data for the purposes of scientific analysis and implementation of the Common Fisheries Policy for the period 2017-2019", funded by the Maritime Affairs and Fisheries Program, co-financed by the European Union through the European Maritime and Fisheries Fund 


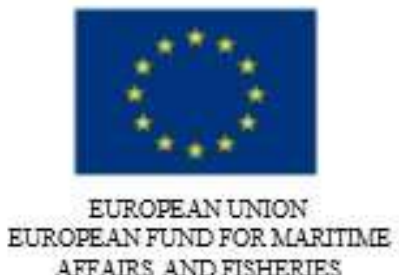

AFFAIRS AND FISHERIES

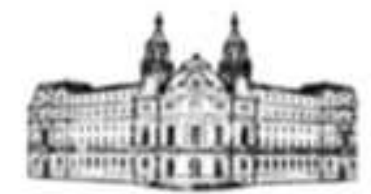

AINISTRY OF AGRICULTURE, FOOD AND FORESTRY

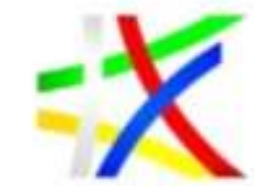

MCARITLE AFFAIRS AND FISHERIES PROGRAM

The length structure of red mullet in the period October-November is presented in Fig. 3.2.1.1. The total length of the specimens presented in the catches varied from $7 \mathrm{~cm}$ to $16 \mathrm{~cm}$. The most frequent in October catches were length classes 9-12 cm and in November 10-13 $\mathrm{cm}$.

\section{IV.3.2.2 Length structure analysis for 2018}

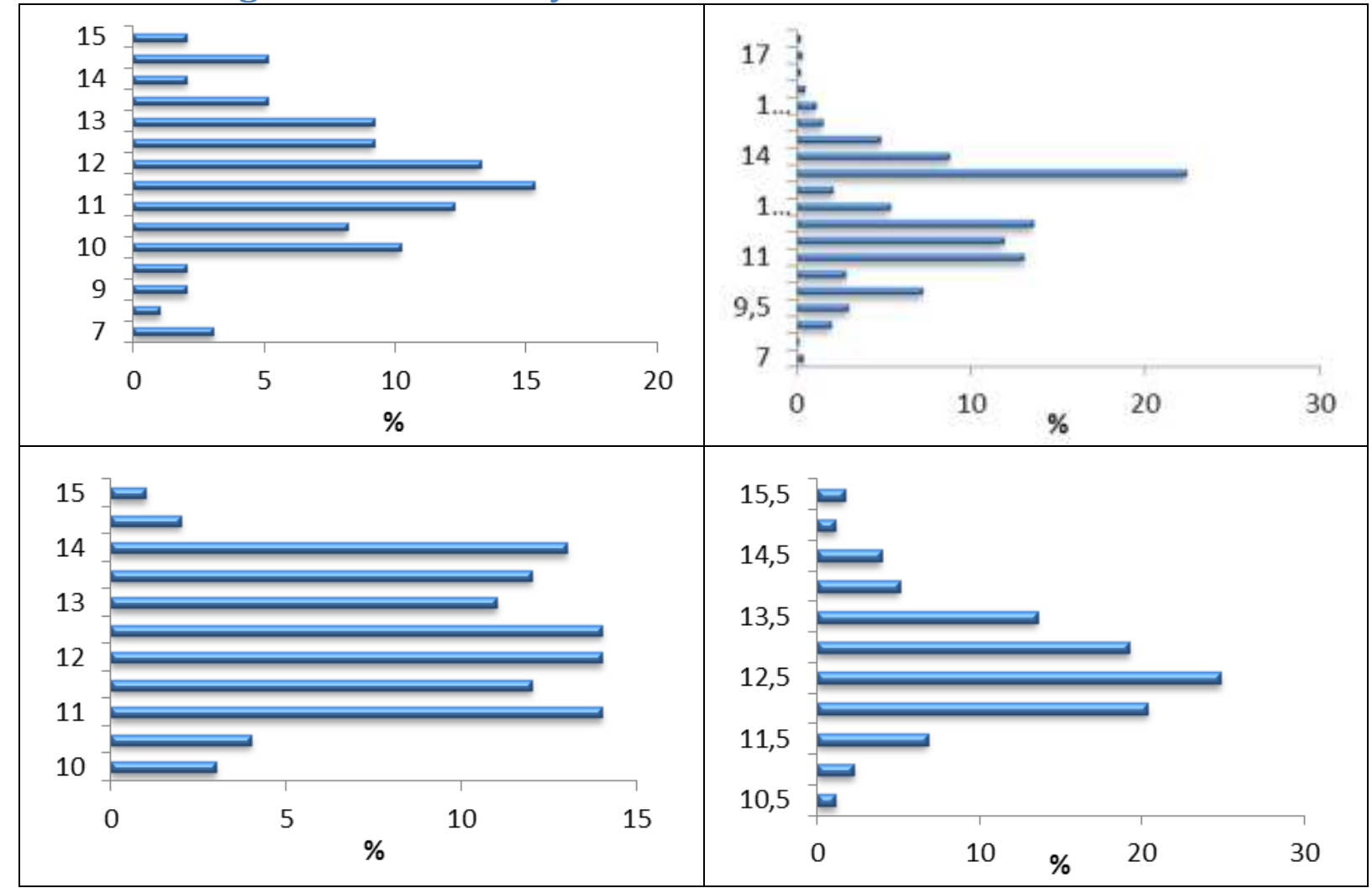

Fig. 3.2.2.1. Length structure of red mullet presented in the catches during the period September-December, 2018

In September, the total length of the specimens presented in the samples varied from $7 \mathrm{~cm}$ to $15 \mathrm{~cm}$. Most frequently presented in the length structure were length classes 11, 11.5 and 12 $\mathrm{cm}$. Less frequent - length classes $7.5,9$ and $9.5 \mathrm{~cm}$. In October, the total length of the sampled red mullet specimens varied in the range $7-17.5 \mathrm{~cm}$. The most frequent length class presented in the length structure of the catches was $13.5 \mathrm{~cm}$. The less frequent were classes $7.5 \mathrm{~cm}$ and $17.5 \mathrm{~cm}$. In November, the total length of the sampled red mullet specimens varied in the range 10-15 cm. Length classes $11,12,12.5$ and $14 \mathrm{~cm}$ were presented with the biggest percentage share in the length structure. The length class $15 \mathrm{~cm}$ was presented with the smallest percentage share. In December, the most frequent length classes were 7, 5, 8 and 10 $\mathrm{cm}$. The less frequent was the length class $11.5 \mathrm{~cm}$.

Project proposal № BG14MFOP001-3.003-0001 "Collection, management and use of data for the purposes of scientific analysis and implementation of the Common Fisheries Policy for the period 2017-2019", funded by the Maritime Affairs and Fisheries Program, co-financed by the European Union through the European Maritime 


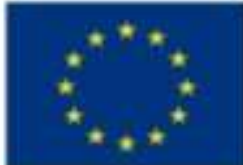

EUROPEAN UNTON EUROPEAN FUND FOR MLARITMIE AFFAIRS AND FISHERIES

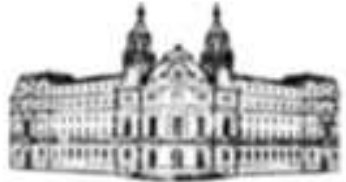

AINISTRY OF AGRICULTURE, FOOD AND FORESTRY
MLARITLE AFFAIRS AND FISHERIES PROGRAM

\section{IV.3.2.3 Length structure analysis for 2019}

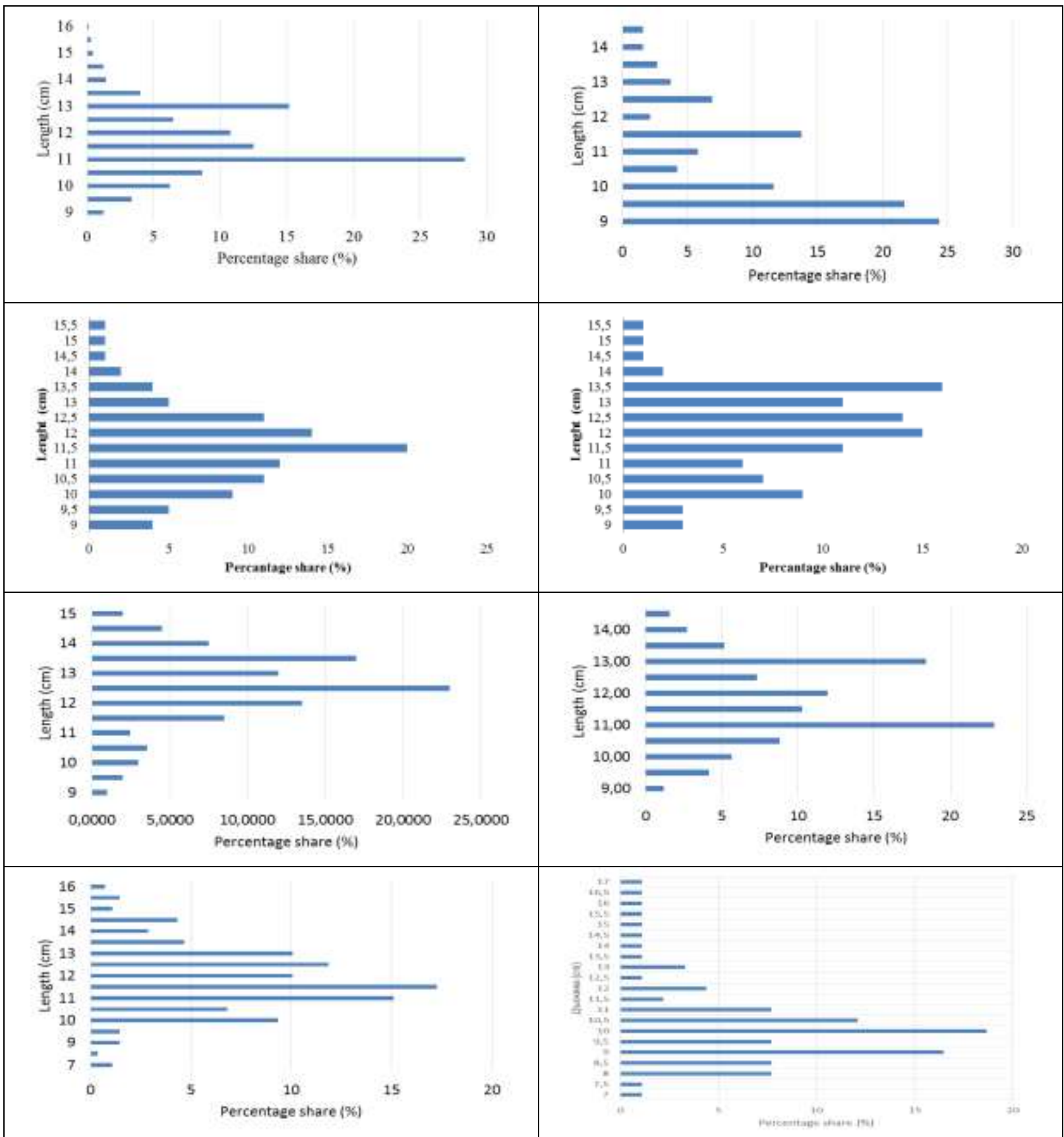

Project proposal № BG14MFOP001-3.003-0001 "Collection, management and use of data for the purposes of scientific analysis and implementation of the Common Fisheries Policy for the period 2017-2019", funded by the Maritime Affairs and Fisheries Program, co-financed by the European Union through the European Maritime 


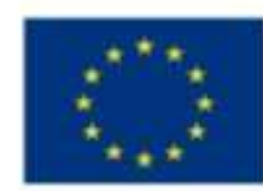

EUROPEAN UNTON EUROPEAN FUND FOR MLARITIIE AFFAIRS AND FISHERIES

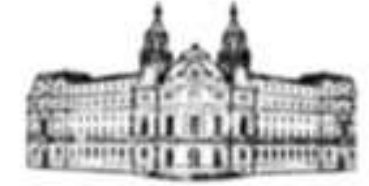

MINISTRY OF AGRICULTURE, FOOD AND FORESTRY

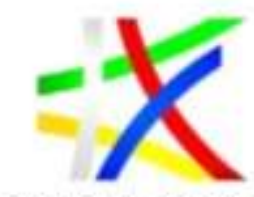

MCARITIE AFFAIRS AND FISHERIES PROGRAM

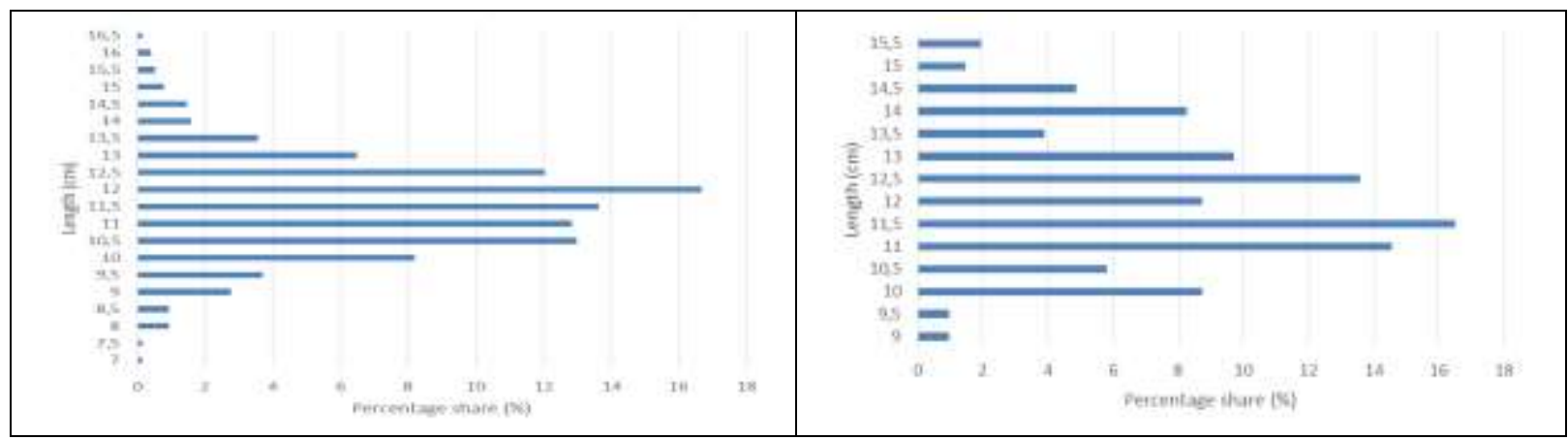

Fig. 3.2.3.1 Length structure of red mullet presented in the catches during the periods February-March and MayDecember, 2019

In February, the total length of the specimens presented in the samples varied from $9 \mathrm{~cm}$ to $16 \mathrm{~cm}$. With the highest percentage share in the length structure were presented length classes $11 \mathrm{~cm}$ and $13 \mathrm{~cm}$. With the lowest - length classes 15, 15.5 and $16 \mathrm{~cm}$. In March, the total length of the specimens presented in the samples varied from $9 \mathrm{~cm}$ to $15.5 \mathrm{~cm}$. Recorded as the most frequent were length classes $9,9.5$ and $11.5 \mathrm{~cm}$. The less frequent classes in the length-frequency samples were $14 \mathrm{~cm}$ and $14.5 \mathrm{~cm}$. In May, length class 11.5 $\mathrm{cm}$ was represented with the biggest percentage share and classes $14.5,15$ and $15.5 \mathrm{~cm}$ were recorded with the smallest shares in the length structure. In June, with the highest frequency of occurrence in the length-frequency samples were length classes $12,12.5$ and $13.5 \mathrm{~cm}$. The lowest frequencies were recorded for $14.5,15$ and $15.5 \mathrm{~cm}$. In July, the total length of the specimens presented in the samples varied from $9 \mathrm{~cm}$ to $15 \mathrm{~cm}$. The most frequent were classes $12.5 \mathrm{~cm}$ and $13.5 \mathrm{~cm}$. The less frequent class was $9 \mathrm{~cm}$. In August, the total length of the specimens presented in the samples varied from $9 \mathrm{~cm}$ to $14.5 \mathrm{~cm}$. The most frequent length classes were $11 \mathrm{~cm}$ and $13 \mathrm{~cm}$. The less frequent class was $9 \mathrm{~cm}$. In September and October with the highest percentage shares in the length structure were recorded length classes $9,10,11$ and $11.5 \mathrm{~cm}$. The lowest percentage shares were recorded for length classes $7 \mathrm{~cm}$ and $8 \mathrm{~cm}$. The rest length classes were recorded with very low frequency of occurrence in the length-frequency samples and that was most probably due to the absence of actively reproducing sexually mature specimens. Furthermore, there were clear indications that the active reproduction period had already passed at that time. In the length-frequency samples collected in November the most frequent was length class $12.5 \mathrm{~cm}$. The less frequent were length classes 7, 8 and $16.5 \mathrm{~cm}$, and in December $-11 \mathrm{~cm}$ and $11.5 \mathrm{~cm}$, and $9 \mathrm{~cm}$ and $9.5 \mathrm{~cm}$, respectively.

Due to the large number of samples collected in 2019, the population dynamics of the red mullet seasonality and individual growth dynamics could be easily followed by the length structure of the samples throughout the year. For the entire period of the research (20172019) most abundant and respectively most frequent in the length structure of the catches were the specimens with total length $9-12 \mathrm{~cm}$. The specimens with total length below $7 \mathrm{~cm}$ were less frequent due to the selectivity of the fishing gears and it could be further considered that in the exploitation phase the specific lengths ranged from $7 \mathrm{~cm}$ to $16 \mathrm{~cm}$. Specimens over $15 \mathrm{~cm}$ length were hardly presented in the catches due to the natural specific physiology and biology of the studied species.

Project proposal № BG14MFOP001-3.003-0001 "Collection, management and use of data for the purposes of scientific analysis and implementation of the Common Fisheries Policy for the period 2017-2019", funded by the Maritime Affairs and Fisheries Program, co-financed by the European Union through the European Maritime and Fisheries Fund 


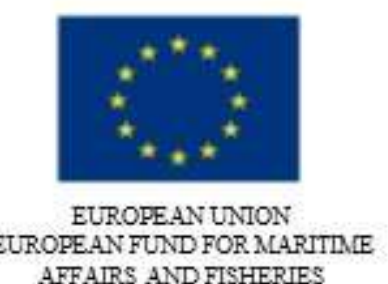

AFFAIRS AND FISHERIES

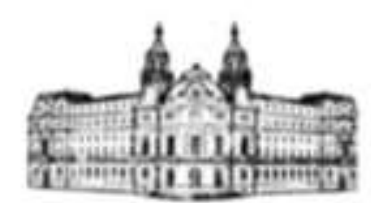

AINISTRY OF AGRICULTURE, FOOD AND FORESTRY
MLARITLIE AFFAIRS AND FISHERIES PROGRAM

\section{IV.3.3 Red mullet age structure analysis in the period 2017-2019}

\section{IV.3.3.1 Age structure analysis for 2017}

Three readers determined the age of red mullet otoliths and one of them read all otoliths twice. The test of symmetry $\left(\chi_{\mathrm{R} 1 \mathrm{vsR} 2}^{2}=8 . d f=6 . P=0.3451 ; \chi_{\mathrm{R} 1 \mathrm{vsR} 3}^{2}=7.09 . d f=6 . \mathrm{P}=0.319\right.$; $\chi_{\mathrm{R} 2 \mathrm{vsR} 3}^{2}=8.24 . d f=9 . P=0.3417$ ) showed that age disagreement was due to simple random error and not to a systematic difference between readers.

Table 3.3.1.1 Indices of precision for age readings of red mullet from the Bulgarian Black Sea waters within and between readers

\begin{tabular}{|l|c|c|}
\hline \multirow{2}{*}{\multicolumn{1}{|c|}{ Index }} & \multicolumn{2}{c|}{ Index comparison } \\
\cline { 2 - 3 } APE [\%] & 1-st reader & Between the readers \\
\hline CV [\%] & 1.924 & 4.961 \\
\hline D [\%] & 2.164 & 3.168 \\
\hline
\end{tabular}

$\mathrm{APE}=$ average percentage error, $\mathrm{CV}=$ coefficient of variation, $\mathrm{D}=$ index of precision

The age structure of the studied specimens contained age groups $0-0+, 1-1+, 2-2+, 3-3+$ and 4+. Old specimens (age 5-5+) were not presented in the catches for the entire research period. The biggest share of representation in October samples had the specimens from age group 1$1+(45.37 \%)$. Age groups 3-3+ and 4-4+ were not significantly presented in the catches age structure (Fig. 3.3.1.1). The biggest share of representation in November samples had the age group 2-2+(42.17\%) (Fig. 3.3.1.1). The presence of age groups 1-1+ and 3-3+ was recorded with almost equal shares. Specimens from age group 5-5+ were again absent in the catches.

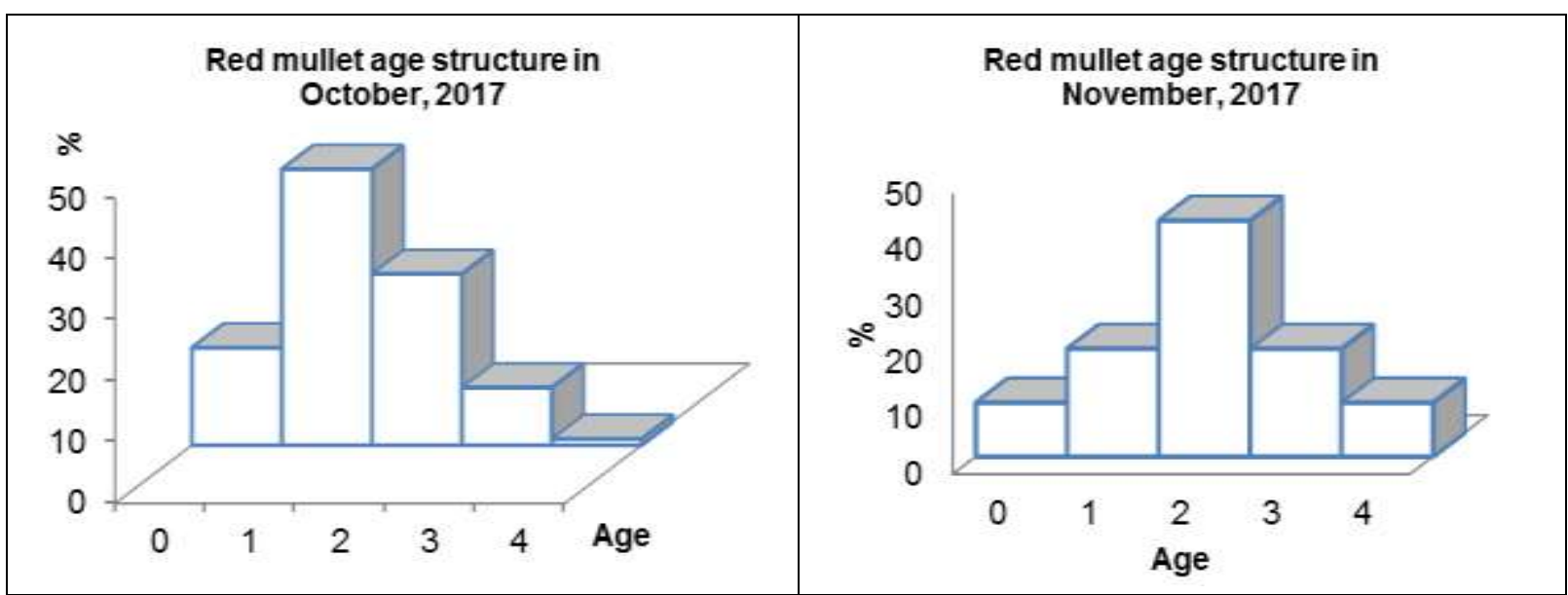

Fig. 3.3.1.1 Age structure of red mullet in October and November, 2017

Project proposal № BG14MFOP001-3.003-0001 "Collection, management and use of data for the purposes of scientific analysis and implementation of the Common Fisheries Policy for the period 2017-2019", funded by the Maritime Affairs and Fisheries Program, co-financed by the European Union through the European Maritime and Fisheries Fund 


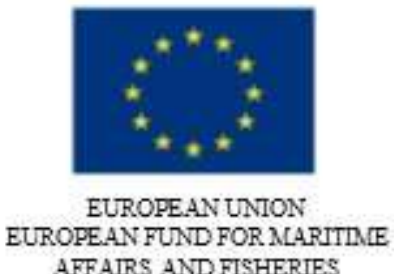

AFFAIRS AND FISHERIES

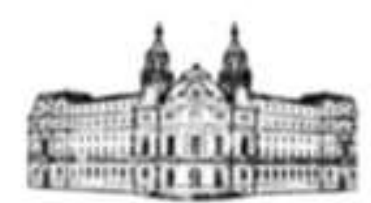

AINISTRY OF AGRICULTURE, FOOD AND FORESTRY
MLARITLIE AFFAIRS AND FISHERIES PROGRAM

\section{IV.3.3.2 Age structure analysis for 2018}

The same technology for age reading as the one applied for 2017 was used for age determination of sampled specimens in 2018. The test of symmetry $\left(\chi^{2}\right.$ R1vsR $2=6 . d f=7 . P=$ 0.5243; $\chi_{\mathrm{R} 1 \mathrm{vsR} 3}^{2}=8.07 . d f=5$. $\left.\mathrm{P}=0.845 ; \chi_{\mathrm{R} 2 \mathrm{vsR} 3}^{2}=7.48 . d f=8 . P=0.2119\right)$ showed that age disagreement was due to simple random error and not to a systematic difference between readers.

Таблица 3.3.2.1 Indices of precision for age readings of red mullet from the Bulgarian Black Sea waters within and between readers

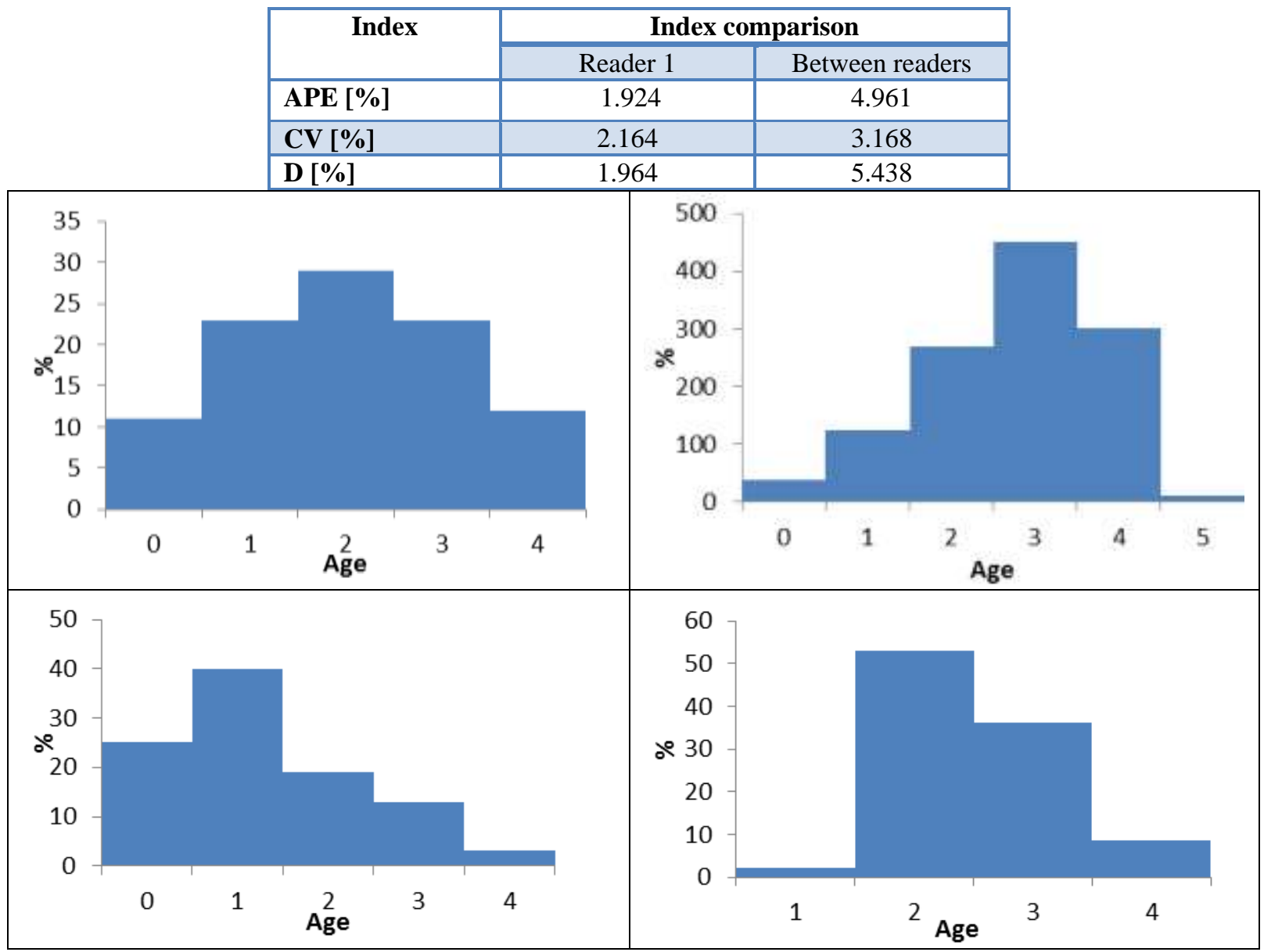

Fig. 3.3.2.1 Age structure of red mullet in the period September - December, 2018

The age structure of the studied specimens in September presented age groups $0-0+, 1-1+, 2-$ $2+, 3-3+$ and 4+. Old specimens (age 5-5+) were absent in the catches for the entire research period. The most frequent in the catches were age groups 2-2+ $(29 \%)$ - in September and December, 3-3+ (38\%) in October and 1-1+ in November (Fig. 3.3.2.1).

Project proposal № BG14MFOP001-3.003-0001 "Collection, management and use of data for the purposes of scientific analysis and implementation of the Common Fisheries Policy for the period 2017-2019", funded by the Maritime Affairs and Fisheries Program, co-financed by the European Union through the European Maritime and Fisheries Fund 


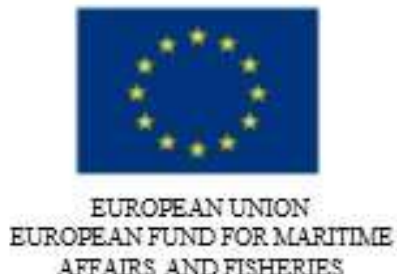

AFFAIRS AND FISHERIES

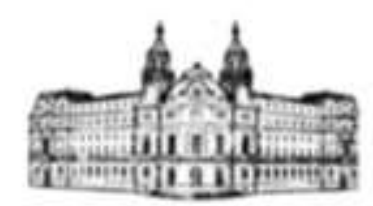

AINISTRY OF AGRICULTURE, FOOD AND FORESTRY
MLARITLE AFFAIRS AND FISHERIES PROGRAM

\section{IV.3.3.3 Age structure analysis for 2019}

The same technology for age reading as the one applied for 2017 was used for age determination of sampled specimens in 2018. The test of symmetry $(\chi 2 \mathrm{R} 1 \mathrm{vsR} 2=3 \mathrm{df}=4 \mathrm{P}$ $\left.=0.1452 ; \chi^{2} \mathrm{R} 1 \mathrm{vsR} 3=7.12 . \mathrm{df}=3 . \mathrm{P}=0.220 ; \chi^{2} \mathrm{R} 2 \mathrm{vsR} 3=6.22 . \mathrm{df}=5 . \mathrm{P}=0.2201\right)$ showed that age disagreement was due to simple random error and not to a systematic difference between readers.

Table 3.3.2.1 Indices of precision for age readings of red mullet from the Bulgarian Black Sea waters within and between readers.

\begin{tabular}{|l|c|c|}
\hline \multicolumn{1}{|c|}{ Index } & \multicolumn{2}{c|}{ Index comparison } \\
\hline & Reader 1 & Between readers \\
\hline APE [\%] & 1.022 & 4.230 \\
\hline CV [\%] & 2.323 & 3.114 \\
\hline D [\%] & 1.401 & 5.006 \\
\hline
\end{tabular}

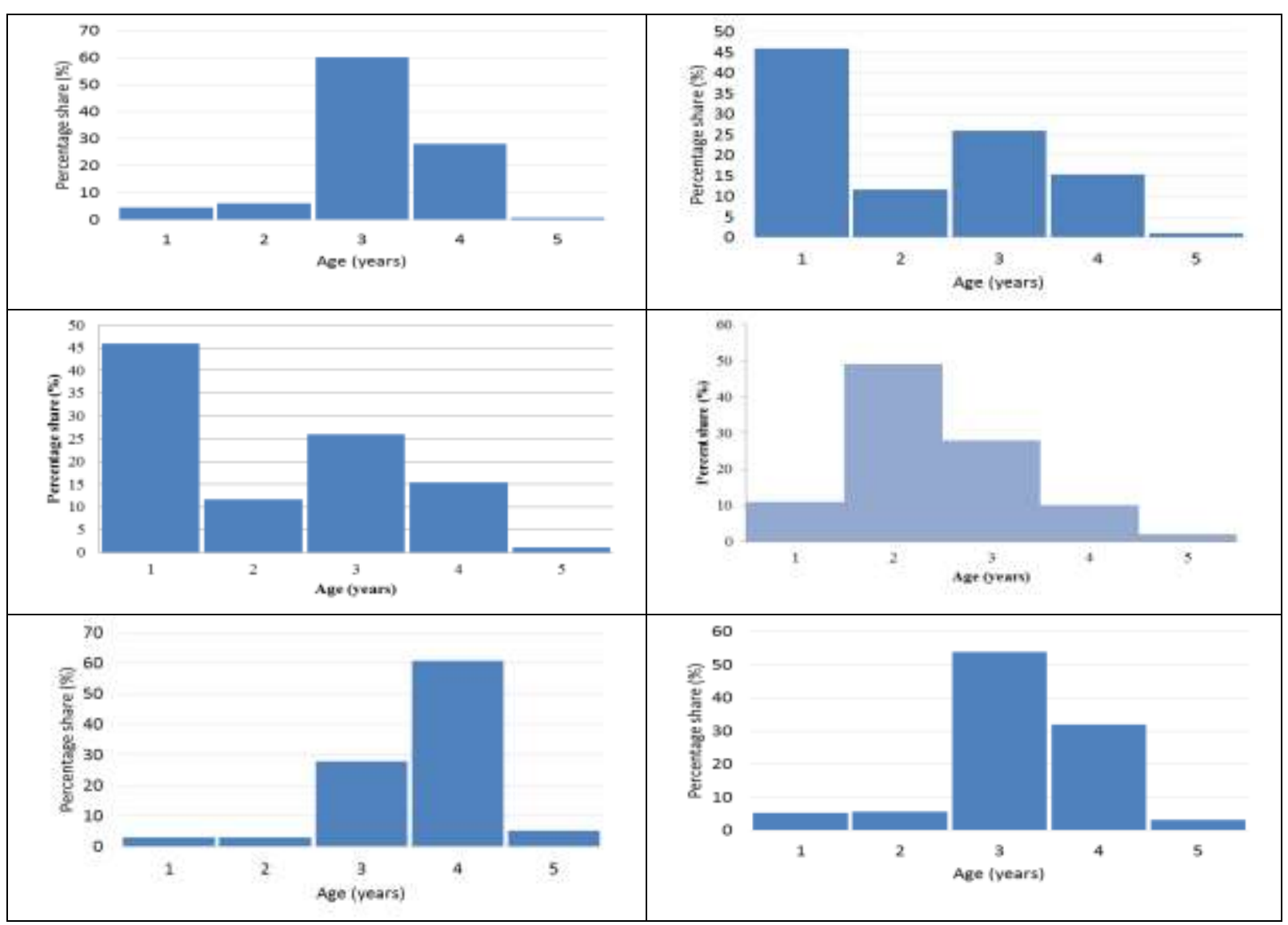

Project proposal № BG14MFOP001-3.003-0001 "Collection, management and use of data for the purposes of scientific analysis and implementation of the Common Fisheries Policy for the period 2017-2019", funded by the Maritime Affairs and Fisheries Program, co-financed by the European Union through the European Maritime and Fisheries Fund 


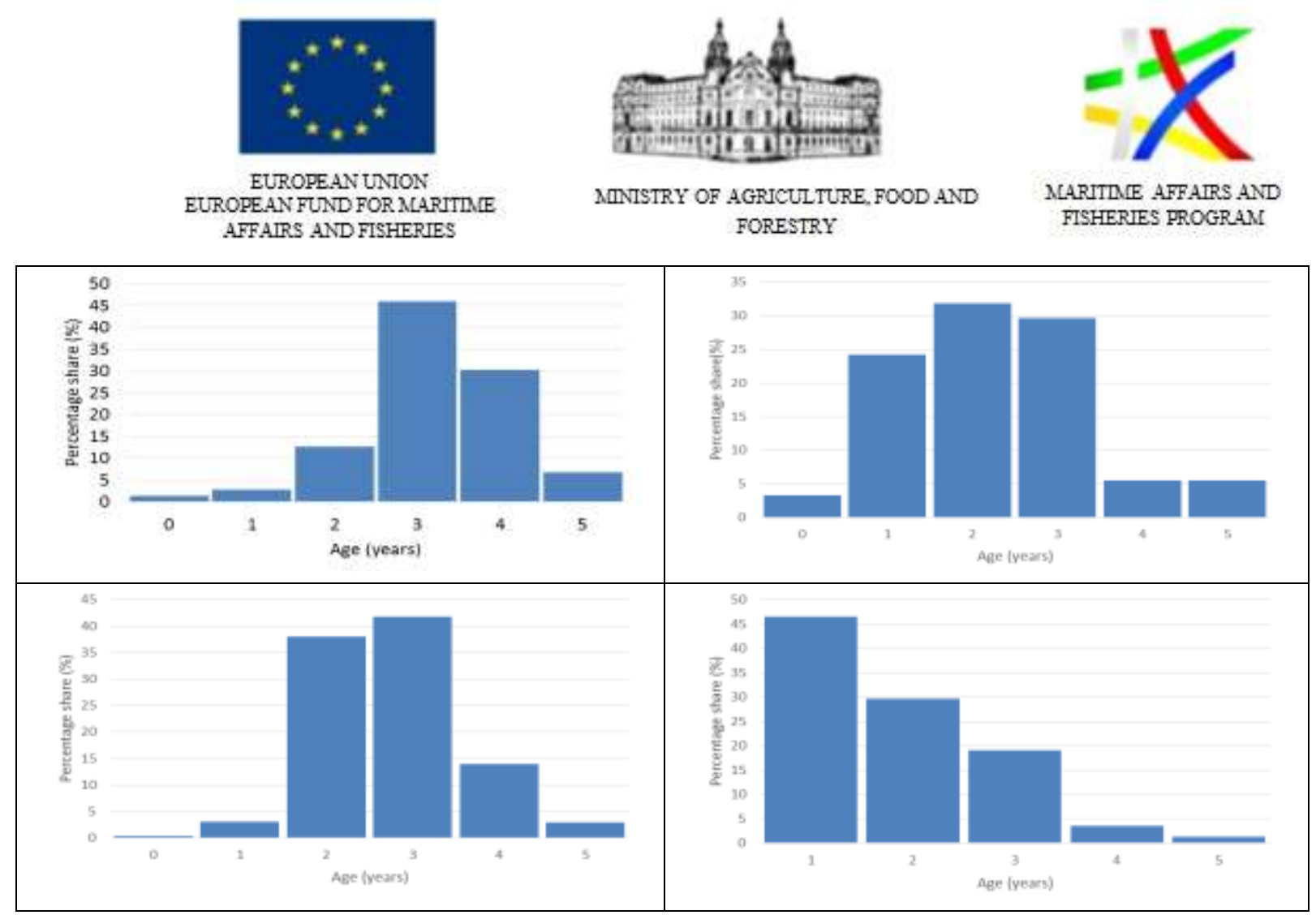

Fig. 3.3.2.1 Age structure of red mullet in the periods February - March and May - December, 2019

3-3+ years old specimens were the most frequent in February (60\%), followed by 4-4+ $(27 \%)$. The younger (1-2+) and the oldest (5+) specimens showed insignificant presence in the catches. March age distribution was predominated $(45 \%)$ by $1-1+$ year old individuals. Second in terms of presence were 3-3+ year old individuals. May age distribution showed prevailance of 2-2+ and 3-3+ age old specimens. In July, 4-4+ year olds reached 60\%, followed by $3-3+$ olds with $28 \%$. The rest of the age groups were presented with very small share. In August, the distribution of the age groups was similar to the one witnessed in July with the exception of the increase of 3-3+ age group share up to 53\% and decrease in 4-4+ age group share to $32 \%$. The age distribution in September was similar to the age distribution in the samples collected in July and August, as 3-3+ and 4-4+ predominated in the catches. In October 2019, 1-3 + year olds predominated. Presence of recruitment $(0+\mathrm{yr}, 30 \%)$ was observed. In November samples, recruitment was absent, 1-1+ age old decreased significantly in the catches and the oldest 5+, 2-3+ yr retained their high percentage, similar to October 2019. The age structure in December 2019 showed significant increase in 1-1+ age group and comparatively lower presence of specimens from age groups $2-2+$ and 3-3+.

\section{IV.3.4 Red mullet Fulton's condition factor analysis in the period 2017-2019}

\section{IV.3.4.1 Red mullet Fulton's condition factor analysis for 2017}

The highest values of Fulton's condition factor for October were calculated for age groups 2$2+$ and 4-4+ (Fig. 3.4.1.1). In November, the highest values were calculated for age groups 0 $0+$ and 1-1+. Such fluctuations were natural for the fish species and were most probably a result of the recruitment process.

Project proposal № BG14MFOP001-3.003-0001 "Collection, management and use of data for the purposes of scientific analysis and implementation of the Common Fisheries Policy for the period 2017-2019", funded by the Maritime Affairs and Fisheries Program, co-financed by the European Union through the European Maritime and Fisheries Fund 


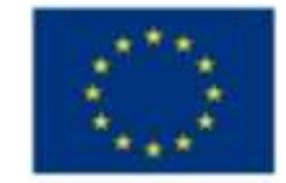

EUROPEAN UNTON EUROPEAN FUND FOR MLARITIIE AFFAIRS AND FISHERIES

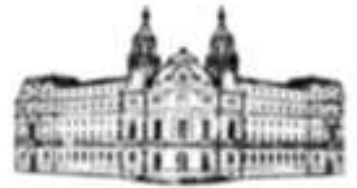

AINTSTRY OF AGRICULTURE, FOOD AND FORESTRY
MLARITLIE AFFAIRS AND FISHERIES PROGRAM

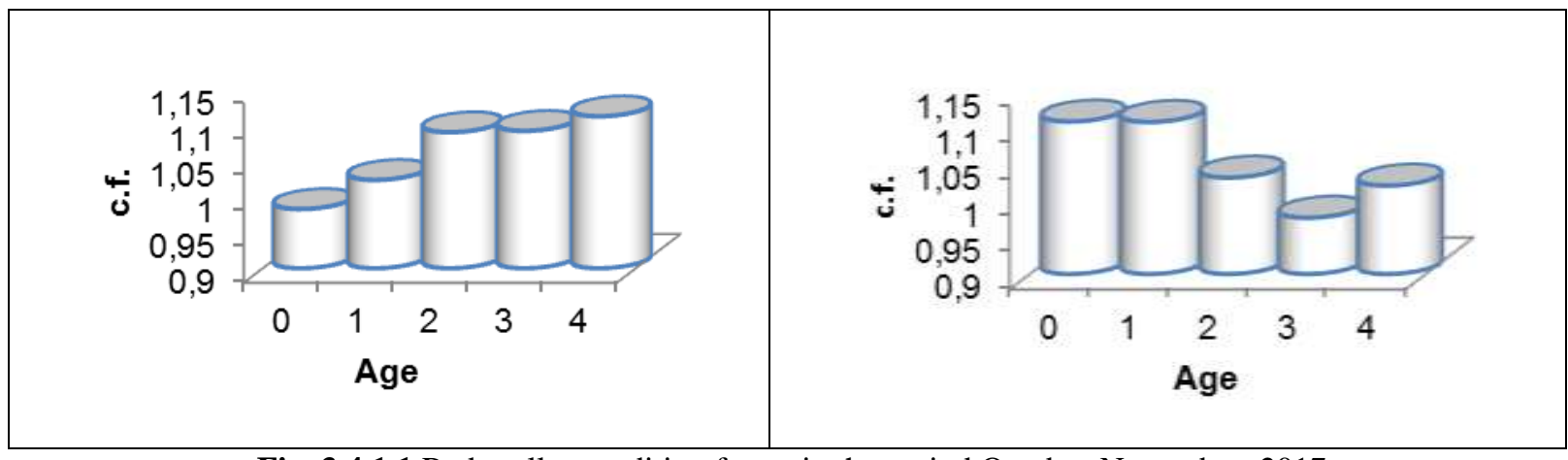

Fig. 3.4.1.1 Red mullet condition factor in the period October-November, 2017

\section{IV.3.4.2 Red mullet Fulton's condition factor analysis for 2018}

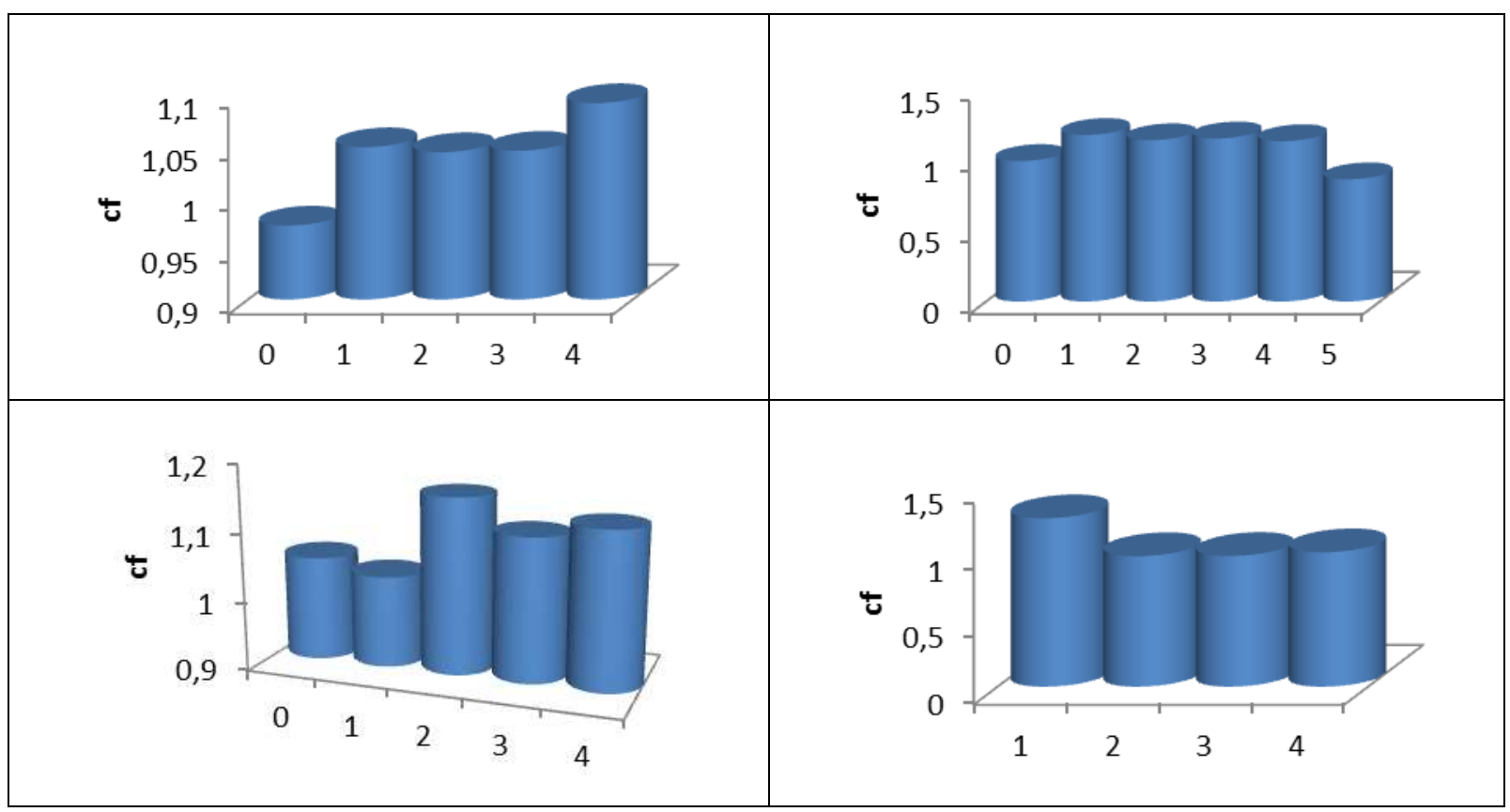

Fig. 3.4.2.1 Red mullet condition factor in the period September-December, 2018

For the period of the research, the natural fluctuations of the Fulton's condition factor which were closely related to the variability and seasonality of the species's growth parameters and its environment were evident.

Project proposal № BG14MFOP001-3.003-0001 "Collection, management and use of data for the purposes of scientific analysis and implementation of the Common Fisheries Policy for the period 2017-2019", funded by the Maritime Affairs and Fisheries Program, co-financed by the European Union through the European Maritime 


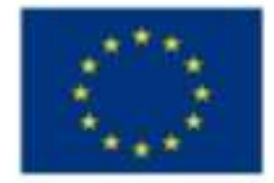

EUROPEANUNTON EUROPE.AN FUND FOR MLARITIIE AFFAIRS AND FISHERIES

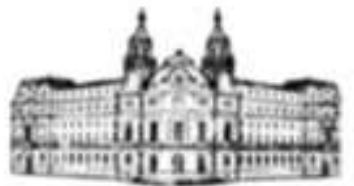

AINISTRY OF AGRICULTURE, FOOD AND FORESTRY

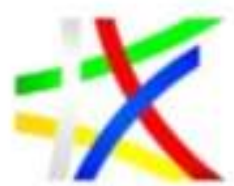

MLARITLIE AFFAIRS AND FISHERIES PROGRAM

\section{IV.3.4.3 Red mullet Fulton's condition factor analysis for 2019}

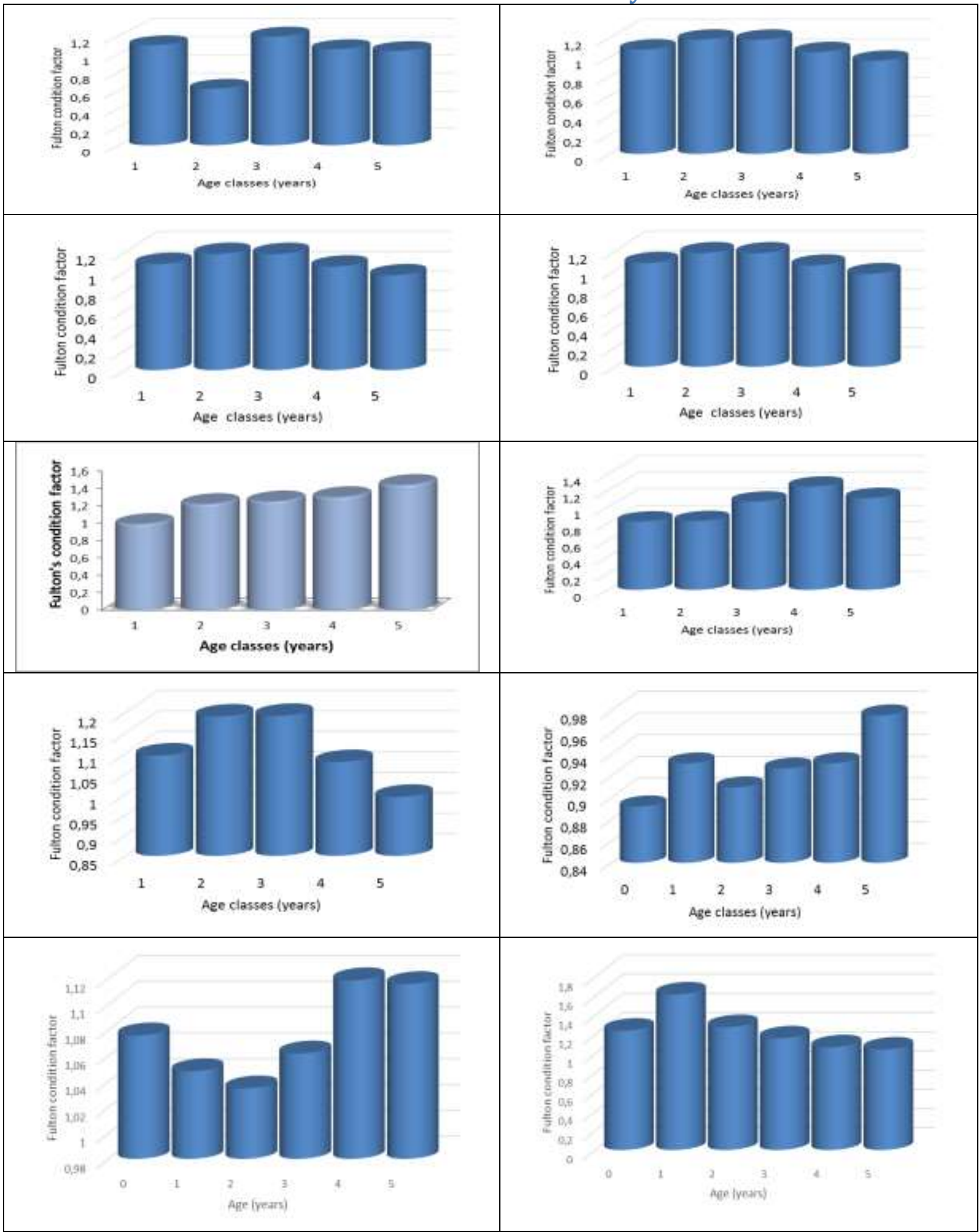

Fig. 3.4.3.1 Red mullet condition factor in the periods February-March and May-December, 2019

Project proposal № BG14MFOP001-3.003-0001 "Collection, management and use of data for the purposes of scientific analysis and implementation of the Common Fisheries Policy for the period 2017-2019", funded by the Maritime Affairs and Fisheries Program, co-financed by the European Union through the European Maritime and Fisheries Fund 


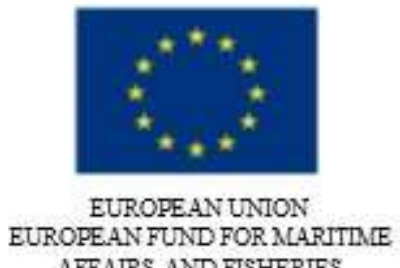

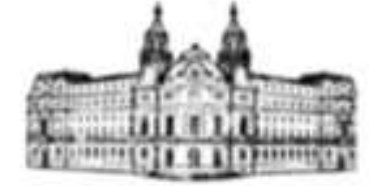

MINISTRY OF AGRICUITURE, FOOD AND FORESTRY

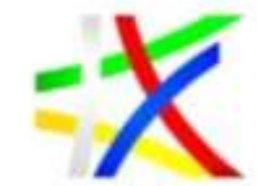

MLARITLE AFFAIRS AND FISHERIES PROGRAM

In 2019, Fulton's condition factor again varied significantly by age groups and those variations were strongly connected to the natural variability of the individual growth parameters, biology and physiology of the studied species as well as its environment and food availability.

\section{IV.3.5 Weight structure of red mullet in the period 2018-2019}

\section{IV.3.5.1 Weight structure in 2018}

Table 3.5.1.1 Weight structure of red mullet by age groups in 2018

\begin{tabular}{|r|r|r|r|r|}
\hline age & September & \multicolumn{1}{c|}{ October } & November & December \\
\hline \multicolumn{5}{|c|}{ Weight (g) } \\
\hline $\mathbf{0}$ & 7.14 & 7.20 & 14.22 & \\
\hline $\mathbf{1}$ & 12.77 & 13.31 & 15.99 & 15.55 \\
\hline $\mathbf{2}$ & 16.51 & 16.03 & 18.68 & 19.26 \\
\hline $\mathbf{3}$ & 20.74 & 23.12 & 27.49 & 20.51 \\
\hline $\mathbf{4}$ & 31.72 & 30.27 & 29.76 & 31.42 \\
\hline $\mathbf{5}$ & & 39.73 & & \\
\hline
\end{tabular}

\section{IV.3.5.2 Weight structure of red mullet in 2019}

2027 sampled specimens were weighted providing the following outcome (Fig. 3.5.2.1)

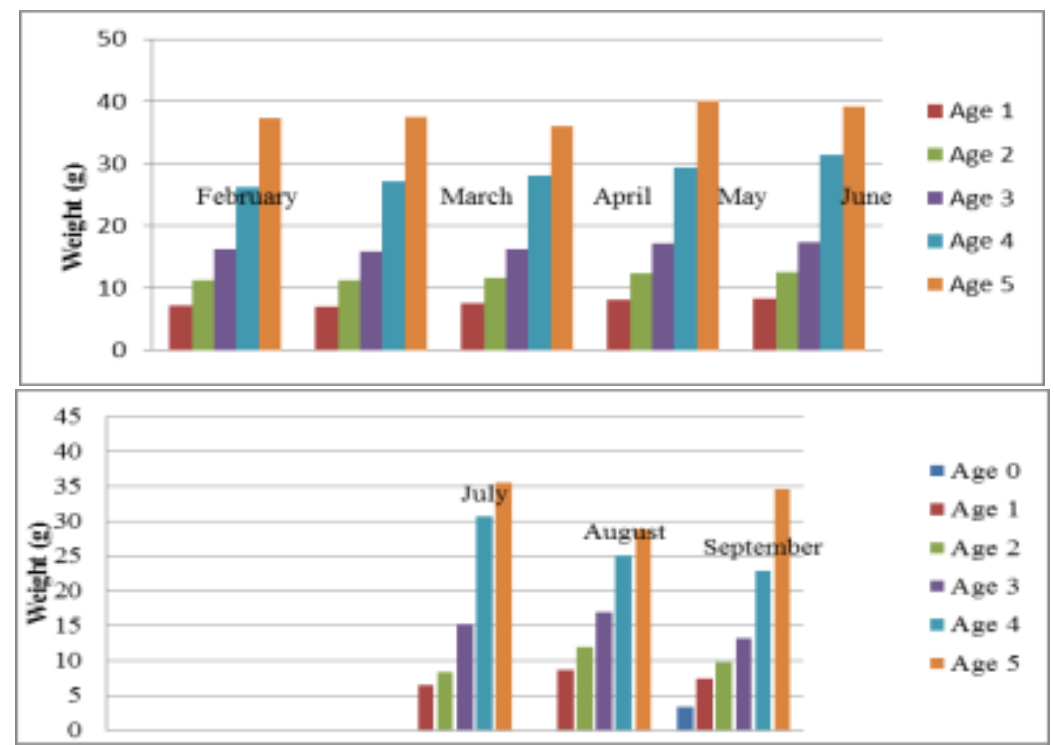

Project proposal № BG14MFOP001-3.003-0001 "Collection, management and use of data for the purposes of scientific analysis and implementation of the Common Fisheries Policy for the period 2017-2019", funded by the Maritime Affairs and Fisheries Program, co-financed by the European Union through the European Maritime and Fisheries Fund 


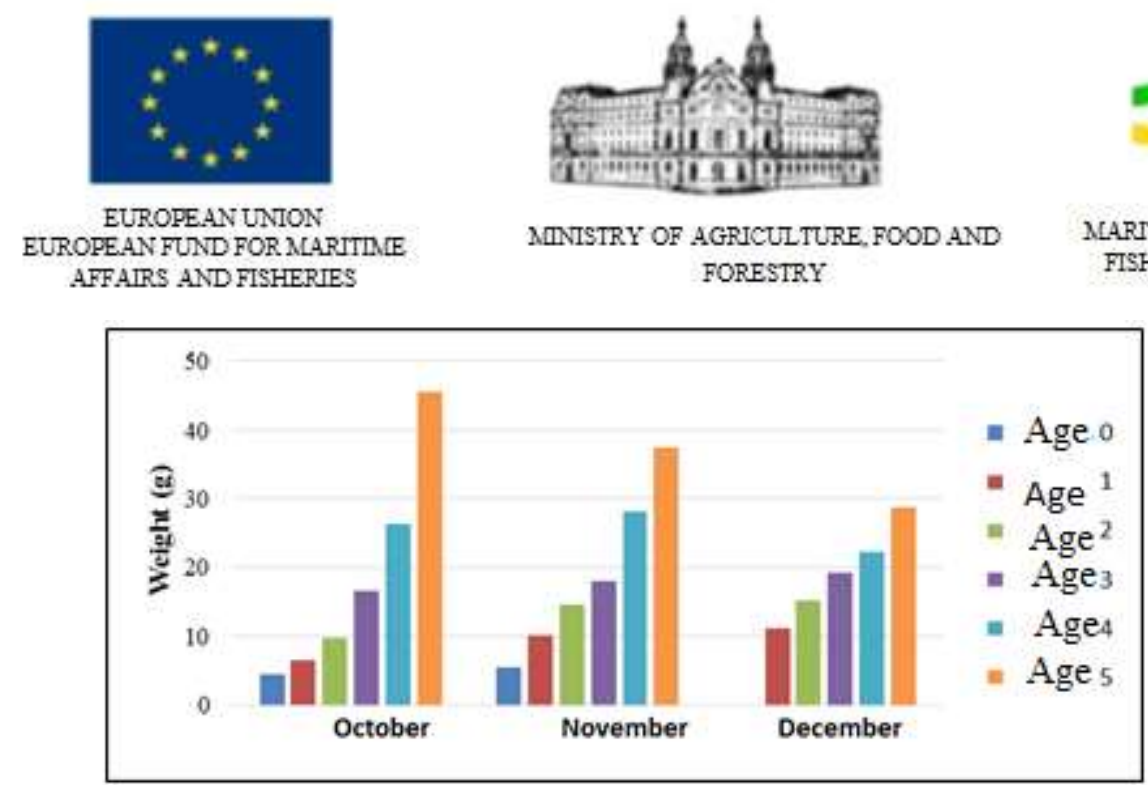

Fig. 3.5.2.1 Weight structure of red mullet by age groups in 2019

The analysis of red mullet weight structure for a large period of time provided insights to the pattern of the natural variability and seasonality of red mullet weight.

\section{IV.3.6 Length structure of red mullet by age groups for the period 2018-} 2019

Table 3.6.1 Length structure by age groups in 2018

\begin{tabular}{|c|c|c|c|c|}
\hline age & September & October & November & December \\
\hline \multicolumn{4}{|c|}{ Length (cm) } & \\
\hline $\mathbf{0}$ & 8.73 & 8.88 & 11.00 & \\
\hline 1 & 10.65 & 10.36 & 13.15 & 10.75 \\
\hline 2 & 3.86 & 11.18 & 13.34 & 12.51 \\
\hline 3 & 12.54 & 12.54 & 13.88 & 12.77 \\
\hline 4 & 14.25 & 13.90 & 14.67 & 14.60 \\
\hline 5 & & 16.64 & & \\
\hline
\end{tabular}

Table 3.6.2 Length structure by age groups in 2019

\begin{tabular}{|c|c|c|c|c|c|c|c|}
\hline & February & March & May & June & July & August & September \\
\hline Age & \multicolumn{7}{|c|}{ Length (cm) } \\
\hline $\mathbf{0}$ & $\mathrm{n} / \mathrm{a}$ & $\mathrm{n} / \mathrm{a}$ & $\mathrm{n} / \mathrm{a}$ & $\mathrm{n} / \mathrm{a}$ & $\mathrm{n} / \mathrm{a}$ & $\mathrm{n} / \mathrm{a}$ & 7.25 \\
\hline 1 & 9.25 & 9.25 & 9.25 & 9.25 & 9.25 & 9.25 & 9.25 \\
\hline 2 & 10 & 10 & 10 & 10 & 10 & 10 & 10.25 \\
\hline 3 & 11.25 & 11.25 & 11.25 & 11.25 & 11.25 & 11.25 & 11.25 \\
\hline 4 & 13.5 & 13.5 & 13.5 & 13.5 & 13.5 & 13.25 & 13.5 \\
\hline 5 & 15.5 & 14.5 & 14.75 & 14.5 & 14.75 & 14.25 & 15.25 \\
\hline
\end{tabular}

Project proposal № BG14MFOP001-3.003-0001 "Collection, management and use of data for the purposes of scientific analysis and implementation of the Common Fisheries Policy for the period 2017-2019", funded by the Maritime Affairs and Fisheries Program, co-financed by the European Union through the European Maritime 


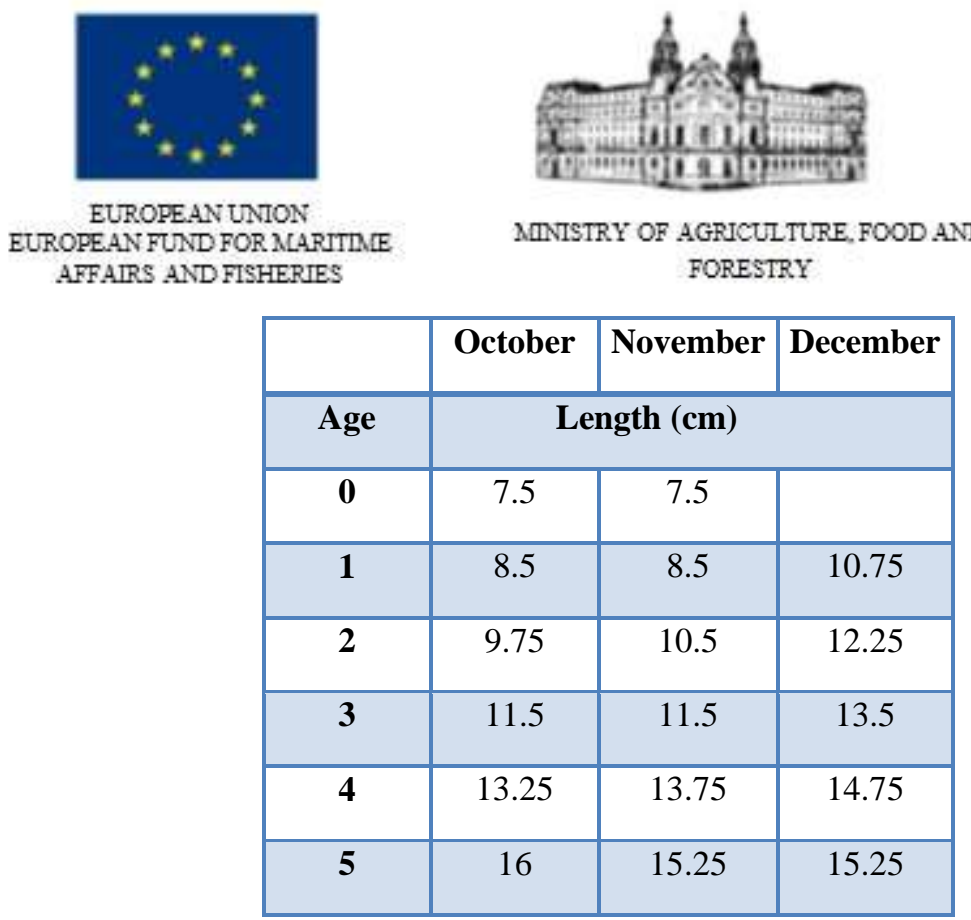

Tables 3.6.1 and 3.6.2 show that in 2019 there was a tendency for a slight decrease in the average lengths by age groups except for ages 5-5+ (which, however, was not reported in the catches for all months during the study period). As weight and length are parameters characterized by a great variability, that observation cannot be considered as a solid base for general conclusions about the stock.

\section{IV.3.7 LWR of red mullet in the period 2018-2019}

\section{IV.3.7.1 LWR in 2018}

LWR model of red mullet in 2018 is described with high coefficient of determination with the following nonlinear equation: $\mathrm{W}=0.0273 * \mathrm{~L}^{2.5675}$

Red mullet growth was alometric negative $(b=2.5675)$.

\section{IV.3.7.1 LWR in 2019}

LWR model of red mullet in 2019 is described with high coefficient of determination with the following nonlinear equation: $\mathrm{W}=0.0222 * \mathrm{~L}^{2.6907}$

Red mullet growth was alometric negative $(b=2.5675)$.

Von Bertalanffy growth parameters were calculated as follows: $\mathrm{L}_{\text {asimpt }}=36.672, \mathrm{~K}=0.0651, \mathrm{t}_{0}=-$ 3.3509 .

\section{IV.3.8 Sex structure of red mulled in the period 2017-2019}

\section{IV.3.8.1 Red mullet sex ration in 2017}

The female specimens $(+)$ were presented with $64 \%$, the male specimens $(\circlearrowleft)$ - with $(36 \%)$.

Project proposal № BG14MFOP001-3.003-0001 "Collection, management and use of data for the purposes of scientific analysis and implementation of the Common Fisheries Policy for the period 2017-2019", funded by the Maritime Affairs and Fisheries Program, co-financed by the European Union through the European Maritime and Fisheries Fund 


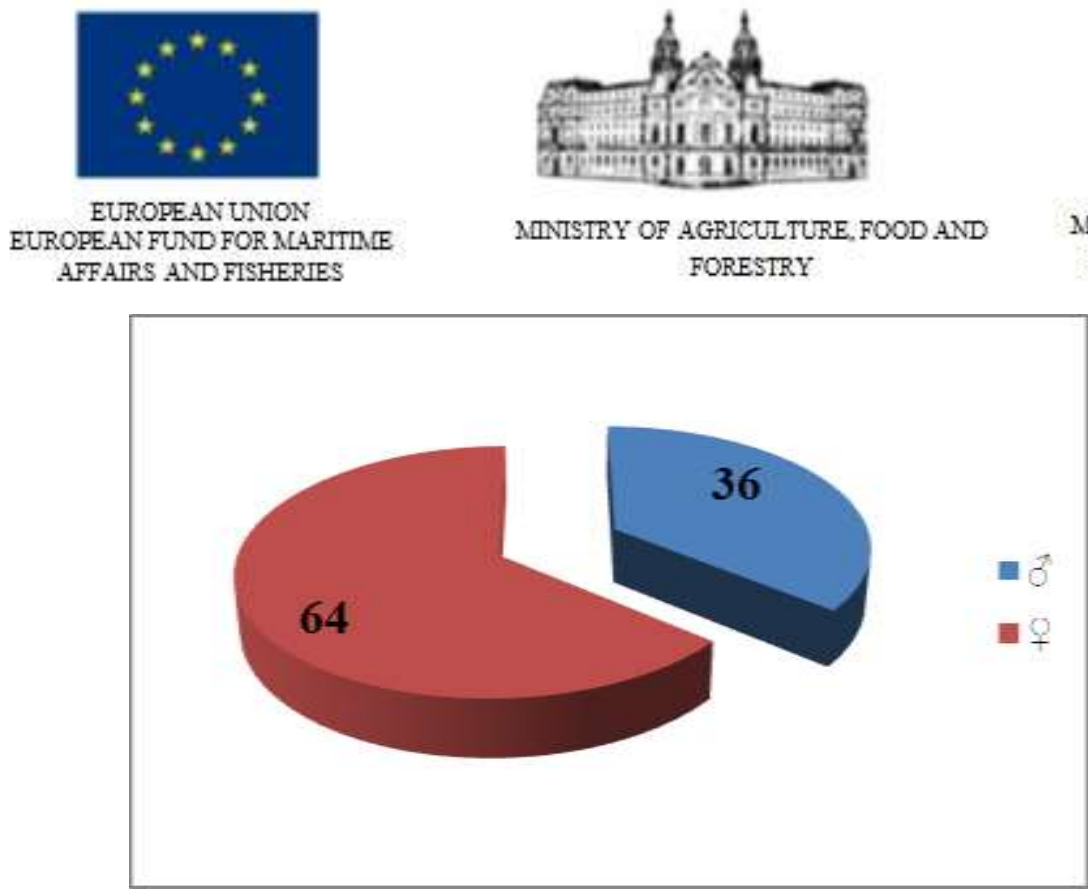

Fig. 3.8.1.1 Red mullet sex structure in 2017

\section{IV.3.8.2 Red mullet sex structure in 2018}

The female specimens ( $(+)$ were presented with $52 \%$, the male specimens $(\circlearrowleft)$ - with $48 \%$.

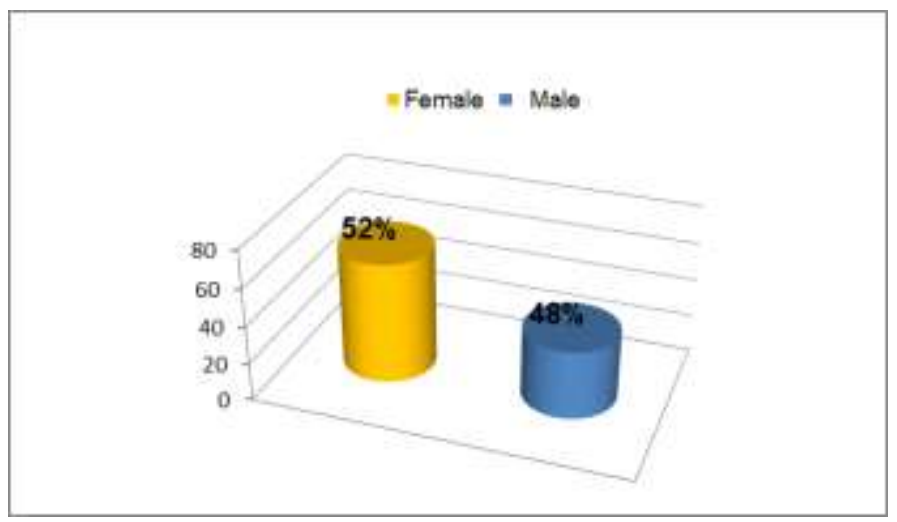

Fig. 3.8.2.1 Red mullet sex structure in 2018

\section{IV.3.8.3 Red mullet sex structure in 2019}

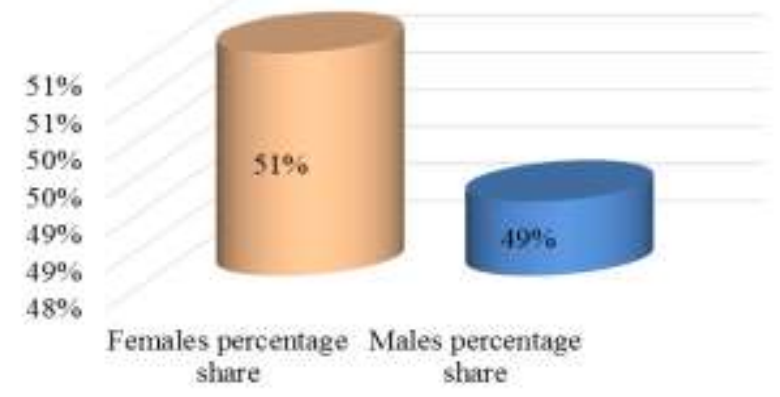

Fig. 3.8.3.1 Red mullet sex structure in 2019

Project proposal № BG14MFOP001-3.003-0001 "Collection, management and use of data for the purposes of scientific analysis and implementation of the Common Fisheries Policy for the period 2017-2019", funded by the Maritime Affairs and Fisheries Program, co-financed by the European Union through the European Maritime and Fisheries Fund 


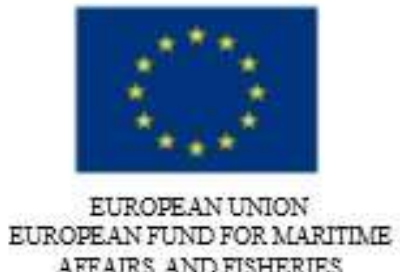
AFFAIRS AND FISHERIES

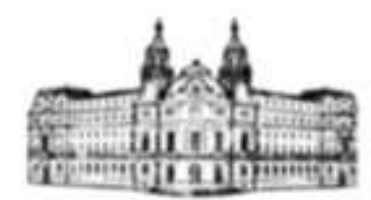

AINISTRY OF AGRICULTURE, FOOD AND FORESTRY

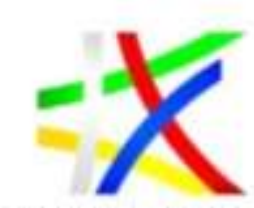

MLARITLE AFFAIRS AND FISHERIES PROGRAM

\section{IV.3.9 Fecundity}

100 specimens were studied for batch fecundity of red mullet. The degree of reproduction during the research period indicated a good level of determinicity $\left(\mathrm{r}^{2}=0.5\right)$ which was directly dependent on the active propagation period of the species.

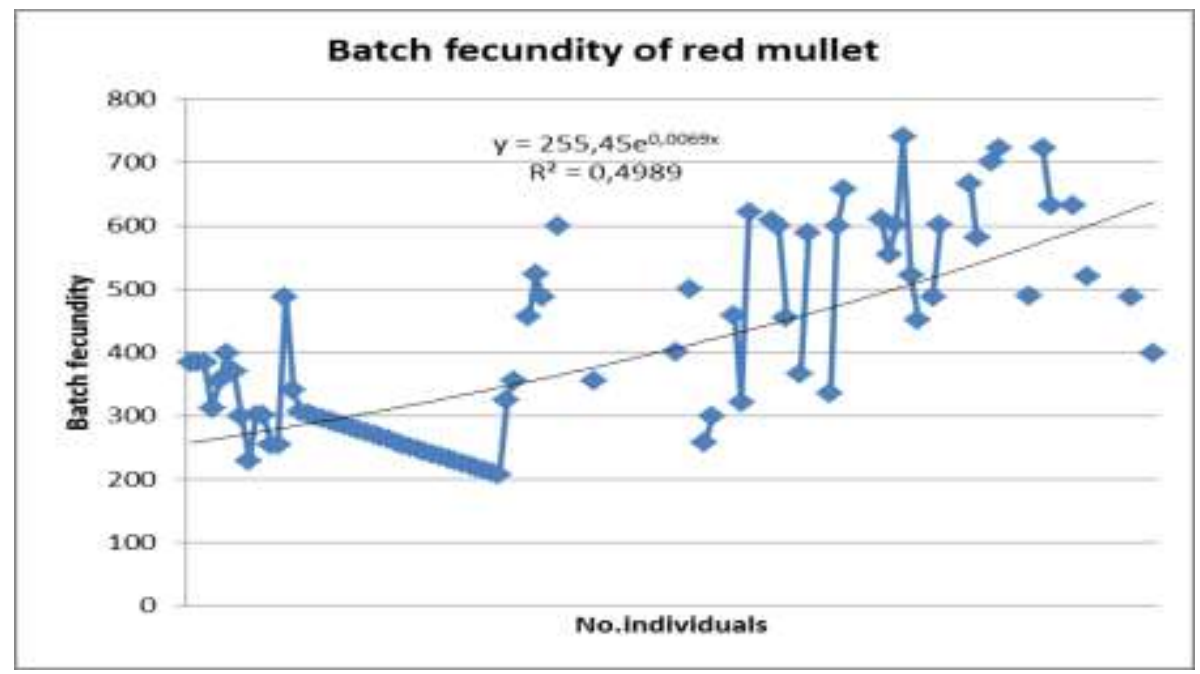

Fig. 3.9.1 Dependence of the fertility on the weight of the measured specimens

The gonadosomatic index for red mullet varied widely with no pronounced correlation between the index and the individual weight of the measured specimens (Fig. 3.9.2).

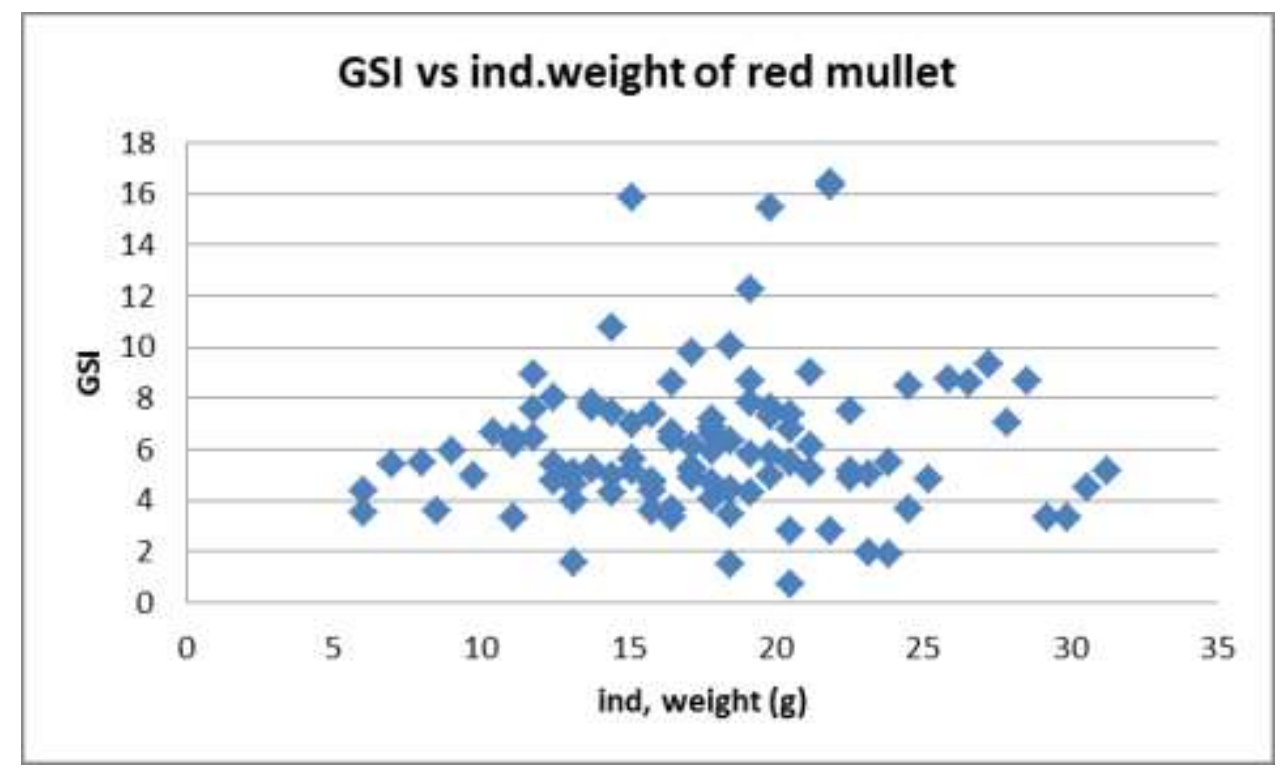

Fig. 3.9.2.Dependence of the gland weight on the GSI

Project proposal № BG14MFOP001-3.003-0001 "Collection, management and use of data for the purposes of scientific analysis and implementation of the Common Fisheries Policy for the period 2017-2019", funded by the Maritime Affairs and Fisheries Program, co-financed by the European Union through the European Maritime and Fisheries Fund 


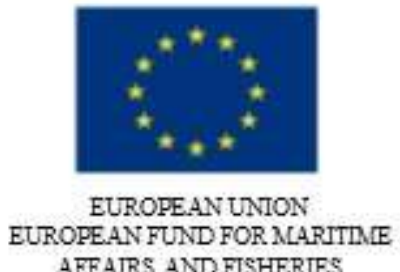

AFFAIRS AND FISHERIES

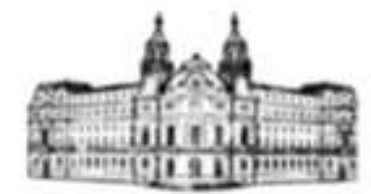

AINISTRY OF AGRICULTURE, FOOD AND FORESTRY

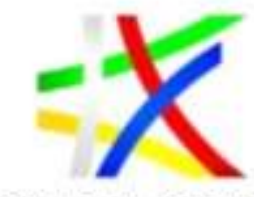

MLARITLE AFFAIRS AND FISHERIES PROGRAM

\section{IV.3.10 Sexual maturity}

250 specimens were examined for maturity determination. Red mullet is a summer breeding species. The beginning of the active breeding of the species was registered in March-April. In June were observed mass mature sex products in over $40 \%$ of the female spesimens.

The October-December period of 2019 was beyond the active breeding season of the species. Sexually immature individuals $(12.5 \%)$ were presented with a relatively high percentage. Individuals with glandular maturity $2 \mathrm{~b}-4 \mathrm{~b}$ (GFCM macroscopic maturity scale for bony fish) predominated.

The active breeding season for the red mullet passed in October-December, 2019. Due to that fact, determination of GSI and fertility could not be performed during the period of research.

\section{IV.3.11 Catch-in-numbers and biomass by age and length}

\section{IV.3.11.1 Catch-in-numbers and biomass analysis of red mullet by age and length for 2017}

Monthly catches (in tons) together with mean weights of red mullet were used to derive the monthly catch numbers. The shares $(\%)$ by age groups and catch numbers were used to create a catch-at-age matrix for selected months by age groups.

Table 3.11.1.1 Catch-at-age $\left(10^{-6}\right)$ matrix and biomass $(\mathrm{kg})$ of red mullet for selected months

\begin{tabular}{|c|c|c|}
\hline \multicolumn{3}{|c|}{ Catch-at-age $\left(10^{-6}\right)$} \\
\hline Age groups & October & November \\
\hline 0 & 1085.969 & 189.133 \\
\hline 1 & 3078.485 & 378.266 \\
\hline 2 & 1909.889 & 827.457 \\
\hline 3 & 642.138 & 378.266 \\
\hline 4 & 68.463 & 189.133 \\
\hline 5 & 6784.944 & \\
\hline$\sum$ & 13569.888 & 1962.255 \\
\hline \multicolumn{3}{|c|}{ Biomass (kg) } \\
\hline Age groups & October & November \\
\hline 0 & 10302361.884 & 2267305.875 \\
\hline 1 & 41593217.618 & 5299927.323 \\
\hline 2 & 36044588.569 & 14074190.54 \\
\hline 3 & 12702249.633 & 7974817.015 \\
\hline 4 & 2158421.913 & 5628665.336 \\
\hline 5 & 102800839.616 & \\
\hline$\sum$ & 102.801 & 35244906.091 \\
\hline
\end{tabular}

Project proposal № BG14MFOP001-3.003-0001 "Collection, management and use of data for the purposes of scientific analysis and implementation of the Common Fisheries Policy for the period 2017-2019", funded by the Maritime Affairs and Fisheries Program, co-financed by the European Union through the European Maritime 


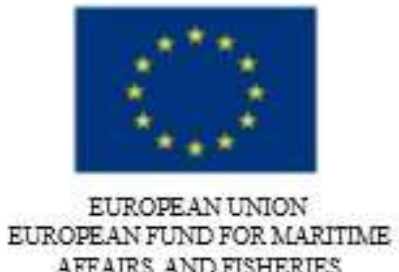
A FEANS AND FOR MLARIT

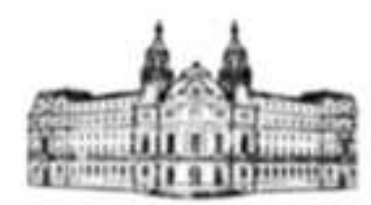

AINISTRY OF AGRICULTURE, FOOD AND FORESTRY
MCARITLIE AFFAIRS AND FISHERIES PROGRAM

Monthly catches (in tons) together with mean weights of red mullet were used to derive the monthly catch numbers. The shares $(\%)$ by length groups and catch numbers were used to create a catch-at-length matrix for selected months by age groups .

Table 3.11.1.1 Catch-at-length $\left(10^{-6}\right)$ matrix and biomass $(\mathrm{kg})$ of red mullet for selected months

\begin{tabular}{|c|c|c|}
\hline \multicolumn{3}{|c|}{ Catch-at-length (millions) } \\
\hline Length group $(\mathbf{c m}))$ & November & December \\
\hline 7.0 & 0.043 & \\
\hline 7.5 & 0.515 & \\
\hline 8.0 & 0.430 & \\
\hline 8.5 & 10.396 & \\
\hline 9.0 & 2.535 & 0.421 \\
\hline 9.5 & 18.859 & 2.946 \\
\hline 10.0 & 23.627 & 5.470 \\
\hline 10.5 & 15.508 & 20.199 \\
\hline 11.0 & 21.050 & 23.144 \\
\hline 11.5 & 10.052 & 29.877 \\
\hline 12.0 & 7.131 & 15.570 \\
\hline 12.5 & 4.811 & 20.619 \\
\hline 13.0 & 4.554 & 7.574 \\
\hline 13.5 & 3.093 & 4.208 \\
\hline 14.0 & 0.387 & 3.366 \\
\hline 14.5 & 0.258 & 0.421 \\
\hline 15.0 & 0.129 & 0.421 \\
\hline 15.5 & 0.086 & 0.421 \\
\hline$\sum$ & 123.419 & 134.657 \\
\hline \multicolumn{3}{|c|}{ Biomass (kg) } \\
\hline Length group (cm) & November & December \\
\hline 7.0 & 0.001 & \\
\hline 7.5 & 0.021 & \\
\hline 8.0 & 0.018 & \\
\hline 8.5 & 0.581 & \\
\hline 9.0 & 0.188 & 0.033 \\
\hline 9.5 & 1.421 & 0.331 \\
\hline 10.0 & 2.429 & 0.700 \\
\hline 10.5 & 1.847 & 2.869 \\
\hline 11.0 & 2.861 & 3.513 \\
\hline
\end{tabular}

Project proposal № BG14MFOP001-3.003-0001 "Collection, management and use of data for the purposes of scientific analysis and implementation of the Common Fisheries Policy for the period 2017-2019", funded by the Maritime Affairs and Fisheries Program, co-financed by the European Union through the European Maritime 


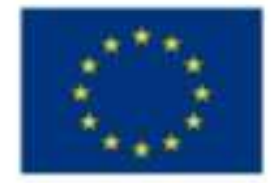

EUROPEAN UNTON EUROPEAN FUND FOR MLARITIIE AFFAIRS AND FISHERIES

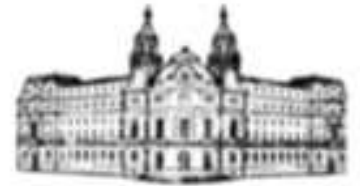

AINISTRY OF AGRICUITURE, FOOD AND FORESTRY
MLARITLE AFFAIRS ANT FISHERIES PROGRAM

\begin{tabular}{|c|c|c|}
\hline $\mathbf{1 1 . 5}$ & 1.680 & 5.394 \\
\hline $\mathbf{1 2 . 0}$ & 1.303 & 3.154 \\
\hline $\mathbf{1 2 . 5}$ & 1.062 & 4.854 \\
\hline $\mathbf{1 3 . 0}$ & 1.130 & 1.994 \\
\hline $\mathbf{1 3 . 5}$ & 0.894 & 1.182 \\
\hline $\mathbf{1 4 . 0}$ & 0.117 & 1.068 \\
\hline $\mathbf{1 4 . 5}$ & 0.086 & 0.151 \\
\hline $\mathbf{1 5 . 0}$ & 0.046 & 0.170 \\
\hline $\mathbf{1 5 . 5}$ & 0.049 & 0.195 \\
\hline$\Sigma$ & 15.734 & 25.610 \\
\hline
\end{tabular}

IV.3.11.2 Catch-in-numbers and biomass analysis of red mullet by age and length for 2018

Monthly catches (in tons) together with mean weights of red mullet were used to derive the monthly catch numbers. The shares $(\%)$ by age groups and catch numbers were used to create a catch-at-age matrix for selected months by age groups (Table 3.11.2.1).

Table 3.11.2.1 Catch-at-age $\left(10^{-6}\right)$ matrix and biomass $(\mathrm{kg})$ of red mullet for selected months

\begin{tabular}{|c|c|c|c|c|}
\hline \multicolumn{5}{|c|}{ Catch-at-age $\quad\left(10^{-6}\right)$} \\
\hline Age groups & September & October & November & December \\
\hline $\mathbf{0}$ & 1.290806 & 0.237491 & 1.40761 & \\
\hline 1 & 2.698959 & 0.768722 & 2.252176 & 0.021824 \\
\hline 2 & 3.403035 & 1.687439 & 1.069784 & 0.512874 \\
\hline 3 & 2.698959 & 2.812399 & 0.731957 & 0.349191 \\
\hline 4 & 1.408152 & 1.881182 & 0.168913 & 0.081842 \\
\hline 5 & & 0.068748 & & \\
\hline \multicolumn{5}{|c|}{ Biomass (kg) } \\
\hline Age groups & September & October & November & December \\
\hline $\mathbf{0}$ & 9222.46 & 1710.941 & 20020.23 & \\
\hline 1 & 34452.32 & 10233.16 & 36002.64 & 339.4325 \\
\hline 2 & 56176.22 & 27051.97 & 19984 & 9880.062 \\
\hline 3 & 55970.46 & 65018.74 & 20122.18 & 7162.121 \\
\hline \multirow[t]{2}{*}{4} & 44668.94 & 56950.04 & 5026.916 & 2571.385 \\
\hline & & 2731.152 & & \\
\hline$\sum$ & 200490.4 & 163696 & 101156 & 19953 \\
\hline
\end{tabular}

Project proposal № BG14MFOP001-3.003-0001 "Collection, management and use of data for the purposes of scientific analysis and implementation of the Common Fisheries Policy for the period 2017-2019", funded by the Maritime Affairs and Fisheries Program, co-financed by the European Union through the European Maritime and Fisheries Fund 


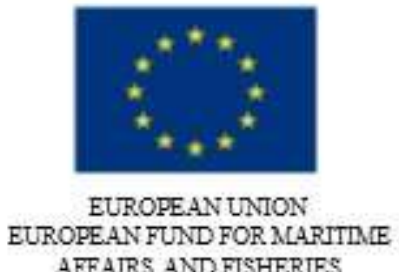

AFFAIRS AND FISHERIES

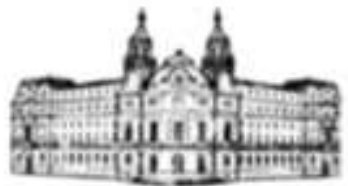

AINISTRY OF AGRCULTURE, FOOD AND FORESTRY
MLARITLIE AFFAIRS AND FISHERIES PROGRAM

Monthly catches (in tons) together with mean weights of red mullet were used to derive the monthly catch numbers. The shares $(\%)$ by length groups and catch numbers were used to create catch-at-length matrix for selected months by age groups.

Table 3.11.2.1 Catch-at-length $\left(10^{-6}\right)$ matrix and biomass $(\mathrm{kg})$ of red mullet for selected months

\begin{tabular}{|c|c|c|c|c|}
\hline \multicolumn{5}{|c|}{ Catch-at-length (millions) } \\
\hline $\begin{array}{c}\text { Length group } \\
(\mathrm{cm})\end{array}$ & September & October & November & December \\
\hline 7.0 & 2.96364061 & 26.8288727 & & \\
\hline 7.5 & 0.9878802 & 6.70721818 & & \\
\hline \multicolumn{5}{|l|}{8.0} \\
\hline \multicolumn{5}{|l|}{8.5} \\
\hline 9.0 & 1.97576041 & 154.266018 & & \\
\hline 9.5 & 1.97576041 & 234.752636 & & \\
\hline 10.0 & 9.87880203 & 570.113545 & 2.84196661 & \\
\hline 10.5 & 7.90304162 & 221.3382 & 3.78928881 & 1.763956599 \\
\hline 11.0 & 11.8545624 & 1039.61882 & 13.2625108 & 3.527913199 \\
\hline 11.5 & 14.818203 & 945.717764 & 11.3678664 & 10.5837396 \\
\hline 12.0 & 12.8424426 & 1079.86213 & 13.2625108 & 31.75121879 \\
\hline 12.5 & 8.89092183 & 422.554745 & 13.2625108 & 38.80704519 \\
\hline 13.0 & 8.89092183 & 160.973236 & 10.4205442 & 29.98726219 \\
\hline 13.5 & 4.93940102 & 1784.12004 & 11.3678664 & 21.16747919 \\
\hline 14.0 & 1.97576041 & 697.550691 & 12.3151886 & 7.937804697 \\
\hline 14.5 & 4.93940102 & 382.311436 & 1.8946444 & 6.173848098 \\
\hline 15.0 & 1.97576041 & 114.022709 & 0.9473222 & 1.763956599 \\
\hline 15.5 & & 80.4866182 & & 2.645934899 \\
\hline 16.0 & & 33.5360909 & & \\
\hline 16.5 & & 13.4144364 & & \\
\hline 17.0 & & 20.1216545 & & \\
\hline 17.5 & & 13.4144364 & & \\
\hline \multicolumn{5}{|c|}{ Biomass (kg) } \\
\hline $\begin{array}{l}\text { Length group } \\
(\mathrm{cm})\end{array}$ & September & October & November & December \\
\hline 7.0 & 0.08061102 & 0.6854777 & & \\
\hline 7.5 & 0.04020672 & 0.26895945 & & \\
\hline 8.0 & & & & \\
\hline
\end{tabular}

Project proposal № BG14MFOP001-3.003-0001 "Collection, management and use of data for the purposes of scientific analysis and implementation of the Common Fisheries Policy for the period 2017-2019", funded by the Maritime Affairs and Fisheries Program, co-financed by the European Union through the European Maritime and Fisheries Fund 


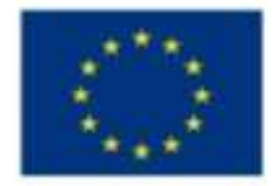

EUROPEAN UNTON EUROPEAN FUND FOR MLARITIIE AFFAIRS AND FISHERIES

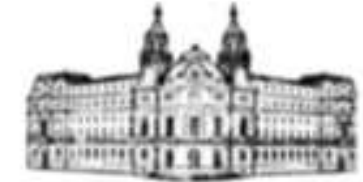

MINISTRY OF AGRICUITURE, FOOD AND FORESTRY
MLARITLIE AFFAIRS ANT FISHERIES PROGRAM

\begin{tabular}{|l|c|c|c|c|}
\hline $\mathbf{8 . 5}$ & & & & \\
\hline $\mathbf{9 . 0}$ & 0.15687538 & 11.2228967 & & \\
\hline $\mathbf{9 . 5}$ & 0.16793963 & 21.6453014 & & \\
\hline $\mathbf{1 0 . 0}$ & 1.06256395 & 64.4843582 & 0.26525022 & \\
\hline $\mathbf{1 0 . 5}$ & 0.94599408 & 32.4128333 & 0.45471466 & 0.28592854 \\
\hline $\mathbf{1 1 . 0}$ & 1.6714933 & 169.929798 & 1.92306407 & 0.52552677 \\
\hline $\mathbf{1 1 . 5}$ & 2.30314391 & 160.074604 & 1.70517996 & 1.51700268 \\
\hline $\mathbf{1 2 . 0}$ & 2.2916845 & 202.396999 & 2.31146617 & 5.45062589 \\
\hline $\mathbf{1 2 . 5}$ & 1.86966207 & 94.273351 & 2.76618083 & 7.3116001 \\
\hline $\mathbf{1 3 . 0}$ & 1.98475012 & 40.1331636 & 2.78512727 & 6.47372072 \\
\hline $\mathbf{1 3 . 5}$ & 1.3573474 & 526.764083 & 3.08827038 & 5.03609609 \\
\hline $\mathbf{1 4 . 0}$ & 0.56309172 & 214.78374 & 3.76086914 & 2.14320727 \\
\hline $\mathbf{1 4 . 5}$ & 1.60105745 & 120.539677 & 0.65365232 & 1.90507313 \\
\hline $\mathbf{1 5 . 0}$ & 0.78190718 & 39.0072023 & 0.35998244 & 0.65266394 \\
\hline $\mathbf{1 5 . 5}$ & & 26.4271104 & & 0.95253656 \\
\hline $\mathbf{1 6 . 0}$ & & 12.0729927 & & \\
\hline $\mathbf{1 6 . 5}$ & & 5.36577455 & & \\
\hline $\mathbf{1 7 . 0}$ & & 8.18280618 & & \\
\hline $\mathbf{1 7 . 5}$ & & 6.10356855 & & \\
\hline & & & & \\
\hline & & & \\
\hline
\end{tabular}

\section{IV.3.11.3 Catch-in-numbers and biomass analysis of red mullet by age and}

length for 2019

Monthly catches (in tons) together with mean weights of red mullet were used to derive the monthly catch numbers. The shares $(\%)$ by age groups and catch numbers were used to create catch-at-age matrix for selected months by age groups.

Table 3.11.3.1 Catch-at -age $\left(10^{-6}\right)$ matrix and biomass $(\mathrm{kg})$ of red mullet for selected months

\begin{tabular}{|c|c|c|c|c|c|c|c|}
\hline \multirow{2}{*}{ Age groups } & \multicolumn{7}{|c|}{ Catch-at-Age *10 $\mathbf{- 1}^{-3}$ (in thousands) } \\
\cline { 2 - 8 } & February & March & May & June & July & August & September \\
\hline $\mathbf{0}$ & 0.007267 & 0.056902 & 0.005932 & 0.003856 & 6.212633 & 2.104962 & 14.53112 \\
\hline $\mathbf{1}$ & 0.390259 & 3.055966 & 0.318579 & 0.207076 & 333.6515 & 113.0477 & 780.3984 \\
\hline $\mathbf{2}$ & 0.303669 & 2.377917 & 0.247893 & 0.161131 & 259.6219 & 87.96497 & 607.2459 \\
\hline $\mathbf{3}$ & 1.7482 & 13.68948 & 1.427102 & 0.927616 & 1494.622 & 506.4072 & 3495.865 \\
\hline $\mathbf{4}$ & 0.754027 & 5.904492 & 0.615532 & 0.400096 & 644.6545 & 218.4216 & 1507.823 \\
\hline $\mathbf{5}$ & 0.046654 & 0.365332 & 0.038085 & 0.024755 & 39.88711 & 13.51453 & 93.29446 \\
\hline & & & \multicolumn{7}{|c|}{ Biomass (kg) } & & \\
\hline Age groups & February & March & May & June & July & August & September \\
\hline $\mathbf{0}$ & $2.04 \mathrm{E}-05$ & 0.00016 & $1.67 \mathrm{E}-05$ & $1.08 \mathrm{E}-05$ & 0.017457 & 0.005915 & 0.040832 \\
\hline $\mathbf{1}$ & 0.002556 & 0.020017 & 0.002087 & 0.001356 & 2.185417 & 0.740462 & 5.111609 \\
\hline
\end{tabular}

Project proposal № BG14MFOP001-3.003-0001 "Collection, management and use of data for the purposes of scientific analysis and implementation of the Common Fisheries Policy for the period 2017-2019", funded by the Maritime Affairs and Fisheries Program, co-financed by the European Union through the European Maritime and Fisheries Fund 


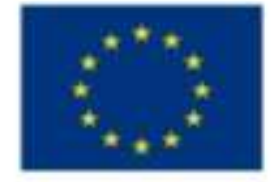

EUROPEAN UNTON EUROPEAN FUND FOR MLARTIDIE AFFAIRS AND FISHERIES

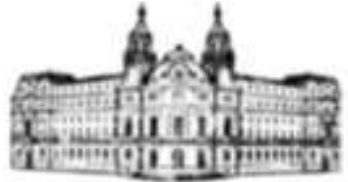

AINISTRY OF AGRCULTURE, FOOD AND FORESTRY
MLARITLIE AFFAIRS AND FISHERIES PROGRAM

\begin{tabular}{|c|c|c|c|c|c|c|c|}
\hline $\mathbf{2}$ & 0.002721 & 0.021306 & 0.002221 & 0.001444 & 2.326212 & 0.788166 & 5.440923 \\
\hline $\mathbf{3}$ & 0.024202 & 0.189517 & 0.019757 & 0.012842 & 20.6915 & 7.010686 & 48.39665 \\
\hline $\mathbf{4}$ & 0.018097 & 0.141708 & 0.014773 & 0.009602 & 15.47171 & 5.242118 & 36.18775 \\
\hline $\mathbf{5}$ & 0.001404 & 0.010993 & 0.001146 & 0.000745 & 1.200203 & 0.406652 & 2.80723 \\
\hline
\end{tabular}

Monthly catches (in tons) together with mean weights of red mullet were used to derive the monthly catch numbers. The share $(\%)$ by length groups and catch numbers were used to create catch-at-length matrix for selected months by age groups.

Table 3.11.3.2 Catch-at-length $\left(10^{-6}\right)$ matrix and biomass $(\mathrm{kg})$ of red mullet for selected months

\begin{tabular}{|c|c|c|c|c|c|c|c|}
\hline \multirow{2}{*}{$\begin{array}{l}\text { Length } \\
\text { groups } \\
(\mathrm{cm})\end{array}$} & \multicolumn{7}{|c|}{ Catch-at-length $* 10^{-3}$ (in thousands) } \\
\hline & February & March & May & June & July & August & September \\
\hline 7 & 0.005616416 & 0.043979979 & 0.00458483 & 0.002980139 & 4.801749418 & 1.626926807 & 11.23111337 \\
\hline 7.5 & 0.001254226 & 0.009821355 & 0.001023858 & 0.000665507 & 1.072298942 & 0.363315896 & 2.508067359 \\
\hline 9 & 0.113130363 & 0.885880003 & 0.092351316 & 0.060028356 & 96.72068812 & 32.77086465 & 226.2260936 \\
\hline 9.5 & 0.240107784 & 1.880190955 & 0.196006354 & 0.12740413 & 205.2799051 & 69.55285489 & 480.1420661 \\
\hline 10 & 0.295851218 & 2.31669617 & 0.241511198 & 0.156982279 & 252.9376969 & 85.70024873 & 591.6118692 \\
\hline 10.5 & 0.333002888 & 2.607616495 & 0.271839093 & 0.17669541 & 284.7004796 & 96.46210198 & 665.903837 \\
\hline 11 & 0.69636906 & 5.452996089 & 0.568464539 & 0.36950195 & 595.3600174 & 201.7196416 & 1392.524946 \\
\hline 11.5 & 0.345898043 & 2.708593447 & 0.282365749 & 0.183537737 & 295.7251785 & 100.197486 & 691.6901979 \\
\hline 12 & 0.335099903 & 2.624037405 & 0.273550941 & 0.177808112 & 286.4933203 & 97.06955154 & 670.0972247 \\
\hline 12.5 & 0.29265404 & 2.291660312 & 0.238901257 & 0.155285817 & 250.2042732 & 84.77411122 & 585.2184929 \\
\hline 13 & 0.336753251 & 2.636984134 & 0.274900613 & 0.178685399 & 287.9068487 & 97.54848267 & 673.4034152 \\
\hline 13.5 & 0.143829577 & 1.126273648 & 0.1174119 & 0.076317735 & 122.9669503 & 41.66361263 & 287.6151249 \\
\hline 14 & 0.059691519 & 0.467421142 & 0.048727771 & 0.031673051 & 51.03320357 & 17.29104951 & 119.3647658 \\
\hline 14.5 & 0.037647169 & 0.294800382 & 0.030732383 & 0.019976049 & 32.18640869 & 10.90538605 & 75.28281329 \\
\hline 15 & 0.010355469 & 0.081089659 & 0.008453444 & 0.005494738 & 8.853397238 & 2.999704491 & 20.70776698 \\
\hline 15.5 & 0.002077393 & 0.016267258 & 0.001695831 & 0.00110229 & 1.77606493 & 0.601765605 & 4.15414984 \\
\hline 16 & 0.000738118 & 0.005779913 & 0.000602545 & 0.000391654 & 0.631052902 & 0.21381309 & 1.476009276 \\
\hline \multirow{3}{*}{$\begin{array}{l}\text { Length } \\
\text { groups } \\
(\mathrm{cm})\end{array}$} & & & & & & & \\
\hline & \multicolumn{7}{|c|}{ Biomass (kg) } \\
\hline & February & March & May & June & July & August & September \\
\hline 7 & $1.53141 \mathrm{E}-05$ & 0.000119919 & $1.25013 \mathrm{E}-05$ & $8.12585 \mathrm{E}-06$ & 0.01309277 & 0.004436087 & 0.030623502 \\
\hline 7.5 & $5.1047 \mathrm{E}-06$ & 3.99729E-05 & $4.1671 \mathrm{E}-06$ & 2.70862E-06 & 0.004364257 & 0.001478696 & 0.010207834 \\
\hline 9 & 0.000789084 & 0.006179013 & 0.00064415 & 0.000418698 & 0.6746268 & 0.228576781 & 1.577927003 \\
\hline 9.5 & 0.001767042 & 0.013837024 & 0.001442484 & 0.000937614 & 1.510731097 & 0.511865303 & 3.533543869 \\
\hline 10 & 0.002673535 & 0.020935414 & 0.002182477 & 0.00141861 & 2.285735801 & 0.774452085 & 5.346251057 \\
\hline 10.5 & 0.003599624 & 0.02818726 & 0.002938469 & 0.001910005 & 3.077494886 & 1.042715579 & 7.198146121 \\
\hline 11 & 0.009593367 & 0.075121936 & 0.00783132 & 0.005090358 & 8.201839253 & 2.778943877 & 19.18379708 \\
\hline
\end{tabular}

Project proposal № BG14MFOP001-3.003-0001 "Collection, management and use of data for the purposes of scientific analysis and implementation of the Common Fisheries Policy for the period 2017-2019", funded by the Maritime Affairs and Fisheries Program, co-financed by the European Union through the European Maritime 


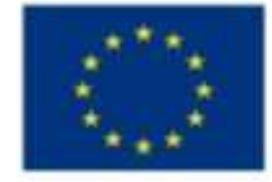

EUROPEAN UNTON EUROPEAN FUND FOR MLARITIIE AFFAIRS AND FISHERIES

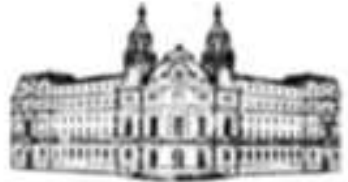

AINISTRY OF AGRICULTURE, FOOD AND FORESTRY
MLARITLIE AFFAIRS AND FISHERIES PROGRAM

\begin{tabular}{|c|c|c|c|c|c|c|c|}
\hline $\mathbf{1 1 . 5}$ & 0.005369785 & 0.042048707 & 0.004383498 & 0.002849274 & 4.590892543 & 1.555484365 & 10.73792698 \\
\hline $\mathbf{1 2}$ & 0.005685766 & 0.044523031 & 0.004641442 & 0.003016937 & 4.861040033 & 1.647015629 & 11.36979191 \\
\hline $\mathbf{1 2 . 5}$ & 0.005290203 & 0.04142553 & 0.004318533 & 0.002807047 & 4.522853782 & 1.532431499 & 10.57878684 \\
\hline $\mathbf{1 3}$ & 0.007416923 & 0.058079045 & 0.006054631 & 0.00393551 & 6.341090405 & 2.148485701 & 14.83157471 \\
\hline $\mathbf{1 3 . 5}$ & 0.00364404 & 0.028535064 & 0.002974727 & 0.001933572 & 3.115468283 & 1.055581711 & 7.286964486 \\
\hline $\mathbf{1 4}$ & 0.00163529 & 0.012805323 & 0.001334931 & 0.000867705 & 1.398089632 & 0.473700167 & 3.27007967 \\
\hline $\mathbf{1 4 . 5}$ & 0.00108531 & 0.008498641 & 0.000885967 & 0.000575879 & 0.927884616 & 0.314385492 & 2.170287619 \\
\hline $\mathbf{1 5}$ & 0.000327517 & 0.002564662 & 0.000267361 & 0.000173785 & 0.280010709 & 0.094873116 & 0.654934639 \\
\hline $\mathbf{1 5 . 5}$ & $7.14658 \mathrm{E}-05$ & 0.000559621 & $5.83394 \mathrm{E}-05$ & $3.79206 \mathrm{E}-05$ & 0.061099594 & 0.02070174 & 0.142909678 \\
\hline $\mathbf{1 6}$ & $3.06282 \mathrm{E}-05$ & 0.000239837 & $2.50026 \mathrm{E}-05$ & $1.62517 \mathrm{E}-05$ & 0.02618554 & 0.008872174 & 0.061247005 \\
\hline
\end{tabular}

Table 3.11.3.3 Catch-at-length $\left(10^{-3}\right)$, catch-at-age $\left(10^{-3}\right)$ and biomass $(\mathrm{kg})$ of the red mullet (October-December, 2019)

\begin{tabular}{|c|c|c|c|c|c|c|}
\hline & \multicolumn{3}{|c|}{ catch-at-length in numbers $* 10-3$} & \multicolumn{3}{|c|}{ Biomass (kg) } \\
\hline Length (cm) & October & November & December & October & November & December \\
\hline 7 & 62.00442 & 58.73555727 & 31.65023796 & 0.232393 & 0.220140875 & 0.118625095 \\
\hline 7.5 & 53.23348 & 50.42702096 & 27.17310072 & 0.232393 & 0.220140875 & 0.118625095 \\
\hline 8 & 232.7179 & 220.4490533 & 118.7911603 & 1.626748 & 1.540986122 & 0.830375665 \\
\hline 8.5 & 218.381 & 206.8679721 & 111.4728599 & 1.626748 & 1.540986122 & 0.830375665 \\
\hline 9 & 490.7018 & 464.8320253 & 250.4793501 & 4.415459 & 4.182676616 & 2.253876806 \\
\hline 9.5 & 483.1639 & 457.6915829 & 246.6316519 & 4.299263 & 4.072606179 & 2.194564259 \\
\hline 10 & 1083.864 & 1026.722633 & 553.2596807 & 11.27104 & 10.67683241 & 5.75331711 \\
\hline 10.5 & 1171.656 & 1109.886023 & 598.0730986 & 14.05975 & 13.31852291 & 7.176818251 \\
\hline 11 & 1129.616 & 1070.062527 & 576.6138127 & 15.5703 & 14.74943859 & 7.947881369 \\
\hline $\mathbf{1 1 . 5}$ & 1022.836 & 968.911989 & 522.1078414 & 16.15128 & 15.29979078 & 8.244444106 \\
\hline 12 & 957.383 & 906.9098807 & 488.69739 & 17.19705 & 16.29042471 & 8.778257034 \\
\hline 12.5 & 636.3233 & 602.7764409 & 324.8120675 & 13.94356 & 13.20845247 & 7.117505703 \\
\hline 13 & 363.8599 & 344.677237 & 185.7327499 & 8.366133 & 7.925071483 & 4.270503422 \\
\hline 13.5 & 156.1741 & 147.9406584 & 79.71929202 & 4.183067 & 3.962535741 & 2.135251711 \\
\hline 14 & 151.6038 & 143.6112519 & 77.38634837 & 3.485889 & 3.302113118 & 1.779376426 \\
\hline 14.5 & 88.78684 & 84.10600874 & 45.32135753 & 2.556318 & 2.42154962 & 1.304876046 \\
\hline 15 & 34.18789 & 32.38551154 & 17.45125431 & 1.161963 & 1.100704373 & 0.593125475 \\
\hline 15.5 & 26.58616 & 25.18454138 & 13.57094007 & 1.045767 & 0.990633935 & 0.533812928 \\
\hline 16 & 10.38626 & 9.838698303 & 5.301680226 & 0.464785 & 0.440281749 & 0.23725019 \\
\hline 16.5 & 4.921486 & 4.662026144 & 2.512179057 & 0.232393 & 0.220140875 & 0.118625095 \\
\hline \multirow[t]{2}{*}{17} & 2.355537 & 2.231353509 & 1.202386984 & 0.116196 & 0.110070437 & 0.059312548 \\
\hline & \multicolumn{3}{|c|}{ catch-at-age in numbers $* 10-3$} & \multicolumn{3}{|c|}{ Biomass (kg) } \\
\hline Age (years) & October & November & December & October & November & December \\
\hline 0+ & 139.3825 & 132.034226 & 71.14795305 & 0.697178 & 0.660422624 & 0.355875285 \\
\hline
\end{tabular}

Project proposal № BG14MFOP001-3.003-0001 "Collection, management and use of data for the purposes of scientific analysis and implementation of the Common Fisheries Policy for the period 2017-2019", funded by the Maritime Affairs and Fisheries Program, co-financed by the European Union through the European Maritime and Fisheries Fund 

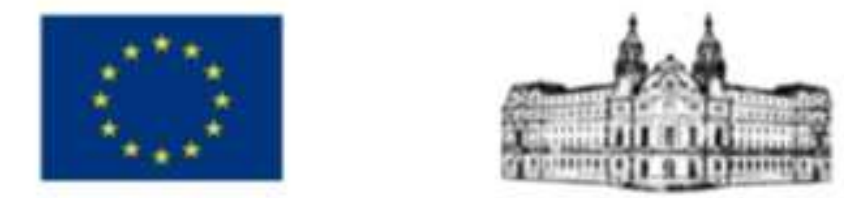

EUROPEAN UNTON EUROPEAN FUND FOR MLARITIE AFFAIRS AND FISHERIES

AINISTRY OF AGRICUITURE, FOOD AND FORESTRY

\begin{tabular}{|l|r|r|r|r|r|r|}
$\mathbf{1}$ & 1799.442 & 1704.575801 & 918.5275878 & 16.38368 & 15.51993165 & 8.363069202 \\
\hline $\mathbf{2}$ & 3357.554 & 3180.543988 & 1713.867694 & 43.806 & 41.49655485 & 22.36083042 \\
\hline $\mathbf{3}$ & 2459.383 & 2329.724398 & 1255.395113 & 44.27079 & 41.9368366 & 22.59808061 \\
\hline $\mathbf{4}$ & 531.4159 & 503.3997282 & 271.2619396 & 13.59497 & 12.87824116 & 6.939568061 \\
\hline $\mathbf{5}$ & 93.56456 & 88.63184724 & 47.76015052 & 3.485889 & 3.302113118 & 1.779376426 \\
\hline
\end{tabular}

\section{IV.3.12 Red mullet coefficient of variations in length}

The dimensionless expressions of CVs showed relatively low magnitude of standard deviation around mean. The variability was within the limits of $0.10-0.22$ and could be estimated as low. This means that the random sampling of red mullet in the months of interest was conducted according to the variation statistics and correctly reflected the general population at this time of the year.

Table 3.12.1 Length coefficient of variation of red mullet samples

\begin{tabular}{|c|c|c|c|c|c|c|c|c|c|c|}
\hline $\begin{array}{c}\text { Coefficient } \\
\text { of } \\
\text { variation } \\
(\mathrm{CV})\end{array}$ & $\begin{array}{c}\text { Februa } \\
\text { ry }\end{array}$ & March & May & June & July & August & $\begin{array}{c}\text { Septemb } \\
\text { er }\end{array}$ & October & $\begin{array}{c}\text { Novembe } \\
\mathbf{r}\end{array}$ & $\begin{array}{c}\text { Decembe } \\
\mathbf{r}\end{array}$ \\
\hline 1st sample & na & na & na & na & $\begin{array}{l}\mathrm{CV}= \\
0.17\end{array}$ & $\begin{array}{c}\mathrm{CV}= \\
0.16\end{array}$ & $\begin{array}{c}\mathrm{CV}= \\
0.15\end{array}$ & $\begin{array}{c}\mathrm{CV}= \\
0.10\end{array}$ & $\begin{array}{c}\mathrm{CV}= \\
0.11\end{array}$ & $\begin{array}{c}\mathrm{CV}= \\
0.13\end{array}$ \\
\hline $\begin{array}{c}\text { 2nd } \\
\text { sample }\end{array}$ & & & & & $\begin{array}{c}\mathrm{CV}= \\
0.18\end{array}$ & $\begin{array}{l}\mathrm{CV}= \\
0.20\end{array}$ & $\begin{array}{l}\mathrm{CV}= \\
0.20\end{array}$ & $\begin{array}{c}\mathrm{CV}= \\
0.14\end{array}$ & $\begin{array}{c}\mathrm{CV}= \\
0.22\end{array}$ & $\begin{array}{c}\mathrm{CV}= \\
0.20\end{array}$ \\
\hline
\end{tabular}

\section{Conclusions and recommendations}

- In the spring season (May-June), the red mullet age structure was characterized by 4-5 age classes. In 2019, one-year-old fish were presented in the age structure in the spring catches (March) with a high participation rate which was associated with its high yield.

- Size and age composition in months and seasons will depend on the seasonal dynamics and the distribution of the stock.

- During the period of study the proportion of male individuals in all age groups was lower than that of females. The breeding rate showed a good degree of determination which was directly dependent on the active breeding season of the species.

- The percentage share of the size group 9-12.5 cm dominated in the catches in OctoberDecember, 2019.

- Recruitment 0+ yr was registered in October, in November it decreased and in December - was completely absent in the catches.

- Red mullet condition was remarkably good during the October-December period with a decline under the situation in December, most noticeable for the $14 \mathrm{~cm}$ size group, corresponding to the age of $4+\mathrm{yr}$.

Project proposal № BG14MFOP001-3.003-0001 "Collection, management and use of data for the purposes of scientific analysis and implementation of the Common Fisheries Policy for the period 2017-2019", funded by the Maritime Affairs and Fisheries Program, co-financed by the European Union through the European Maritime 

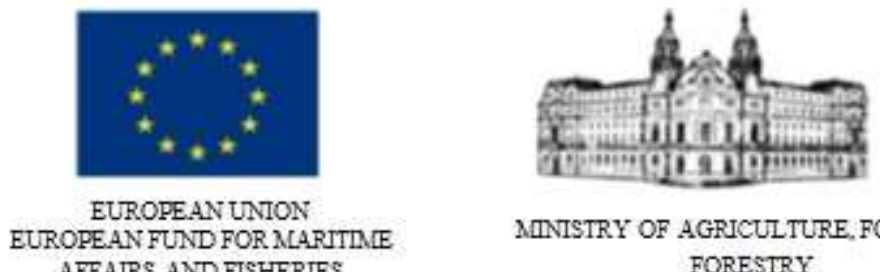

AFFAIRS AND FISHERIES

MINTSTRY OF AGRICUITURE, FOOD AND FORESTRY
MLARITLIE AFFAIRS AND FISHERIES PROGRAM

- According to the growth model, the growth rate was very low at the expense of the maximum theoretical dimensions.

- The active breeding season for the red mullet passed in October-December, 2019. Due to that fact, determination of GSI and batch fecundity could not be performed during the period of study.

- Recommendations: The presence of recruitment in the coming months should be monitored in order to draw conclusions about the reproductive potential of the species.

Project proposal № BG14MFOP001-3.003-0001 "Collection, management and use of data for the purposes of scientific analysis and implementation of the Common Fisheries Policy for the period 2017-2019", funded by the Maritime Affairs and Fisheries Program, co-financed by the European Union through the European Maritime and Fisheries Fund 


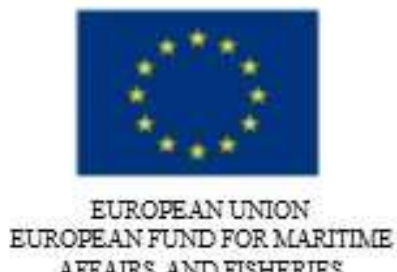

AFFAIRS AND FISHERIES

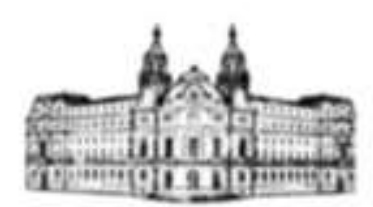

AINTSTRY OF AGRICULTURE, FOOD AND FORESTRY

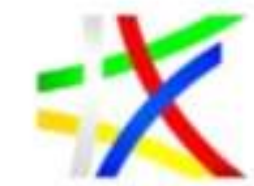

MCARITLE AFFAIRS AND FISHERIES PROGRAM

\section{Biological monitoring of anchovy (Engraulis encrasicolus) \\ V.1 Objectives}

The European anchovy (Engraulis encrasicolus) is a small pelagic coastal marine fish forming large schools. This species is essential for fishing and the economy of the countries bordering the Black Sea. Information on the age of individual fish species significantly enhances the quality of studies on population characteristics such as growth, recruitment, mortality and reproduction. It is often a prerequisite for more detailed studies on life history, strategies and stock assessment. Multiannual biological monitoring on the landings provides the so called "Fishery dependent" information. The aim of this study was to collect and analyze dynamics in length and weight, as well as to determine the condition of anchovy species using the so-called condition factor. The condition factor is also a useful index for monitoring of feeding intensity, age and growth rates in fish. It is strongly influenced by both biotic and abiotic environmental conditions and can be used as an index to assess the status of the aquatic ecosystem in which fish live. The purpose was to define the age of anchovy as one of the important indicators for the assessment of fishing reserves. Biological information on a given species collected each month, analyzed and compared to previous periods could be used for estimation of growth parameters. These indicators are very important for the species. Reliable and informative long-term data are crucial for the assessment of fish stocks, fisheries management and the decision-making process in general.

\section{V.2 Sampling}

\section{V.2.1.1 Geographic area coverage}

Data of the present analysis were collected from landing ports on the Bulgarian Black Sea coast.

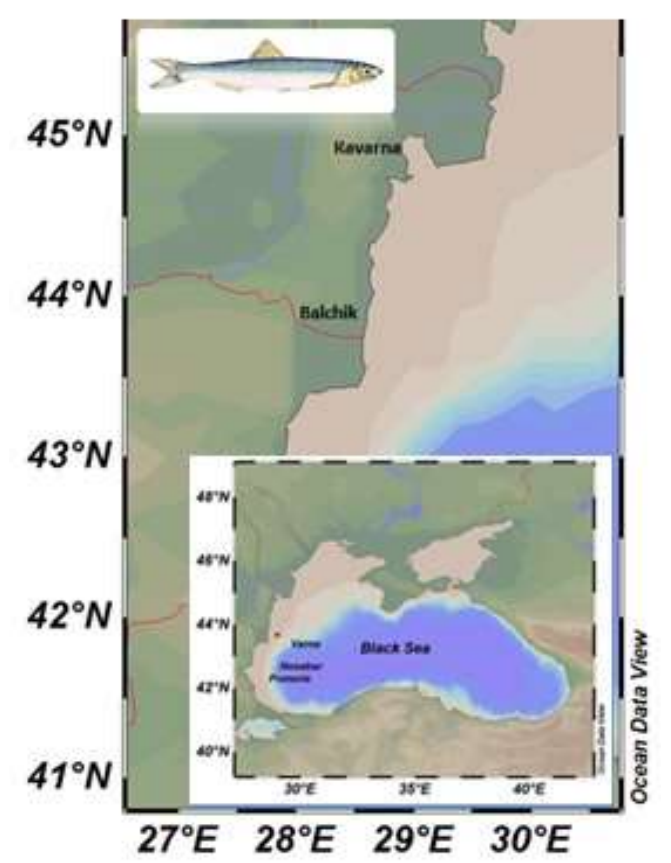

Fig. 2.1.1 Map of ports for sampling of anchovy in the period 2017-2019

Project proposal № BG14MFOP001-3.003-0001 "Collection, management and use of data for the purposes of scientific analysis and implementation of the Common Fisheries Policy for the period 2017-2019", funded by the Maritime Affairs and Fisheries Program, co-financed by the European Union through the European Maritime and Fisheries Fund 


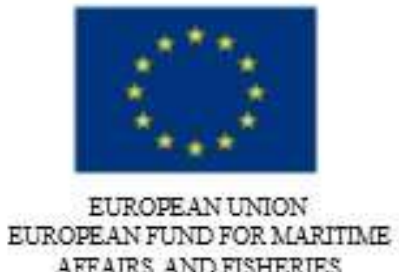

AFFAIRS AND FISHERIES

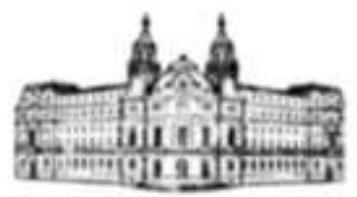

AINISTRY OF AGRICULTURE, FOOD AND FORESTRY
MLARITLE AFFAIRS AND FISHERIES PROGRAM

In 2017, 3 samples with 1525 species were collected.

In 2018, 2 samples with 1550 species were collected.

In 2019, 8 samples with 1643 species were collected.

\section{V.2.1.2 Sampling period}

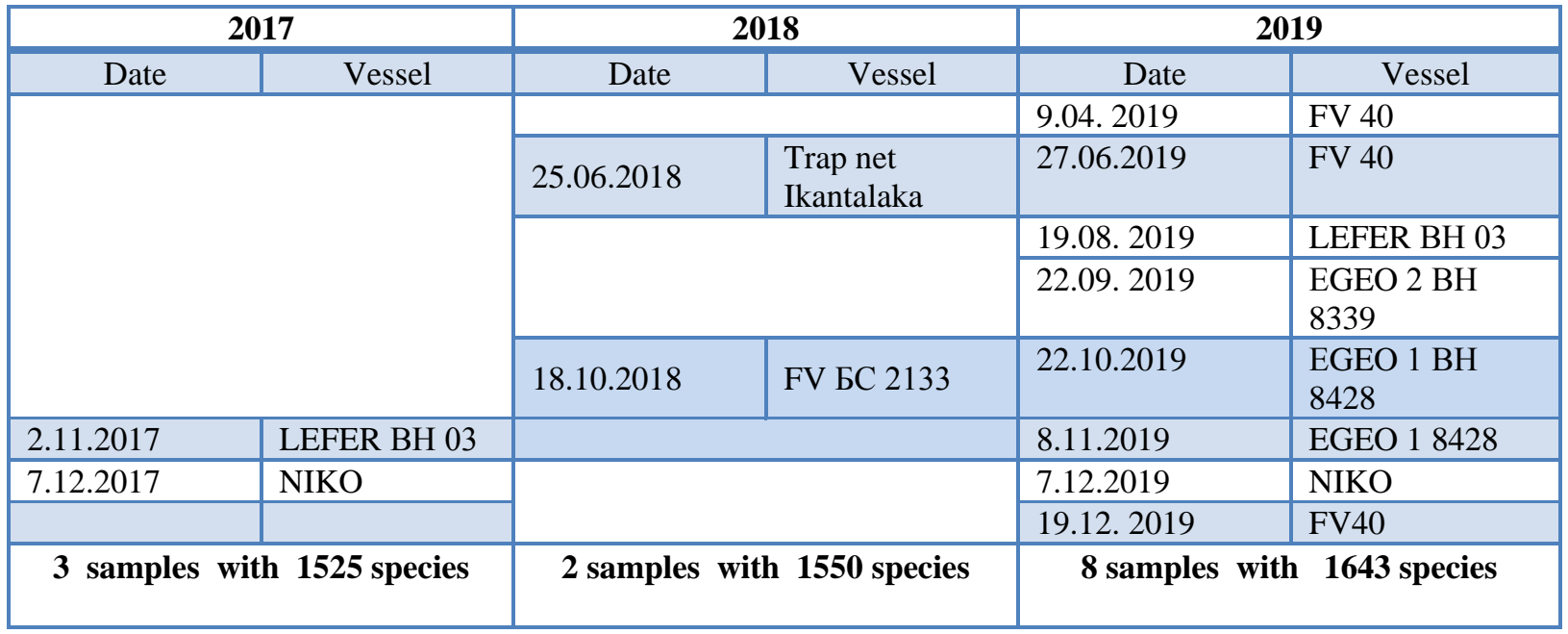

\section{V.2.1.3 Statistical analysis of data}

Refer to the methodology used for sprat stock analysis.

\section{V.3.1 Catch statistics for the period 2017-2019}

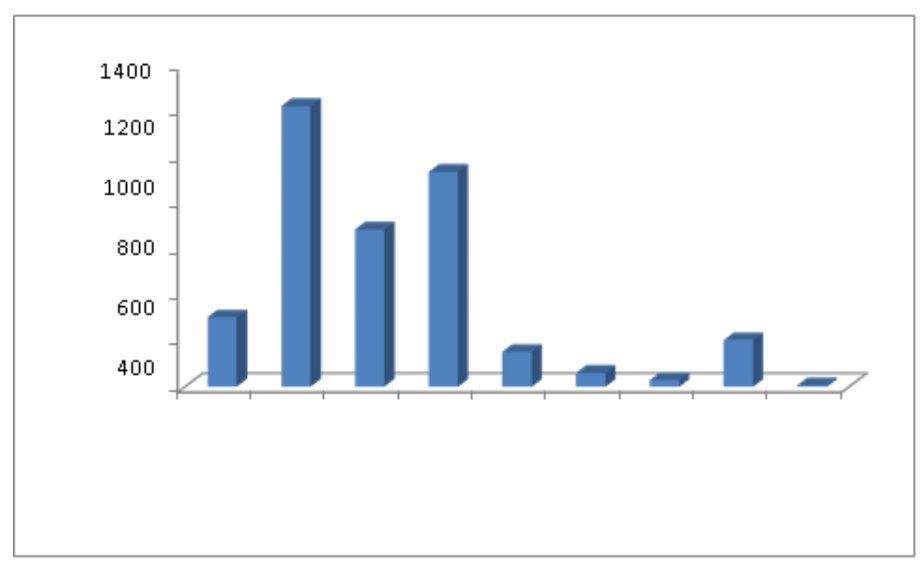

Fig. 3.1.1 Landing statistics for 2017

Project proposal № BG14MFOP001-3.003-0001 "Collection, management and use of data for the purposes of scientific analysis and implementation of the Common Fisheries Policy for the period 2017-2019", funded by the Maritime Affairs and Fisheries Program, co-financed by the European Union through the European Maritime and Fisheries Fund 


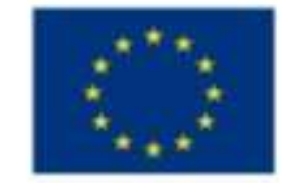

EUROPEAN UNTON EUROPEAN FUND FOR MLARITIIE AFFAIRS AND FISHERIES

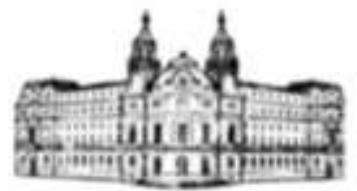

AINTSTRY OF AGRICULTURE, FOOD AND FORESTRY
MLARITLIE AFFAIRS AND FISHERIES PROGRAM

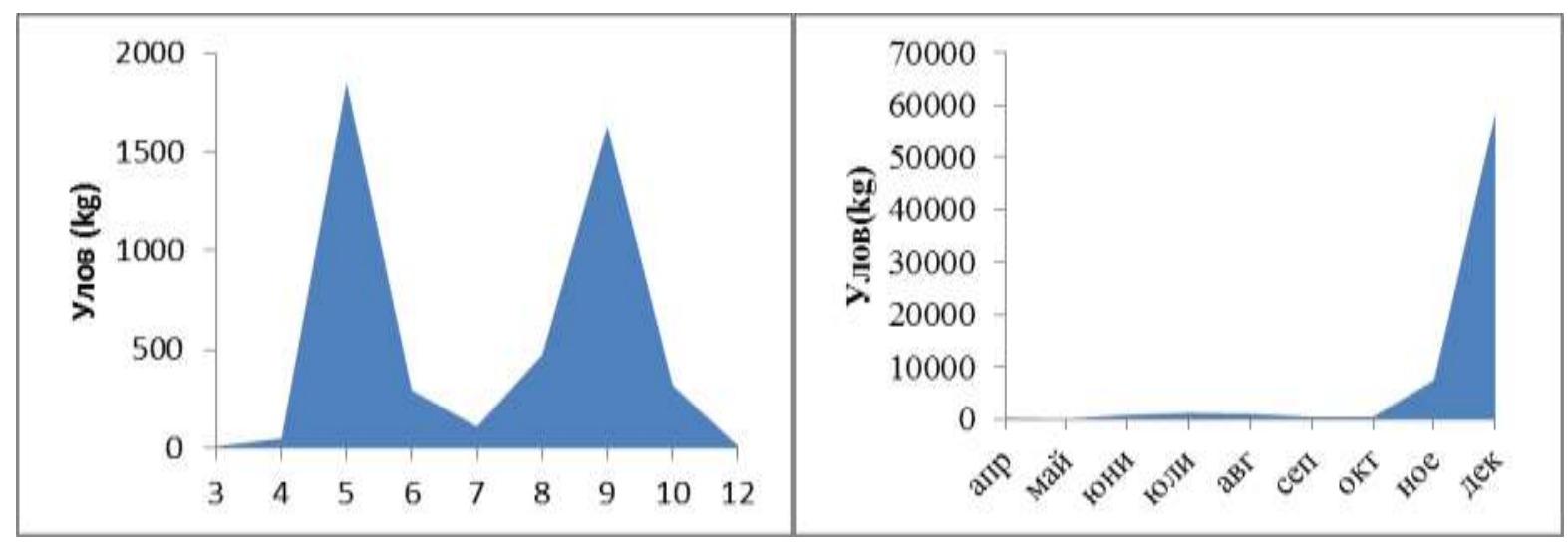

Fig. 3.1.2 Landings statistics for 2018 (left) and 2019 (right)

\section{V.3.2 Size structure in the period 2017-2019}

\section{V.3.2.1 Size structure analysis for 2017}

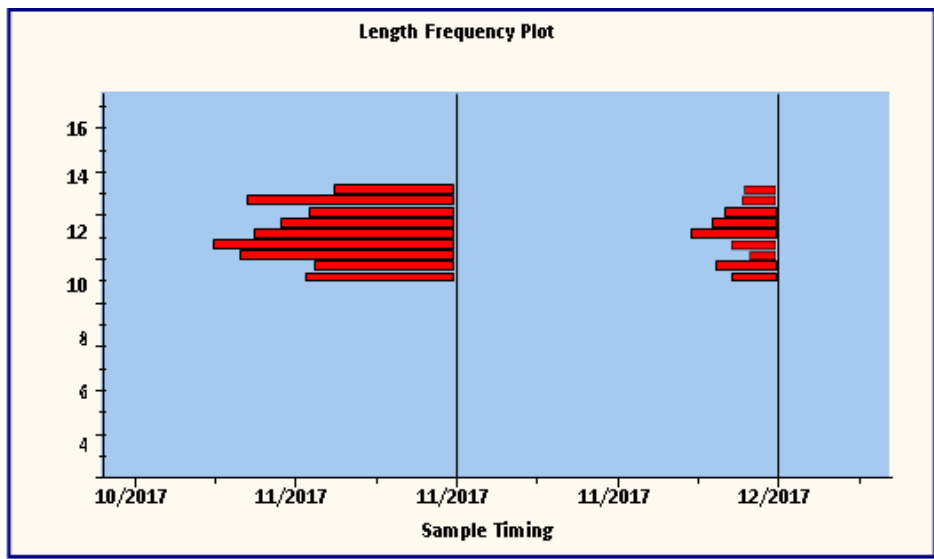

Fig. 3.2.1.1 Frequency of anchovy length from landings in 2017

\section{V.3.2.2 Size structure analysis for 2018}
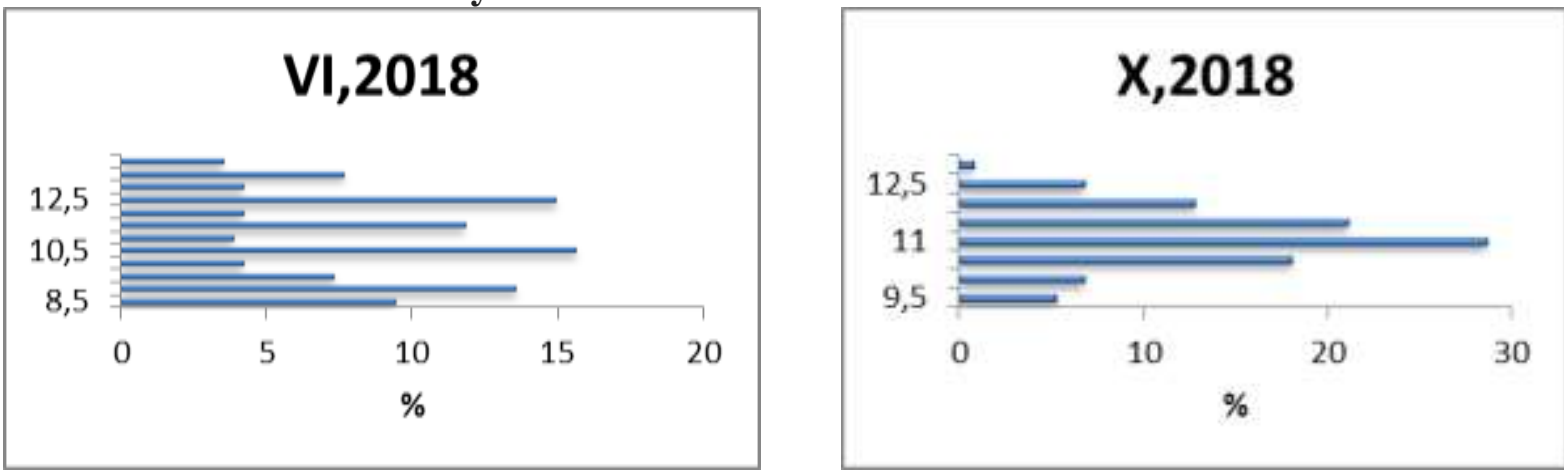

Fig. 3.2.2.1 Frequency of anchovy from landings in 2018

Project proposal № BG14MFOP001-3.003-0001 "Collection, management and use of data for the purposes of scientific analysis and implementation of the Common Fisheries Policy for the period 2017-2019", funded by the Maritime Affairs and Fisheries Program, co-financed by the European Union through the European Maritime and Fisheries Fund 


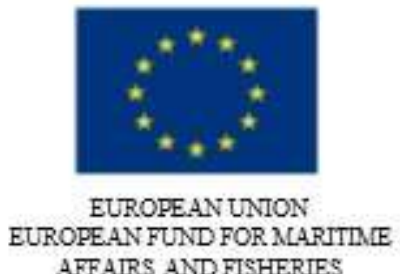

AFFAIRS AND FISHERIES

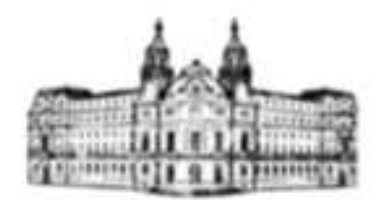

AINISTRY OF AGRICULTURE, FOOD AND FORESTRY

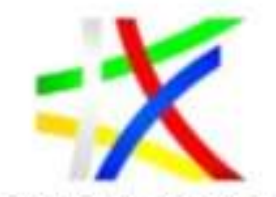

MCARITLE AFFAIRS AND FISHERIES PROGRAM

\section{V.3.2.3 Size structure analysis for 2019}

In the catches from the Bulgarian Black Sea area in April 2019, the size composition was represented by individuals with a body length from $9.0 \mathrm{~cm}$ to $13.0 \mathrm{~cm}$. There was dominance of the individual class $11 \mathrm{~cm}$ in June, $10.5 \mathrm{~cm}$ - in August and October, $10 \mathrm{~cm}$ - in September, $9.0 \mathrm{~cm}$ - in November and $9.5 \mathrm{~cm}$ - in December. On Fig. 3.2.3.1 is shown that during the different months the variation order was interrupted and it is absent or represented by very weak individuals with definite dimensions. In June, the anchovy with a body length of $8.5-9$ $\mathrm{cm}$ had less share. In December, it impressed with the absence of an individual measures between 11.5-12.5 cm. The absence of certain size groups in the catches during the season indicated that they did not reflect the composition of the population proportionately.

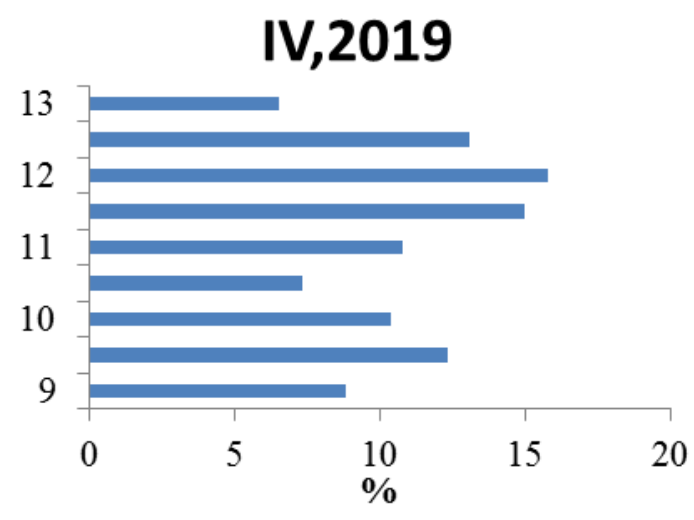

VIII,2019

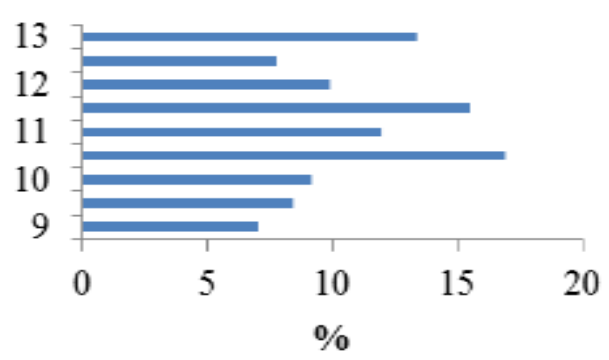

$\mathbf{X}, 2019$

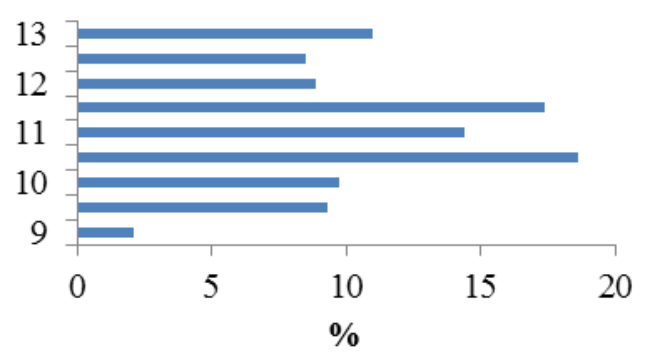

VI, 2019

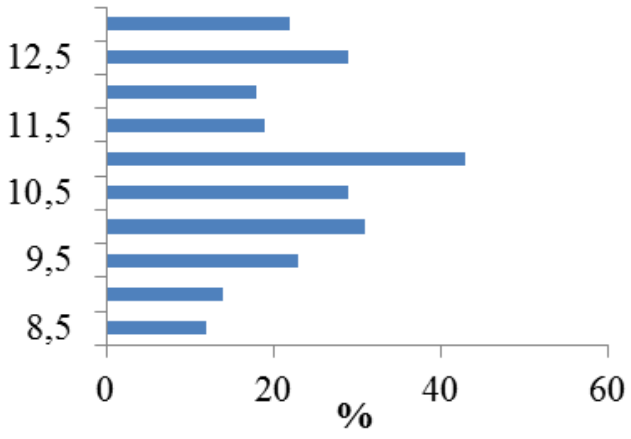

IX,2019

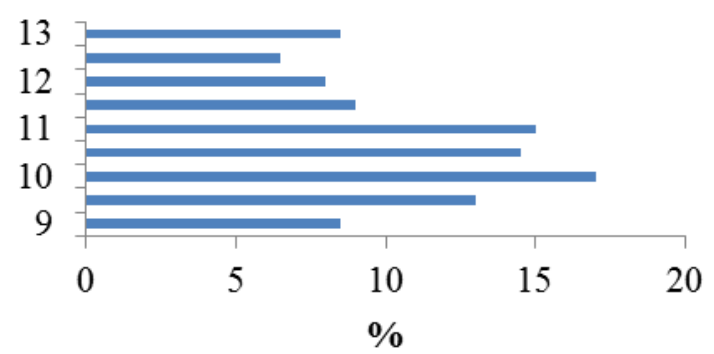

XI,2019

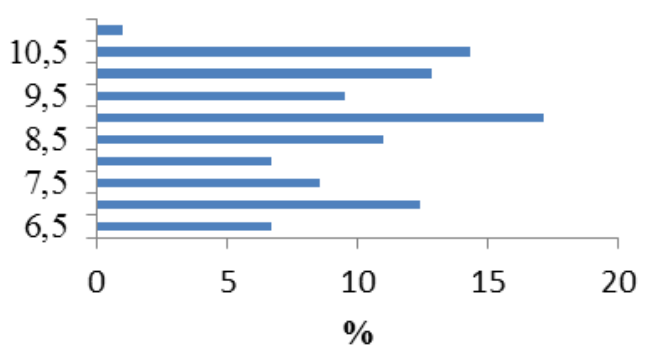

Project proposal № BG14MFOP001-3.003-0001 "Collection, management and use of data for the purposes of scientific analysis and implementation of the Common Fisheries Policy for the period 2017-2019", funded by the Maritime Affairs and Fisheries Program, co-financed by the European Union through the European Maritime and Fisheries Fund 


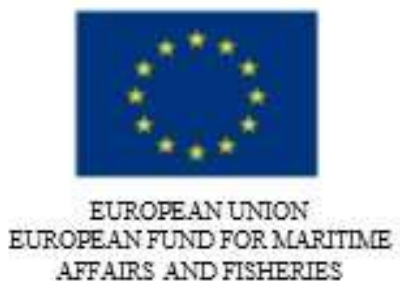

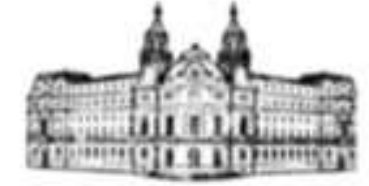

MINISTRY OF AGRICUITURE, FOOD AND FORESTRY

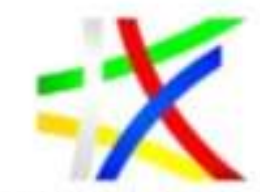

MLARITLE AFFAIRS AND FISHERIES PROGRAM

\section{XII,2019}

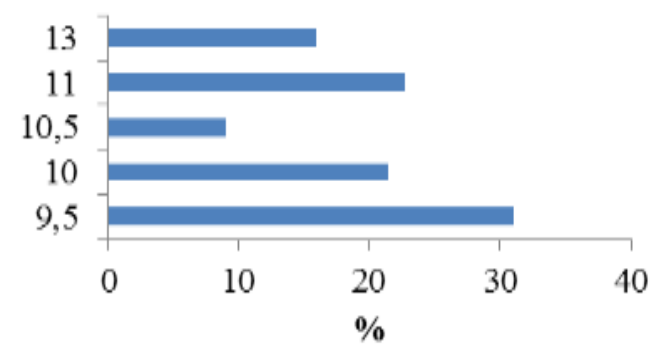

Fig. 3.2.3.1 Frequency of anchovy length from landings in 2019

\section{V.3.3 Age structure of landings}

During the accounting period (2017 - 2019), in separate years, deviations were reported in some of the typical biological parameters: number and condition of the new generations, agelinear and weight structure, condition factor and gonadosomatic index. The age structure of the anchovy during the period 2017-2019 was characterised by 5 age classes. During the period 2017 - 2019, the senior age groups (five and six years) were missing. The most indicative, in terms of the biological state of the species, was the age composition in the spring which most closely reflectsed the real qualitative composition in the catches of the species in the Bulgarian Black Sea waters. A larger share had the two-year-olds in June, 2018 (30.9\%) and to some extent in 2019 (28.75\%). The three-year-olds were well represented during that period with a percentage varying between $24.3 \%$ (June, 2018) and 26.67\% (June, 2019). Young age groups (annuals) were covered in the catches with a participation varying between $17.92 \%$ (June, 2018) and 22.92\% (June, 2019). On Fig. 3.3.1 is presented the range of variation of the percentage composition in the different age classes in June. In a multiannual plan this age distribution remained below normal for the species due to the low participation of senior age groups (5-6 years old).

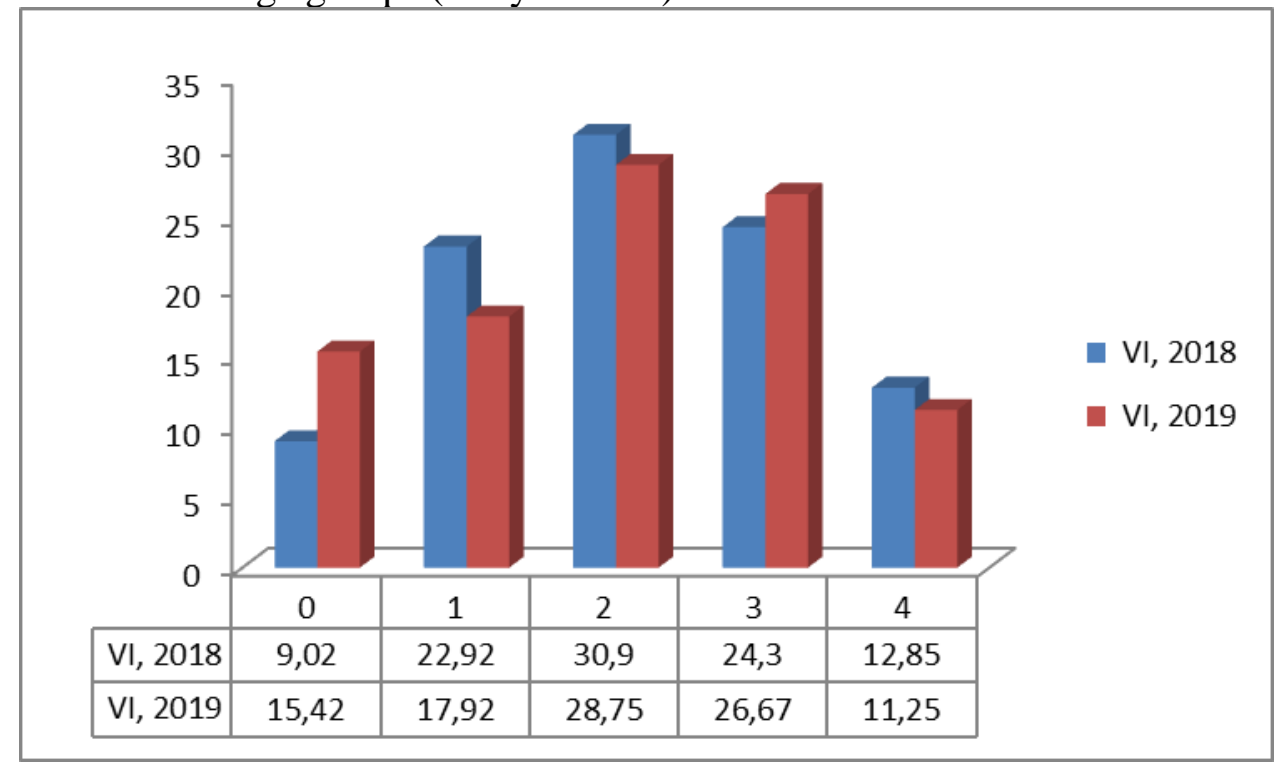

Project proposal № BG14MFOP001-3.003-0001 "Collection, management and use of data for the purposes of scientific analysis and implementation of the Common Fisheries Policy for the period 2017-2019", funded by the Maritime Affairs and Fisheries Program, co-financed by the European Union through the European Maritime and Fisheries Fund 


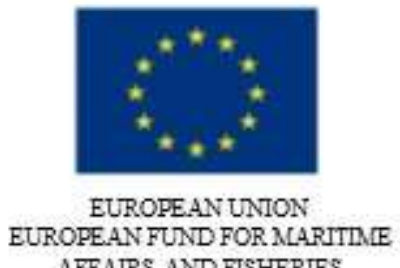

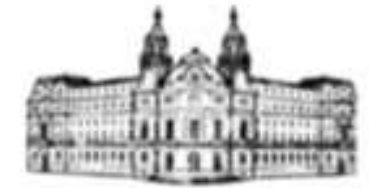

MINISTRY OF AGRICUITURE, FOOD AND FORESTRY

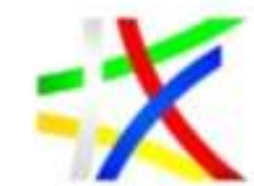

MLARITLE AFFAIRS AND FISHERIES PROGRAM

Fig. 3.3.1 Variation of the percentage participation of anchovy by age groups in June 2018-2019

Note: For June, 2017 no comparative analysis data were available.

In the autumn season of the accounting period (2017-2019), three-year-olds dominated with a significant share in the catches, reaching 40.6\% (October, 2018) and 39.8\% (October, 2019).

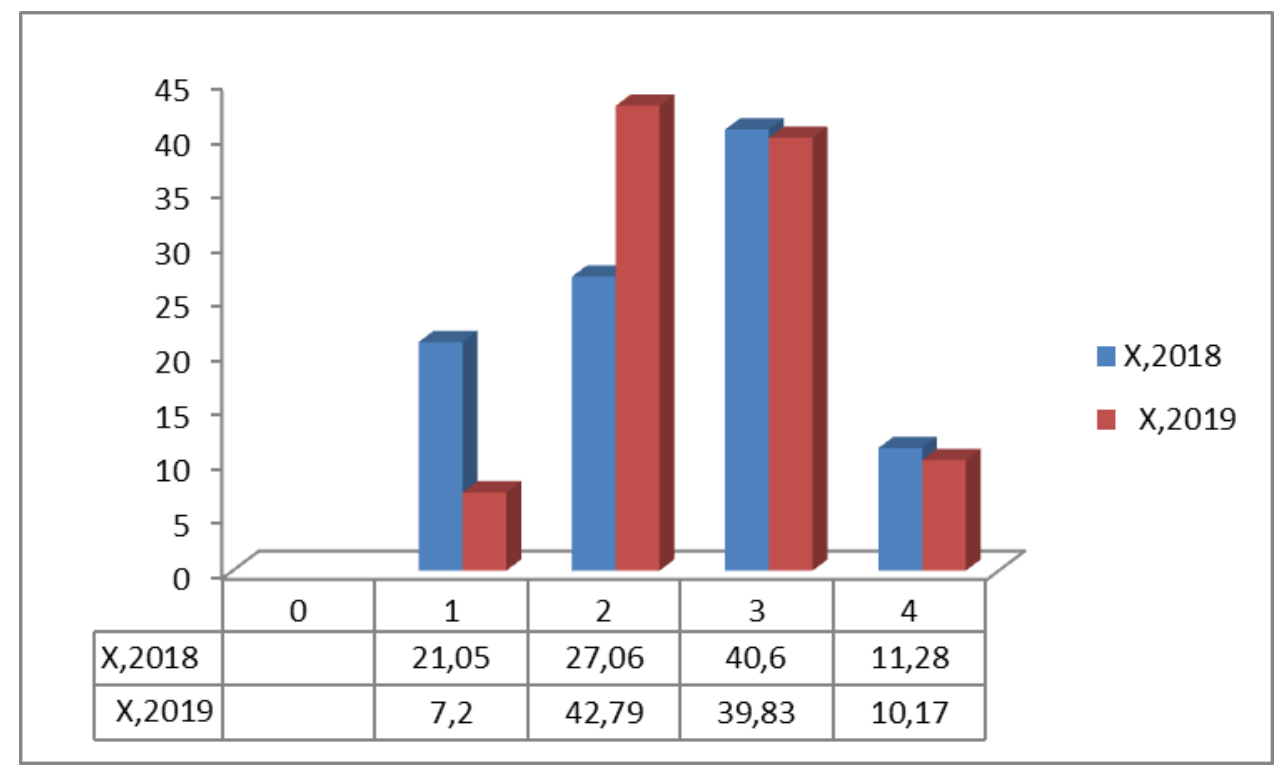

Fig. 3.3.2 Variation of the percentage participation of anchovy by age groups in October, 2018 and 2019 Note: For June, 2017 no comparative analysis data were available.

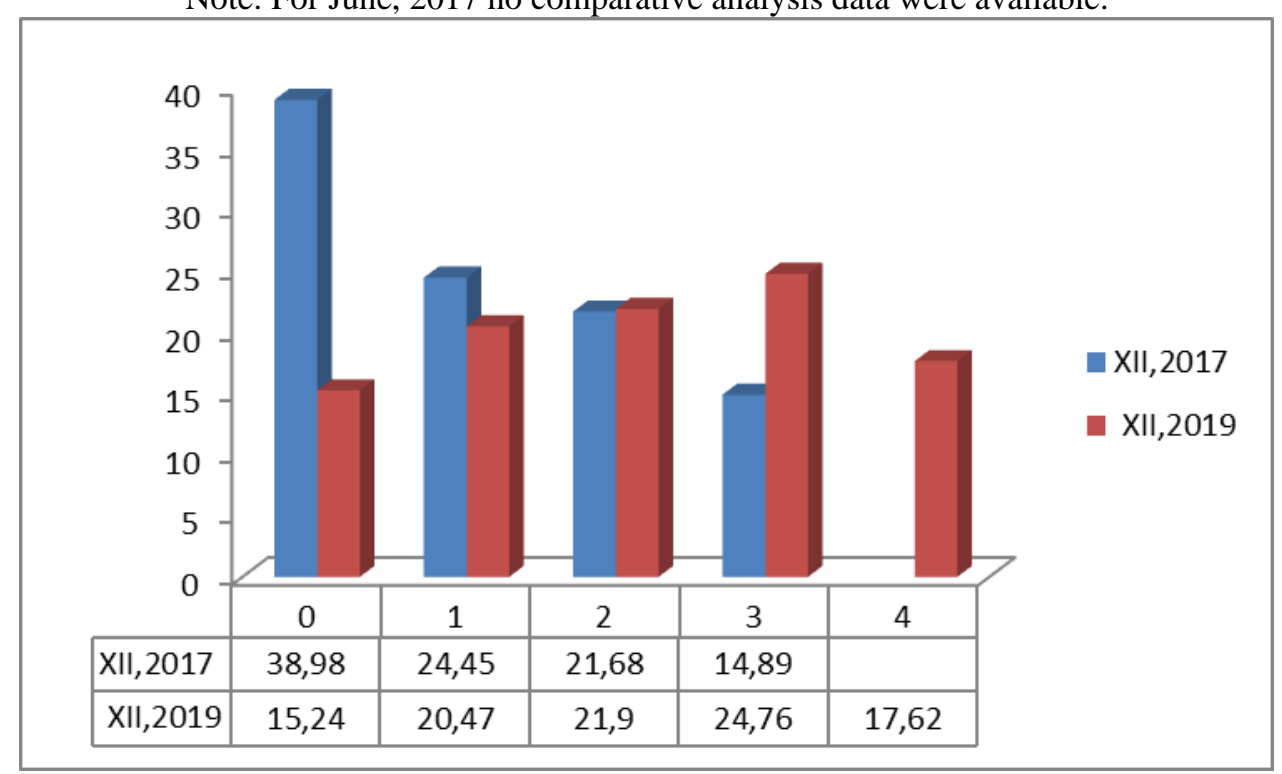

Fig. 3.3.3 Variation of the percentage participation of anchovy by age groups in December, 2017 and 2019 Note: For June, 2018 no comparative analysis data were available.

Project proposal № BG14MFOP001-3.003-0001 "Collection, management and use of data for the purposes of scientific analysis and implementation of the Common Fisheries Policy for the period 2017-2019", funded by the Maritime Affairs and Fisheries Program, co-financed by the European Union through the European Maritime and Fisheries Fund 


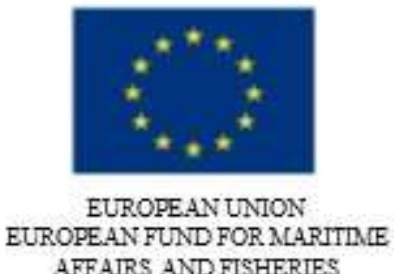

AFFAIRS AND FISHERIES

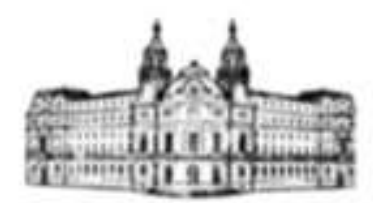

AINISTRY OF AGRICULTURE, FOOD AND FORESTRY

\section{3.4 Condition factor}

During the spring migration along our coast in June, the species was with condition factor $\mathrm{K}=$ 0.60-0.65 in 2019 and lower values in the same period of 2018 (Fig. 3.4.1).

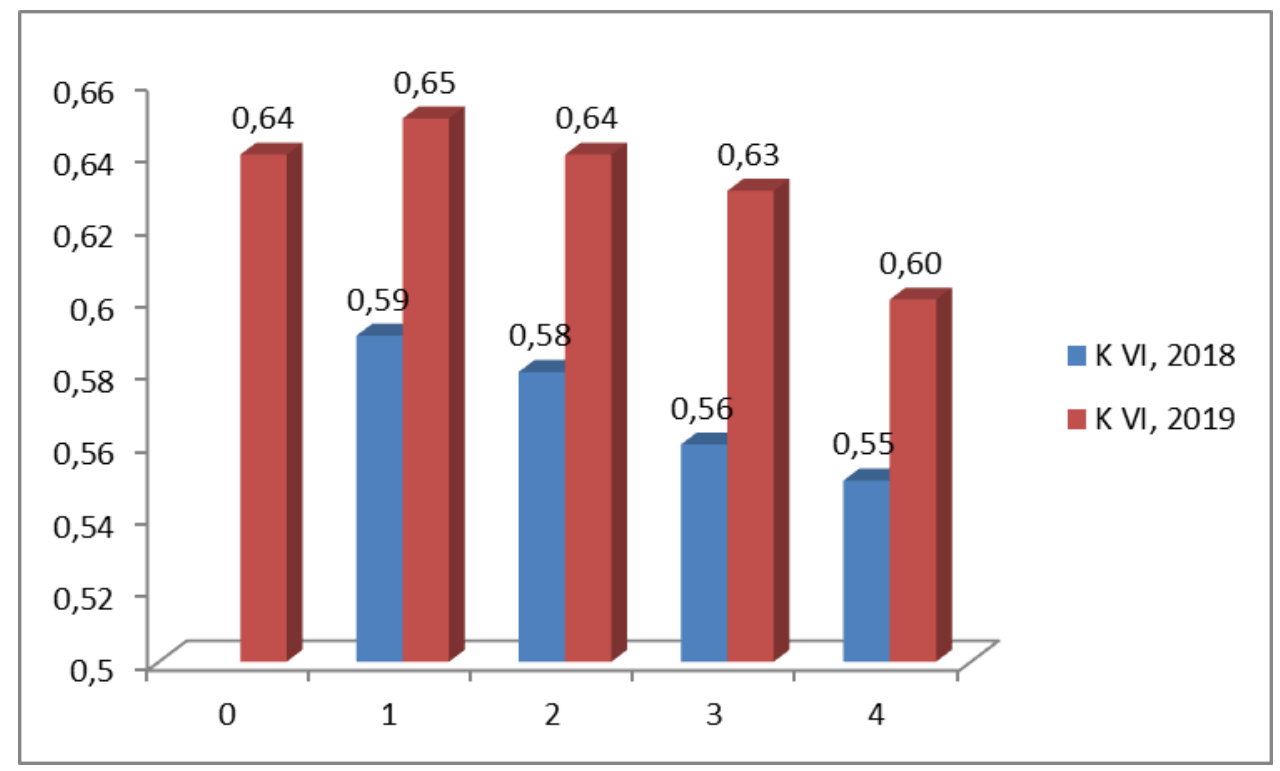

Fig. 3.4.1 Condition factor by age groups in June, 2018 and 2019

Note: For June, 2017 no comparative analysis data were available.

The condition factor in 2019 marked a slight increase compared to 2018. In June 2019, a particularly typical increase was observed in 2+ year-olds. With the onset of the active propagation period and the accumulation of spare fats, Fulton's condition factor showed relatively high values in October 2018 and 2019 (Fig. 3.4.2).

Autumn months were characterized by higher values of K coefficient (October 2018). The autumn coefficients reach lower values ranging from 0.51 to 0.53 in September, 2019. In November 2017, the condition factor was relatively higher for one-year-olds compared to the following years.

Project proposal № BG14MFOP001-3.003-0001 "Collection, management and use of data for the purposes of scientific analysis and implementation of the Common Fisheries Policy for the period 2017-2019", funded by the Maritime Affairs and Fisheries Program, co-financed by the European Union through the European Maritime and Fisheries Fund 


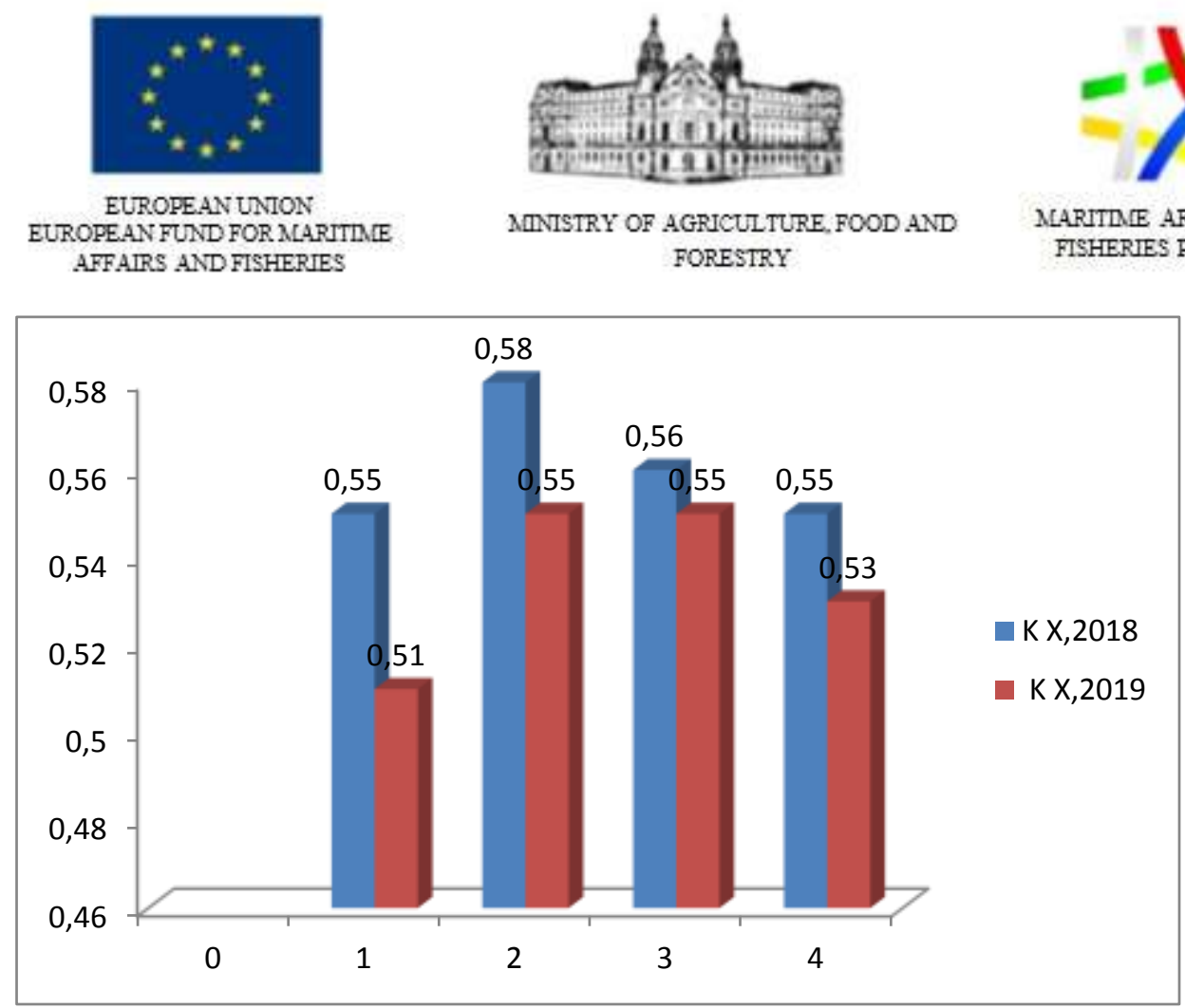

Fig. 3.4.2 Condition factor by age groups in October 2018 and 2019

Note: For October, 2017 no comparative analysis data were available.

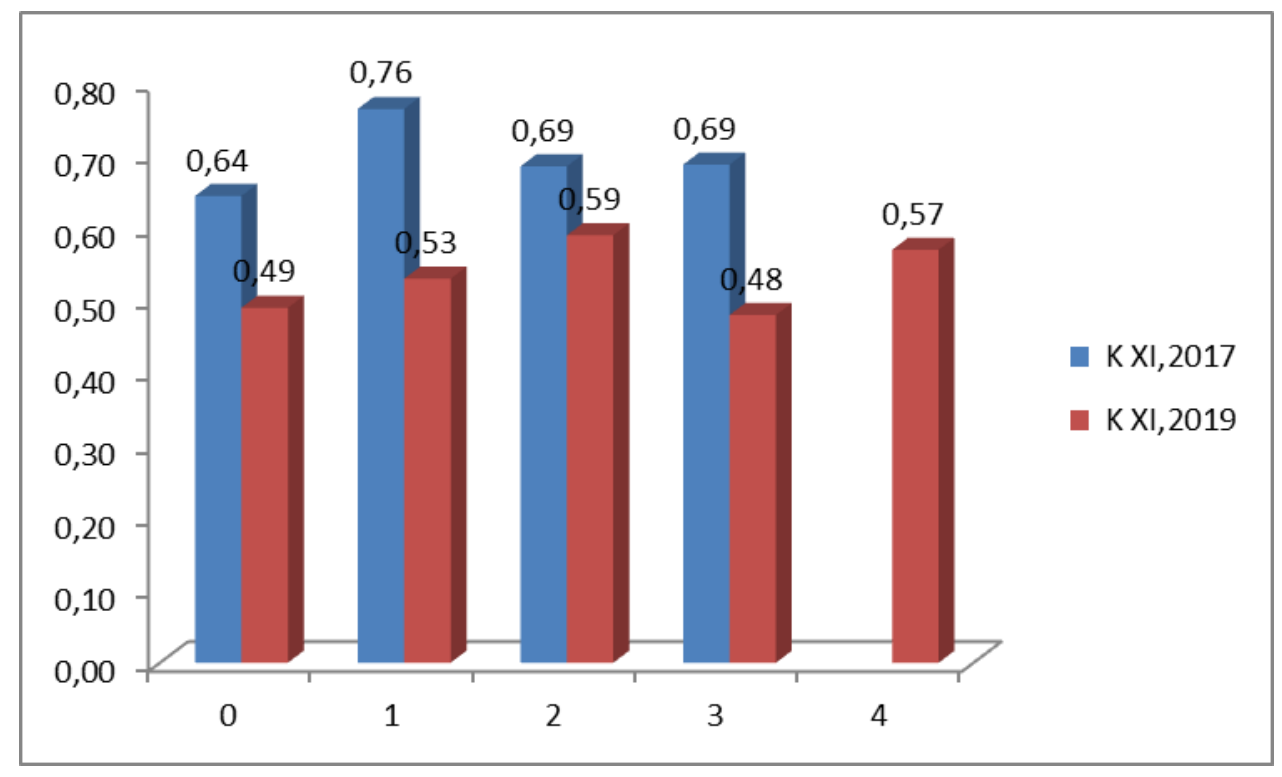

Fig. 3.4.3 Condition factor by age groups in November 2017 and 2019

Note: For November, 2018 no comparative analysis data were available.

Project proposal № BG14MFOP001-3.003-0001 "Collection, management and use of data for the purposes of scientific analysis and implementation of the Common Fisheries Policy for the period 2017-2019", funded by the Maritime Affairs and Fisheries Program, co-financed by the European Union through the European Maritime and Fisheries Fund 


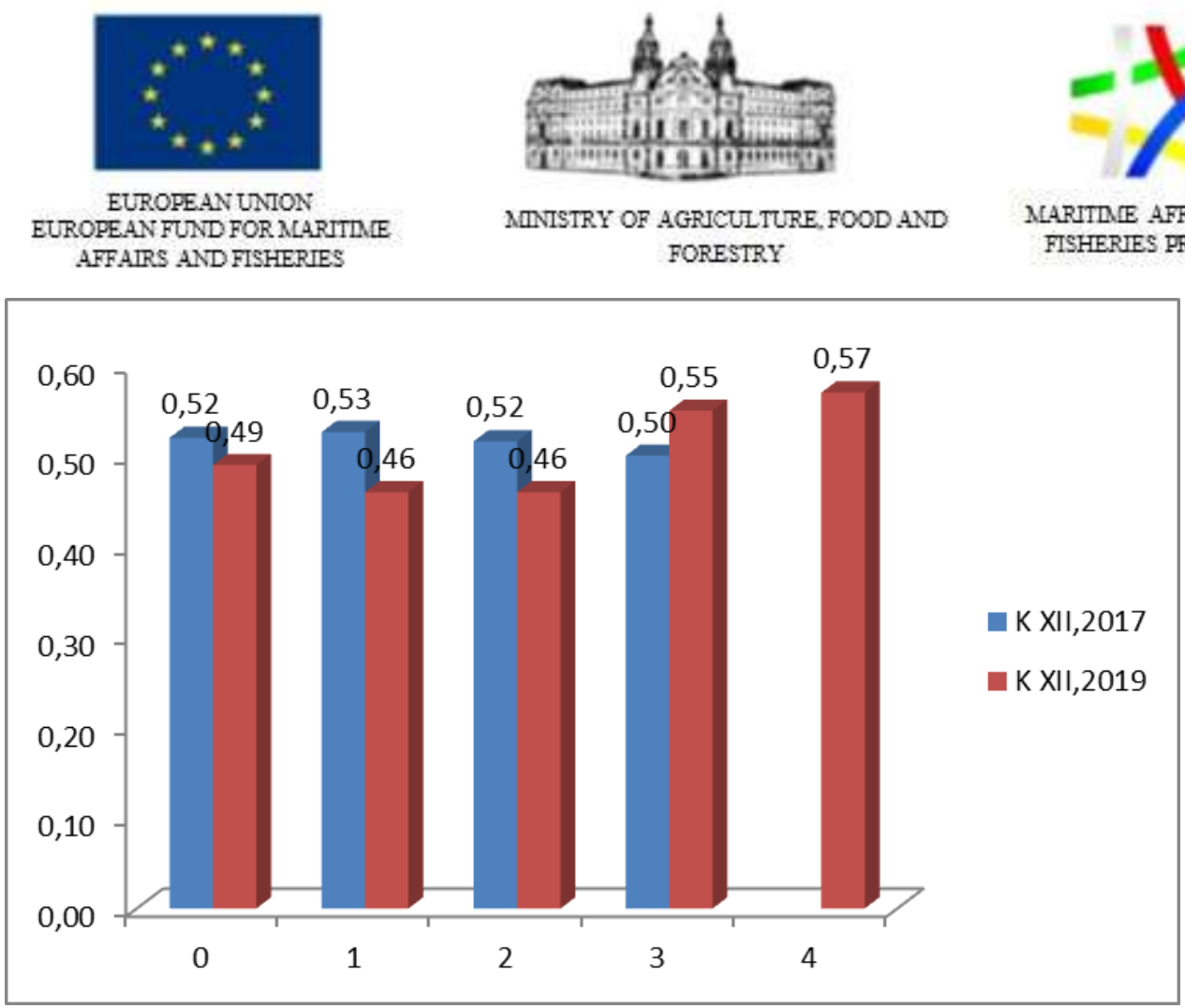

Fig. 3.4.4 Condition factor by age groups in December 2017 and 2019 Note: For, December, 2018 no comparative analysis data were available.

\section{V.3.5 Sex ratio}

In 2019, females (ㅇ) dominated by $61 \%$, followed by males (ठ઼) with (39\%) (Fig. 3.5.1).

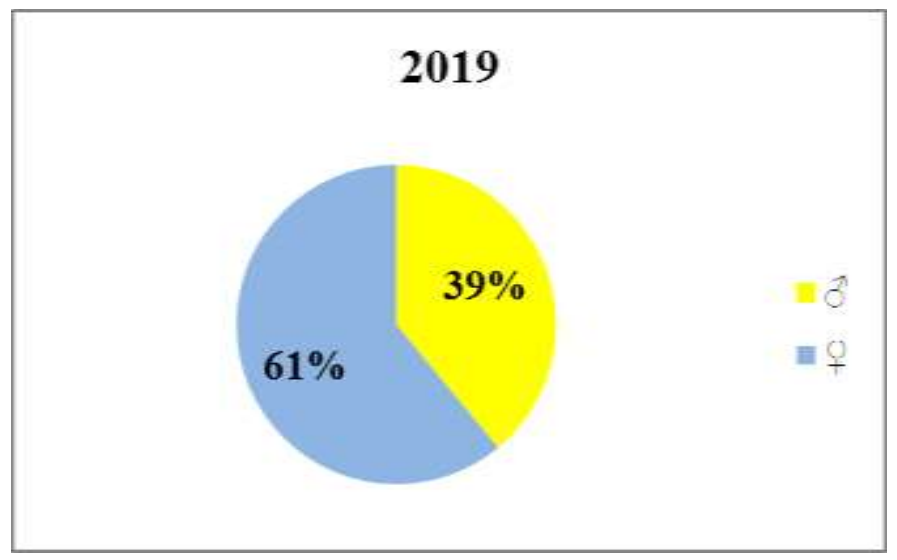

Fig. 3.5.1 Sex ratio of anchovy

\section{V3.6 Weight structure}

In June and October, the weight structure referred to the average multiannual data showed a similar picture (Fig. 3.6.1). In connection with the onset of the breeding period in June 2019, the values of the individual weights and the condition factor associated with the accumulation of fats increased.

Project proposal № BG14MFOP001-3.003-0001 "Collection, management and use of data for the purposes of scientific analysis and implementation of the Common Fisheries Policy for the period 2017-2019", funded by the Maritime Affairs and Fisheries Program, co-financed by the European Union through the European Maritime and Fisheries Fund 


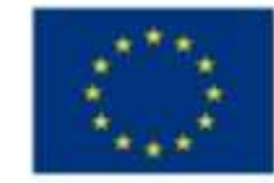

EUROPEAN UNTON EUROPEAN FUND FOR MLARITIE AFFAIRS AND FISHERIES

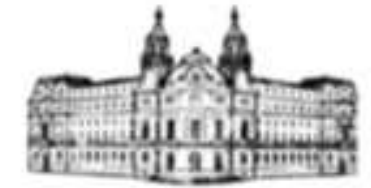

MINISTRY OF AGRICULTURE, FOOD AND FORESTRY
MLARITLE AFFAIRS AND FISHERIES PROGRAM

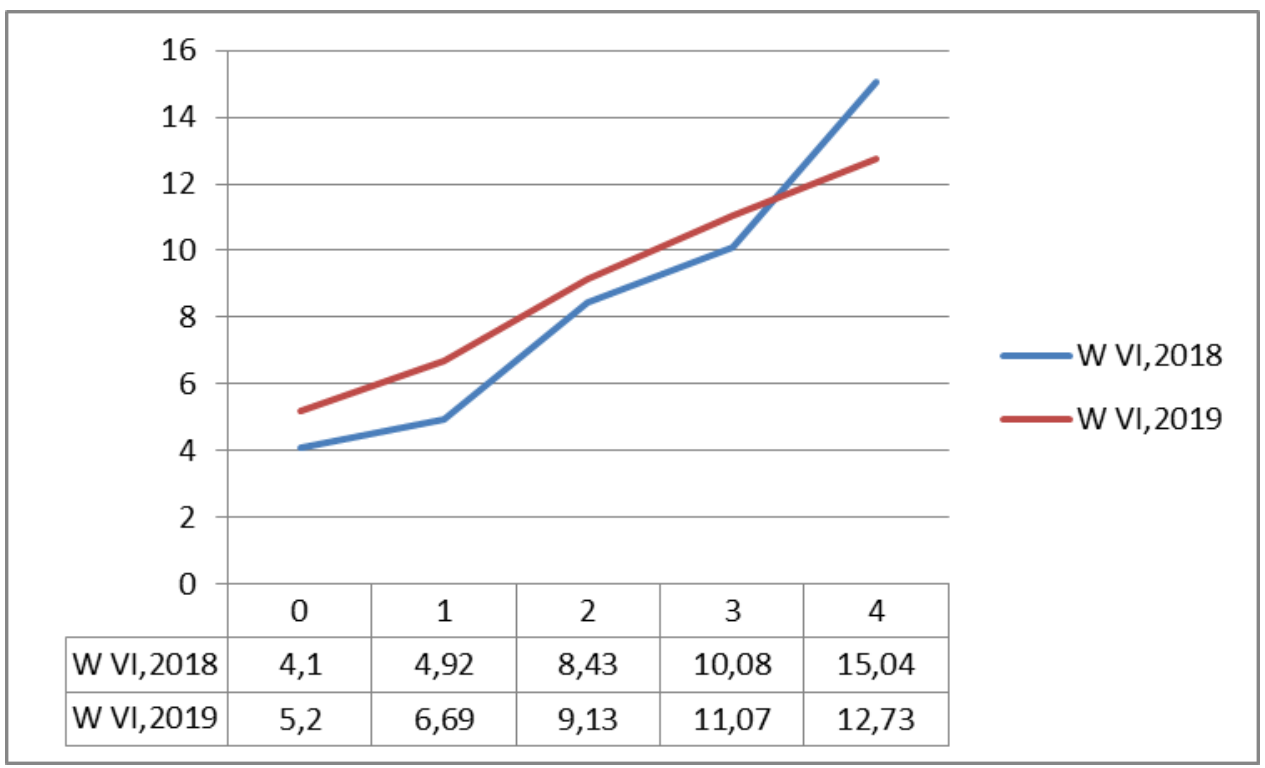

Fig. 3.6.1 Variation of the average weights by age groups in June, 2018 and 2019

It is noticeable that during the period 2018-2019, the linear sizes at different ages remained almost constant in October compared to November 2017. In November 2019, the average weights by age group showed a decrease.

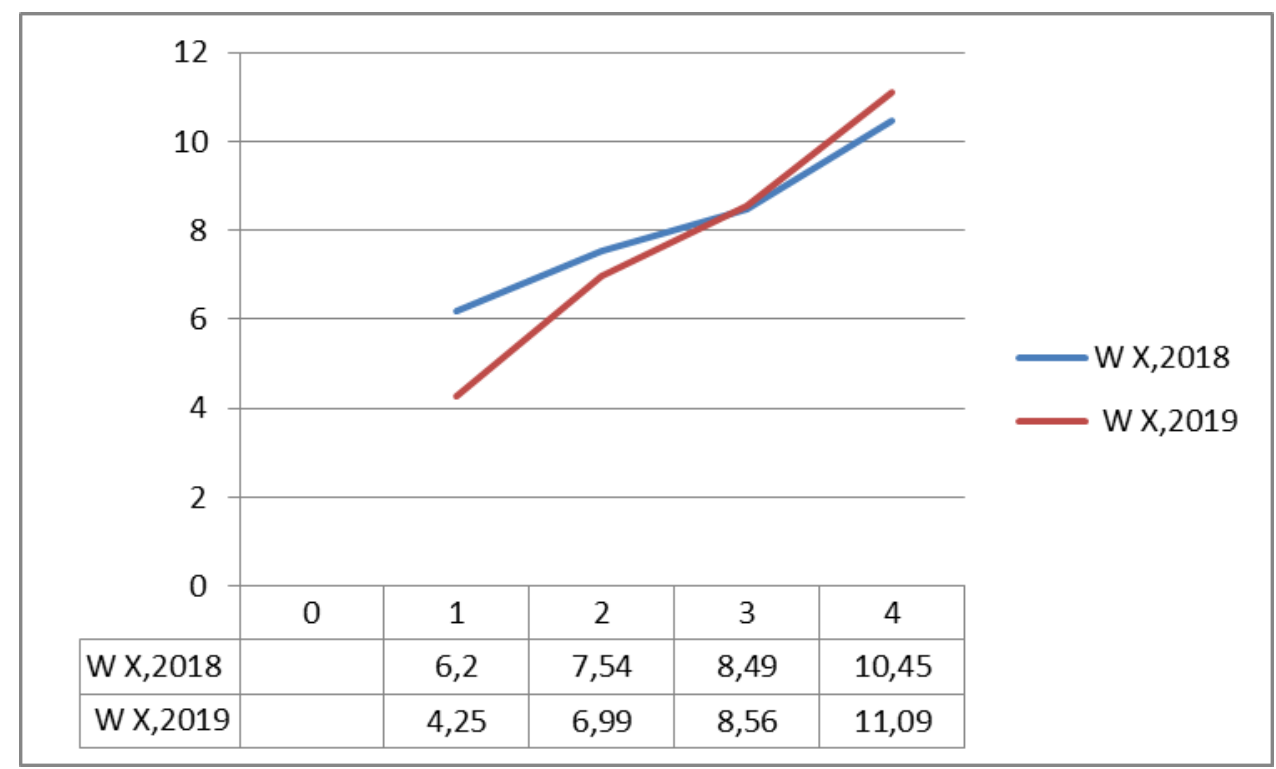

Fig. 3.6.2 Variation of the average weights by age groups in October, 2018 and 2019

Project proposal № BG14MFOP001-3.003-0001 "Collection, management and use of data for the purposes of scientific analysis and implementation of the Common Fisheries Policy for the period 2017-2019", funded by the Maritime Affairs and Fisheries Program, co-financed by the European Union through the European Maritime and Fisheries Fund 


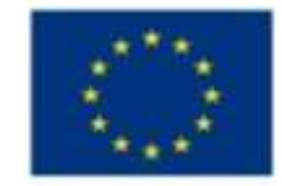

EUROPEAN UNTON EUROPEAN FUND FOR MLARITIE AFFAIRS AND FISHERIES

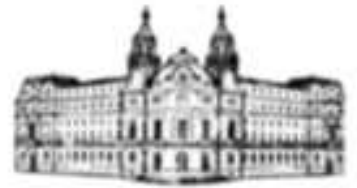

MINTSTRY OF AGRICUITURE, FOOD AND FORESTRY
MLARITLE AFFAIRS AND FISHERIES PROGRAM

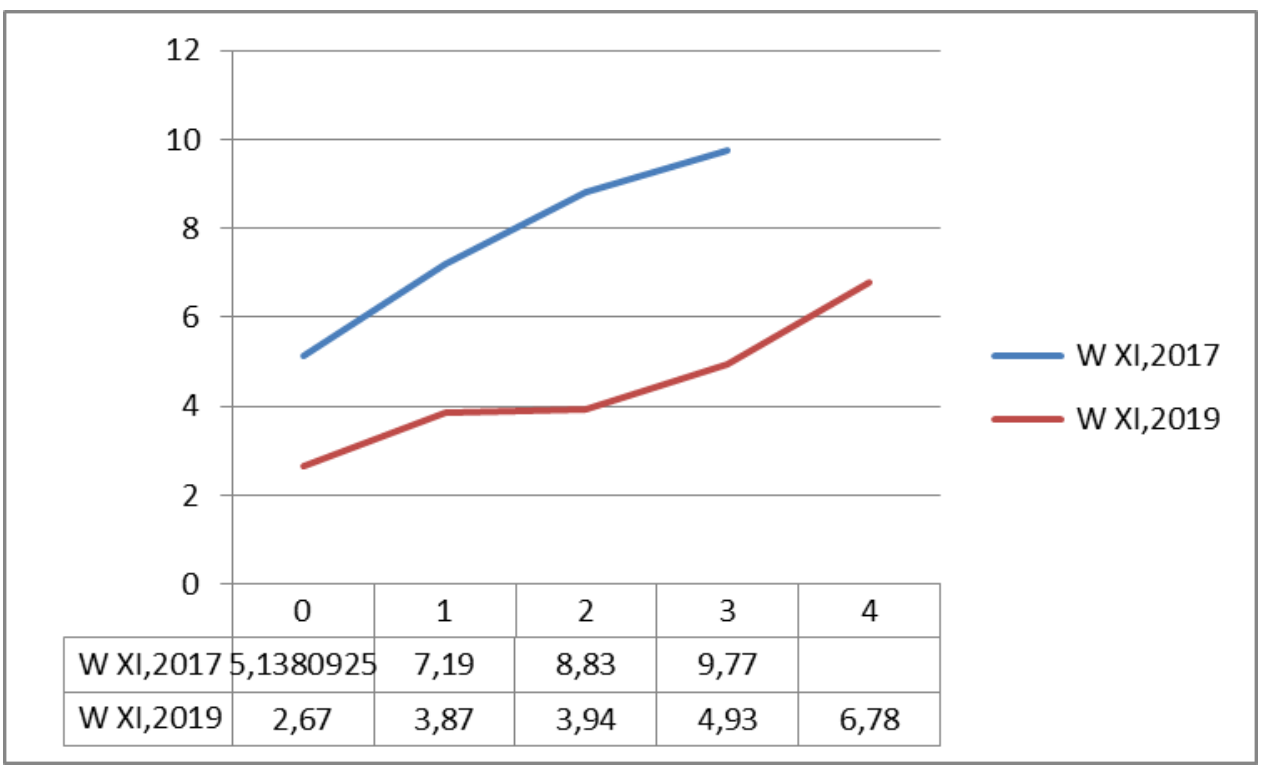

Fig. 3.6.3 Variation of the average weights by age groups in November, 2017 and 2019

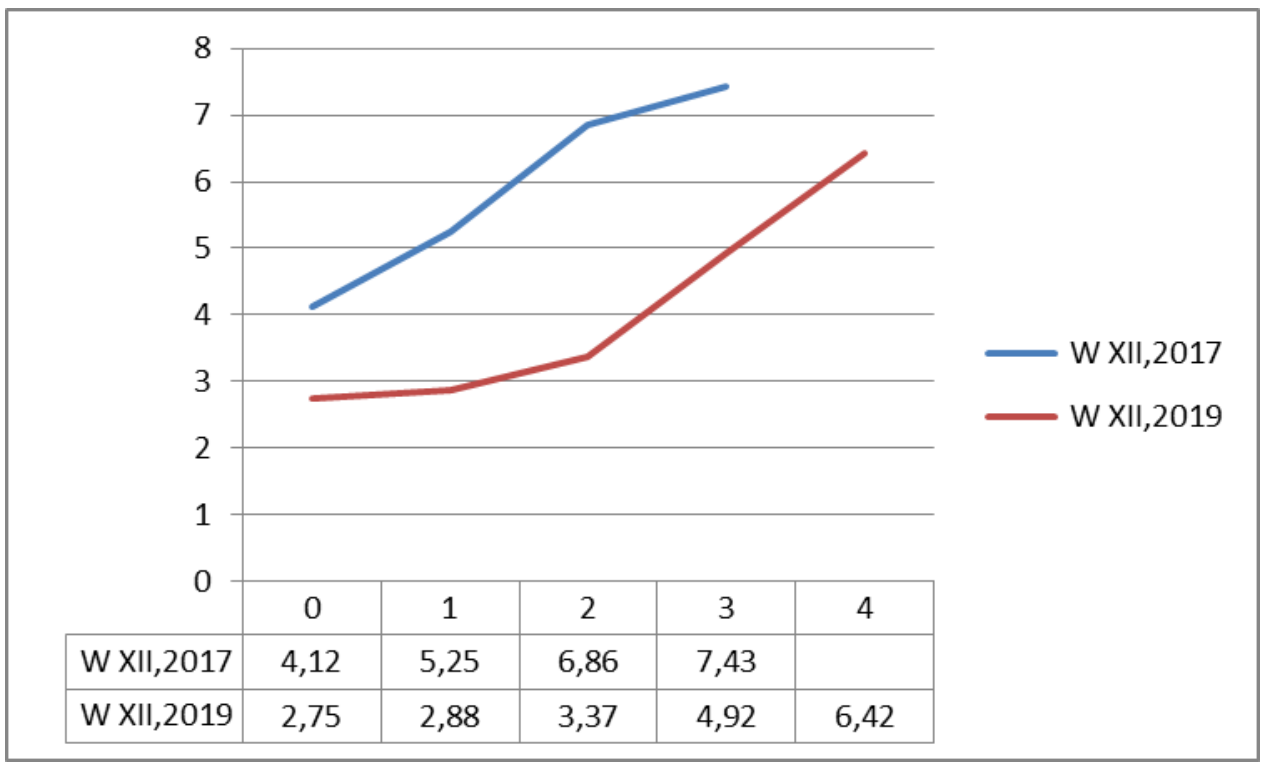

Fig. 3.6.4 Variation of the average weights by age groups in December, 2017 and 2019

\section{V.3.7 Size structure}

In June of the reporting period, the average linear dimensions of age $1+$ showed values within the average multiannual data of 9.24-10.04 cm. That was an indication of a good increase in replenishment.

Project proposal № BG14MFOP001-3.003-0001 "Collection, management and use of data for the purposes of scientific analysis and implementation of the Common Fisheries Policy for the period 2017-2019", funded by the Maritime Affairs and Fisheries Program, co-financed by the European Union through the European Maritime 


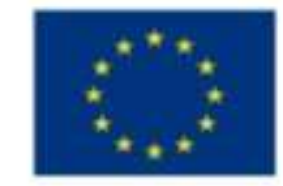

EUROPEAN UNTON EUROPEAN FUND FOR MLARITIIE AFFAIRS AND FISHERIES

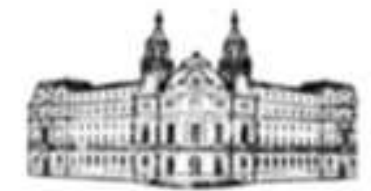

MINISTRY OF AGRICULTURE, FOOD AND FORESTRY
MLARITLE AFFAIRS AND FISHERIES PROGRAM

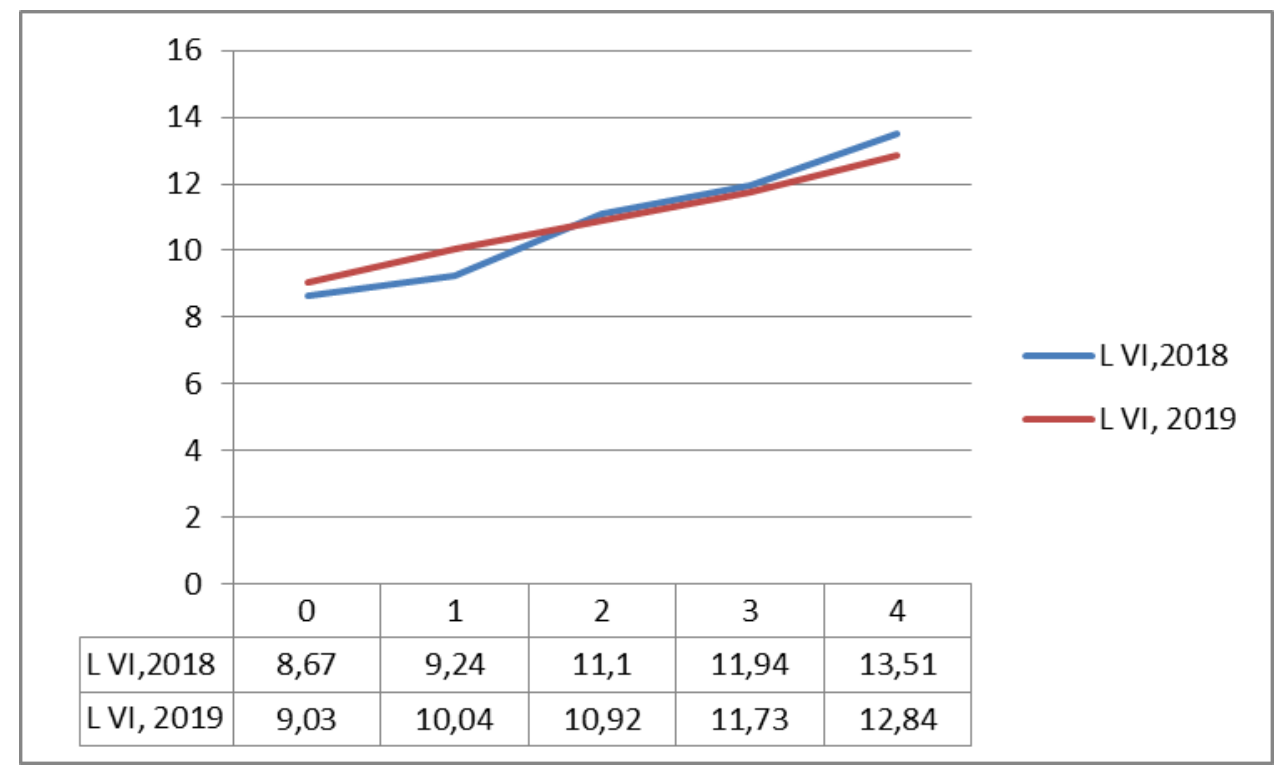

Fig. 3.7.1 Variation of the average lengths by age groups in June, 2018 and 2019

In October of the reporting period, the average linear dimensions of age $1+$ showed values within the range of $6.19-10.72 \mathrm{~cm}$, which lowered only in 2018. The increase in two-and three-year-old fish compared to the average level was lower with 3.97- $4.3 \mathrm{~cm}$ (Fig. 3.7.2).

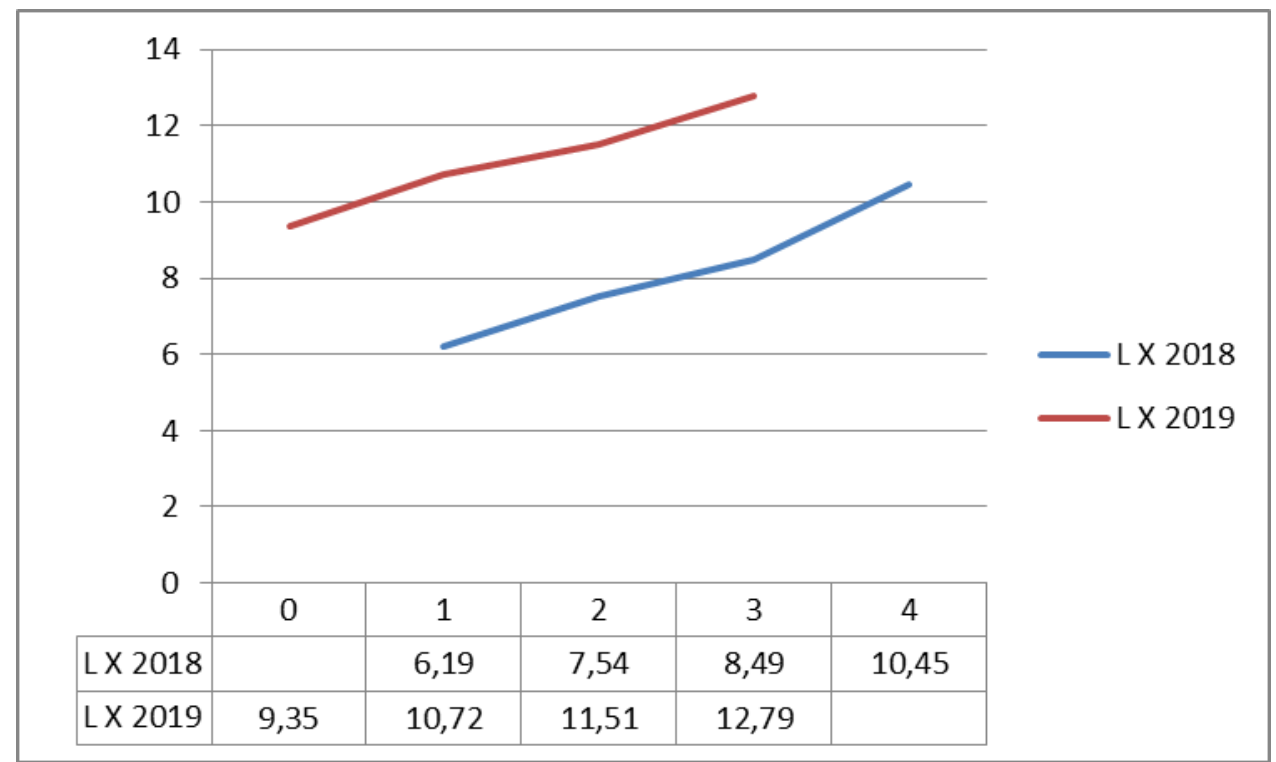

Fig. 3.7.2 Variation of the average lengths by age groups in October, 2018 and 2019

Project proposal № BG14MFOP001-3.003-0001 "Collection, management and use of data for the purposes of scientific analysis and implementation of the Common Fisheries Policy for the period 2017-2019", funded by the Maritime Affairs and Fisheries Program, co-financed by the European Union through the European Maritime and Fisheries Fund 


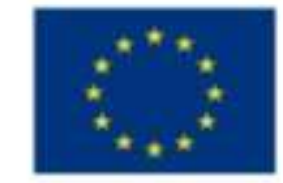

EUROPEAN UNTON EUROPEAN FUND FOR MLARITLIE AFFAIRS AND FISHERIES

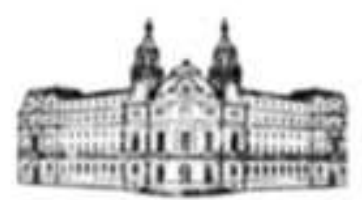

AINTSTRY OF AGRICULTURE, FOOD AND FORESTRY
MLARITLE AFFAIRS AND FISHERIES PROGRAM

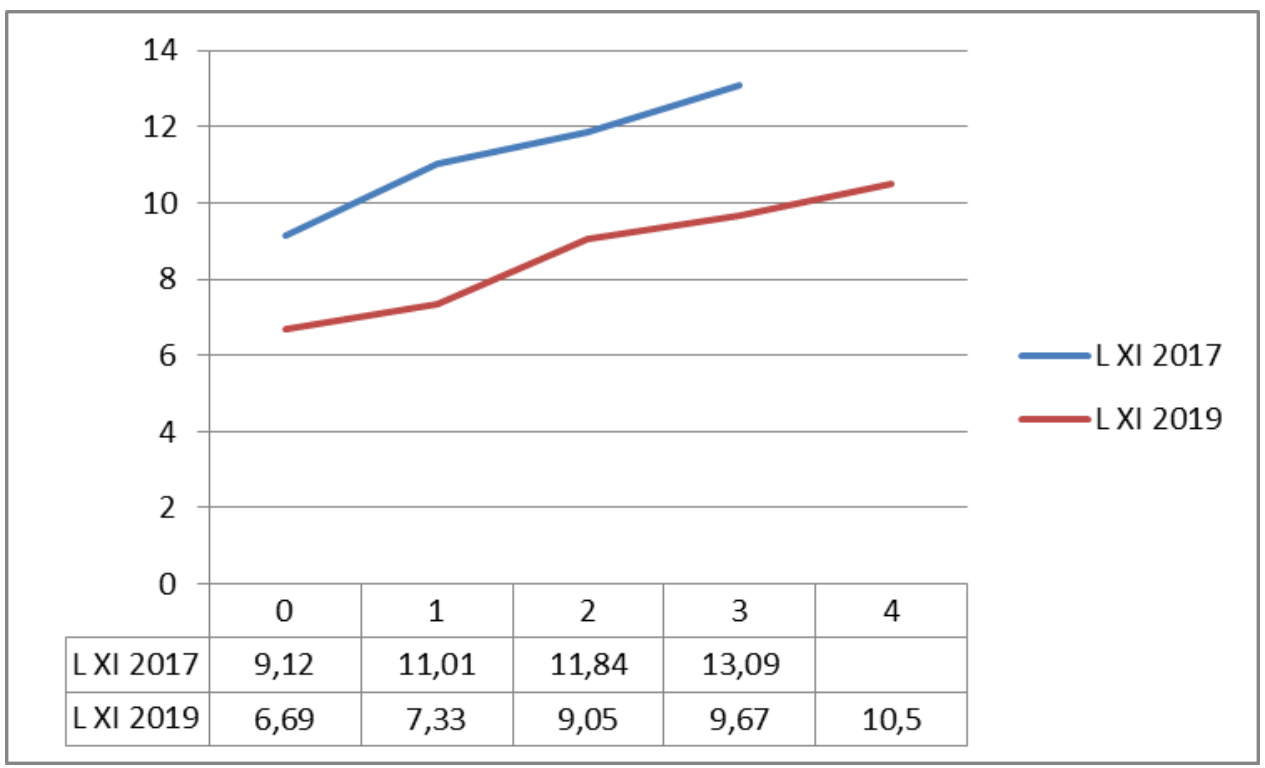

Fig. 3.7.3 Variation of the average lengths by age groups in November, 2017 and 2019

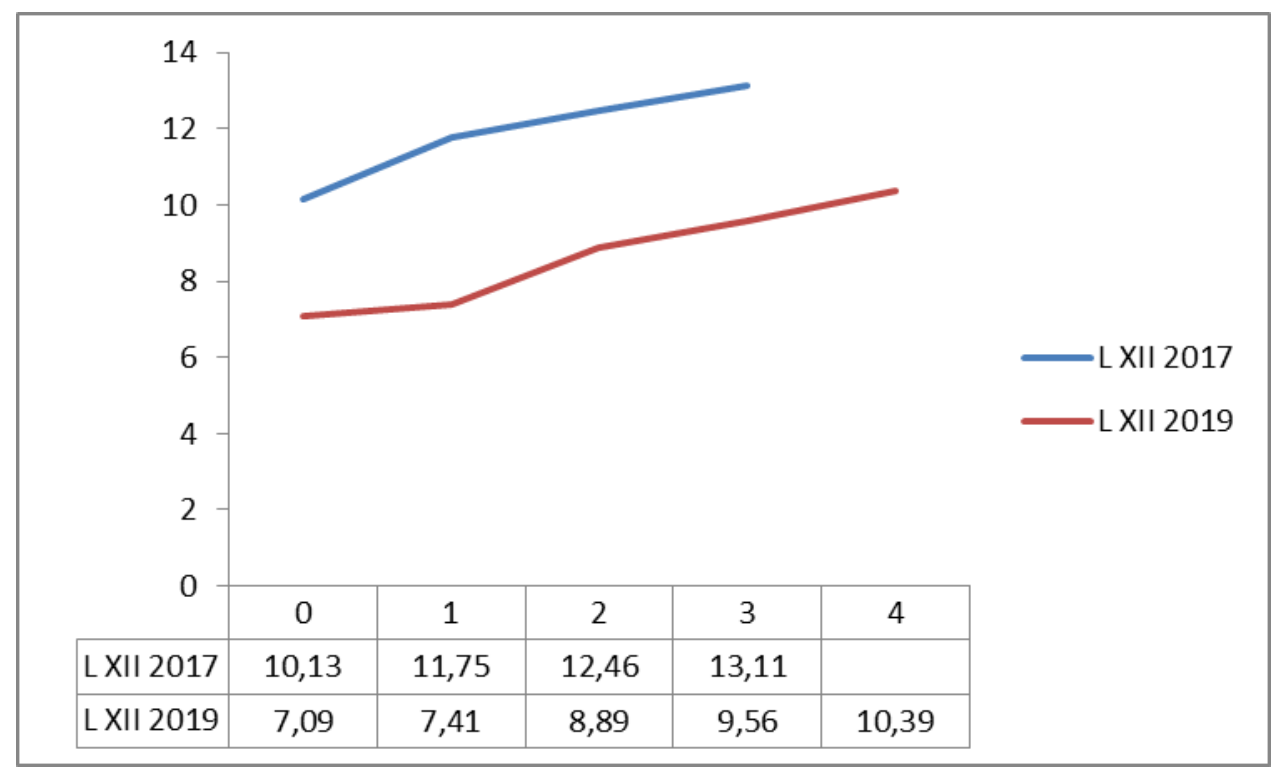

Fig. 3.7.4 Variation of the average lengths by age groups in December, 2017 and 2019

\section{V.3.8 Length- weight relationship}

It followed from the analysis that the increase in anchovy was allometric.

$$
\begin{aligned}
& \mathrm{W}=0.0167 * \mathrm{~L}^{2.5582} \text { for } 2018 \\
& \mathrm{~W}=0.0129 * \mathrm{~L}^{2.2921} \text { for } 2019
\end{aligned}
$$

Project proposal № BG14MFOP001-3.003-0001 "Collection, management and use of data for the purposes of scientific analysis and implementation of the Common Fisheries Policy for the period 2017-2019", funded by the Maritime Affairs and Fisheries Program, co-financed by the European Union through the European Maritime 


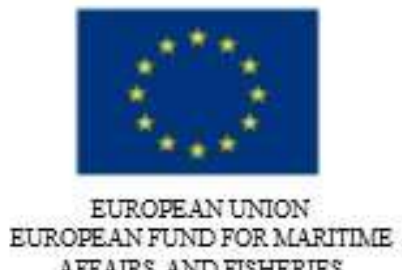
AFFAIRS AND FISHERIES

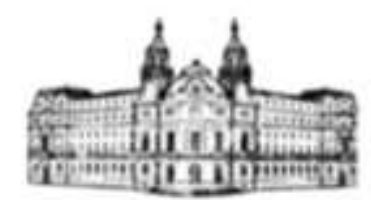

AINISTRY OF AGRICULTURE, FOOD AND FORESTRY
MARITLIE AFFAIRS AND FISHERIES PROGRAM

\section{II.3.9 Fertility}

The gonadosomatic index was highly dependent on the weight of the gonads which was associated with the high rate of maturation of females in late spring and summer and the breeding process of anchovy.

\section{V.3.10 Sexual maturity}

All investigated specimens showed a degree of maturity V-VII as a small percentage of $5 \%$ were in the range of II-IV. In June, mass mature sex products in over $40 \%$ of the examined female specimens were observed.

\section{V.3.11 Catch numbers and biomass by age and length}

\section{V.3.11.1 Catch numbers and biomass by age and length in 2017}

Monthly catches (in tons) together with mean weights of anchovy were used to derive the monthly catch numbers. The shares $(\%)$ by age groups and catch numbers were used to create catch-at-age matrix for selected months by age groups.

Table 3.11.1.1 Catch-at-age $\left(10^{-3}\right)$ matrix and biomass $(\mathrm{kg})$ for selected months

\begin{tabular}{|c|c|c|}
\hline Age groups & November & December \\
\hline 0 & 0.004 & 0.00053 \\
\hline 1 & 0.010 & 0.00033 \\
\hline 2 & 0.007 & 0.00029 \\
\hline 3 & 0.005 & 0.00020 \\
\hline$\Sigma$ & 0.026 & 0.00135 \\
\hline \multicolumn{3}{|c|}{ Biomass (kg) } \\
\hline Age groups & November & December \\
\hline 0 & 19.729 & 2.167 \\
\hline 1 & 71.211 & 1.732 \\
\hline 2 & 59.977 & 2.006 \\
\hline 3 & 51.086 & 1.493 \\
\hline$\Sigma$ & 202.004 & 7.398 \\
\hline
\end{tabular}

Table 3.11.1.2 Catch-at-length $\left(10^{-3}\right)$ matrix and biomass $(\mathrm{kg})$ for selected months

\begin{tabular}{|c|c|c|}
\hline \multicolumn{3}{|c|}{ Catch-at-length (millions) } \\
\hline TL.cm & November & December \\
\hline 9.0 & 108.087 & 56.091 \\
\hline 9.5 & 102.244 & 75.888 \\
\hline 10.0 & 155.800 & 34.644 \\
\hline 10.5 & 174.302 & 57.741 \\
\hline 11.0 & 145.089 & 105.583 \\
\hline 11.5 & 125.614 & 80.837 \\
\hline
\end{tabular}

Project proposal № BG14MFOP001-3.003-0001 "Collection, management and use of data for the purposes of scientific analysis and implementation of the Common Fisheries Policy for the period 2017-2019", funded by the Maritime Affairs and Fisheries Program, co-financed by the European Union through the European Maritime 


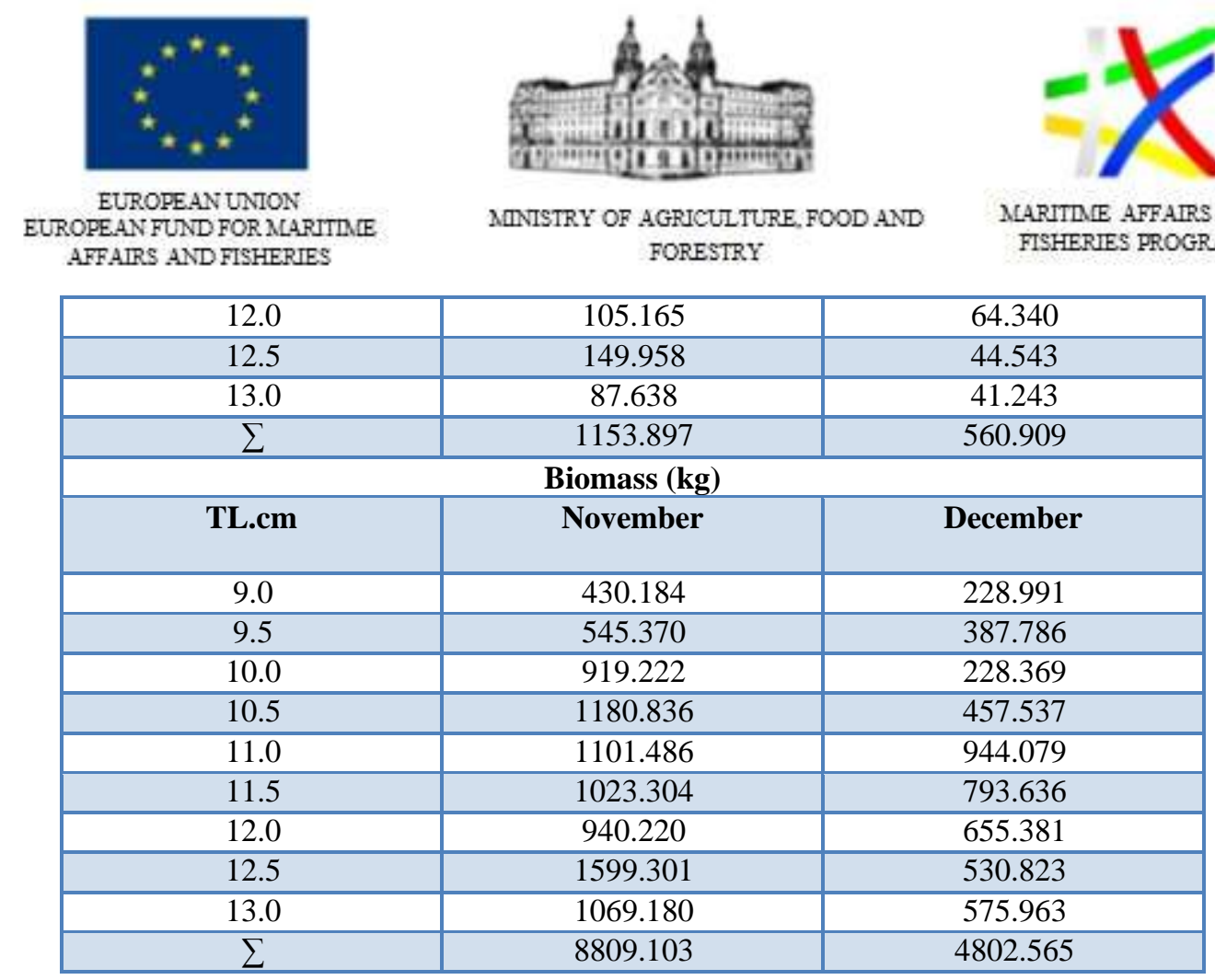

\section{V.3.11.2 Catch numbers and biomass by age and length in 2018}

Table 3.11.2.1 Catch-at-age $\left(10^{-3}\right)$ matrix and biomass $(\mathrm{kg})$ for selected months

\begin{tabular}{|c|c|c|}
\hline \multicolumn{3}{|c|}{ Catch-at-age } \\
\hline Age groups & June & October \\
\hline $\mathbf{0}$ & 0.003135 & \\
\hline $\mathbf{1}$ & 0.007958 & 0.008463 \\
\hline $\mathbf{2}$ & 0.010732 & 0.01088 \\
\hline $\mathbf{3}$ & 0.008441 & 0.016321 \\
\hline $\mathbf{4}$ & 0.004462 & 0.004533 \\
\hline & & \\
\hline & Biomass (kg) & October \\
\hline Age groups & June & \\
\hline 0 & 12.87816 & 52.43894 \\
\hline 1 & 39.1831 & 138.6383 \\
\hline 2 & 90.47244 & 47.37698 \\
\hline 3 & 85.13827 & 320.5 \\
\hline 4 & 67.12803 & \\
\hline$\sum$ & 294.8 & \\
\hline
\end{tabular}

Project proposal № BG14MFOP001-3.003-0001 "Collection, management and use of data for the purposes of scientific analysis and implementation of the Common Fisheries Policy for the period 2017-2019", funded by the Maritime Affairs and Fisheries Program, co-financed by the European Union through the European Maritime and Fisheries Fund 


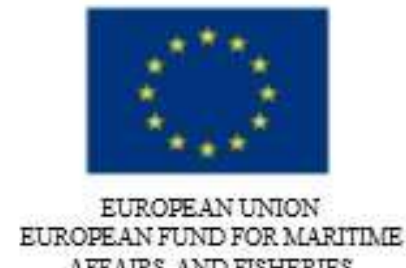

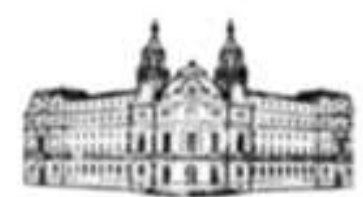

MINISTRY OF AGRICUITURE, FOOD AND FORESTRY
MLARITLIE AFFAIRS AND FISHERIES PROGRAM

Table 3.11.2.2 Catch-at-length $\left(10^{-3}\right)$ matrix and biomass $(\mathrm{kg})$ for selected months

\begin{tabular}{|c|c|c|}
\hline \multicolumn{3}{|c|}{ Catch-at-length (millions) } \\
\hline Length group (cm) & June & October \\
\hline 8.5 & 25.03848 & \\
\hline 9.0 & 36.16669 & \\
\hline 9.5 & 19.47437 & 6.567834 \\
\hline 10.0 & 11.12821 & 8.444358 \\
\hline 10.5 & 41.73079 & 22.51829 \\
\hline 11.0 & 10.20086 & 35.65396 \\
\hline 11.5 & 31.52993 & 26.27134 \\
\hline 12.0 & 11.12821 & 15.95045 \\
\hline 12.5 & 39.87609 & 8.444358 \\
\hline 13.0 & 11.12821 & 0.938262 \\
\hline 13.5 & 20.40172 & \\
\hline 14.0 & 9.27351 & \\
\hline \multicolumn{3}{|c|}{ Biomass (kg) } \\
\hline Length group (cm) & June & October \\
\hline 8.5 & 0.976501 & \\
\hline 9.0 & 1.627501 & \\
\hline 9.5 & 0.973719 & 0.319478 \\
\hline 10 & 0.754245 & 0.530118 \\
\hline 10.5 & 2.944775 & 1.556671 \\
\hline 11 & 0.80772 & 2.751829 \\
\hline 11.5 & 2.673738 & 2.242728 \\
\hline 12 & 1.014559 & 1.527303 \\
\hline 12.5 & 4.784242 & 0.894914 \\
\hline 13 & 1.580206 & 0.001267 \\
\hline 13.5 & 3.060258 & \\
\hline 14.0 & 1.474488 & \\
\hline
\end{tabular}

\section{V.3.11.3 Catch numbers and biomass by age and length in 2019}

Table 3.11.3.1 Catch-at-age $\left(10^{-3}\right)$ matrix and biomass $(\mathrm{kg})$ for selected months

\begin{tabular}{|c|c|c|c|c|c|c|c|}
\hline \multicolumn{7}{|c|}{ Catch-at-Age *10 } & (in thousands) \\
\hline Age groups & April & June & August & September & October & November & December \\
\hline $\mathbf{0}$ & 3.849928 & 2.950136 & 0.590027 & 0.560526 & 1.475068 & 2.212155 & 818.0846 \\
\hline $\mathbf{1}$ & 5.356421 & 4.104537 & 0.820907 & 0.779862 & 2.052269 & 3.077781 & 1138.205 \\
\hline $\mathbf{2}$ & 10.62915 & 8.144941 & 1.628988 & 1.547539 & 4.072471 & 6.107473 & 2258.625 \\
\hline $\mathbf{3}$ & 8.034632 & 6.156806 & 1.231361 & 1.169793 & 3.078403 & 4.616672 & 1707.307 \\
\hline $\mathbf{4}$ & 3.766234 & 2.886003 & 0.577201 & 0.548341 & 1.443001 & 2.164065 & 800.3001 \\
\hline$\sum$ & $\mathbf{3 1 . 6 4}$ & $\mathbf{2 4 . 2 4}$ & $\mathbf{4 . 8 5}$ & $\mathbf{4 . 6 1}$ & $\mathbf{1 2 . 1 2}$ & $\mathbf{1 8 . 1 8}$ & $\mathbf{6 7 2 2 . 5 2 1}$ \\
\hline \multicolumn{7}{|c|}{ Биомаса (кг) } \\
\hline
\end{tabular}

Project proposal № BG14MFOP001-3.003-0001 "Collection, management and use of data for the purposes of scientific analysis and implementation of the Common Fisheries Policy for the period 2017-2019", funded by the Maritime Affairs and Fisheries Program, co-financed by the European Union through the European Maritime and Fisheries Fund 


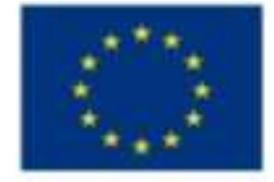

EUROPEAN UNTON EUROPEAN FUND FOR MAARTIME AFFAIRS AND FISHERIES

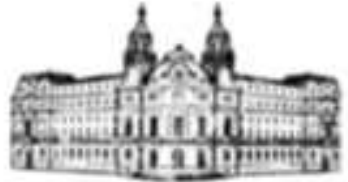

AINISTRY OF AGRICUITURE, FOOD AND FORESTRY
MLARITLIE AFFAIRS AND FISHERIES PROGRAM

\begin{tabular}{|c|c|c|c|c|c|c|c|}
\hline Age groups & April & June & August & September & October & November & December \\
\hline $\mathbf{0}$ & 20.34988 & 15.59378 & 3.118756 & 2.962818 & 7.79689 & 11.69297 & 4324.217 \\
\hline $\mathbf{1}$ & 32.85364 & 25.1752 & 5.03504 & 4.783288 & 12.5876 & 18.87759 & 6981.183 \\
\hline $\mathbf{2}$ & 85.83827 & 65.77645 & 13.15529 & 12.49753 & 32.88823 & 49.32238 & 18240.07 \\
\hline $\mathbf{3}$ & 77.19408 & 59.15255 & 11.83051 & 11.23899 & 29.57628 & 44.35546 & 16403.24 \\
\hline $\mathbf{4}$ & 44.81684 & 34.34241 & 6.868481 & 6.525057 & 17.1712 & 25.7516 & 9523.286 \\
\hline$\sum$ & $\mathbf{2 6 1 . 0 5}$ & $\mathbf{2 0 0 . 0 4}$ & $\mathbf{4 0 . 0 1}$ & $\mathbf{3 8 . 0 1}$ & $\mathbf{1 0 0 . 0 2}$ & $\mathbf{1 5 0}$ & $\mathbf{5 5 4 7 2}$ \\
\hline
\end{tabular}

Table 3.11.3.2 Catch-at-length $\left(10^{-3}\right)$ matrix and biomass $(\mathrm{kg})$ for selected months

\begin{tabular}{|c|c|c|c|c|c|c|c|}
\hline \multicolumn{8}{|c|}{ Catch-at-length (millions) } \\
\hline $\begin{array}{l}\text { Length } \\
\text { group } \\
\text { (cm) }\end{array}$ & April & June & August & September & October & November & December \\
\hline 8.5 & 0.502164502 & 0.384800385 & 0.07696 & 0.073112 & 0.192400192 & 0.288600289 & 106.7066835 \\
\hline 9.0 & 1.966810967 & 1.50713484 & 0.301427 & 0.286356 & 0.75356742 & 1.13035113 & 417.9345103 \\
\hline 9.5 & 3.640692641 & 2.78980279 & 0.557961 & 0.530063 & 1.394901395 & 2.092352092 & 773.6234552 \\
\hline 10.0 & 3.933621934 & 3.014269681 & 0.602854 & 0.572711 & 1.50713484 & 2.260702261 & 835.8690205 \\
\hline 10.5 & 3.891774892 & 2.982202982 & 0.596441 & 0.566619 & 1.491101491 & 2.236652237 & 826.9767969 \\
\hline 11.0 & 4.937950938 & 3.783870451 & 0.756774 & 0.718935 & 1.891935225 & 2.837902838 & 1049.282387 \\
\hline 11.5 & 3.431457431 & 2.629469296 & 0.525894 & 0.499599 & 1.314734648 & 1.972101972 & 729.162337 \\
\hline 12.0 & 3.138528139 & 2.405002405 & 0.481 & 0.45695 & 1.202501203 & 1.803751804 & 666.9167717 \\
\hline 12.5 & 3.640692641 & 2.78980279 & 0.557961 & 0.530063 & 1.394901395 & 2.092352092 & 773.6234552 \\
\hline 13.0 & 2.552669553 & 1.956068623 & 0.391214 & 0.371653 & 0.978034311 & 1.467051467 & 542.425641 \\
\hline$\sum$ & 31.64 & 24.24 & 4.85 & 4.61 & 12.12 & 18.18 & 6722.521 \\
\hline \multicolumn{8}{|c|}{ Biomass (kg) } \\
\hline $\begin{array}{c}\text { Length } \\
\text { group } \\
\text { (cm) }\end{array}$ & April & June & August & September & October & November & December \\
\hline 8.5 & 1.988571 & 1.52381 & 0.304762 & 0.289524 & 0.761904762 & 1.142857 & 422.5585 \\
\hline 9.0 & 8.358947 & 6.405323 & 1.281065 & 1.217011 & 3.202661536 & 4.803992 & 1776.222 \\
\hline 9.5 & 20.09662 & 15.39971 & 3.079942 & 2.925945 & 7.6998557 & 11.54978 & 4270.401 \\
\hline 10 & 24.89983 & 19.08033 & 3.816065 & 3.625262 & 9.54016354 & 14.31025 & 5291.051 \\
\hline 10.5 & 28.38531 & 21.75119 & 4.350239 & 4.132727 & 10.87559724 & 16.3134 & 6031.693 \\
\hline 11 & 40.17244 & 30.78348 & 6.156695 & 5.84886 & 15.39173767 & 23.08761 & 8536.381 \\
\hline 11.5 & 31.74648 & 24.3268 & 4.865361 & 4.622093 & 12.16340244 & 18.2451 & 6745.92 \\
\hline 12 & 31.28359 & 23.9721 & 4.79442 & 4.554699 & 11.98605099 & 17.97908 & 6647.56 \\
\hline 12.5 & 40.95324 & 31.38179 & 6.276359 & 5.962541 & 15.69089707 & 23.53635 & 8702.297 \\
\hline 13 & 33.16769 & 25.41585 & 5.08317 & 4.829012 & 12.70792582 & 19.06189 & 7047.917 \\
\hline$\sum$ & 261.05 & 200.04 & 40.01 & 38.01 & 100.02 & 150 & 55472 \\
\hline
\end{tabular}

\section{V.3.12 Coefficient of variation of length}

The coefficients of variation showed a relatively low degree of standard deviation around the average. The variability was in the range of 0.09-0.22 and can be rated as low. This means that the random sampling of anchovy in the studied months was conducted according to the variation statistics and correctly reflected the general condition at that time of the year.

Project proposal № BG14MFOP001-3.003-0001 "Collection, management and use of data for the purposes of scientific analysis and implementation of the Common Fisheries Policy for the period 2017-2019", funded by the Maritime Affairs and Fisheries Program, co-financed by the European Union through the European Maritime and Fisheries Fund 

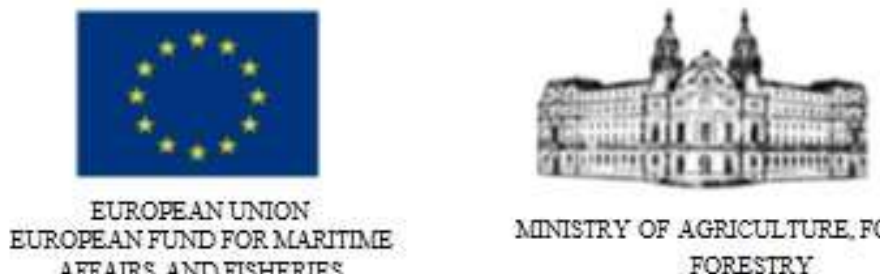

MINISTRY OF AGRICUITURE, FOOD AND FORESTRY

Table 3.12.1 Length coefficient of variation of anchovy

\begin{tabular}{|c|c|c|}
\hline $\begin{array}{c}\text { coefficient of variation } \\
\text { (CV) }\end{array}$ & November & December \\
\hline 1 sample & $\mathrm{CV}=0.09$ & $\mathrm{CV}=0.22$ \\
\hline 2 samples & $\mathrm{CV}=0.14$ & $\mathrm{CV}=0.18$ \\
\hline 3 samples & $\mathrm{CV}=0.10$ & \\
\hline
\end{tabular}

\section{Conclusions}

The analysis of the biological parameters of anchovy makes it possible to draw the following conclusions:

- The age composition was built of 5 age classes which was indicative for its normalization but still reduced by symbolic participation of the senior age classes as of 5-year-old fish.

- A larger share had the two-year-olds in June 2018 (30.9\%) and to some extent in 2019 $(28.75 \%)$. The three-year-olds were well represented during that period with a percentage varying between $24.3 \%$ (June, 2018) and 26.67\% (June, 2019). Young age groups (annuals) were covered in the catches with a participation varying between $17.92 \%$ (June, 2018) and 22.92\% (June, 2019).

- In June and October, the weight structure referred to the average multiannual data showed a similar picture.

- It follows from the analysis that the increase in anchovy during the investigation period was allometric.

- The values of Fulton's condition factor indicated a good physiological state of the species.

- The dynamics of the GSI during propagation and spawning showed a characteristic rapid maturation of the sexual products.

Project proposal № BG14MFOP001-3.003-0001 "Collection, management and use of data for the purposes of scientific analysis and implementation of the Common Fisheries Policy for the period 2017-2019", funded by the Maritime Affairs and Fisheries Program, co-financed by the European Union through the European Maritime and Fisheries Fund 


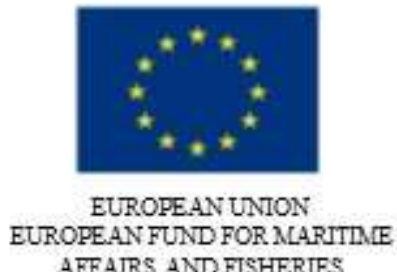

AFFAIRS AND FISHERIES

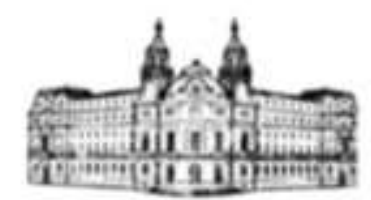

MINTSTRY OF AGRICULTURE, FOOD AND FORESTRY

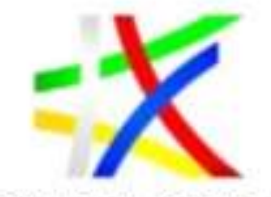

MCARITLE AFFAIRS AND FISHERIES PROGRAM

\section{Biological monitoring of picked dogfish (Squalus acanthias)}

\section{VI.1 Objectives}

Studies on the population dynamics of the Black sea picked dogfish are rare. The present research investigated the population structure of the picked dogfish by analyzing samples collected as bycatch in commercial catches of targeted species.

\section{VI.2 Sampling in the period 2018-2019}

\section{IV.2.1 Geographical area of coverage}

The sampled specimens were weighted and measured onboard of the fishing vessels.

\section{VI.2.2 Sampling description}

In 2018, 57 specimens ( 25 male and 32 female) were collected and processed for length, weight and sex structure analyses.

In 2019, 148 specimens were collected and processed for length, weight, sex structure and population dynamics analyses.

\begin{tabular}{|l|l|l|l|}
\hline \multicolumn{1}{|c|}{ Date } & \multicolumn{1}{|c|}{$\begin{array}{c}\text { Sampling } \\
\text { ports }\end{array}$} & \multicolumn{1}{c|}{ Species } & \multicolumn{1}{c|}{ Fishing vessel } \\
\hline $09 / 02 / 2019$ & Balchik & picked dogfish & VN 8112 \\
\hline $23 / 05 / 2019$ & Carevo & picked dogfish & GG-2 ЦP 212 \\
\hline $24 / 06 / 2019$ & Balchik & picked dogfish & Beni VN 2998 \\
\hline $10 / 08 / 2019$ & Carevo & picked dogfish & Evropa ЦP 576 \\
\hline $05 / 09 / 2019$ & Balchik & picked dogfish & VN 8112 \\
\hline $26 / 09 / 2019$ & Balchik & picked dogfish & VN 8112 \\
\hline $17 / 10 / 2019$ & Kavarna & picked dogfish & Viking VN 8406 \\
\hline $11 / 11 / 2019$ & Kavarna & picked dogfish & Galiver KB5562 \\
\hline $11 / 11 / 2019$ & Kavarna & picked dogfish & Viking VN 8406 \\
\hline $18 / 11 / 2019$ & Дurankulak & picked dogfish & ШБ 6056 \\
\hline $9 / 12 / 2019$ & Kavarna & picked dogfish & Гondola VN4321 \\
\hline $17 / 12 / 2019$ & Carevo & picked dogfish & VARDA ЦP720 \\
\hline
\end{tabular}

\section{IV.2.3 Statistical analysis}

Refer to the methodology used for sprat stock analysis.

Project proposal № BG14MFOP001-3.003-0001 "Collection, management and use of data for the purposes of scientific analysis and implementation of the Common Fisheries Policy for the period 2017-2019", funded by the Maritime Affairs and Fisheries Program, co-financed by the European Union through the European Maritime 


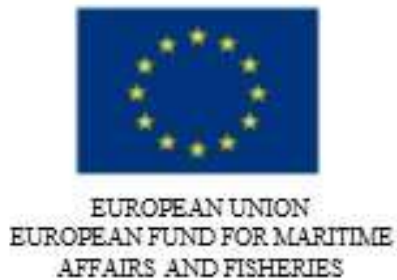

AFFAIRS AND FISHERIES

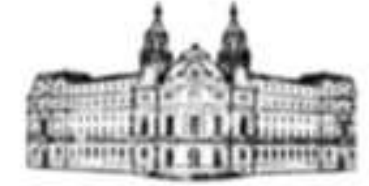

AINISTRY OF AGRICULTURE, FOOD AND FORESTRY

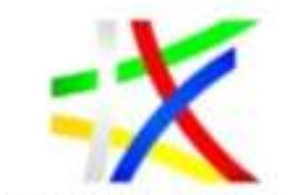

MCARITLE AFFAIRS AND FISHERIES PROGRAM

\section{IV.3 Results}

\section{IV.3.1 Landings statistics 2018-2019}

Official statistics of picked dogfish catches landed on ports in 2018 is presented on Fig. 3.1.1. The average catch was estimated to $840.18 \mathrm{~kg}$. The smallest catch in weight (142 kg) was reported in November and the biggest one was reported in January $(2937 \mathrm{Kg})$.

Official statistics for picked dogfish catches in 2019 is presented on Fig.3.1.2. The biggest catches in weight were declared in October $(2774 \mathrm{~kg})$.

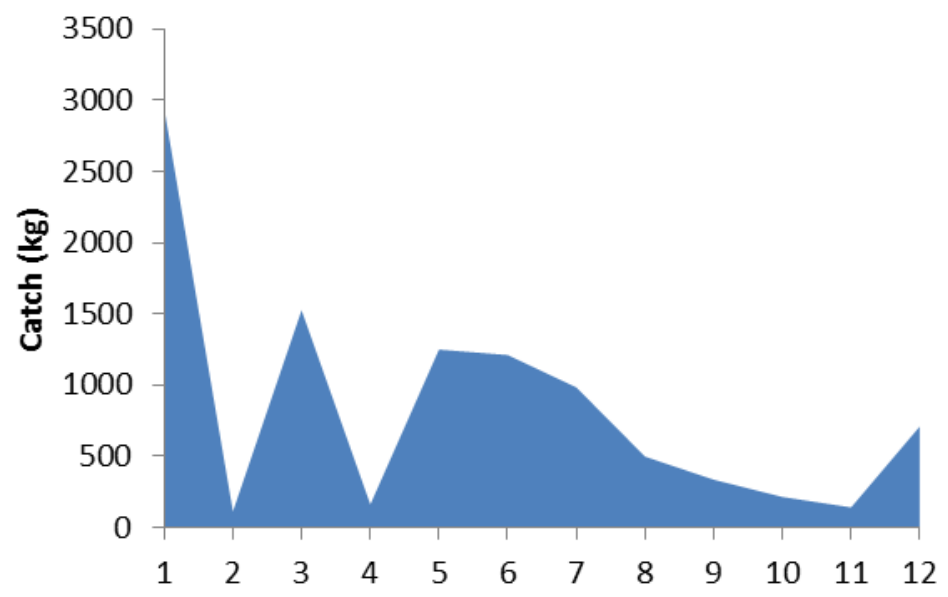

Fig.. 3.1.1 Official picked dogfish landing statistics in 2018

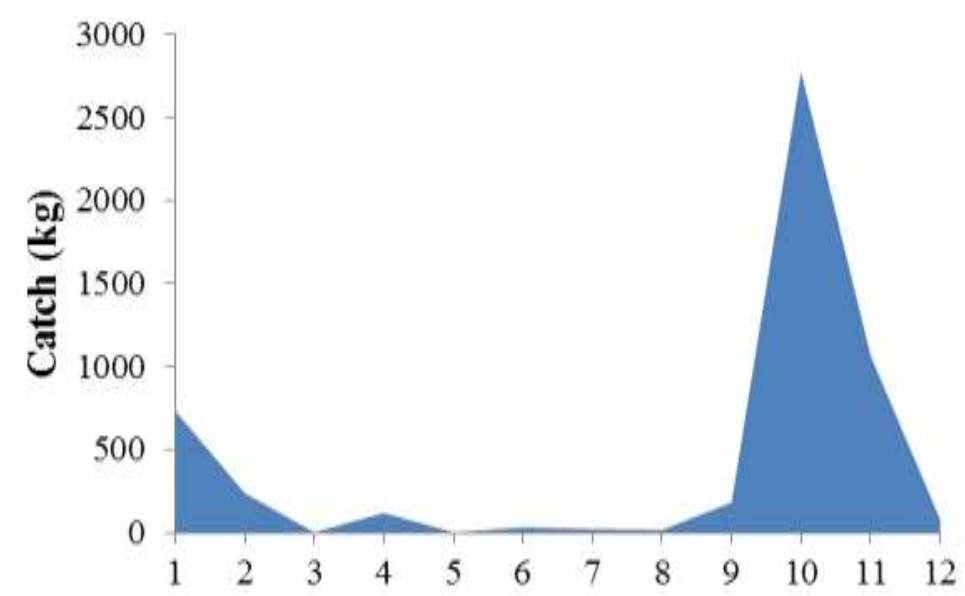

Fig.. 3.1.2 Official picked dogfish landing statistics in 2019

\section{VI.3.2 Sex, length and weight structure of picked dogfish in the period 2018 $-2019$}

\section{IV.3.2.1 Sex, length and weight structure of picked dogfish in 2018}

The samples collected were processed and analyzed and the outcome showed that the female specimens were represented with $56 \%$ and the male ones - with $44 \%$. The mean total length of the studied specimens was calculated as $116.75 \pm 0.135 \mathrm{~cm}$. Male specimens' length varied scientific analysis and implementation of the Common Fisheries Policy for the period 2017-2019", funded by the Maritime Affairs and Fisheries Program, co-financed by the European Union through the European Maritime 


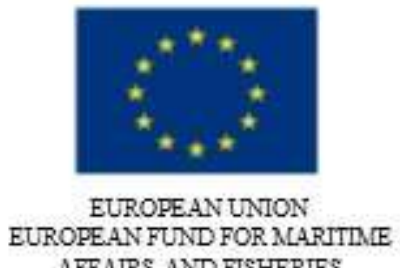

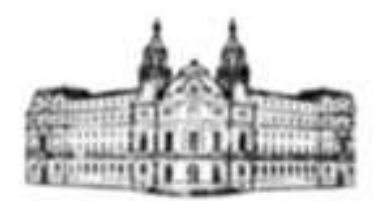

MINISTRY OF AGRICUITURE, FOOD AND FORESTRY

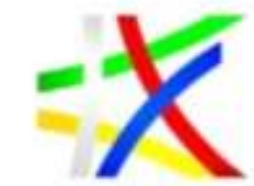

MLARITLE AFFAIRS AND FISHERIES PROGRAM

in the range of 109-123 cm, and the the female - in the range of 114-125 cm (Fig. 3.2.1.1, Fig. 3.2.1.2). The mean weight registered for the female specimens was $6.1 \mathrm{~kg}$. The mean and maximum weight for the male specimens were $6.0 \mathrm{~kg}$ and $7.3 \mathrm{~kg}$, respectively (Fig. 3.2.1.3, Fig. 3.2.1.4).

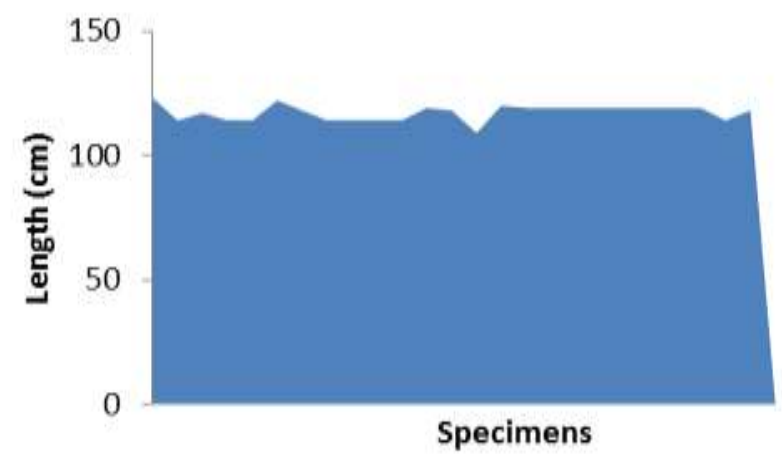

Fig. 3.2.1.1 Picked dogfish length structure $\left({ }^{\Uparrow}\right)$ presented in catches in 2018

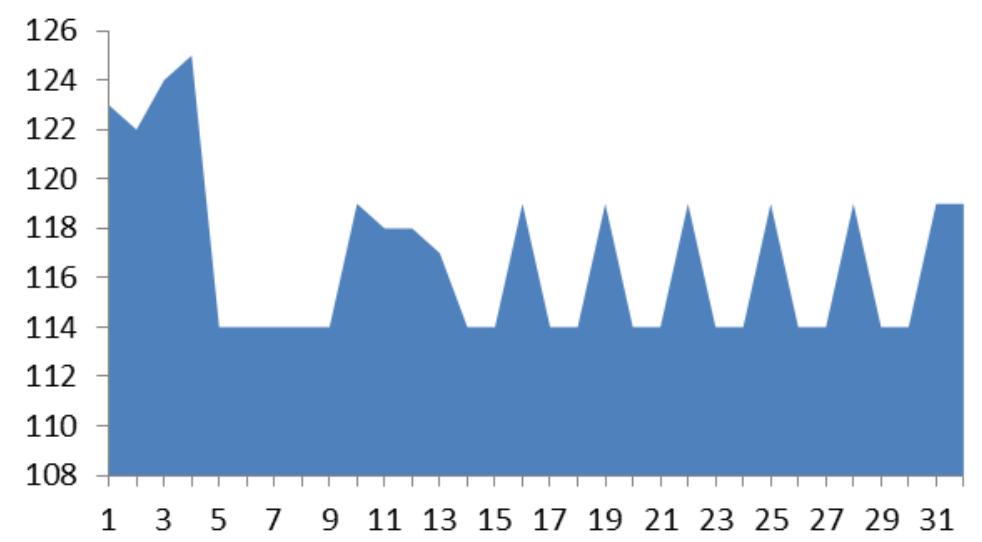

Fig. 3.2.1.2 Picked dogfish length structure (ㅇ) presented in catches in 2018

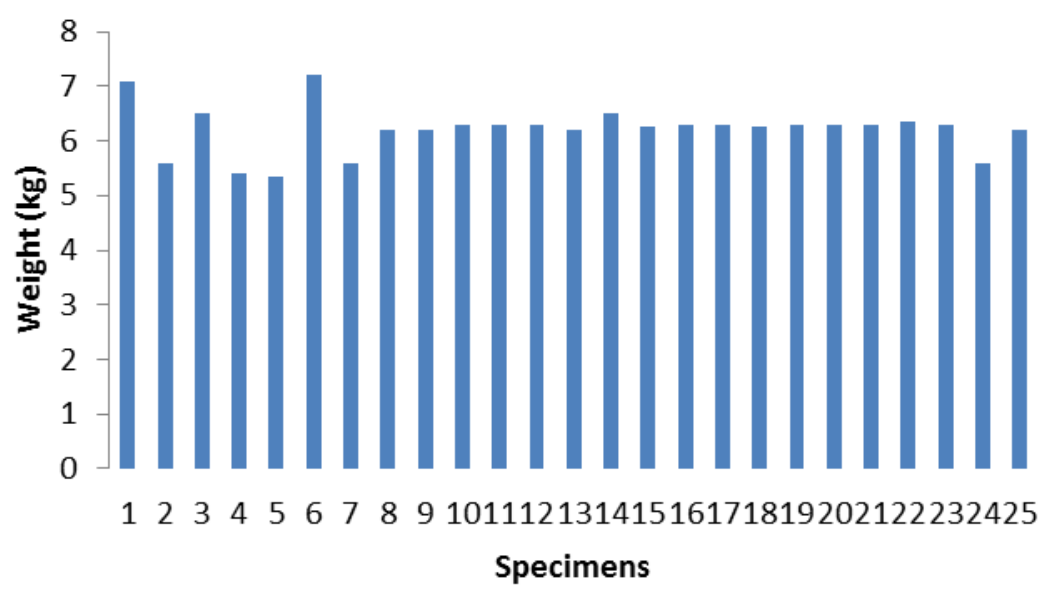

Fig. 3.2.1.3 Picked dogfish weight structure $\left({ }^{\Uparrow}\right)$ presented in catches in 2018

Project proposal № BG14MFOP001-3.003-0001 "Collection, management and use of data for the purposes of scientific analysis and implementation of the Common Fisheries Policy for the period 2017-2019", funded by the Maritime Affairs and Fisheries Program, co-financed by the European Union through the European Maritime and Fisheries Fund 

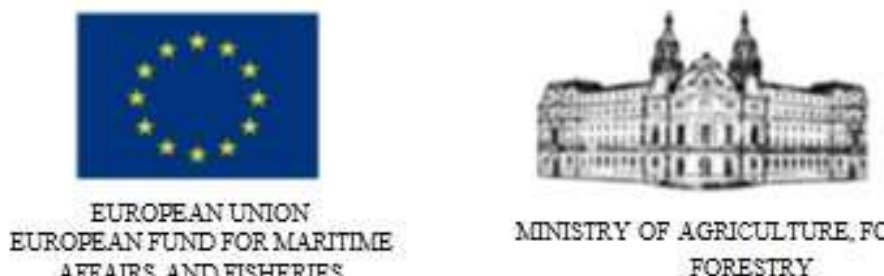

MINISTRY OF AGRICUITURE, FOOD AND FORESTRY

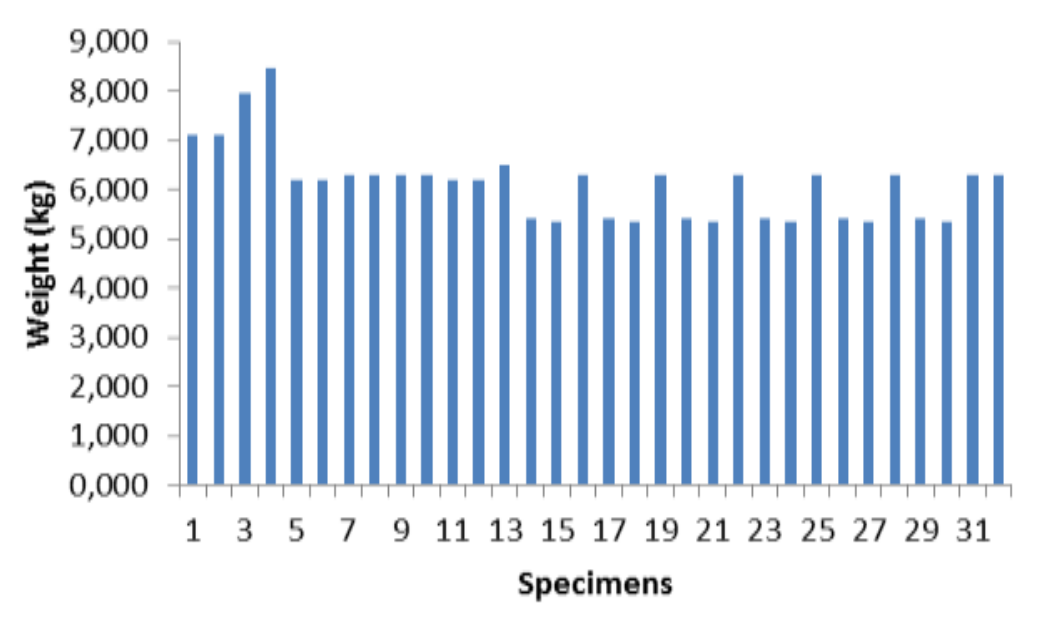

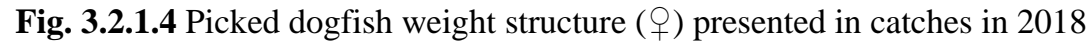

\section{IV.3.2.2 Sex, length and weight structure of picked dogfish in 2019}

Fig. 3.2.2.1 shows the results of weight and length structure analyses for the samples collected in 2019. The mean weight calculated for the female specimens (represented with $3.64 \%$ in the catches' structure) was $7.1 \mathrm{Kg}$ corresponding to mean length of $102 \mathrm{~cm}$. The male specimens' (93.6\%) mean length was calculated to be $111.76 \mathrm{~cm}$ with corresponding mean weight of $6.183 \mathrm{~kg}$.

$$
W_{q}=7.1 \mathrm{~kg} . L_{\mathrm{cp}, q}=102 \mathrm{~cm} . W_{\mathrm{cp}_{\mathrm{g}}}=6.183 \mathrm{~kg} . L_{\mathrm{cp}, \mathrm{g}}=111.7556 \mathrm{~cm}
$$

Project proposal № BG14MFOP001-3.003-0001 "Collection, management and use of data for the purposes of scientific analysis and implementation of the Common Fisheries Policy for the period 2017-2019", funded by the Maritime Affairs and Fisheries Program, co-financed by the European Union through the European Maritime and Fisheries Fund 


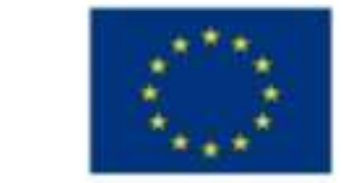

EUROPEAN UNTON EUROPE.AN FUND FOR MLARITIIE AFFAIRS AND FISHERIES

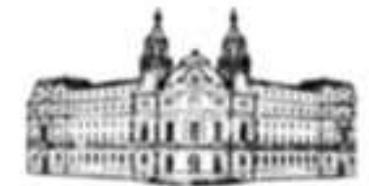

MINISTRY OF AGRICUITURE, FOOD AND FORESTRY
MARITLE AFFATRS AND FISHERIES PROGRAM

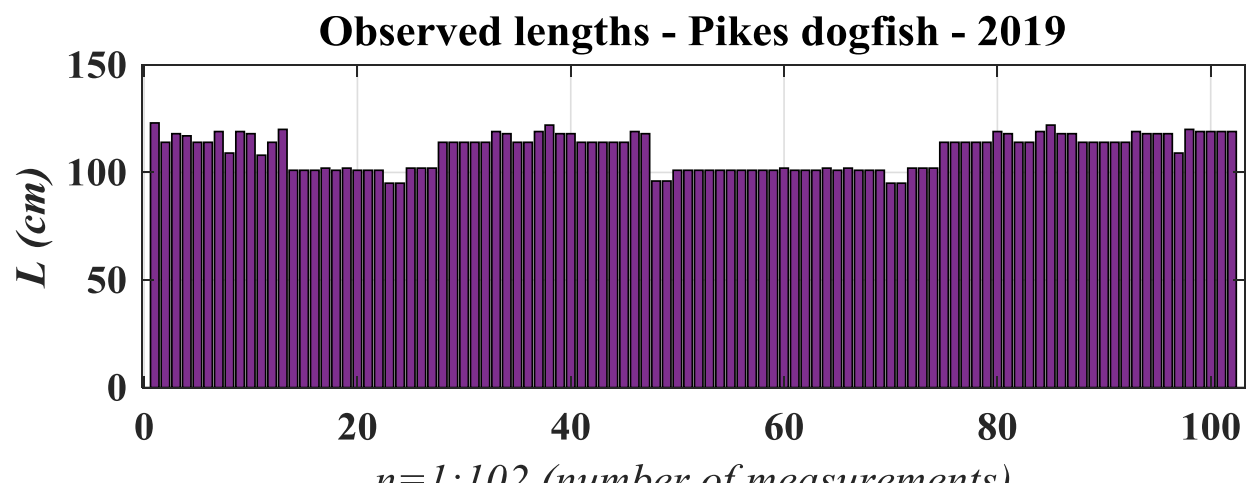

$n=1: 102$ (number of measurements)

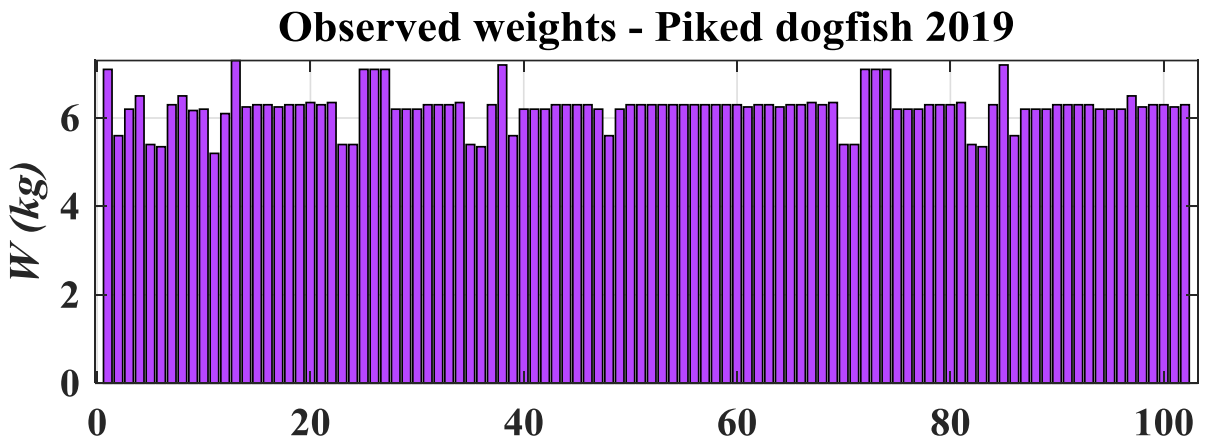

$n=1: 102$ (number of measurements)
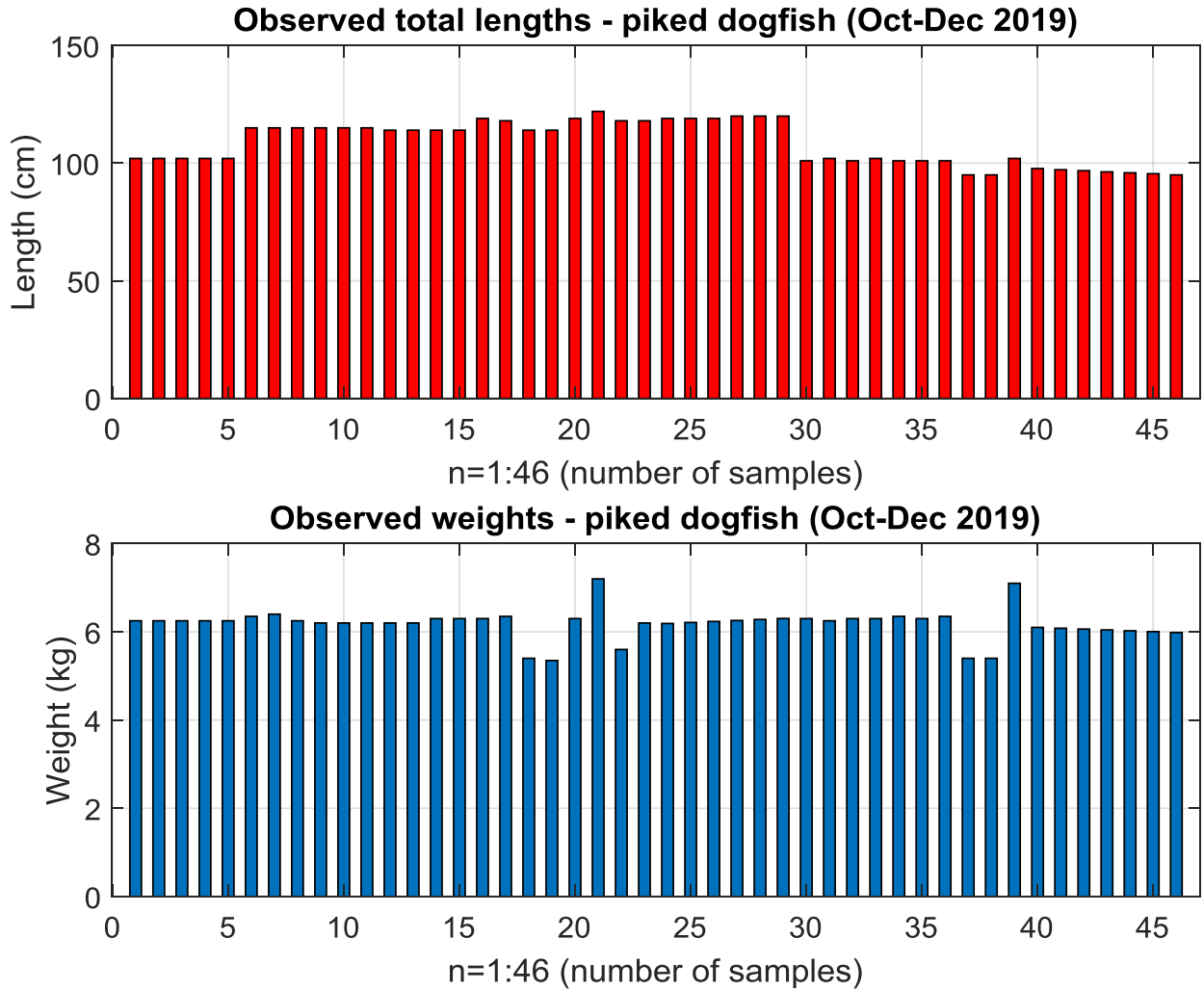

Project proposal № BG14MFOP001-3.003-0001 "Collection, management and use of data for the purposes of scientific analysis and implementation of the Common Fisheries Policy for the period 2017-2019", funded by the Maritime Affairs and Fisheries Program, co-financed by the European Union through the European Maritime and Fisheries Fund 


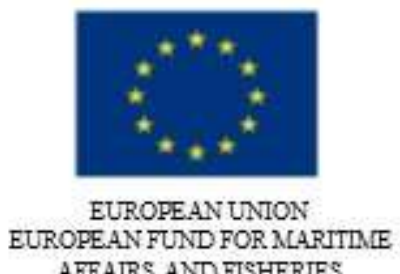

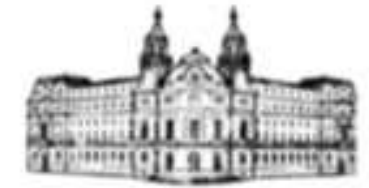

AMNISTRY OF AGRICULTURE, FOOD AND FORESTRY

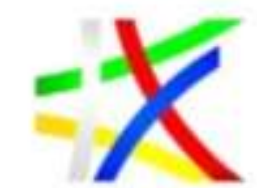

MLARITLE AFFAIRS AND FISHERIES PROGRAM

Fig. 3.2.2.1 Picked dogfish (presented in catches) length and weight structure

The total length of the picked dogfish in the period October-December 2019 varied from 95 $\mathrm{cm}$ to $122 \mathrm{~cm}$, and the weight varied in the range of 5.350-7.200 kg.

$$
\begin{aligned}
& W_{\text {meanfemale }}=6.277083 \mathrm{~kg} . L_{\text {mean }_{\text {female }}}=118.375 \mathrm{~cm} . \\
& W \text { mean male } \\
& W .14503 \mathrm{~kg} . L_{\text {mean }_{\text {malp }}}=105.0111 \mathrm{~cm}
\end{aligned}
$$

The mean weight of females equalled to $6.277 \mathrm{~kg}$, and the mean TL was $118 \mathrm{~cm}$. Males exhibited lower mean weight of $6.14 \mathrm{~kg}$ corresponding to TL of $105 \mathrm{~cm}$.

Sex was determined on 50 specimens (January-June 2019). The sample was composed of 96. $36 \%$ males and $3.64 \%$ females.

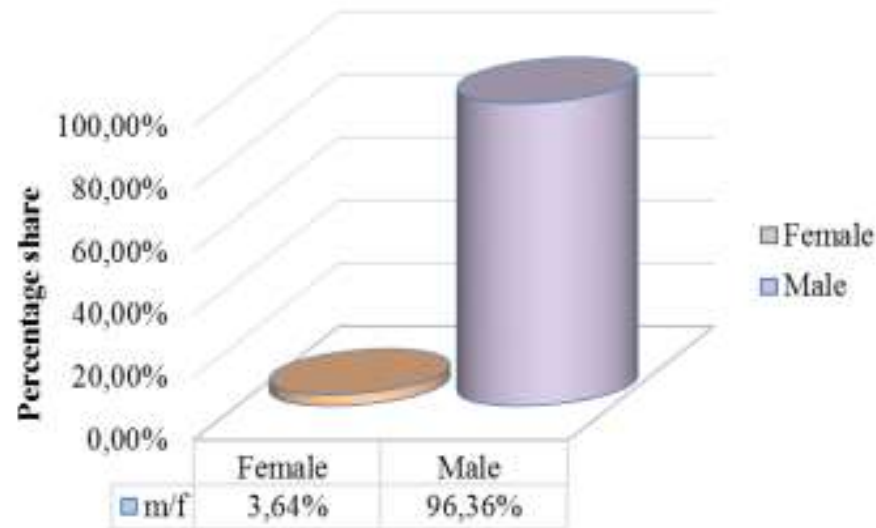

Fig. 3.2.2.2 Picked dogfish sex ratio in the samples collected (January-June)

Sex was determined on 46 specimens (October-December 2019). Males predominated in the samples by $74 \%$, and females hold lower share of $26 \%$.
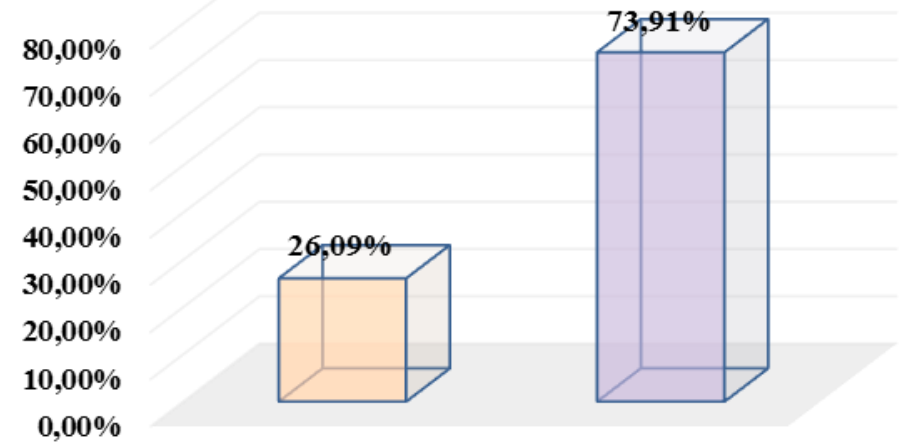

Female

Male

Fig. 3.2.2.3 Picked dogfish sex ratio in the samples collected October-December, 2019

Length-weight relationship of picked dogfish is best described by the following non-linear general model $: \mathrm{f}(\mathrm{x})=\mathrm{a}^{*} \exp \left(-\mathrm{b}^{*} \mathrm{x}\right)+\mathrm{c}$. where: $\mathrm{a}=0.8147, \mathrm{~b}=0.9058, \mathrm{c}=6.281$ (CL6.241. 6.322)

$W=0.8147 * e^{(-0.9058 * L)}+6.281$

Project proposal № BG14MFOP001-3.003-0001 "Collection, management and use of data for the purposes of scientific analysis and implementation of the Common Fisheries Policy for the period 2017-2019", funded by the Maritime Affairs and Fisheries Program, co-financed by the European Union through the European Maritime and Fisheries Fund 

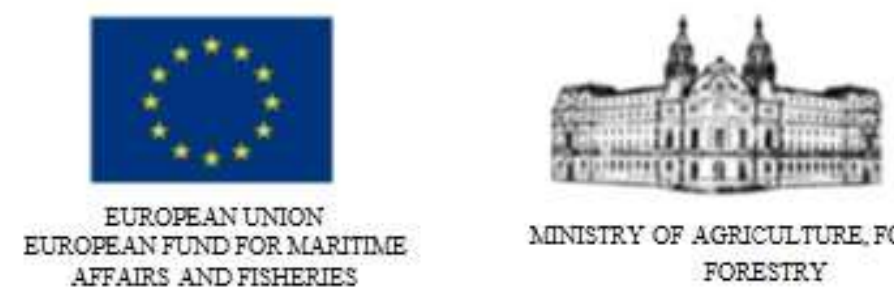

AINTSTRY OF AGRICUITURE, FOOD AND FORESTRY

W vs. $L$ - model fit

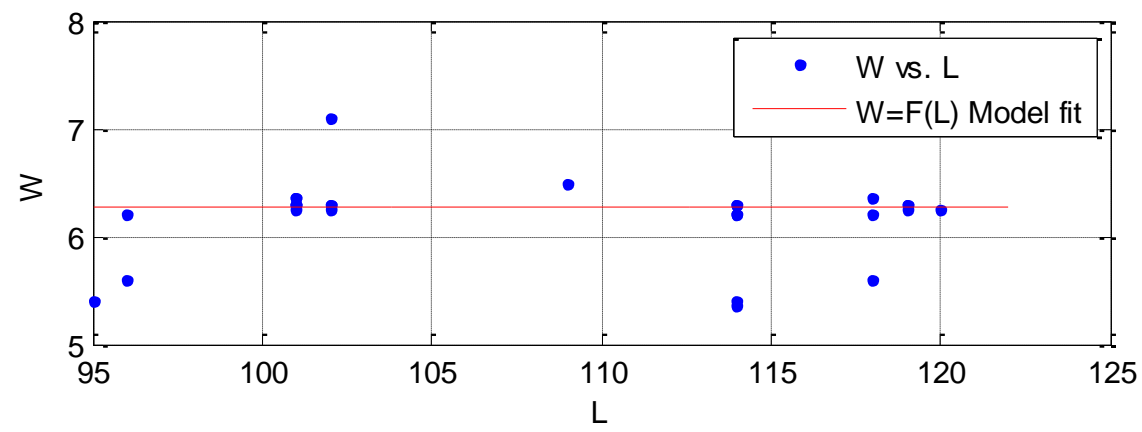

Residuals plot

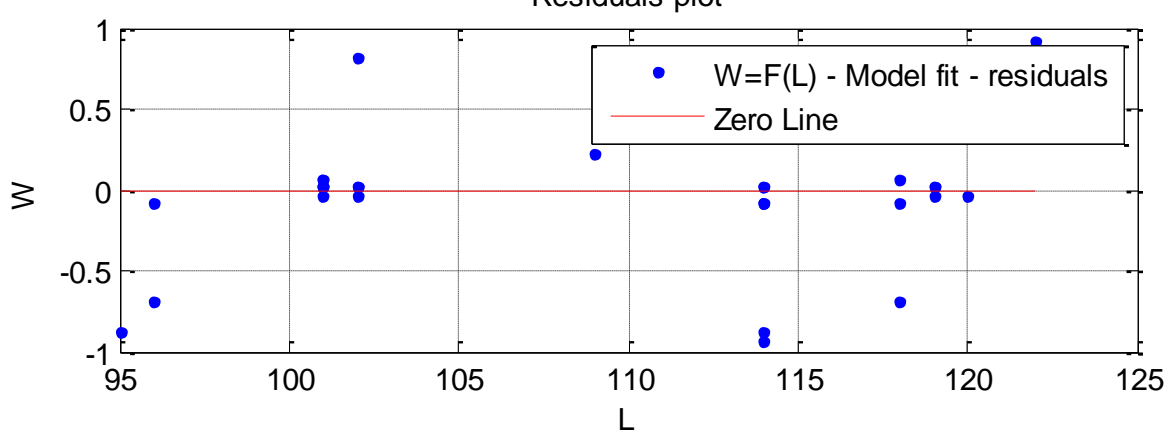

Fig. 3.2.2.4 LWR model of picked dogfish (January-June)

LWR analysis for the period October-December is best described with the following polynomial model:

Linear model Poly4:

$$
f(x)=p 1 * x^{\wedge} 4+p 2 * x^{\wedge} 3+p 3 * x^{\wedge} 2+p 4 * x+p 5
$$

where $x$ is normalized by mean 108.5 and std 9.261

Coefficients (with 95\% confidence bounds):

$$
\begin{aligned}
& p 1=0.1055(-0.0938 .0 .3049) \\
& p 2=0.1529(0.06213 .0 .2437) \\
& p 3=-0.2791(-0.7377 .0 .1796) \\
& p 4=-0.1461(-0.2696 .-0.02253) \\
& p 5=6.362(6.155 .6 .569)
\end{aligned}
$$

Goodness of fit:

SSE: $1.038 . \quad R$-square: 0.8016

Adjusted R-square: 0.7822. RMSE: 0.1591

The coefficient of determination for the approximating model of $L W R$ is $R^{2}=0.7822$.

Project proposal № BG14MFOP001-3.003-0001 "Collection, management and use of data for the purposes of scientific analysis and implementation of the Common Fisheries Policy for the period 2017-2019", funded by the Maritime Affairs and Fisheries Program, co-financed by the European Union through the European Maritime 


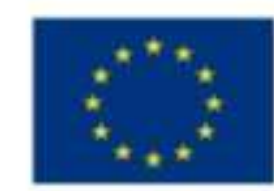

EUROPEAN UNTON EUROPEAN FUND FOR MLARITIE AFFAIRS AND FISHERIES

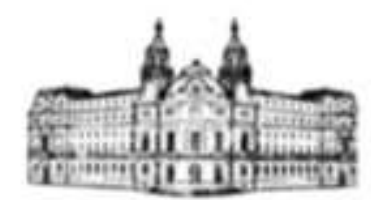

AINISTRY OF AGRICULTURE, FOOD AND FORESTRY

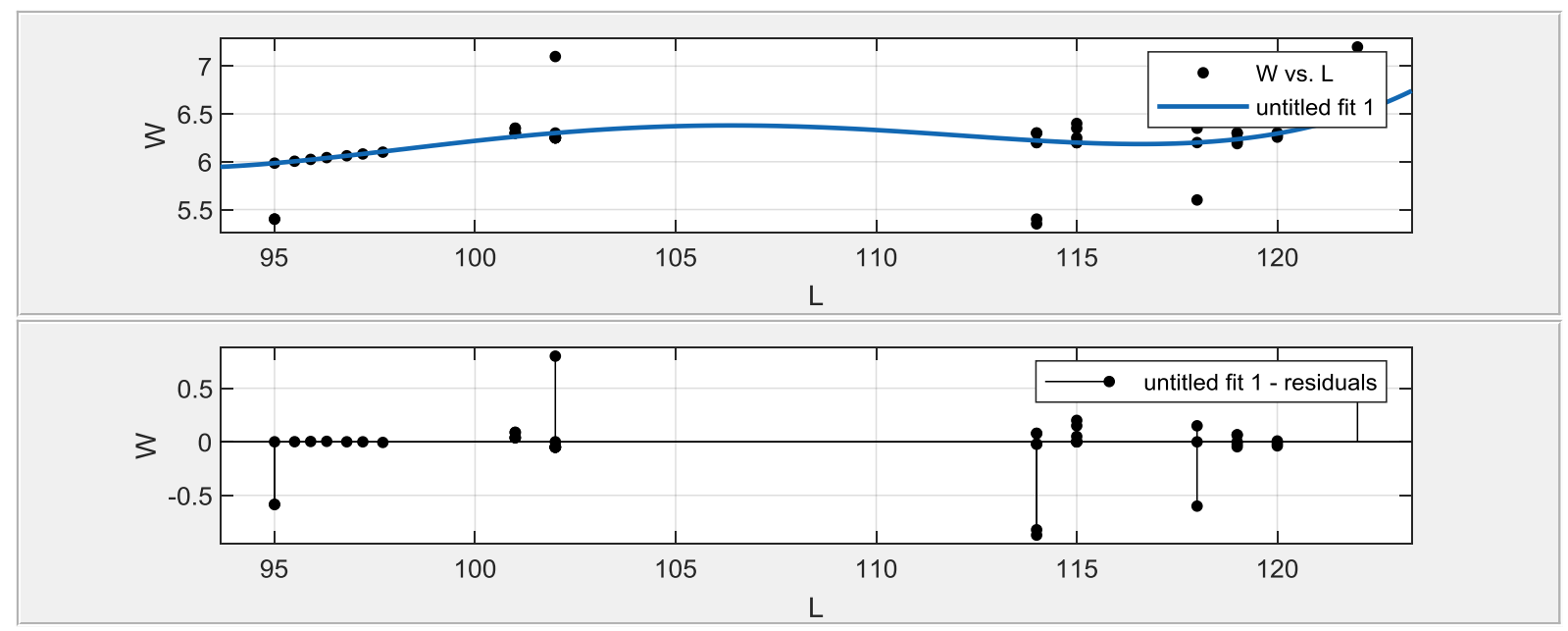

Fig. 3.2.2.5 LWR model of picked dogfish (October-December)

\section{IV.3.2.3 Fecundity}

30 samples were used for maturity analysis (January-June). In that period, the female specimens were sexually mature with apparent presence of embryos. Additional 46 samples were used for maturity analysis (July-December). In that period, actively ripening gonads were observed in all male individuals. The females were found with developed gonads, occupying a large part of the abdominal cavity with a high degree of maturity.

\section{Conclusions and recommendations}

Studies on this species are rare and regular monitoring studies are essential to understand the dynamics of exploited spiny dogfish stocks under the pressure of environmental changes in the Black Sea ecosystem.

- Male individuals predominated in the observed period $(73.91 \%: 26.09 \%)$.

- Females had higher individual sizes and weights than males.

Recommendation:

A study of the proportion between non-sexually mature and sexually mature individuals of both sexes should be monitored for the remainder of the active breeding season.

Project proposal № BG14MFOP001-3.003-0001 "Collection, management and use of data for the purposes of scientific analysis and implementation of the Common Fisheries Policy for the period 2017-2019", funded by the Maritime Affairs and Fisheries Program, co-financed by the European Union through the European Maritime and Fisheries Fund 